FY 2008

\title{
EVALUATION OF THE 2007 TOYOTA CAMRY HYBRID SYNERGY DRIVE SYSTEM
}

Prepared by:

Oak Ridge National Laboratory

Mitch Olszewski, Program Manager

\section{Submitted to:}

Energy Efficiency and Renewable Energy

FreedomCAR and Vehicle Technologies

Vehicle Systems Team

Susan A. Rogers, Technology Development Manager 
NATIONAL LABORATORY

MANAGED BY UT-BATTELLE

FOR THE DEPARTMENT OF ENERGY

\title{
Engineering Science and Technology Division
}

\section{EVALUATION OF THE 2007 TOYOTA CAMRY HYBRID SYNERGY DRIVE SYSTEM}

\author{
T. A. Burress \\ C. L. Coomer \\ S. L. Campbell \\ L. E. Seiber \\ L. D. Marlino \\ R. H. Staunton \\ J. P. Cunningham
}

Revised: April 2008

Publication Date: January 2008

Prepared by the

OAK RIDGE NATIONAL LABORATORY

Oak Ridge, Tennessee 37831 managed by

UT-BATTELLE, LLC

for the

U.S. DEPARTMENT OF ENERGY

Under contract DE-AC05-00OR22725 


\title{
DOCUMENT AVAILABILITY
}

Reports produced after January 1, 1996, are generally available free via the U.S. Department of Energy (DOE) Information Bridge:

Web site: http://www.osti.gov/bridge

Reports produced before January 1, 1996, may be purchased by members of the public from the following source:

\author{
National Technical Information Service \\ 5285 Port Royal Road \\ Springfield, VA 22161 \\ Telephone: 703-605-6000 (1-800-553-6847) \\ TDD: $703-487-4639$ \\ Fax: 703-605-6900 \\ E-mail: info@ntis.fedworld.gov \\ Web site: http://www.ntis.gov/support/ordernowabout.htm
}

Reports are available to DOE employees, DOE contractors, Energy Technology Data Exchange (ETDE) representatives, and International Nuclear Information System (INIS) representatives from the following source:

Office of Scientific and Technical Information

P.O. Box 62

Oak Ridge, TN 37831

Telephone: 865-576-8401

Fax: 865-576-5728

E-mail: reports@osti.gov

Web site: http://www.osti.gov/contact.html

This report was prepared as an account of work sponsored by an agency of the United States Government. Neither the United States government nor any agency thereof, nor any of their employees, makes any warranty, express or implied, or assumes any legal liability or responsibility for the accuracy, completeness, or usefulness of any information, apparatus, product, or process disclosed, or represents that its use would not infringe privately owned rights. Reference herein to any specific commercial product, process, or service by trade name, trademark, manufacturer, or otherwise, does not necessarily constitute or imply its endorsement, recommendation, or favoring by the United States Government or any agency thereof. The views and opinions of authors expressed herein do not necessarily state or reflect those of the United States Government or any agency thereof. 


\section{TABLE OF CONTENTS}

Page

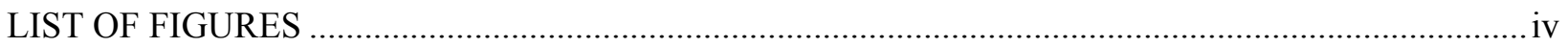

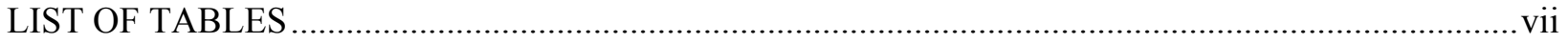

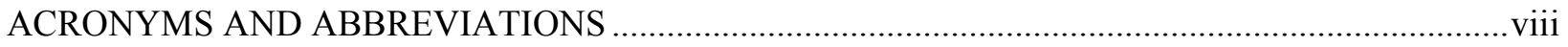

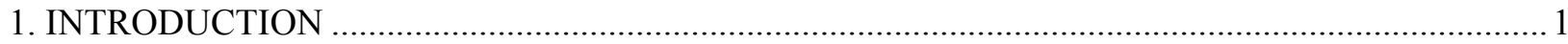

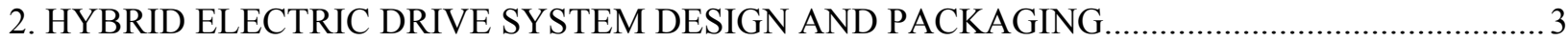

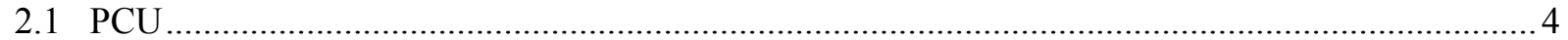

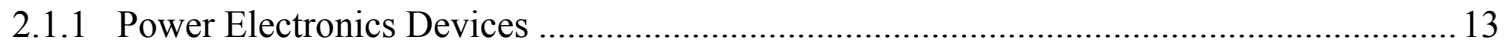

2.1.2 Capacitor Test Results .............................................................................................. 19

2.1.2.1 Static capacitor test results of the $2098 \mu \mathrm{F}$ dc-link smoothing capacitor

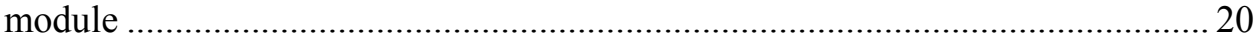

2.1.2.2 Dynamic capacitor test results from large dc-link capacitor module................... 25

2.1.2.3 Static capacitor test results of single sub-cell capacitor of smoothing

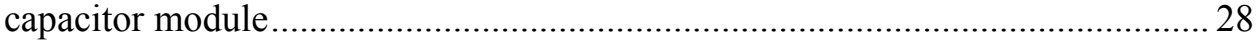

2.1.2.4 Inspection into positive reactance measurement of large dc-link

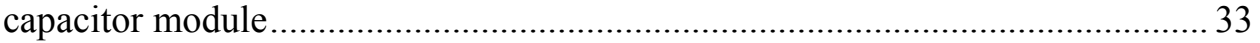

2.1.2.5 Static capacitor test results of battery level filter capacitor evaluations ............... 35

2.1.2.6 Static capacitor test results of small dc-link capacitor evaluations.........................36

2.2 TRANSAXLE.

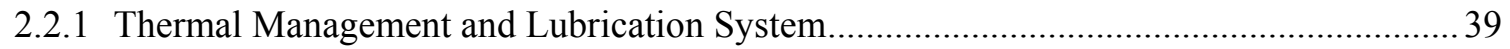

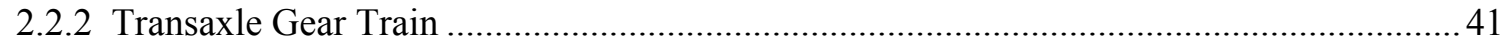

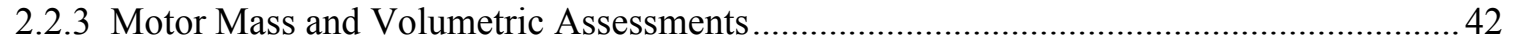

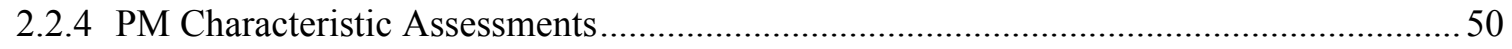

3. BENCHMARKING TESTS OF CAMRY PMSM AND INVERTER ……........................................5

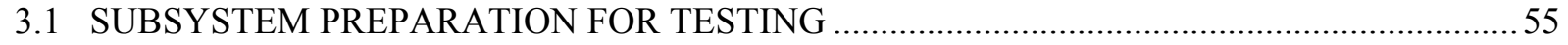

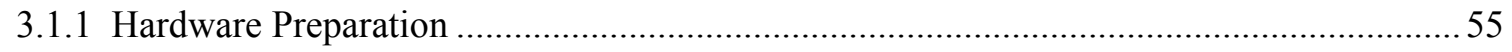

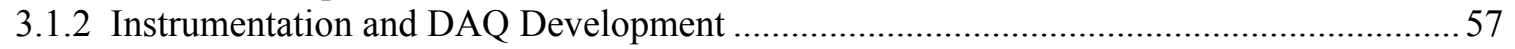

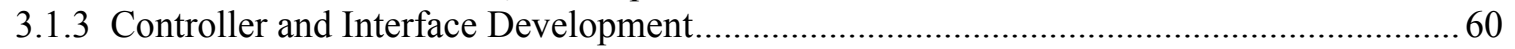

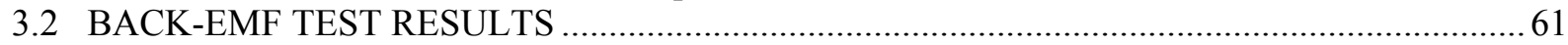

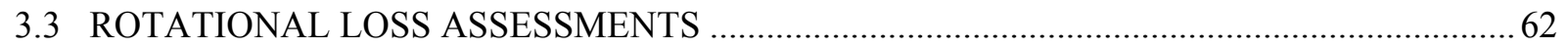

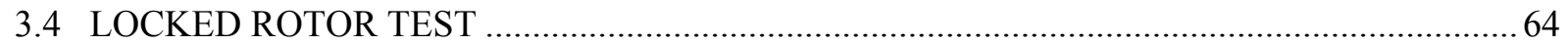

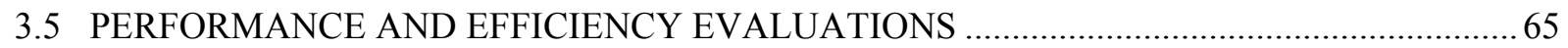

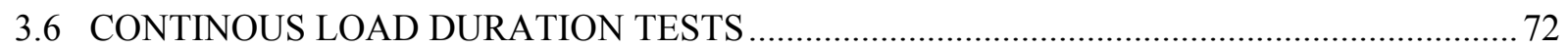

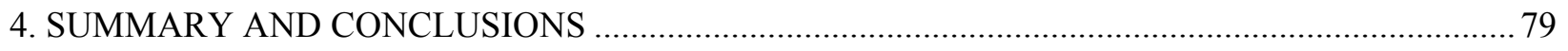

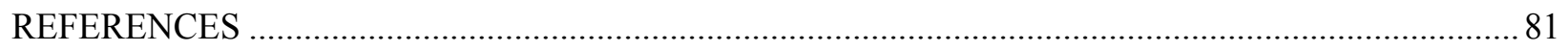

APPENDIX A: 2004 PRIUS POWER CONVERTER UNIT PACKAGING ASSESSMENTS ............... 82

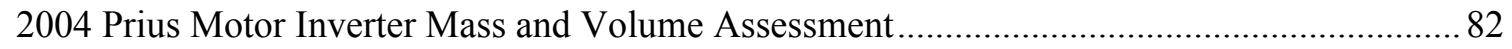

2004 Prius Bi-Directional Boost Converter Mass and Volume Assessment ............................... 83 


\section{TABLE OF CONTENTS (cont'd)}

APPENDIX B: PRIUS AND CAMRY CAPACITOR TEST RESULTS ……………………………..... 85

APPENDIX C: 2004 PRIUS TRANSAXLE PACKAGING ASSESSMENTS......................................... 90

2004 Prius Motor Mass and Volume Assessment …………………………………………...... 90

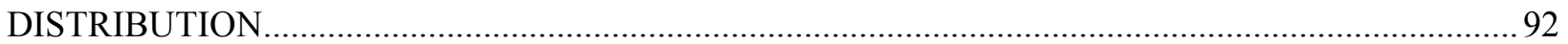




\section{LIST OF FIGURES}

Figure

Page

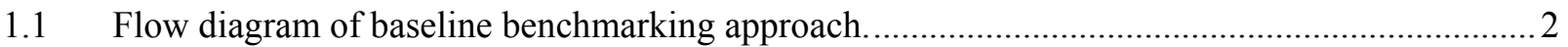

2.1 Subsystems of the Camry inverter and converter assembly.................................................... 4

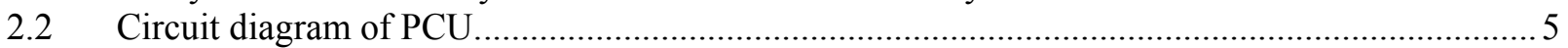

2.3 Boost converter compartment with lid and IPM driver board removed..................................... 6

2.4 Inverter compartment with dc-link capacitor and casing removed. ....................................... 6

2.5 General assembly and packaging of the Camry inverter and converter..................................... 7

2.6 Coolant flow paths in mating converter and inverter cold plates............................................... 8

2.7 Converter assembly with subsections shown consistent with volume measurements. ................ 10

2.8 Non-optimized packaging used in the 2004 Prius converter................................................... 10

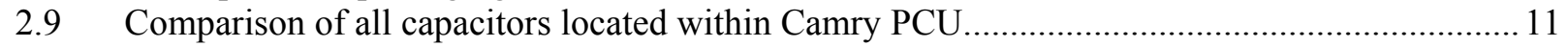

2.10 Cutaway of dc-link capacitor removed from shell and $\mathrm{x}$-ray of module.................................. 11

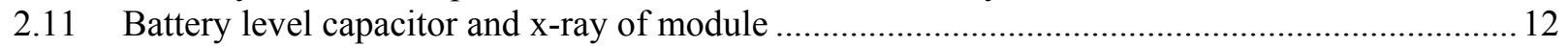

2.12 Small dc-link capacitor: overhead view and $\mathrm{x}$-ray of module - side view................................. 12

2.13 Side housing removed from inverter section of PCU....................................................... 13

2.14 Comparison of Camry inverter IPM and Prius inverter IPM ............................................. 14

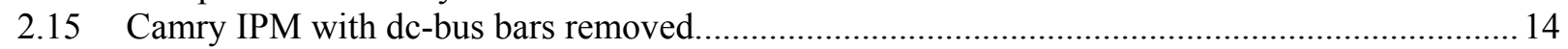

2.16 Dimensions (in mm) of Camry inverter IPM and Prius inverter IPM.................................... 15

2.17 Close-up view of Camry inverter IGBT and Prius inverter IGBT. ........................................ 16

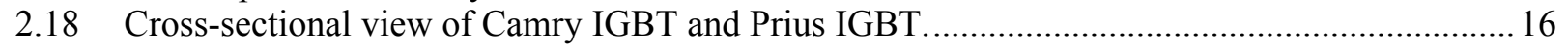

2.19 Close-up view of Camry inverter diode and Prius inverter diode .............................................. 17

2.20 Comparison of Camry converter IPM and Prius converter IPM............................................ 17

2.21 Close-up comparison of Camry converter IPM and Prius converter IPM. .............................. 18

2.22 Camry capacitor module equivalent capacitance vs. frequency............................................20

2.23 Prius capacitor module equivalent capacitance vs. frequency. ...............................................2 21

2.24 Camry capacitor module equivalent capacitance variation with ambient temperature...............2 21

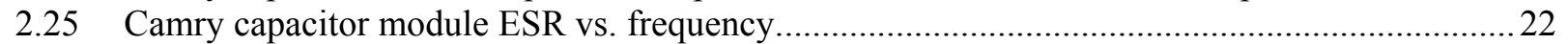

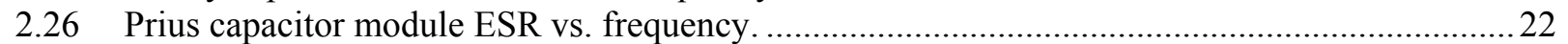

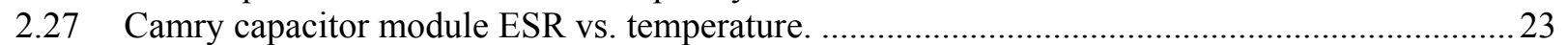

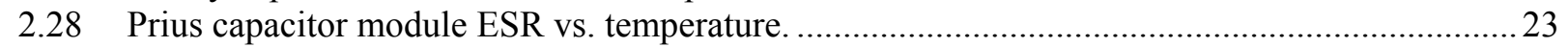

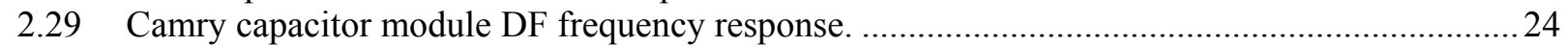

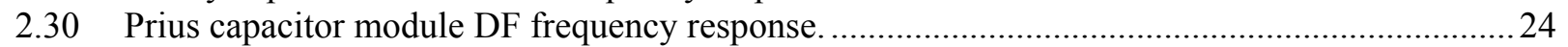

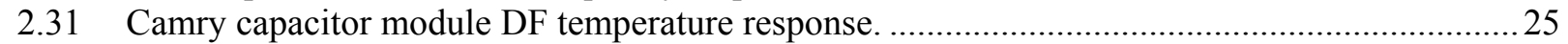

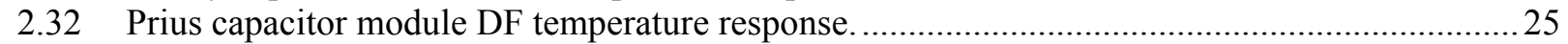

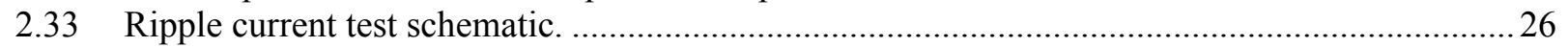

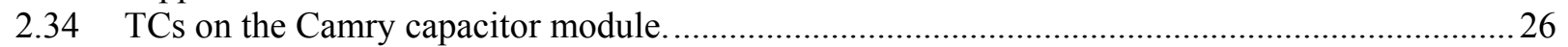

2.35 Camry capacitor module steady-state temperature response vs. ripple current. ........................227

2.36 Prius capacitor module steady-state temperature response vs. ripple current at $4 \mathrm{kHz} \ldots \ldots \ldots \ldots \ldots . . .27$

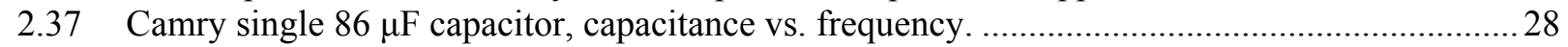

2.38 Camry single $86 \mu \mathrm{F}$ capacitor, ESR vs. frequency............................................................29

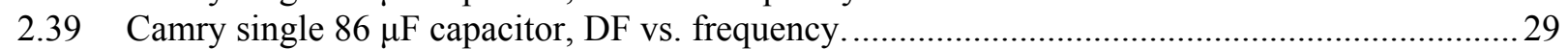

2.40 Camry single $86 \mu \mathrm{F}$ capacitor, capacitance, ESR, and DF vs. temperature at $1 \mathrm{kHz} \ldots \ldots \ldots \ldots \ldots . . . . . . .30$

2.41 Camry single $86 \mu \mathrm{F}$ capacitor, capacitance, ESR, and DF vs. temperature at $5 \mathrm{kHz} \ldots \ldots \ldots \ldots \ldots . . . . .30$

2.42 Camry single $86 \mu \mathrm{F}$ capacitor, capacitance, ESR, and DF vs. temperature at $15 \mathrm{kHz} \ldots \ldots \ldots \ldots \ldots . . . . .31$

2.43 Camry single $86 \mu \mathrm{F}$ capacitor, capacitance, ESR, and DF vs. temperature at $35 \mathrm{kHz} . \ldots \ldots \ldots \ldots \ldots . . . . .31$

2.44 Camry single $86 \mu \mathrm{F}$ capacitor, capacitance, ESR, and DF vs. frequency at $20^{\circ} \mathrm{C} \ldots \ldots \ldots \ldots \ldots \ldots . . . . . . . . .32$ 


\section{LIST OF FIGURES (cont'd)}

Figure

Page

2.45 Camry single $86 \mu \mathrm{F}$ capacitor, capacitance, ESR, and DF vs. frequency at $140^{\circ} \mathrm{C} \ldots \ldots \ldots \ldots \ldots . . . . . . . .32$

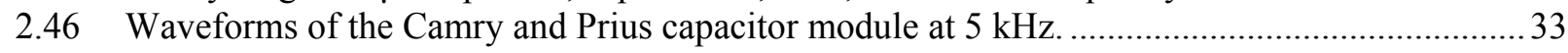

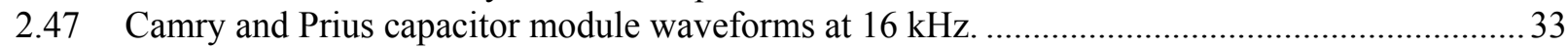

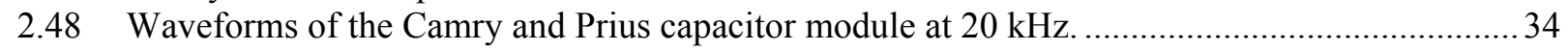

2.49 Camry capacitor module voltage and current response to frequency....................................... 35

2.50 Prius capacitor module voltage and current response to frequency. ......................................... 35

2.51 Camry battery level $378 \mu \mathrm{F}$ capacitor, capacitance, ESR, and DF vs. frequency.......................36

2.52 Prius battery level $282 \mu \mathrm{F}$ capacitor, capacitance, ESR, and DF vs. frequency...........................36

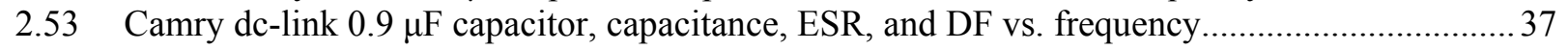

2.54 Prius dc-link $0.1 \mu \mathrm{F}$ capacitor, capacitance, ESR, and DF vs. frequency.................................. 37

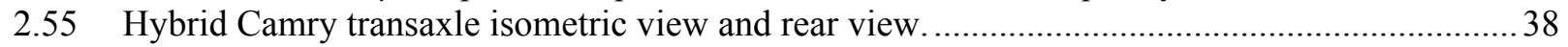

2.56 Camry generator front view with ICE spline removed and motor rear view ............................ 38

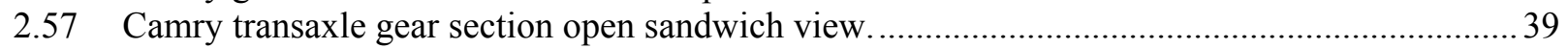

2.58 Trochoid oil pump view from outside rear and from inside motor section............................... 40

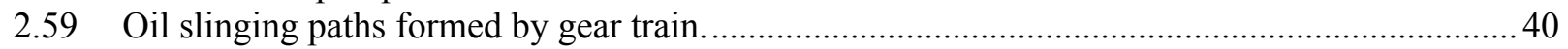

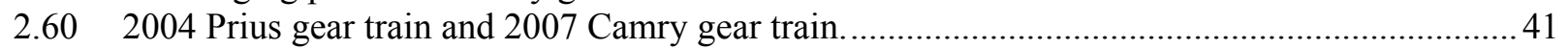

2.61 Camry speed reduction planetary and power split planetary ................................................... 42

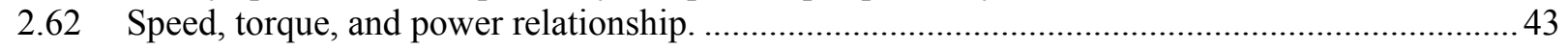

2.63 Camry motor assembly after separation from generator assembly. ........................................ 44

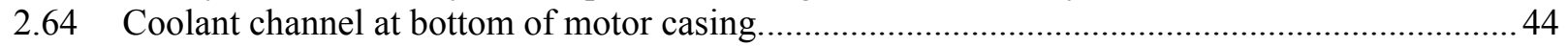

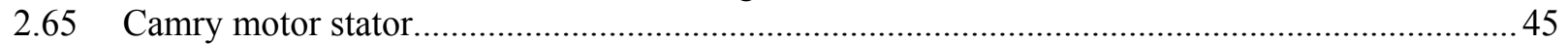

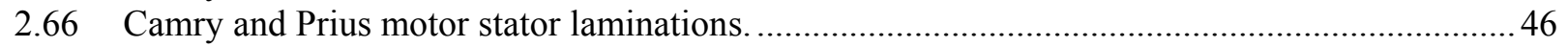

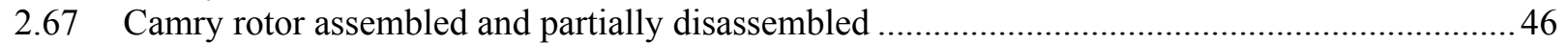

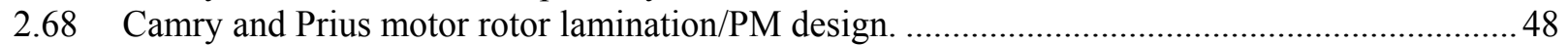

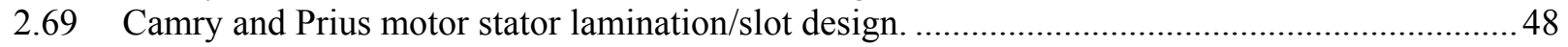

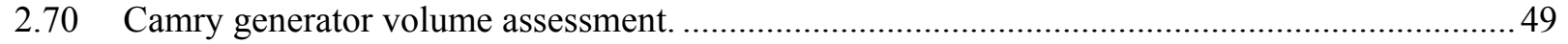

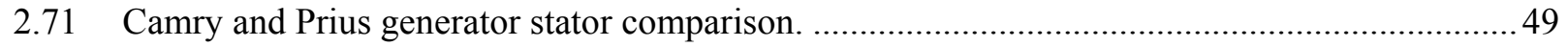

2.72 Camry and Prius generator rotor comparison........................................................................ 49

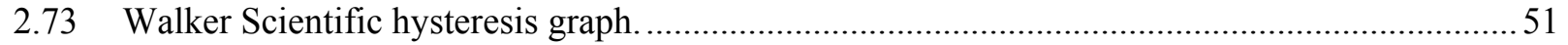

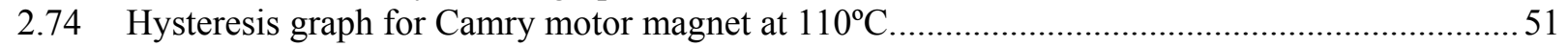

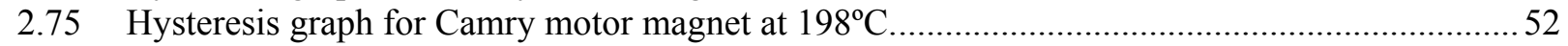

2.76 Intrinsic hysteresis graphs for Camry motor magnet at various temperatures. ........................52

2.77 Intrinsic hysteresis graphs for Prius motor magnet at various temperatures.............................53

2.78 Remanent flux density for Camry and Prius motor magnet. ..................................................5

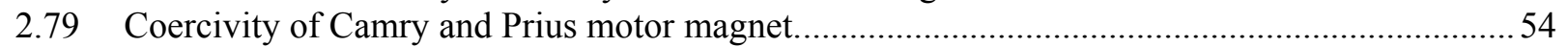

3.1 First test setup approach with welded Camry planetary gear..................................................56

3.2 Second test setup approach with modified motor rotor shaft................................................56

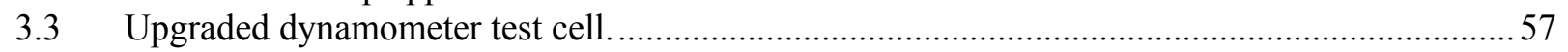

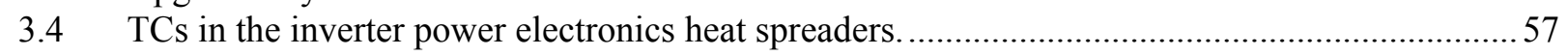

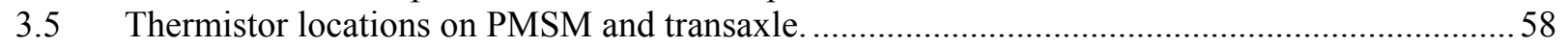

3.6 Viewport and window locations implemented on transaxle ...................................................59

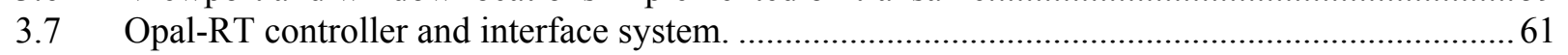

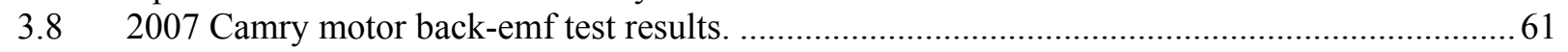

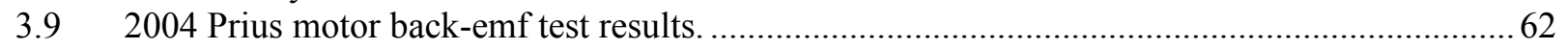

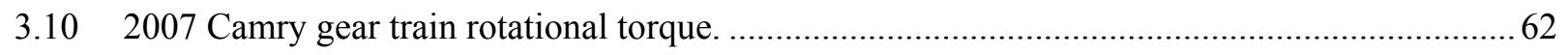

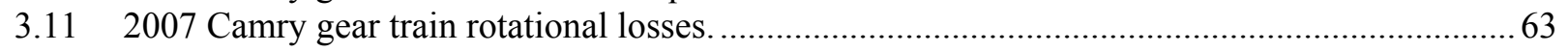




\section{LIST OF FIGURES (cont'd)}

Figure

Page

3.12 2007 Camry motor rotational losses 63

2007 Camry gear losses vs. oil temperature at various ring gear speeds. .64

2007 Camry locked rotor torque vs. position for various de currents.

2007 Camry and Prius peak locked rotor torque vs. de current. 65

2007 Camry and Prius peak locked rotor torque vs. dc current. 65

2007 Camry motor efficiency contours.

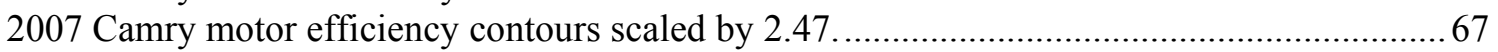

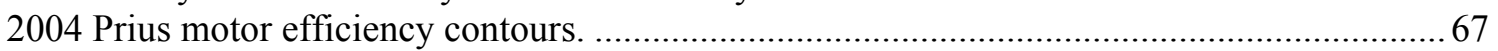

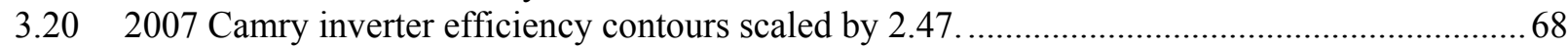

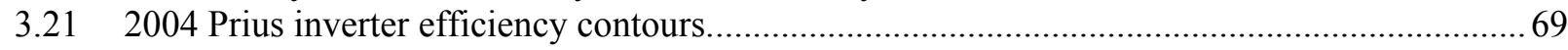

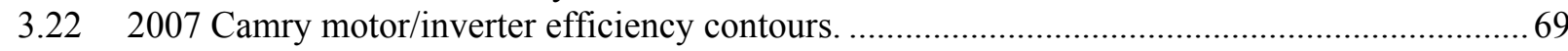

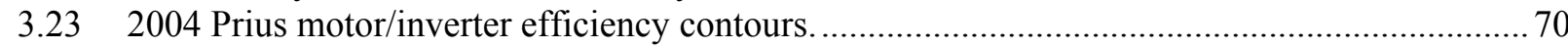

3.242007 Camry inverter efficiency vs. switching frequency for various dc-link voltages............... 70

3.252007 Camry boost converter efficiency vs. input current for various dc-link voltages. .............. 71

3.26 Prius boost converter efficiency vs. input current for various dc-link voltages......................... 71

3.27 Camry $50 \mathrm{~kW}$ continuous duration test at $5000 \mathrm{rpm}$ with $50^{\circ} \mathrm{C}$ coolant. ................................. 72

3.28 Camry $50 \mathrm{~kW}$ continuous duration test at $7000 \mathrm{rpm}$ with $65^{\circ} \mathrm{C}$ coolant................................ 73

3.29 Camry $25 \mathrm{~kW}$ continuous duration test at $5000 \mathrm{rpm}$ with $65^{\circ} \mathrm{C}$ coolant................................. 73

3.30 Camry $33.5 \mathrm{~kW}$ continuous duration test at $3000 \mathrm{rpm}$ with $65^{\circ} \mathrm{C}$ coolant.............................. 74

3.31 Camry $25 \mathrm{~kW}$ continuous duration vs. speed with $65^{\circ} \mathrm{C}$ coolant.......................................... 75

3.32 Camry $33.5 \mathrm{~kW}$ continuous duration vs. speed with $35^{\circ} \mathrm{C}$ coolant. ...................................... 75

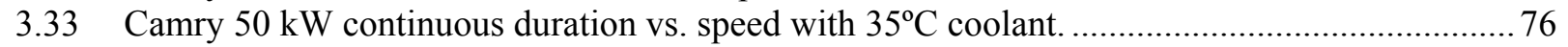

3.34 Camry $50 \mathrm{~kW}$ continuous duration vs. speed with $65^{\circ} \mathrm{C}$ coolant.........................................76

3.35 Camry continuous duration at $3000 \mathrm{rpm}$ with various power levels and coolant temperatures... 77

3.36 Camry continuous duration at $5000 \mathrm{rpm}$ with various power levels and coolant temperatures...77

3.37 Camry continuous duration at $7000 \mathrm{rpm}$ with various power levels and coolant temperatures...78

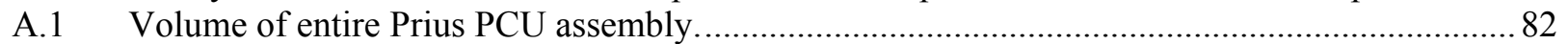

A.2 Empty inverter/converter housing showing cold plate surfaces.......................................... 83

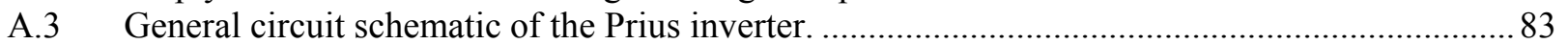

B.1 Prius single $141 \mu \mathrm{F}$ capacitor from $1,130 \mu \mathrm{F}$ module, capacitance vs. frequency...................... 85

B.2 Prius single $141 \mu \mathrm{F}$ capacitor from $1,130 \mu \mathrm{F}$ module, ESR vs. frequency. ............................... 85

B.3 Prius single $141 \mu \mathrm{F}$ capacitor from $1,130 \mu \mathrm{F}$ module, DF vs. frequency................................... 86

B.4 Camry single $86 \mu \mathrm{F}$ capacitor, capacitance, ESR, and DF vs. temperature at $10 \mathrm{kHz} \ldots \ldots \ldots \ldots \ldots . . . . .86$

B.5 Camry single $86 \mu \mathrm{F}$ capacitor, capacitance, ESR, and DF vs. temperature at $25 \mathrm{kHz} \ldots \ldots \ldots \ldots \ldots . . . . .87$

B.6 Camry single $86 \mu \mathrm{F}$ capacitor, capacitance, ESR, and DF vs. temperature at $30 \mathrm{kHz} \ldots \ldots \ldots \ldots \ldots . . . . . .87$

B.7 Camry single $86 \mu \mathrm{F}$ capacitor, capacitance, ESR, and DF vs. frequency at $-40^{\circ} \mathrm{C} \ldots \ldots \ldots \ldots \ldots \ldots . . . . . . . . .88$

B. 8 Prius single $141 \mu \mathrm{F}$ capacitor, capacitance, ESR, and DF vs. temperature at $1 \mathrm{kHz} . \ldots \ldots \ldots \ldots \ldots . . . . . . .88$

B.9 Prius single $141 \mu \mathrm{F}$ capacitor, capacitance, ESR, and DF vs. temperature at $5 \mathrm{kHz}$................ 89

B.10 Prius single $141 \mu \mathrm{F}$ capacitor, capacitance, ESR, and DF vs. temperature at $15 \mathrm{kHz} . \ldots \ldots \ldots \ldots . . . . . .89$

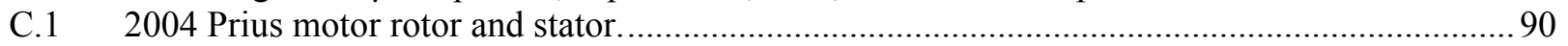

C.2 Casing of the 2004 Prius PMSM with dimensions and volume calculations.............................91 


\section{LIST OF TABLES}

Table

2.1 Comparison of hybrid Camry and the Prius design features and published specifications............ 3

2.2 Comparison of hybrid Camry and the Prius PCU component specifications................................5

2.3 Mass and volume measurements for the hybrid Camry inverter and converter......................... 9

2.4 Specific power and power density estimates for inverter/converter.......................................... 9

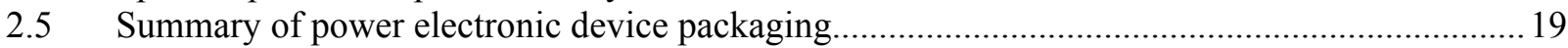

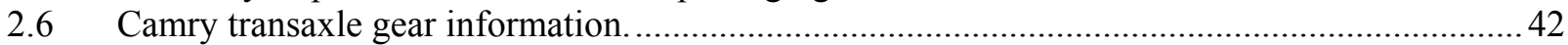

2.7 Specific power and power density estimates for the PMSM.................................................. 44

$2.8 \quad 2007$ Camry/2004 Prius motor design comparison highlights. .................................................. 47

2.92007 Camry/2004 Prius generator design comparison highlights...........................................50

4.1 2007 Camry/2004 Prius design comparison highlights..................................................... 80 


\section{ACRONYMS AND ABBREVIATIONS}

$\begin{array}{lrlr}\text { A/C } & \text { air conditioning } & \text { ID } & \text { inner diameter } \\ \text { ac } & \text { alternating current } & \text { IGBT } & \text { insulated-gate bipolar transistor } \\ \text { ANL } & \text { Argonne National Laboratory } & \text { IPM } & \text { intelligent power module } \\ \text { AWG } & \text { America wire gauge } & \text { LV } & \text { low voltage } \\ \text { CAN } & \text { controller area network } & \text { MG } & \text { motor-generator } \\ \text { CT } & \text { current transformer } & \text { NdFeB } & \text { neodymium iron boron } \\ \text { DAQ } & \text { data acquisition system } & \text { Nm } & \text { Newton meter } \\ \text { dc } & \text { direct current } & \text { NTRC } & \text { National Transportation Research Center } \\ \text { DF } & \text { dissipation factor } & \text { OD } & \text { outer diameter } \\ \text { DOE } & \text { U.S. Department of Energy } & \text { ORNL } & \text { Oak Ridge National Laboratory } \\ \text { ECU } & \text { electronic control unit } & \text { PC } & \text { personal computer } \\ \text { ECVT } & \text { electronically controlled continuously } & \text { PCU } & \text { power control unit } \\ & \text { variable transmission } & \text { PEEMRC } & \text { Power Electronics and Electric } \\ \text { emf } & \text { electromotive force (measured in volts) } & & \text { Machinery Research Center } \\ \text { EMI } & \text { electromagnetic interference } & \text { PI } & \text { proportional-integral } \\ \text { ESR } & \text { equivalent series resistance } & \text { PM } & \text { permanent magnet } \\ \text { EV } & \text { electric vehicle } & \text { PMSM } & \text { permanent magnet synchronous motor } \\ \text { FCVT } & \text { FreedomCAR and Vehicle Technologies } & \text { rms } & \text { root mean square } \\ \text { HEV } & \text { hybrid electric vehicle } & \text { rpm } & \text { revolutions per minute } \\ \text { HV } & \text { high voltage } & \text { Si } & \text { silicon } \\ \text { IC } & \text { integrated circuit } & \text { TC } & \text { THS } \\ \text { ICE } & \text { internal combustion engine } & \text { thermocouple } \\ & & & \text { Toyota Hybrid System }\end{array}$




\section{INTRODUCTION}

The U.S. Department of Energy (DOE) and American automotive manufacturers General Motors, Ford, and DaimlerChrysler began a five-year, cost-shared partnership in 1993. Currently, hybrid electric vehicle (HEV) research and development is conducted by DOE through its FreedomCAR and Vehicle Technologies (FCVT) program. The mission of the FCVT program is to develop more energy efficient and environmentally friendly highway transportation technologies. Program activities include research, development, demonstration, testing, technology validation, and technology transfer. These activities are aimed at developing technologies that can be domestically produced in a clean and cost-competitive manner.

Under the FCVT program, support is provided through a three-phase approach [1] which is intended to:

- Identify overall propulsion and vehicle-related needs by analyzing programmatic goals and reviewing industry's recommendations and requirements, then develop the appropriate technical targets for systems, subsystems, and component research and development activities;

- Develop and validate individual subsystems and components, including electric motors, emission control devices, battery systems, power electronics, accessories, and devices to reduce parasitic losses; and

- Determine how well the components and subassemblies work together in a vehicle environment or as a complete propulsion system and whether the efficiency and performance targets at the vehicle level have been achieved.

The research performed in this area will help remove technical and cost barriers to enable technology for use in such advanced vehicles as hybrid electric, plug-in hybrid electric, electric, and fuel-cell-powered vehicles.

The Oak Ridge National Laboratory's (ORNL) Power Electronics and Electric Machinery Research Center (PEEMRC) performed benchmark assessments and subsystem testing of the 2004 Toyota Prius in 2004-2005. This work has been fully reported in two reports [2,3]. In 2006, the PEEMRC performed similar work on the hybrid version of the 2005 Honda Accord [4]. This report presents the results of benchmark testing of the 2007 Toyota Camry electric drive subsystems.

Subsystem-level testing was conducted by the PEEMRC at ORNL, which is a broad-based research center for power electronics and electric machinery (motor) development. Located in the national user facility known as the National Transportation Research Center (NTRC), the PEEMRC has more than 9000 square feet of space for developing and building the next generation prototypes of power electronics and electric machine technologies.

The 2007 Toyota Camry hybrid is equipped with the Hybrid Synergy Drive system which includes an internal combustion engine (ICE), an electric motor, and a generator. These components are integrated with a power splitting planetary gear which provides various power flow configurations for different modes of operation. The electric motor assists the ICE in providing mechanical drive power for the vehicle and also acts as a generator to recharge the battery during regenerative braking. According to published specifications, Toyota claims the motor can deliver a peak power output of $105 \mathrm{~kW}(143 \mathrm{hp})$ at 4500 revolutions per minute (rpm). Toyota has not published a rated torque (or power) versus speed graph for the Camry electric motor and no specifications have been published for the generator. The hybrid version of the Camry features a 2.4-liter 4-cylinder, 16-valve engine, which has a specified peak power output of $110 \mathrm{~kW}(147 \mathrm{hp})$ at $6000 \mathrm{rpm}[5]$. 
The Camry electric drive system has several features in common with the Toyota Prius system as they both use the Toyota Hybrid System (THS) II. Both make use of the electric motor to provide all of the traction power during acceleration from a stop. This continues until the engine is needed for any of several reasons (more torque, low battery state of charge, high battery temperature, etc.) Both vehicles have a dedicated generator, which is used to route power from the ICE to the electric motor. Both use a clutch-less, electronically controlled continuously variable transmission (ECVT) which uses a planetary gear to manage power flow from the ICE and motor to the differential gear unit. The planetary gear configuration of the ECVT provides the opportunity to operate the ICE throughout a more efficient torque-speed range, depending on the torques and speeds of the generator and electric motor.

Unlike the Toyota Camry and Prius, which are both considered to be full hybrids, the Honda Accord hybrid with its smaller motor is considered to be a "mild hybrid" since the motor never propels the vehicle without engine power. In operation, the 2005 Accord hybrid exhibits enhanced performance compared to the conventionally powered Accord, but little or no gain in fuel economy.

In order to fully benchmark the HEV technology used in the 2007 Camry, a design characterization study was conducted to evaluate the vehicle's hybrid electric drive subsystem. A flow diagram which portrays the baseline benchmarking approach is shown in Fig. 1.1. The characterization study included (1) a design review, (2) a packaging and fabrication assessment, (3) bench-top electrical tests, (4) back-electromotive force (emf) and locked rotor tests, (5) performance and efficiency tests on the motor and inverter, (6) efficiency tests on the bi-directional boost converter, and (7) continuous duration tests of the drive motor and inverter. The design and packaging review includes comparisons to the 2004 Toyota Prius, which was evaluated during previous years. Results from the performance and efficiency tests were used to map electrical and thermal data for motor/inverter operation over the full range of speeds and shaft loads that the motor is capable of producing. The results of the design and packaging assessments are presented in Section 2 and the performance and efficiency tests results are presented in Section 3.

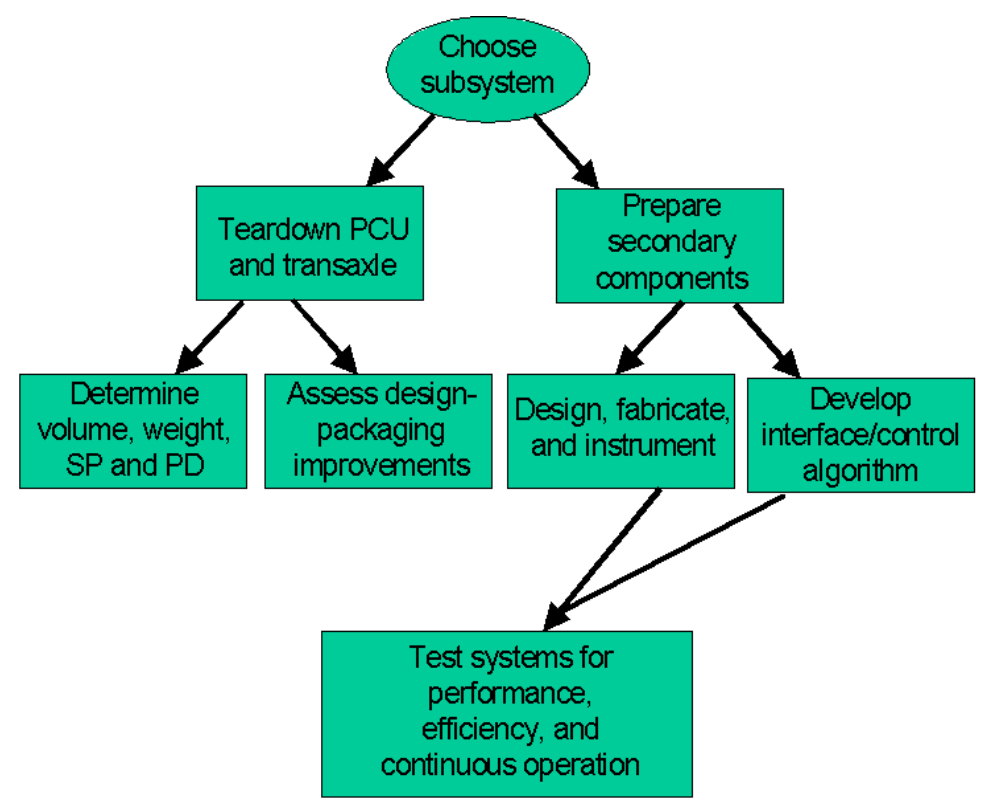

Fig. 1.1. Flow diagram of baseline benchmarking approach. 


\section{HYBRID ELECTRIC DRIVE SYSTEM DESIGN AND PACKAGING}

The hybrid Camry includes significant advancements in HEV technology since the electric drive system features higher peak power and more extensive continuous operation capabilities, yet the size and weight of the system has decreased when compared to that of the Prius. This is primarily due to the care taken in packaging the inverter/converter system and the design of a higher-speed, higher voltage permanent magnet synchronous motor (PMSM). The Camry HEV subsystem design and packaging will be assessed and summarized in this section.

Table 2.1 presents an overview of several general HEV design features and published specifications and indicates similarities and differences between the Camry and Prius vehicles. The primary drive PMSM is referred to as MG2 and the generator is referred to as MG1. Although both PMSMs can function as a motor or a generator, MG2 is commonly referred to as "motor" and MG1 is commonly referred to as "generator." Both MG1 and MG2 are powered by separate three-phase inverters which share the same direct current $(\mathrm{dc})$-link. The battery voltage is boosted by a bi-directional boost converter which feeds the dc-link. This configuration facilitates the use of multiple power flow modes wherein the ICE, MG1, and/or MG2 may supply energy to the battery pack, the battery pack may supply MG1/MG2 alone, or the ICE and battery pack can simultaneously power the vehicle.

Table 2.1. Comparison of hybrid Camry and the Prius design features and published specifications

\begin{tabular}{|c|c|c|}
\hline Design Feature & Hybrid Camry & 2004 Prius \\
\hline Motor peak power rating & $105 \mathrm{~kW} @ 4500 \mathrm{rpm}$ (disputed to be 70kW) & $50 \mathrm{~kW} @ 1200-1540 \mathrm{rpm}$ \\
\hline Motor peak torque rating & $\begin{array}{c}270 \text { Newton meter }(\mathrm{Nm}) \\
(667 \text { after speed reduction gear })\end{array}$ & $400 \mathrm{Nm}$ \\
\hline Top rotational speed & $14,000 \mathrm{rpm}(5,670 \mathrm{rpm}$ after speed reduction) & $6,000 \mathrm{rpm}$ \\
\hline Separate generator used? & $\begin{array}{l}\text { Yes (although the motor also serves as a } \\
\text { generator during regenerative braking) }\end{array}$ & Same as Camry \\
\hline Generator specifications & Not published & $33 \mathrm{~kW}$ \\
\hline Source of power to MG2 & Battery and/or ICE via generator & Same as Camry \\
\hline PMSM rotor design & $\begin{array}{l}\text { Interior permanent magnets (PMs) with "V" } \\
\text { configuration at each pole with a } \\
\text { reinforcement web in the laminations (middle } \\
\text { of the V) to enable high-speed operation }\end{array}$ & $\begin{array}{l}\text { Interior PMs with "V" } \\
\text { configuration at each pole } \\
\text { (no reinforcement) }\end{array}$ \\
\hline Motor winding configuration & Parallel & Series \\
\hline Number of rotor poles & 8 & Same as Camry \\
\hline Boost converter output voltage & $250-650$ Vdc output & 200-500 Vdc output \\
\hline Boost converter power rating & $30 \mathrm{~kW}$ & $20 \mathrm{~kW}$ \\
\hline PMSM cooling & $\begin{array}{l}\text { Oil circulation with water/glycol heat } \\
\text { exchanger }\end{array}$ & Same as Camry \\
\hline Inverter/converter cooling & Water/glycol loop & Same as Camry \\
\hline Hybrid transaxle & $\begin{array}{l}\text { Planetary gears used for speed reduction and } \\
\text { power split }\end{array}$ & $\begin{array}{l}\text { A single planetary gear } \\
\text { used for power split }\end{array}$ \\
\hline $\begin{array}{l}\text { Fan-cooled high-voltage (HV) } \\
\text { Ni-MH battery }\end{array}$ & $244.8 \mathrm{~V}, 6.5 \mathrm{Ah}, 30 \mathrm{~kW}$ & $201.6 \mathrm{~V}, 6.5 \mathrm{Ah}, 20 \mathrm{~kW}$ \\
\hline
\end{tabular}

Design and packaging assessments are presented in Subsections 2.1 and 2.2 beginning with the power control unit (PCU) and concluding with the transaxle. Studies on the PCU include subjects such as general design and packaging, power electronic devices, and multifaceted capacitor assessments. Assessment topics associated with the transaxle are general design and packaging, PMSM design, and magnet hysteresis measurements. These assessments provide useful feedback regarding technological developments and other characteristics needed to determine packaging complexity and fabrication costs. 


\subsection{PCU}

The general locations of the Camry inverters and the bi-directional boost converter assembly are shown in Fig. 2.1. The figure makes evident the fact that the motor and generator inverters, dc-link capacitor, and half of the cold plate comprise about $65 \%$ of the total volume. The buck/boost converter and half the cold plate comprise the remaining $35 \%$. The size and proportions of the PCU are similar to that of a conventional $12 \mathrm{Vdc}$ car battery.

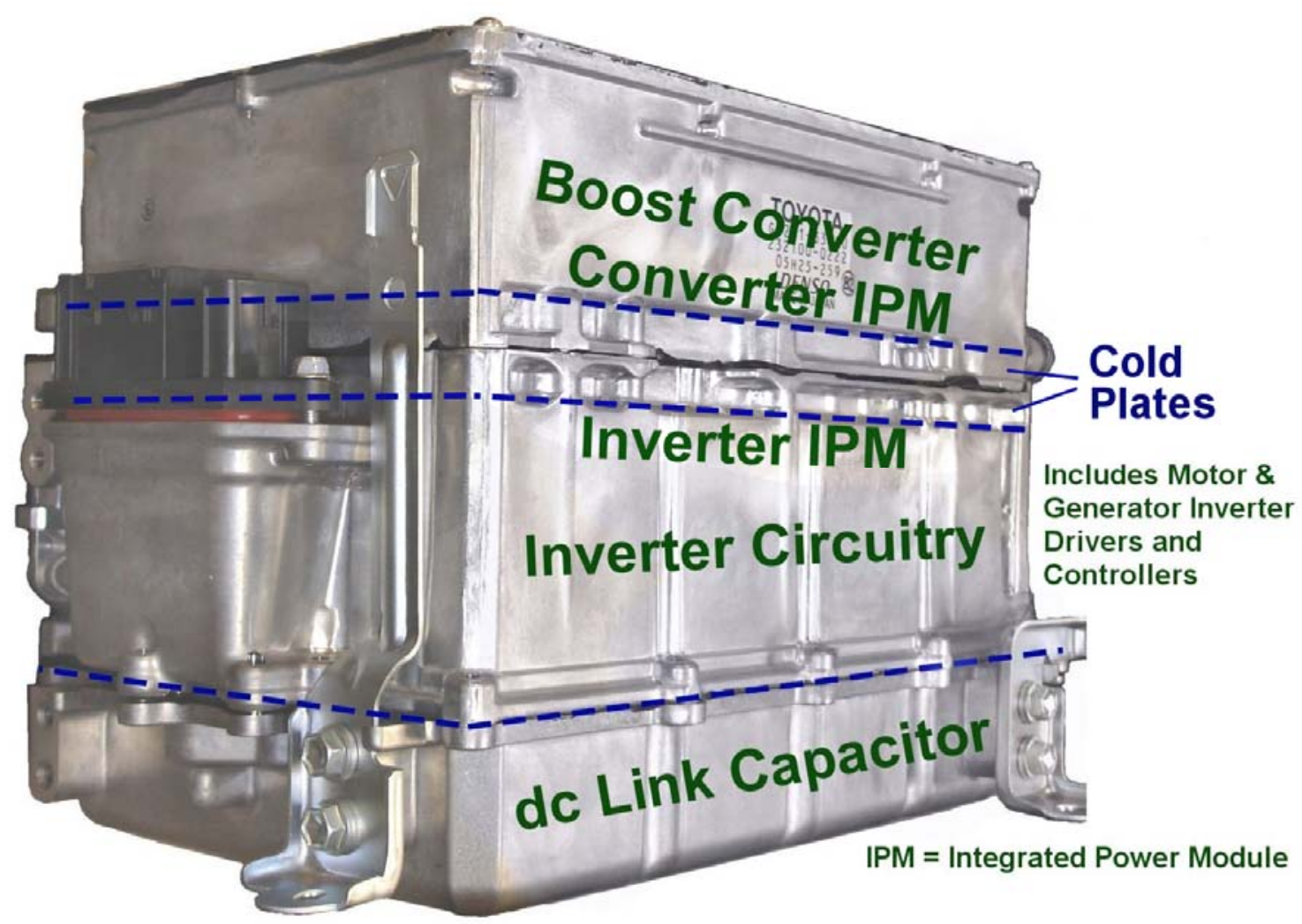

Fig. 2.1. Subsystems of the Camry inverter and converter assembly.

Because the Ni-MH battery is rated at $30 \mathrm{~kW}$, it is assumed that the boost converter will not operate at power levels exceeding $30 \mathrm{~kW}$. Similarly, it is assumed that the motor inverter has a peak power rating that matches the measured power rating of the motor.

The overall circuit diagram of the PCU is shown in Fig. 2.2. A $250 \mathrm{Vdc}$ battery supplies power to the PCU, which is connected to the low voltage (LV) side of the boost converter. A $500 \mathrm{~V}, 378 \mu \mathrm{F}$ capacitor is connected across the input with a $212 \mu \mathrm{H}$ inductor between the battery and the boost converter power electronics module. A small $53.8 \mathrm{k} \Omega$ resistor, $750 \mathrm{~V}, 0.9 \mu \mathrm{F}$ filter capacitor, and $750 \mathrm{~V}, 2098 \mu \mathrm{F}$ smoothing capacitor is located on the HV side of the boost converter. This HV bus serves as the de link for both the motor and generator inverter. Table 2.2 provides specification comparisons between the components found in the Prius and Camry PCU. The boosted voltage ranges from 250-650 Vdc depending on driving conditions such as desired acceleration and required regenerative braking and is controlled accordingly by commands from the MG electronic control unit (ECU) and the THS ECU. Detailed capacitor test results are provided in Section 2.1.3. 


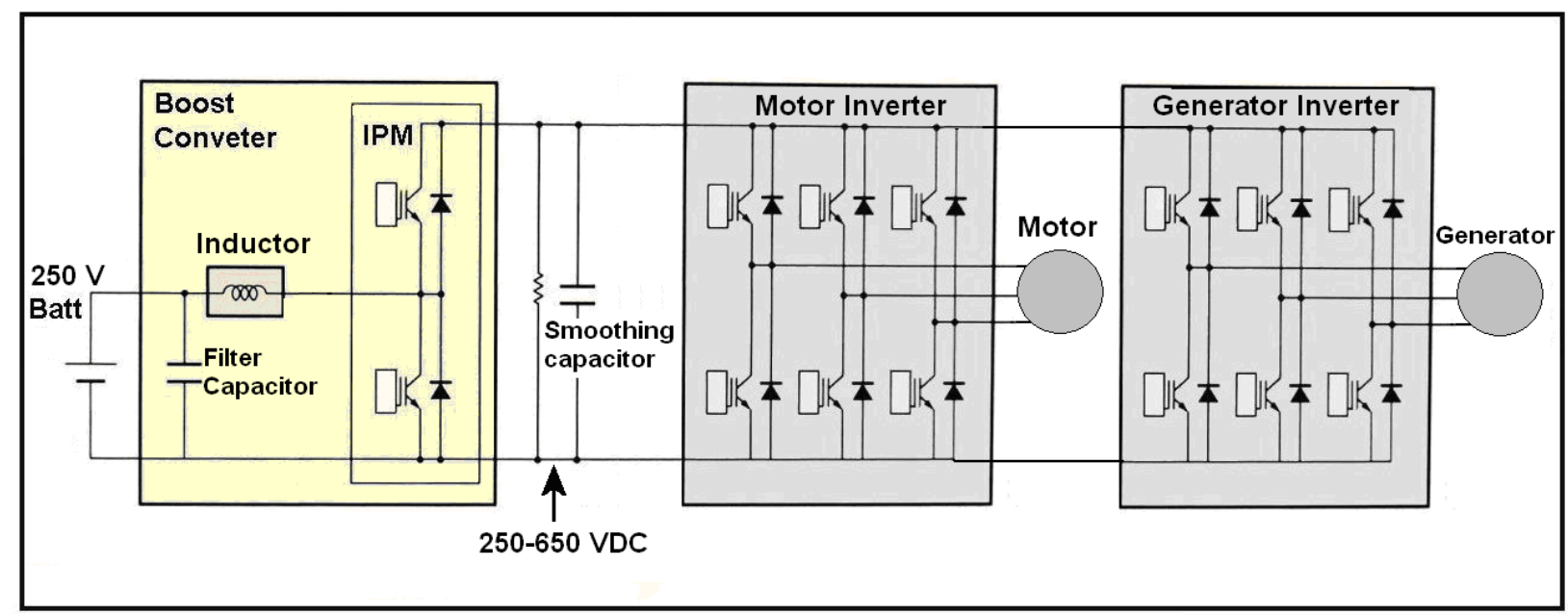

Fig. 2.2. Circuit diagram of PCU.

Table 2.2. Comparison of hybrid Camry and the Prius PCU component specifications

\begin{tabular}{|l|c|c|}
\hline \multicolumn{1}{|c|}{ Design Feature } & Hybrid Camry & 2004 Prius \\
\hline Boost converter power rating & $30 \mathrm{~kW}$ & $20 \mathrm{~kW}$ \\
\hline Battery voltage & $244.8 \mathrm{~V}$ & $201.6 \mathrm{~V}$ \\
\hline Filter capacitor (LV side) & $500 \mathrm{Vdc}, 378 \mu \mathrm{F}$ & $600 \mathrm{Vdc}, 282 \mu \mathrm{F}$ \\
\hline Inductor & $212 \mu \mathrm{H}$ at $1 \mathrm{kHz}$ & $373 \mu \mathrm{H}$ at $1 \mathrm{kHz}$ \\
\hline Small resistor (HV side) & $53.8 \mathrm{k} \Omega$ & $64.3 \mathrm{k} \Omega$ \\
\hline Small capacitor (HV side) & $750 \mathrm{Vdc}, 0.9 \mu \mathrm{F}$ & $750 \mathrm{Vdc}, 0.1 \mu \mathrm{F}$ \\
\hline Smoothing capacitor & $750 \mathrm{Vdc}, 2098 \mu \mathrm{F}$ & $600 \mathrm{Vdc}, 1,130 \mu \mathrm{F}$ \\
\hline
\end{tabular}

Figures 2.3 and 2.4 show the converter and inverter compartments, respectively, prior to disassembly. Figure 2.5 shows the general assembly and packaging of the major subcomponents of the Camry inverter and converter. Not shown for the inverter is the dc-link capacitor and its casing which serves as a cover to the inverter assembly. Because the inverter/converter assembly was designed to be integrated into an existing vehicle (the non-hybrid Camry), there was a need to package the unit in a minimal volume, which is evident in the figures provided in this section. The Camry MG ECU is located within the PCU just above the inverter driver board. Communication between the Camry MG ECU and other ECUs is accomplished though controller area network (CAN) digital data transmission. The Prius MG ECU is located outside of the PCU with analog control signals being transmitted over a conductor length of several feet. Together, the MG ECU and THS ECU monitor vehicle conditions and control the PCU components to orchestrate proper system operation.

In the inverter compartment, the controller board includes power regulation electronics, two identical MG microprocessors, a boost-converter microprocessor, two Tamagawa AU2802 integrated circuits (IC) for MG speed/position detection, hardware for CAN communication, MG current measurement, safety interlock devices, and temperature feedback. The driver board includes regulated isolation power supplies, isolated driver electronics, and hardware to prevent faults and overlapping as well as voltage, current, and temperature sensing circuitry for each insulated-gate bipolar transistor (IGBT). More information regarding the power electronics modules for the inverters and converter is provided in Section 2.1.2. 


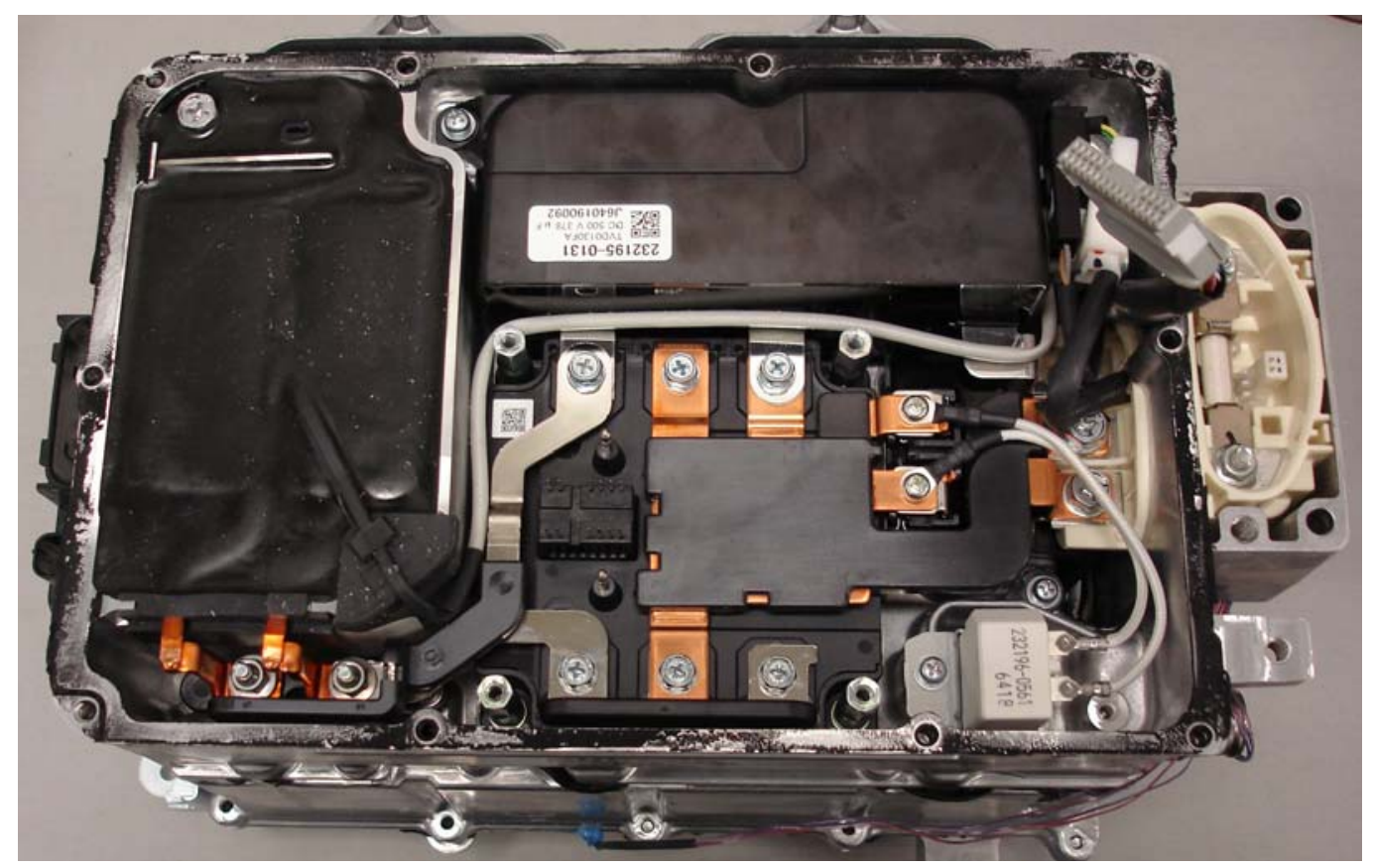

Fig. 2.3. Boost converter compartment with lid and intelligent power module (IPM) driver board removed.

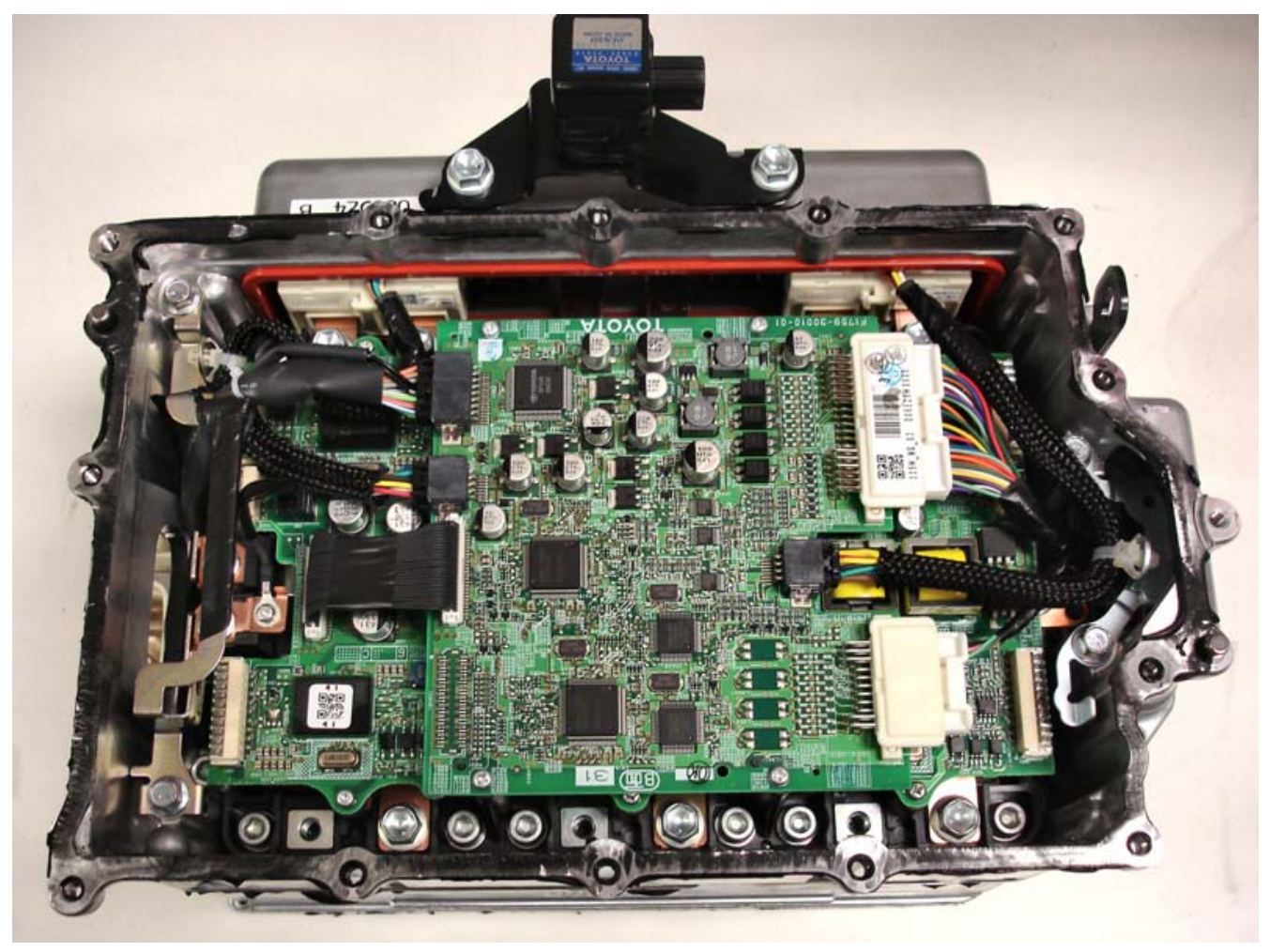

Fig. 2.4. Inverter compartment (upside down) with dc-link capacitor and casing removed. 


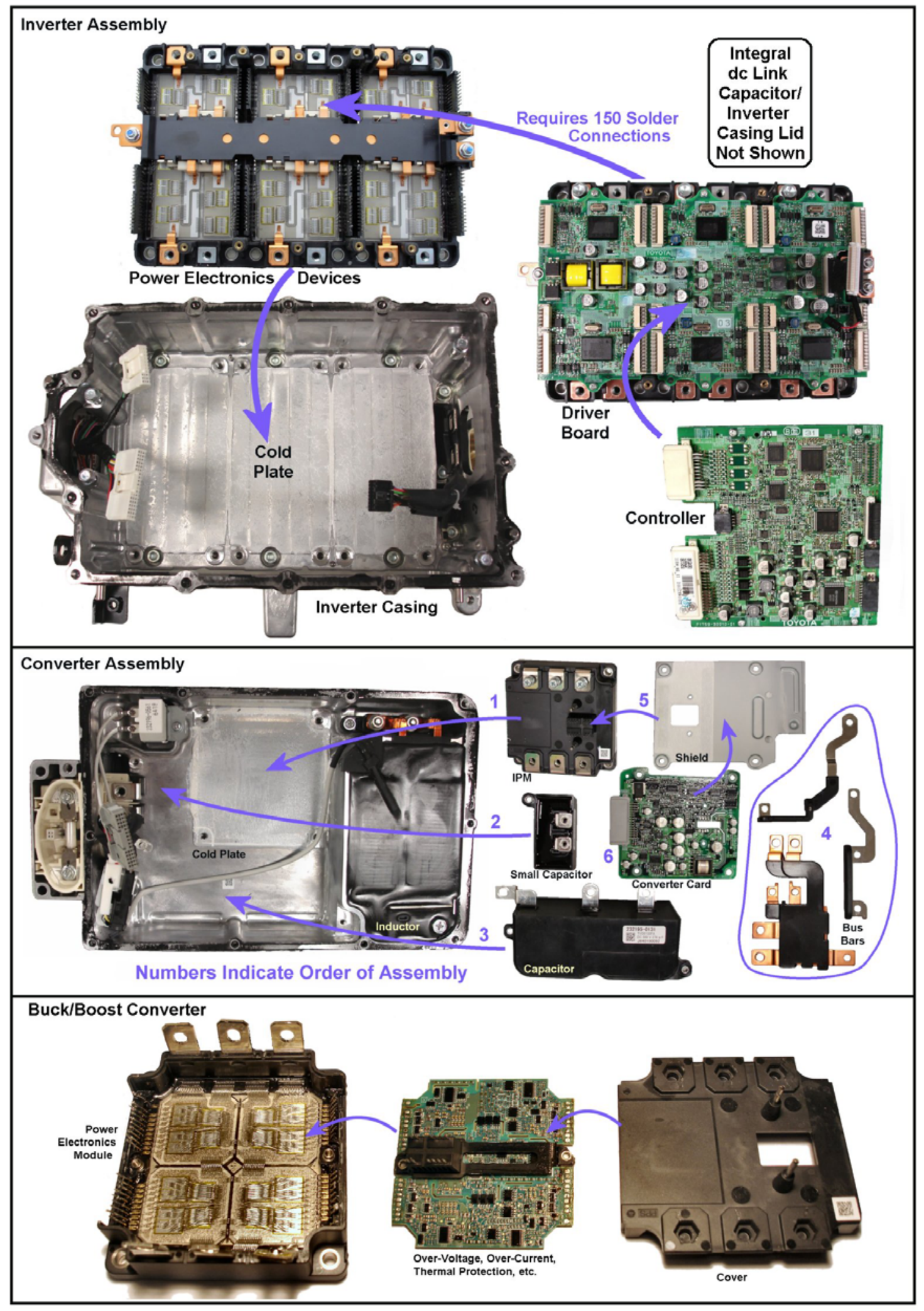

Fig. 2.5. General assembly and packaging of the Camry inverter and converter. 
The converter compartment contains the IPM, IPM driver, power supply board, LV filter capacitor, large inductor, bus bars, and an electromagnetic interference (EMI) shield for the circuit board. Additionally, a small filter capacitor and resistor are located in the upper portion of the PCU and are connected to the HV dc link. Connectors are also included for the inductor thermistor and safety interlock device feedback signals.

The Prius has an inverter which supplies power to the air conditioning $(\mathrm{A} / \mathrm{C})$ compressor, and it is located in the bottom section of the PCU, whereas the Camry A/C inverter is not housed within the PCU. A dc-dc converter which converts the high battery voltage of about $200 \mathrm{~V}$ to an accessory voltage level of about $14 \mathrm{~V}$ is also located in the bottom section of the Prius PCU, whereas this component is located in the battery module of the Camry.

Figure 2.6 shows the cooling plate coolant paths for the converter (top view) and inverter (bottom view) and an enlargement of the converter coolant path configuration. The inverter photo was flipped to make comparisons easier. The holes for the inlet and outlet coolant fittings are shown in the upper and lower left-hand corners of the cold plates. The fins increase the surface area and heat transfer, and the ripples are fabricated in the fin casting to create turbulence, which also increases heat transfer. Asymmetric features in the channel walls and/or no-fin areas promote mixing. In general, the design features are likely the result of detailed heat transfer/coolant flow modeling.

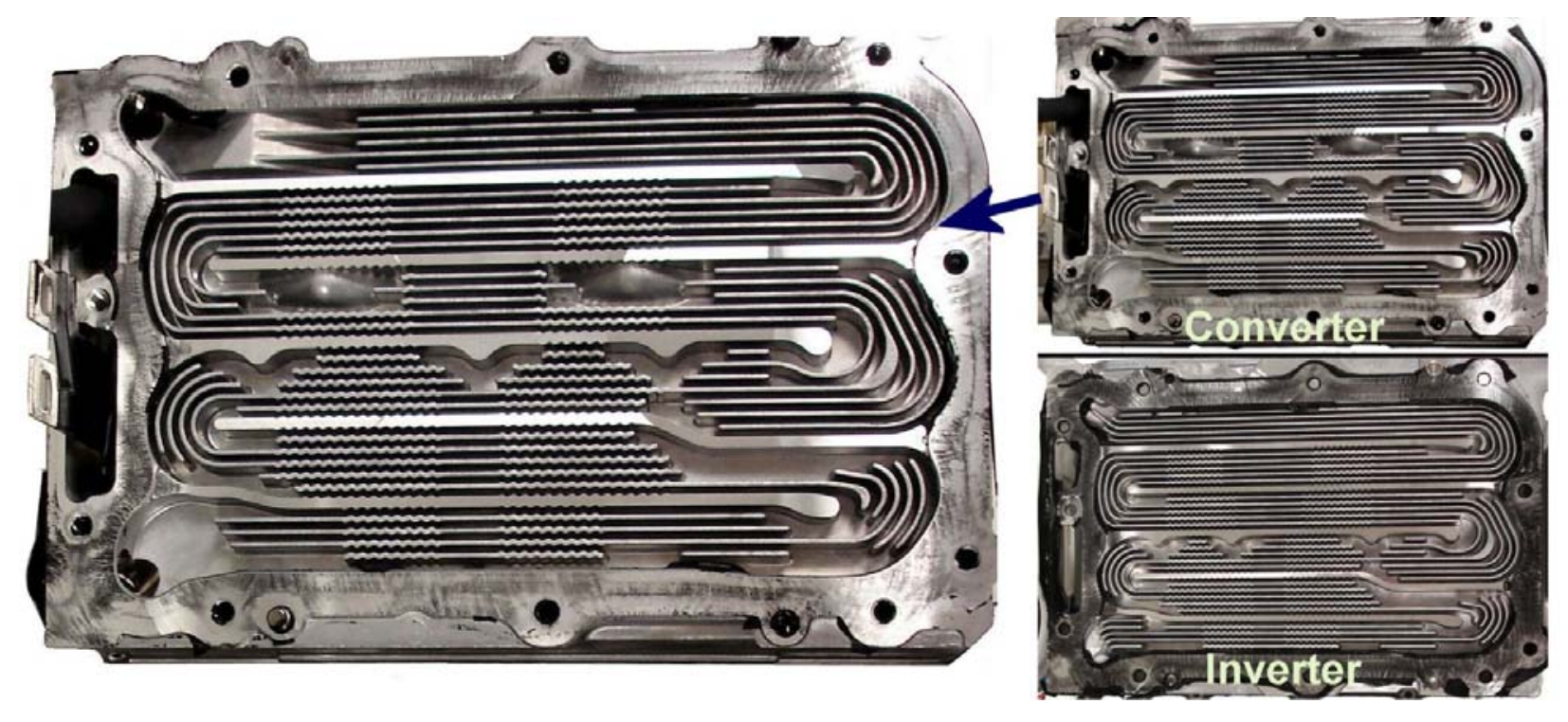

Fig. 2.6. Coolant flow paths in mating converter and inverter cold plates.

Table 2.3 provides physical measurements of the hybrid Camry inverter and boost converter. The inverter/converter casing was unbolted and separated in order to obtain precise mass measurements that are reflected in the total mass shown for each subsystem. The table also gives estimates for the mass and volume of the motor inverter by itself (i.e., excluding the generator inverter).

For certain components, the dimensions and volumes are approximate since the geometries are sometimes irregular. The entire aluminum casing unbolts and separates midway through the thickness of the cold plate and the volumes are divided up between the inverter and converter accordingly.

The mass of the large, potted inductor used in the buck/boost converter, although an integral part of the converter casing, is estimated to be $3.0 \mathrm{~kg}$. This estimate was derived by subtracting the estimated mass of the converter aluminum $(2.0 \mathrm{~kg})$ from the total measured mass of the two $(5.02 \mathrm{~kg})$. 
Table 2.3. Mass and volume measurements for the hybrid Camry inverter and converter

\begin{tabular}{|c|c|c|c|}
\hline Item & Mass (kg) & Volume (L) & Dimensions (cm) \\
\hline Inverter/converter as received from OEM. & $\begin{array}{c}17.86 \\
\text { (17.42 without } \\
\text { mounting } \\
\text { brackets) }\end{array}$ & 11.7 & $\begin{array}{l}\text { Summation of inverter and } \\
\text { converter sections (below) }\end{array}$ \\
\hline \multicolumn{4}{|l|}{ Inverters (MG1 and MG2) } \\
\hline DC-link capacitor mold in an aluminum case. & 3.57 & 2.6 & $18.5 \times 27 \times 5.3$ \\
\hline $\begin{array}{l}\text { Side housing assembly containing the three- } \\
\text { phase bus connectors and current transformers } \\
\text { (CTs). }\end{array}$ & 1.2 & 0.98 & $\sim 4.5 \times 23 \times 9.5$ \\
\hline $\begin{array}{l}\text { Inverter electronics and main casing to mid- } \\
\text { point of cooling plate. }\end{array}$ & 5 & 4.3 & $18.5 \times 27 \times 10.5$ \\
\hline Connector and housing at end of casing. & (incl. above) & 0.31 & $10.2 \times 3.8 \times \sim 8$ \\
\hline Complete inverters & 9.8 & 8.19 & Combine the above \\
\hline \multicolumn{4}{|l|}{ Inverter for motor only } \\
\hline DC-link capacitor mold in an aluminum case. & 3.57 & 2.6 & $18.5 \times 27 \times 5.3$ \\
\hline $\begin{array}{l}\text { Side housing assembly containing the three- } \\
\text { phase bus connectors and CTs. }\end{array}$ & 0.69 & 0.56 & $\sim 4.5 \times 12 \times 9.5$ \\
\hline $\begin{array}{l}\text { Inverter electronics and main casing to mid- } \\
\text { point of cooling plate. }\end{array}$ & $\sim 3.3$ & $\sim 2.8$ & $11.1 \times 27 \times 10.5$ \\
\hline Complete motor inverter & $\sim 7.5$ & $\sim 6$ & Combine the above \\
\hline \multicolumn{4}{|l|}{ Converter } \\
\hline Boost converter inductor. & $\sim 3.5$ & 1.14 & $8.8 \times 17.5 \times 7.4$ \\
\hline Converter filter capacitor. & 0.57 & 0.84 & $6.3 \times 18.1 \times 7.4$ \\
\hline Electronics compartment and casing. & $\sim 0.9+1.7$ & 1.51 & $11.3 \times 18.1 \times 7.4$ \\
\hline Complete converter & $\sim 6.6$ & 3.5 & $17.5 \times 26.9 \times 7.4$ \\
\hline
\end{tabular}

Based on the results shown in Table 2.3, Table 2.4 provides the peak power density and peak specific power of both the motor inverter and the bi-directional boost converter. Comparisons to corresponding estimates for the Prius are also shown. The Camry specifications in Table 2.4 are very impressive as the power density of the motor inverter and bi-directional boost converter has more than doubled when compared to that of the Prius. The Camry motor inverter specific power is also significantly larger, yet the boost converter specific power is only slightly higher as the mass increase closely followed the rated power increase.

Table 2.4. Specific power and power density estimates for inverter/converter

\begin{tabular}{|l|c|c|}
\hline \multicolumn{1}{|c|}{ Parameter } & Camry & Prius \\
\hline $\begin{array}{l}\text { Motor inverter peak specific power } \\
\text { (without converter), } \mathrm{kW} / \mathrm{kg} .\end{array}$ & $70 / \sim 7.5=\sim \mathbf{9 . 3}$ & $50 / 8.8=\mathbf{5 . 7}$ \\
\hline $\begin{array}{l}\text { Motor inverter peak power density } \\
\text { (without converter), kW/L. }\end{array}$ & $70 / \sim 6=\sim \mathbf{1 1 . 7}$ & $50 / 8.7=\mathbf{5 . 7}$ \\
\hline $\begin{array}{l}\text { Bi-directional boost converter specific } \\
\text { power, } \mathrm{kW} / \mathrm{kg} .\end{array}$ & $30 / \sim 6.6=\sim \mathbf{4 . 5}$ & $20 / 4.8=\mathbf{4 . 2}$ \\
\hline $\begin{array}{l}\text { Bi-directional boost converter power } \\
\text { density, } \mathrm{kW} / \mathrm{L} .\end{array}$ & $30 / 3.5=\mathbf{8 . 6}$ & $20 / 5.1=\mathbf{3 . 9}$ \\
\hline
\end{tabular}


It is interesting to note that the converter mass increased by $38 \%$ and the volume decreased by $31 \%$ in going from the 2004 Prius to the 2007 Camry PCU design. A mass increase is likely unavoidable given that the power increased from $\sim 20 \mathrm{~kW}$ to $\sim 30 \mathrm{~kW}$. Regarding the decrease of volume, the Camry converter has a small amount of associated null space as is evident in Fig. 2.7 while the Prius converter design (Fig. 2.8) integrates a tall inductor next to a short IPM resulting in wasted space above the IPM and additional wasted space exists around both components. Not shown in Fig. 2.8 is the volume of the converter portion of the monolithic capacitor module and surrounding space. Although the potential exists for easily reducing the volume of the Prius converter, the volume calculation is based on the actual dimensions of the casing. However, the component specifications are provided separately to allow for various approaches of calculating specific power and power density. See Appendix A for details on the measurement of the Prius PCU and motor inverter mass and volumetric assessment details.
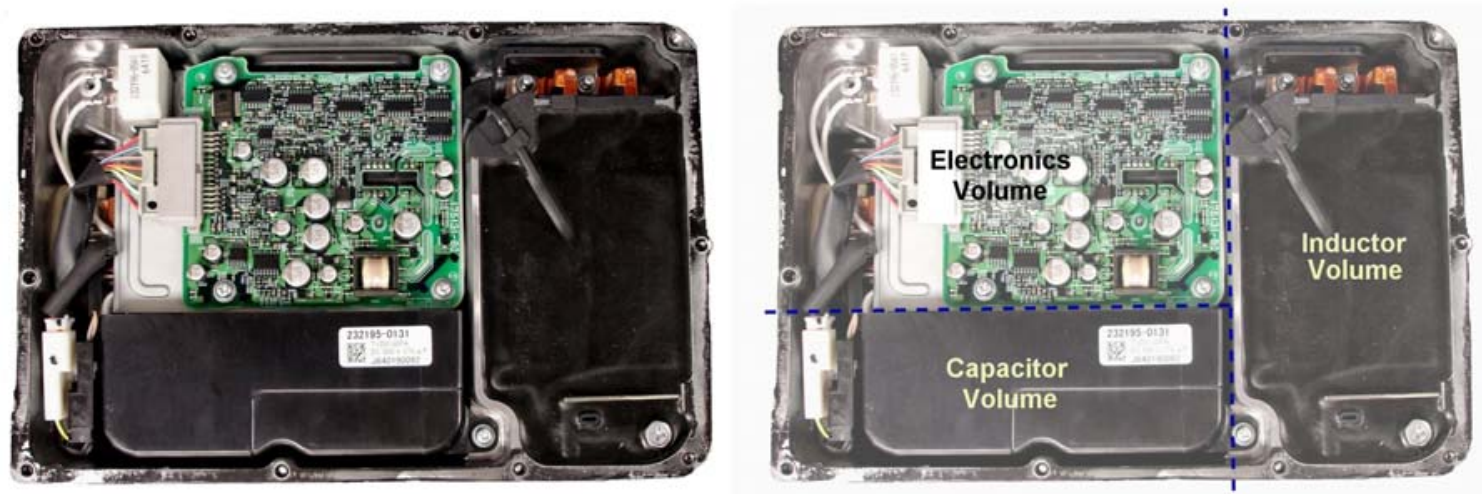

Fig. 2.7. Converter assembly with subsections shown consistent with volume measurements.

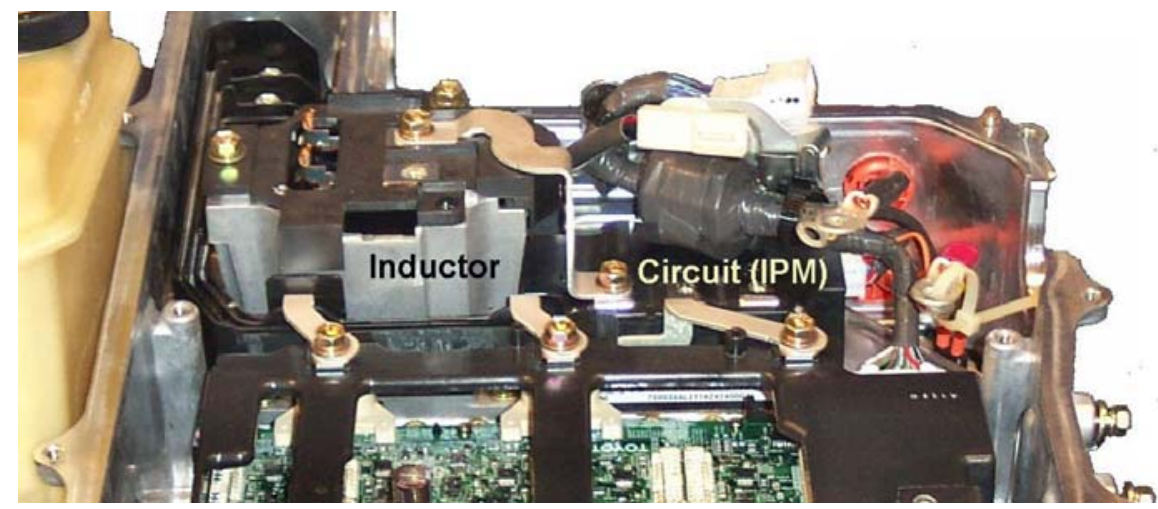

Fig. 2.8. Non-optimized packaging used in the 2004 Prius converter.

All capacitors located within the Camry PCU are shown in Fig. 2.9 for a comparison of sizes. It is important to note that that the Prius capacitor module contains both capacitors which are connected to the HV and LV side of the bi-directional boost converter as well as a small filter capacitor, whereas the Camry capacitors are housed in separate modules. Figure 2.10 shows the Camry dc-link capacitor and a negative image of an x-ray of the capacitor. The x-ray shows that there are two rows of 12 discrete submodules inside the entire capacitor module, with each capacitor having a capacitance of $87 \mu \mathrm{F}$. The equivalent Prius capacitor has $8-142 \mu \mathrm{F}$ capacitors in parallel to provide a total capacitance of $1,130 \mu \mathrm{F}$. Figure 2.11 shows the $378 \mu \mathrm{F}$ Camry filter capacitor and an $\mathrm{x}$-ray of the capacitor which is across the battery input of the PCU. As suggested by the x-ray image, the $378 \mu \mathrm{F}$ capacitance is attained with two $189 \mu \mathrm{F}$ capacitors in parallel. Similarly, the small $0.9 \mu \mathrm{F}$ capacitor is made up of two $0.45 \mu \mathrm{F}$ capacitors, 
as shown in Fig. 2.12. Various characteristics of these capacitors were measured and are presented in Section 2.1.3.

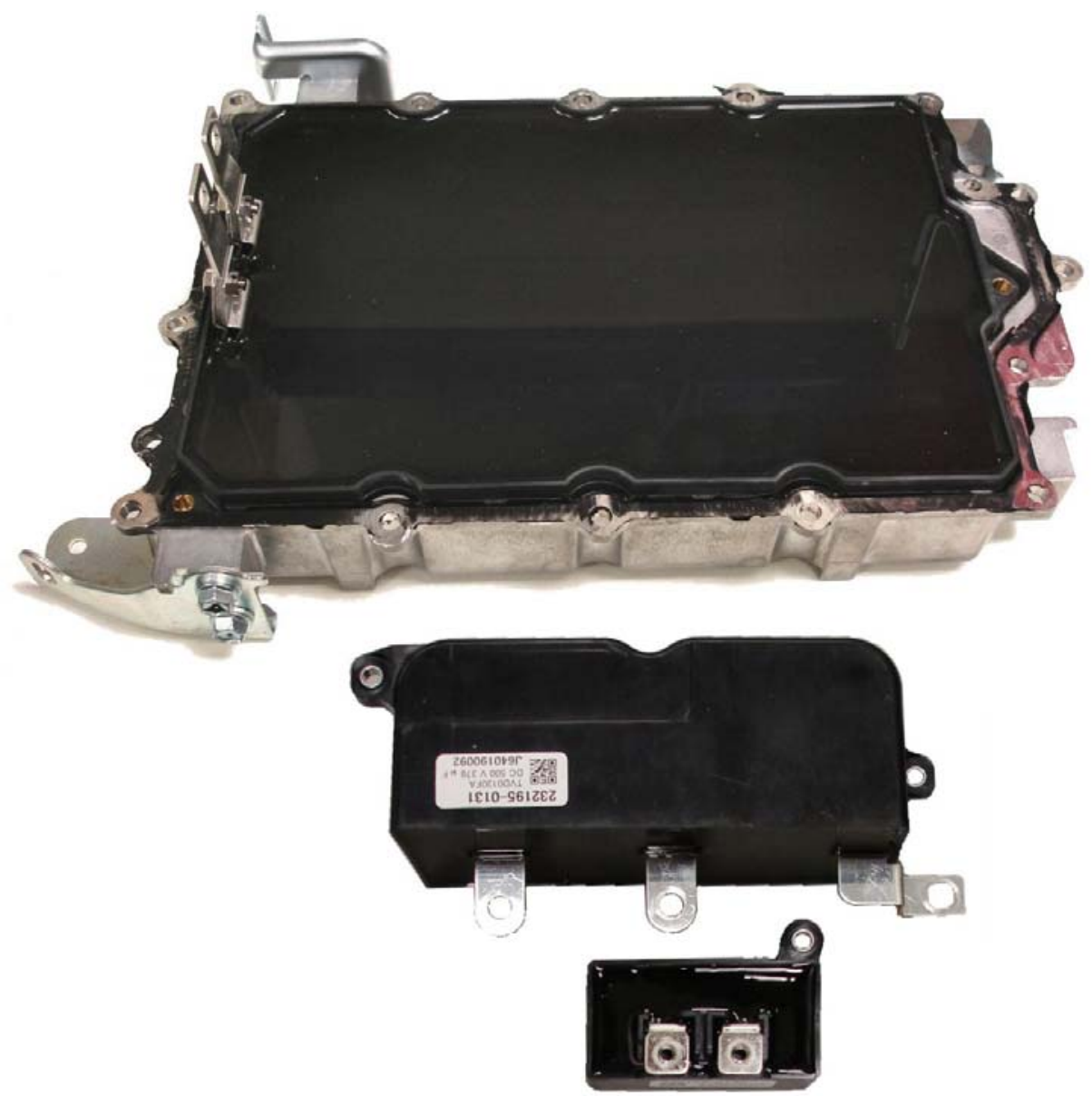

Fig. 2.9. Comparison of all capacitors located within Camry PCU.

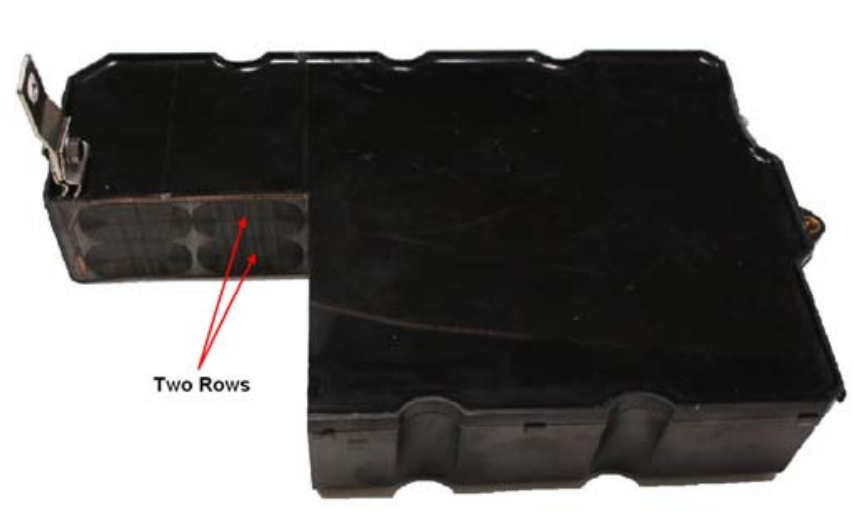

dc Link Capacitor: 2098 ufd @ 700 v

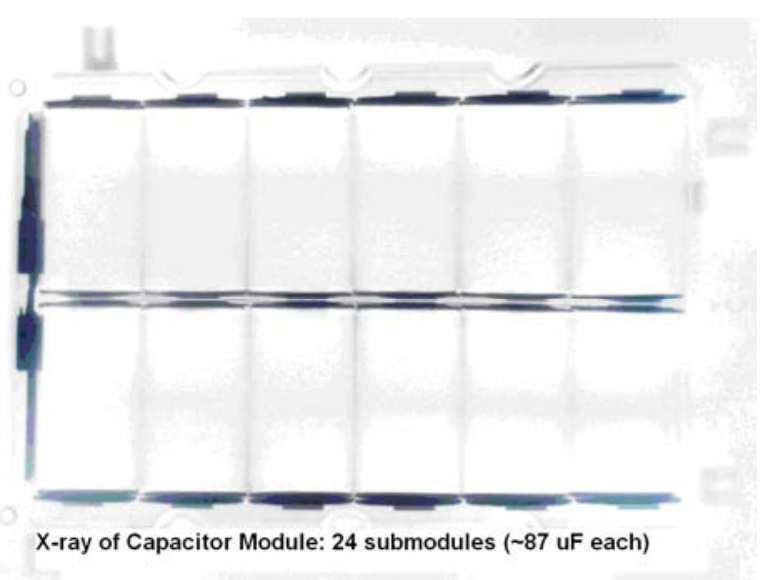

X-ray of Capacitor Module: 24 submodules ( $\sim 87$ uF each)

Fig. 2.10. Cutaway of de-link capacitor removed from shell (left) and $x$-ray of module (right). 


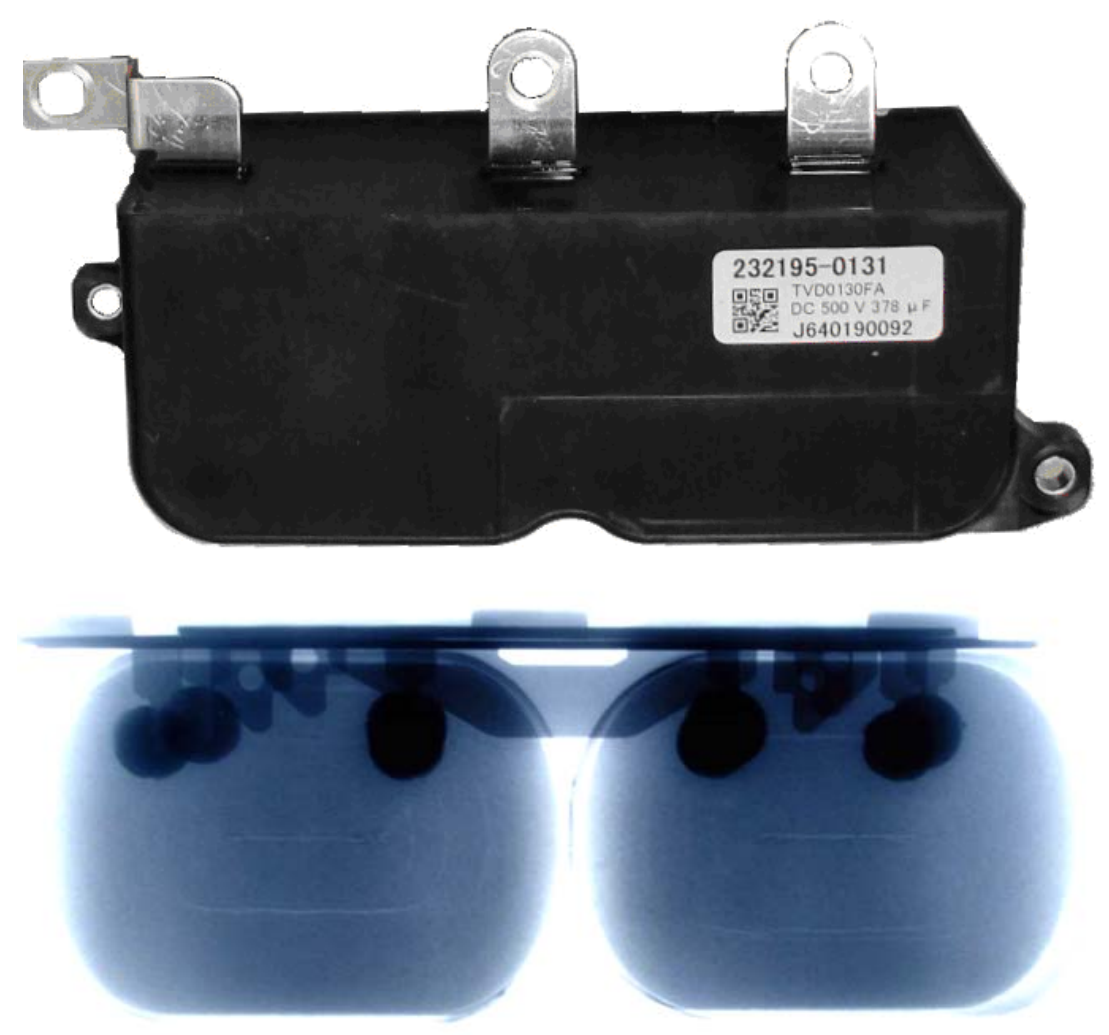

Fig. 2.11. Battery level capacitor (upper) and x-ray of module (lower).
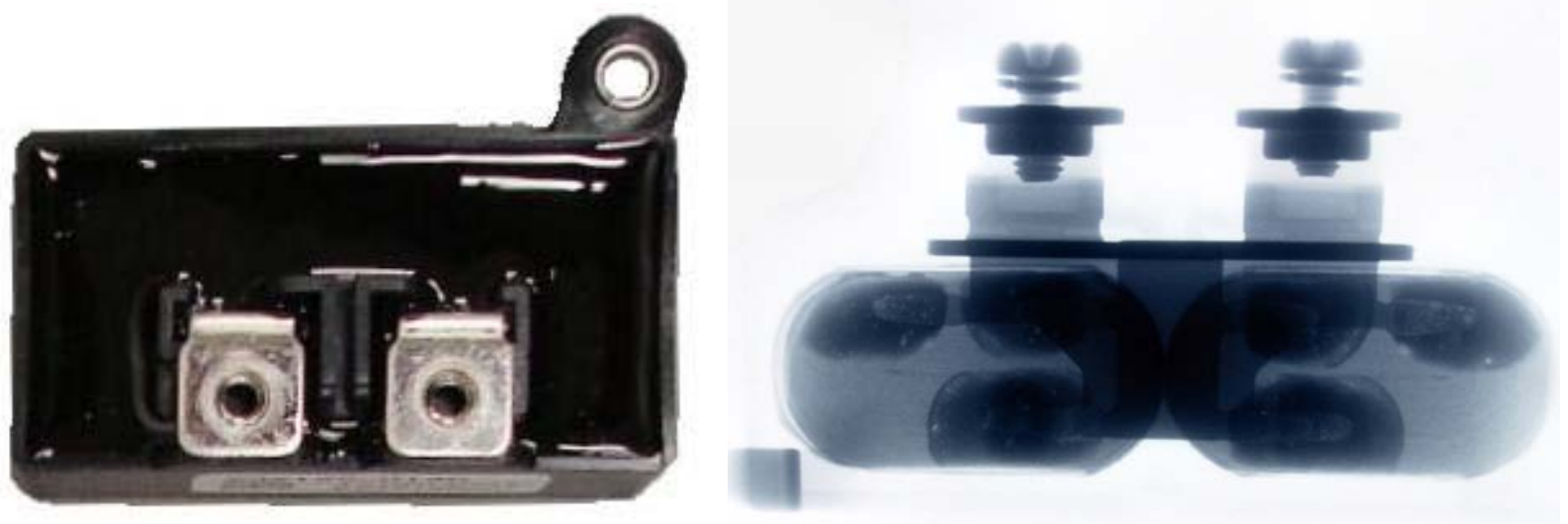

Fig. 2.12. Small dc-link capacitor: overhead view (left) and $x$-ray of module - side view (lower).

Figure 2.13 shows a view of the inverter/converter assembly upside down with the three-phase motor and generator bus connector assembly unbolted and detached. It can be seen that CTs are used on two of the three bus connectors. The red rubber seal inserts into the inverter housing in order to facilitate a sealed union. In general, the inverter and converter housings are very well sealed and are water tight to prevent contamination and corrosion from environmental effects. 


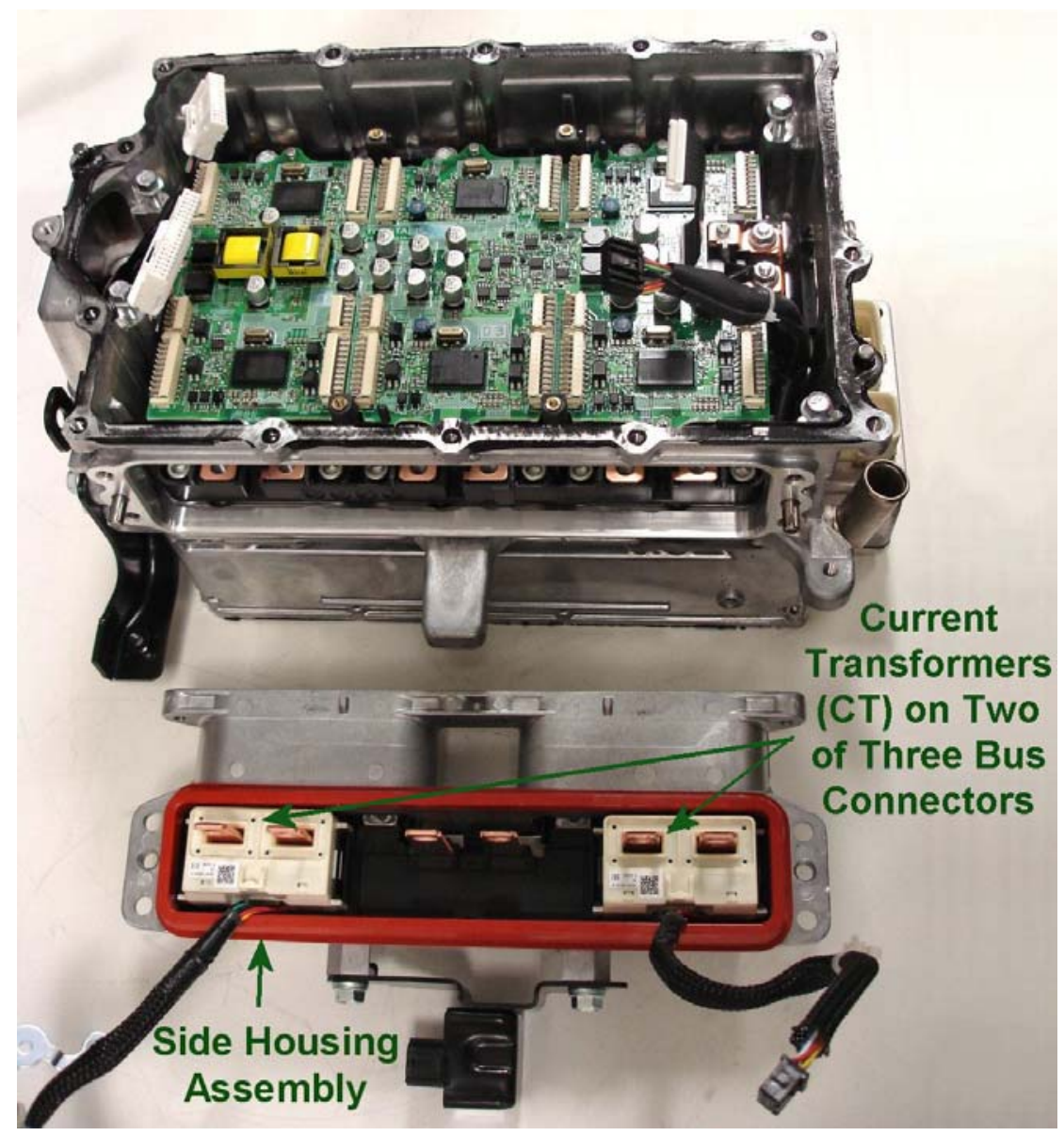

Fig. 2.13. Side housing removed from inverter section of PCU (shown upside down).

\subsubsection{Power Electronics Devices}

The general packaging features of the Camry inverter and converter power electronic devices were assessed and compared to the Prius designs. Figure 2.14 shows a comparison between the Camry and the Prius IPMs which were photographed while sitting adjacent to each other. All power electronic devices shown are immersed in a high-temperature, protective silicone gel. Although the power capability of the IPM increases from the Prius to the Camry, the size of the IPM noticeably decreases. The general layout of the IPM design is similar, wherein the shared dc bus, indicated by the red line, runs between the motor and generator inverters. However, a closer inspection yields several differences between the two. Bus bars are used to interconnect the dc link and phase outputs to the power electronics devices of the Prius IPM, yet the Camry IPM does not use a conventional bus bar architecture to accomplish this task. Instead, a more interweaved layout is used which enhances the area utilization of the IPM. The Camry IPM layout allows for the space below the dc-bus bars to be used as extra surface area for power electronics devices, as shown in Fig. 2.15. It can also be noticed that there is enough space for the Camry generator inverter to contain twice the number of IGBTs than what is currently present. Toyota has made an effort to standardize the size of the PCU and this space is likely utilized in HEVs with larger power trains, such as the Toyota Highlander HEV or the Lexus GS450h. The maximum power supplied to the motor inverter must be less than (due to losses) the sum of the battery power and the generator power. It is likely that the full capability of the motor inverter is not fully utilized in the vehicle, as the generator inverter can supply only $1 / 3$ of the power capability to the motor inverter and any additional power must be supplied by the battery which has a power rating of $30 \mathrm{~kW}$, and the combined peak power is approximately $70 \mathrm{~kW}$. 

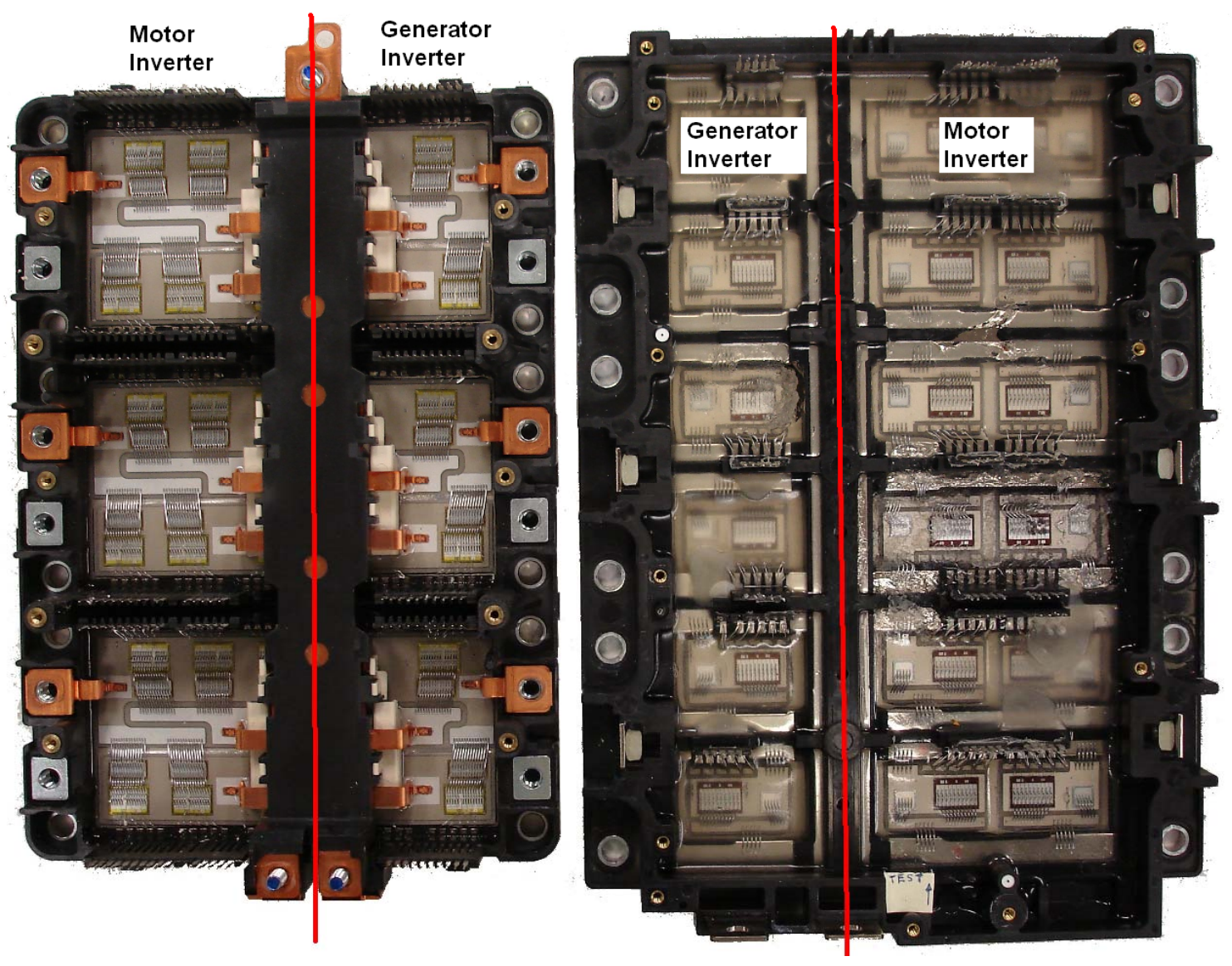

Fig. 2.14. Comparison of Camry inverter IPM (left) and Prius inverter IPM (right).

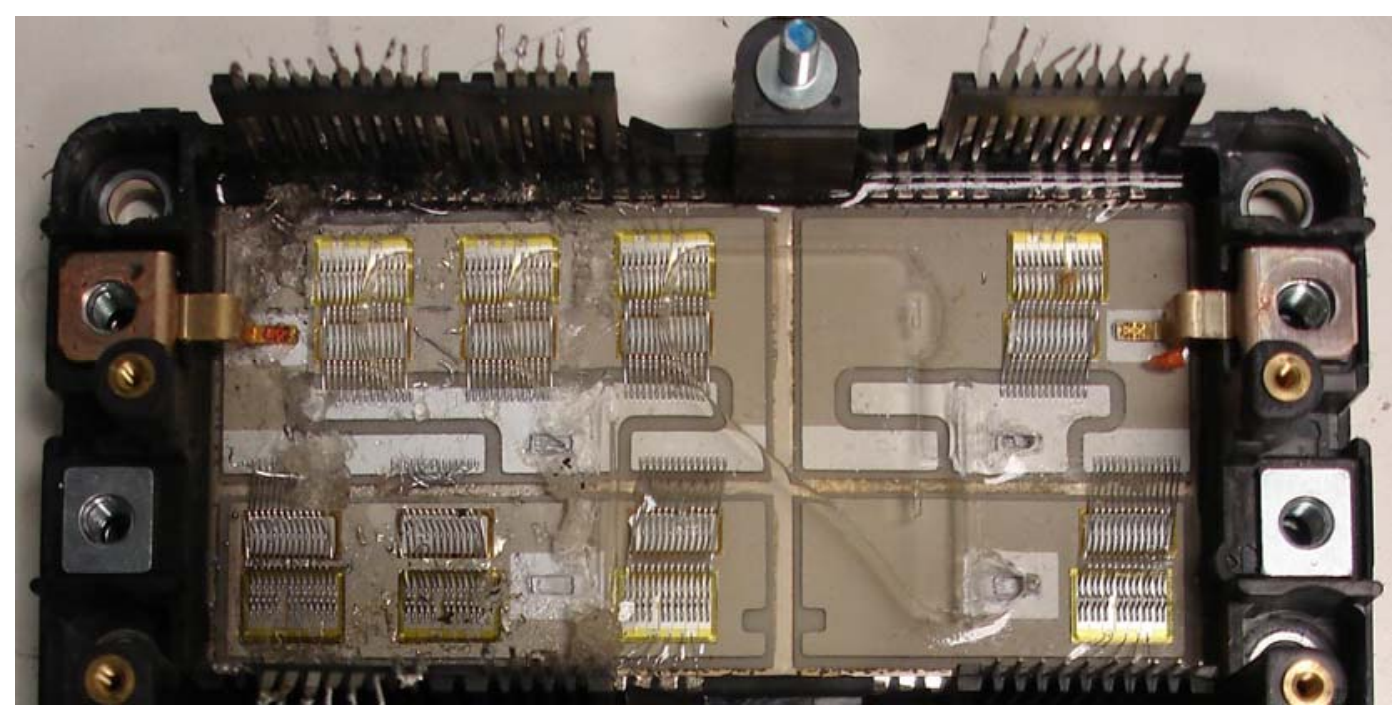

Fig. 2.15. Camry IPM with dc-bus bars removed.

Figure 2.16 provides a more detailed representation of the design discrepancies as well as a dimensional comparison of the IGBTs and diodes of the Camry and Prius inverter power electronics. Since the emitters and collectors of the Camry IPM are not connected to bus bars as they are in the Prius, additional room is available for situating the diodes in an orientation which is more efficient in terms of surface area 
utilization. In the Prius inverter image shown in Fig. 2.16, the IGBT emitter and diode anode are tied to a common metal plate, which is connected to a bus bar that is partially visible on the left edge of the image. The IGBT collector and diode cathode are connected to a bar which is just beyond the right edge of the image. Conversely, the Camry dc link and three-phase outputs connect directly to the emitter-anode common plate and the collector-cathode surface, thereby eliminating the use of a bus bar infrastructure.

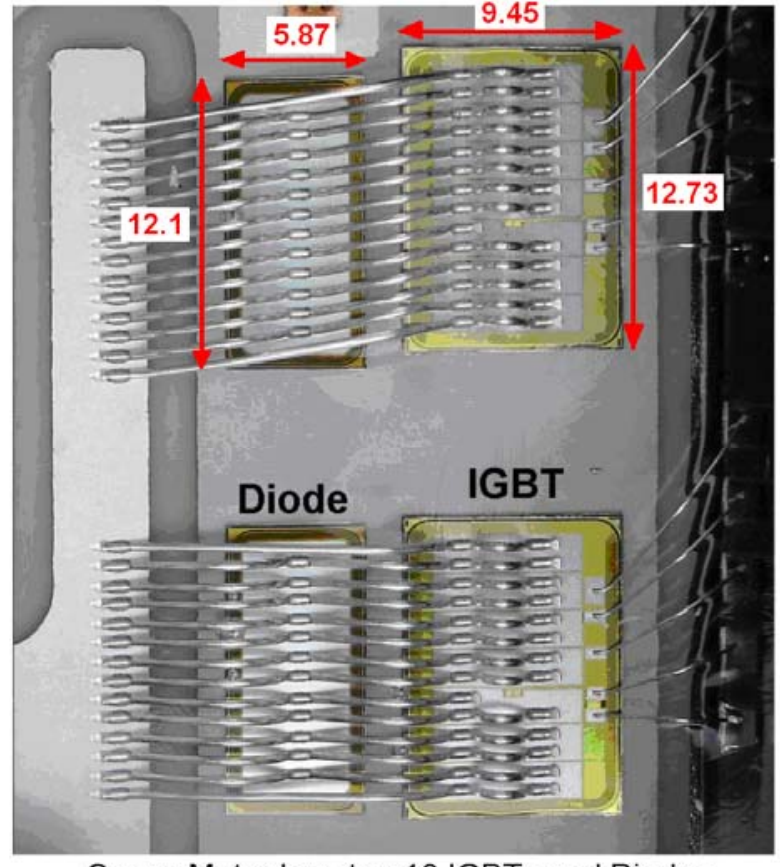

Camry Motor Inverter: 18 IGBTs and Diodes

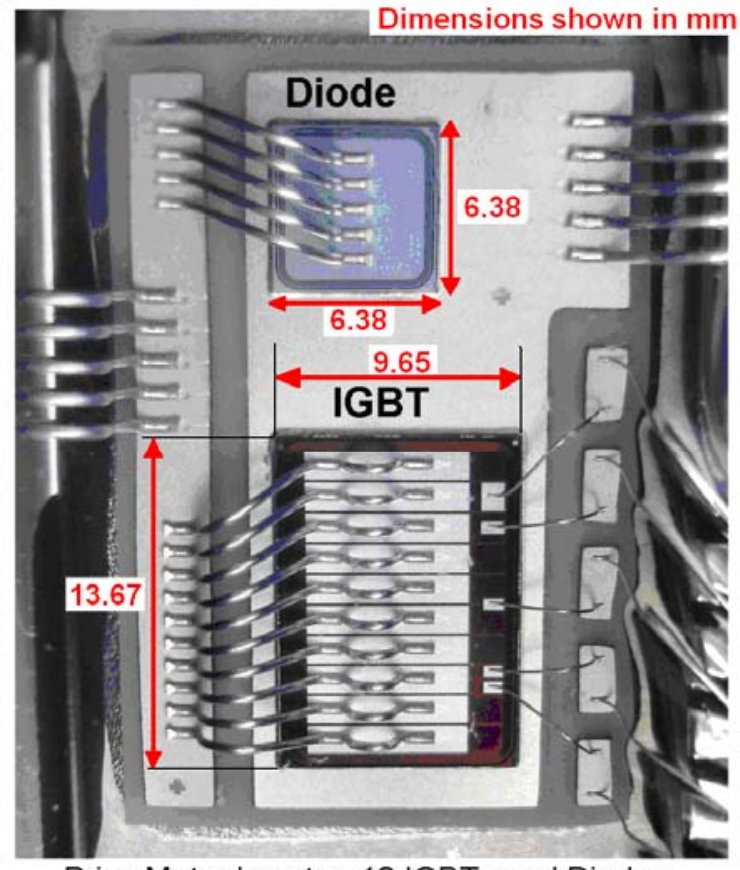

Prius Motor Inverter: 12 IGBTs and Diodes

Fig. 2.16. Dimensions (in mm) of Camry inverter IPM (left) and Prius inverter IPM (right).

As indicated by the labeled dimensions, the Camry inverter IGBT size has decreased from the Prius inverter IGBT size in both length and width, whereas the size of the diode increased significantly. Although the Camry IGBT chip size has decreased when compared to that of the Prius IGBT, the power capability has increased slightly. This is primarily due to the use of a trench gate structure as opposed to the planar gate structure used in the Prius. The planar gate structure includes areas in the drift region below the emitter " $n+$ " and " $p$ " regions which do not pass as much current as the drift region areas below the gate. This inefficiency is due to the shape of the inversion layer which is formed when using a planar gate structure. An IGBT with a trench gate structure forms a more uniform inversion layer during on-state operation, and therefore higher current densities are created in the drift region. Additionally, the voltage rating of the Camry IGBT devices has increased, facilitating higher power capability and higher power density of the generator, motor, and the respective inverters.

A detailed comparison of the Camry and Prius IGBTs is shown in Fig. 2.17. The Camry IGBT contains two wire bonds for each emitter strip, whereas the Prius only has one wire bond for each emitter strip. Both IGBTs include leads for semiconductor junction temperature measurement feedback, gate voltage control, current measurement, and emitter voltage feedback. These signals are used to control the device and prevent fault conditions from occurring. Cross-sectional views of the IGBTs are provided in Fig. 2.18. Small metallic nodes are visible on the Camry IGBT, yet there is no evidence of these nodes on the Prius IGBT. These nodes are likely associated with the trench gate structure, but are not directly associated with the trench pitch as the metal nodes are separated by about $20 \mu \mathrm{m}$, which is much larger than typical trench pitches. 


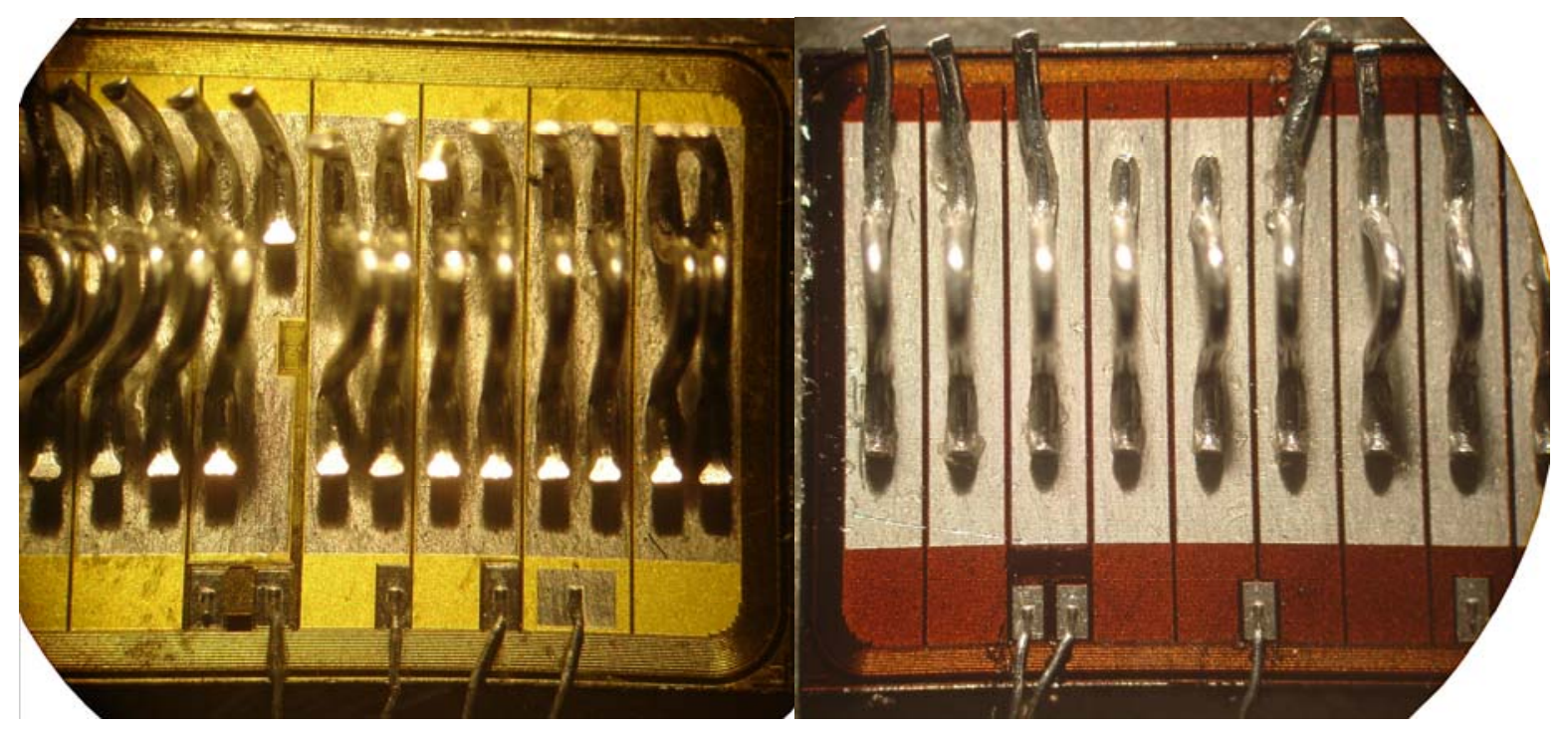

Fig. 2.17. Close-up view of Camry inverter IGBT (left) and Prius inverter IGBT (right).
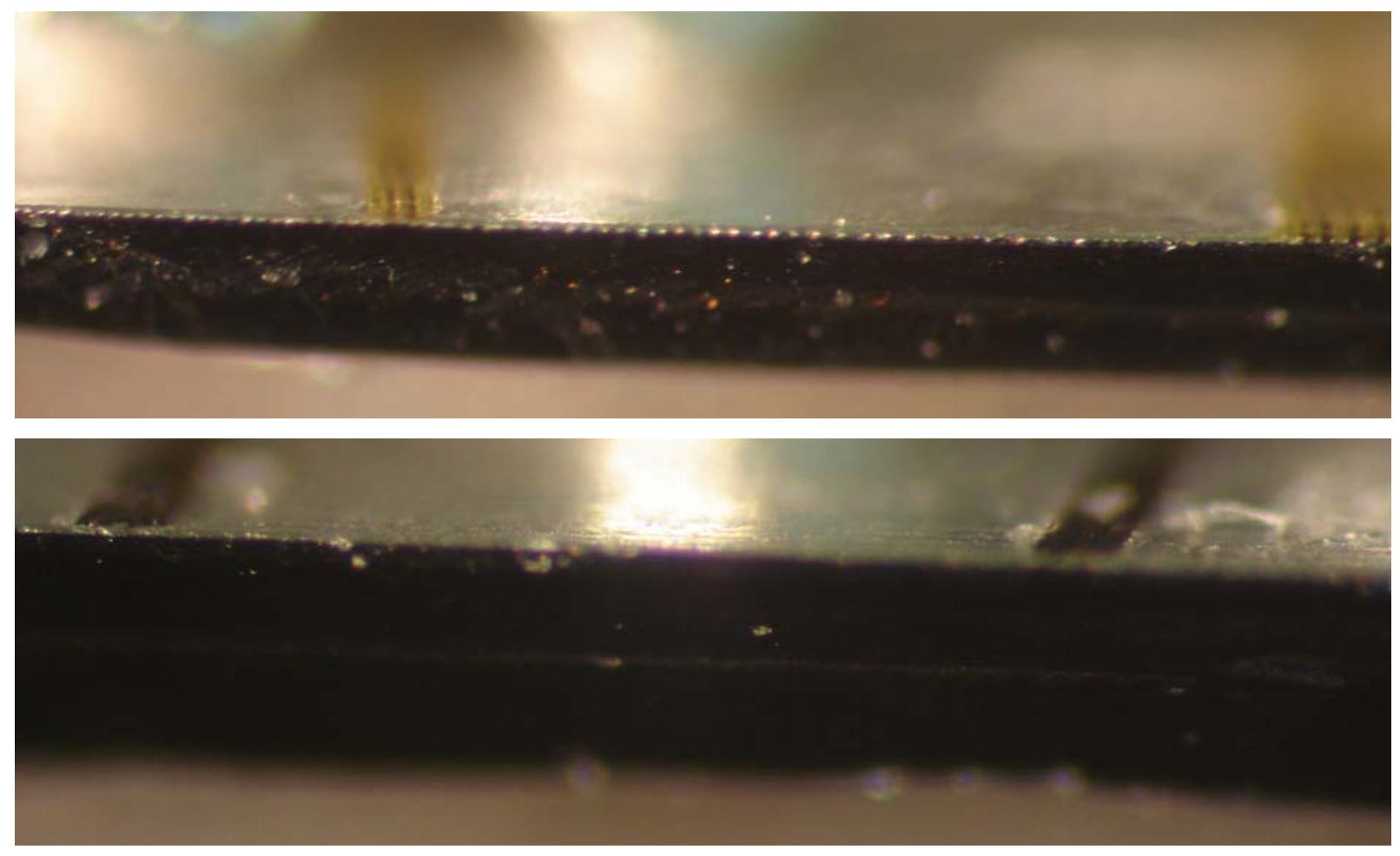

Fig. 2.18. Cross-sectional view of Camry IGBT (upper) and Prius IGBT (lower).

Diodes from the Camry and Prius inverters are shown in Fig. 2.19. The shape of the Camry inverter diode is elongated providing well-suited orientation with the adjacent IGBT. Several traces are located around the perimeter of the Camry and Prius diodes and IGBTs, which is possibly a preventative measure against catastrophic arcing. 


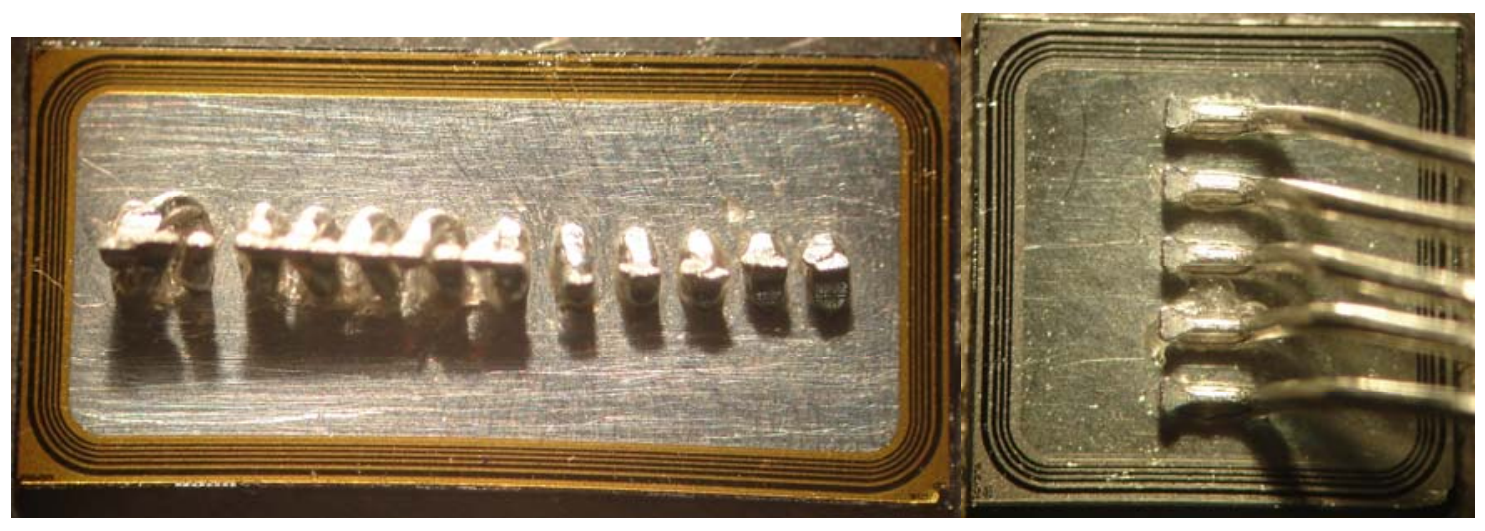

Fig. 2.19. Close-up view of Camry inverter diode (left) and Prius inverter diode (right).

The Camry and Prius boost converter IPMs are shown in Fig. 2.20. Although the power rating of the boost converter has increased by 50\% from the Prius, the area of the Camry boost converter IPM footprint is only slightly larger than that of the Prius. Similar to the discrepancies between the inverters, smaller bus architecture is used in the Camry boost converter IPM. There is a considerably larger amount of null space within the Prius boost converter module. The Camry boost converter has four IGBTs and diodes in parallel for the upper portion of the IPM and four IGBTs and diodes in parallel for the lower portion of the IPM. The four upper IGBTs and four lower diodes are primarily used during regenerative braking and recharging situations. The four lower IGBTs and four upper diodes are primarily used to boost the battery voltage. The Prius boost converter IPM is similar in functionality, but has only two IGBTs and two diodes in parallel for the upper and lower portions. The Prius boost converter IPM also only has three terminals versus six on the Camry IPM, four of which are used to conduct power. The upper-left terminal does not connect to the IPM, but serves as a support for the negative dc-link bus bar and capacitor connection. The lower-left terminal serves as a support for the positive dc-link bus bar (which connects to the inductor) and capacitor connection, and through a small wire it is connected to a pin which interfaces with the IPM driver-board.
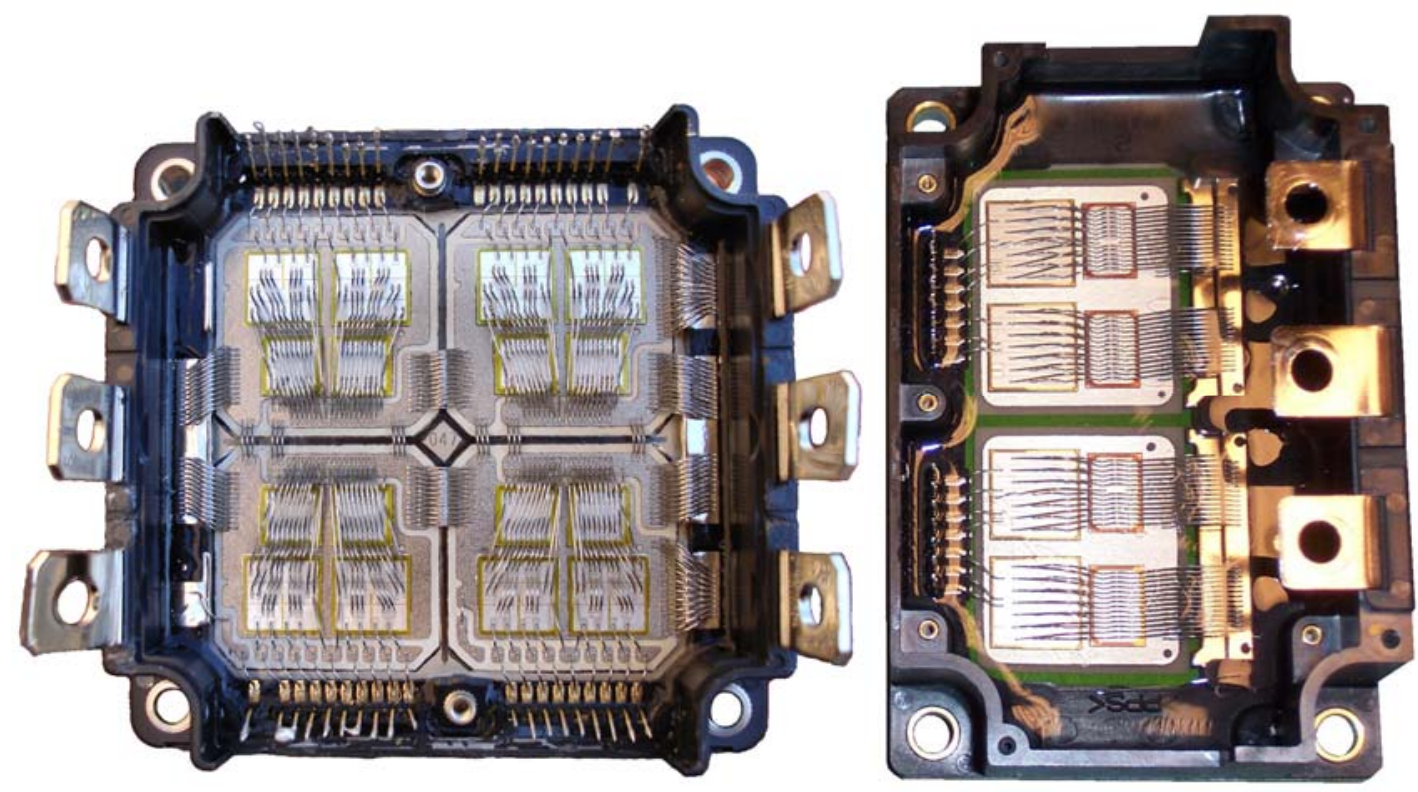

Fig. 2.20. Comparison of Camry converter IPM (left) and Prius converter IPM (right). 
Figure 2.21 provides a close-up comparison of the power electronics devices of the Camry and Prius boost converter IPMs. The fabrication process for the Camry boost converter IPM is more intricate due to the increased number of devices that need to be interconnected, thereby increasing wire bond count and driver and sensor feedback signals.

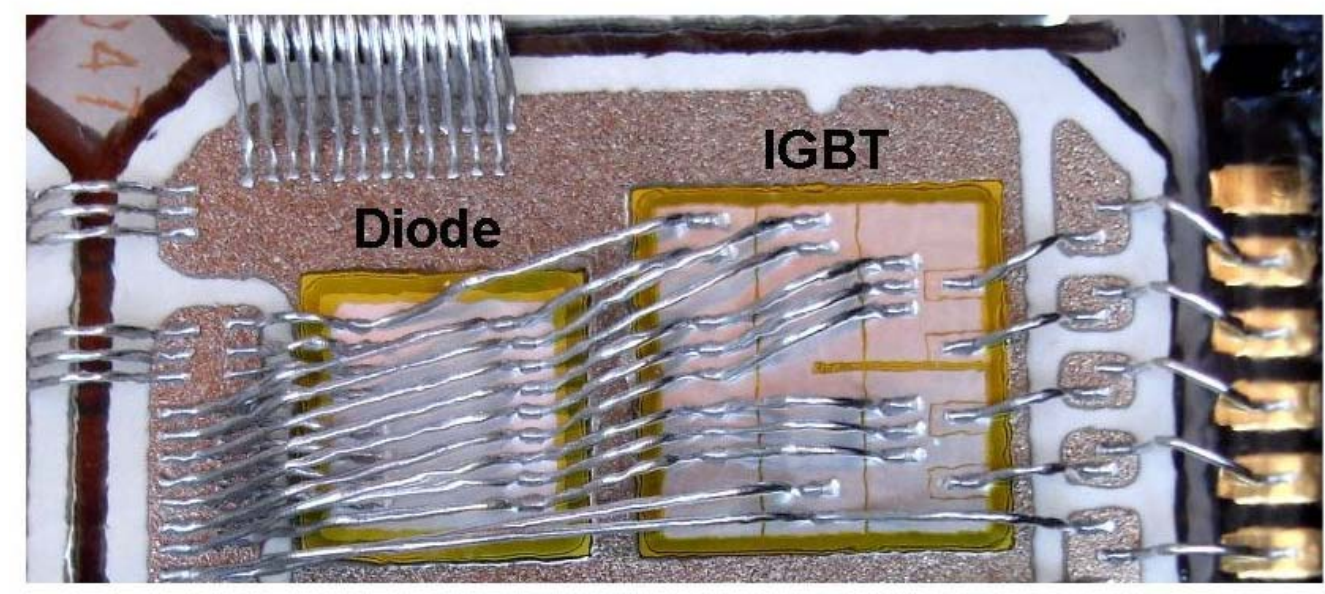

\section{Camry Converter: 8 IGBTs and Diodes}

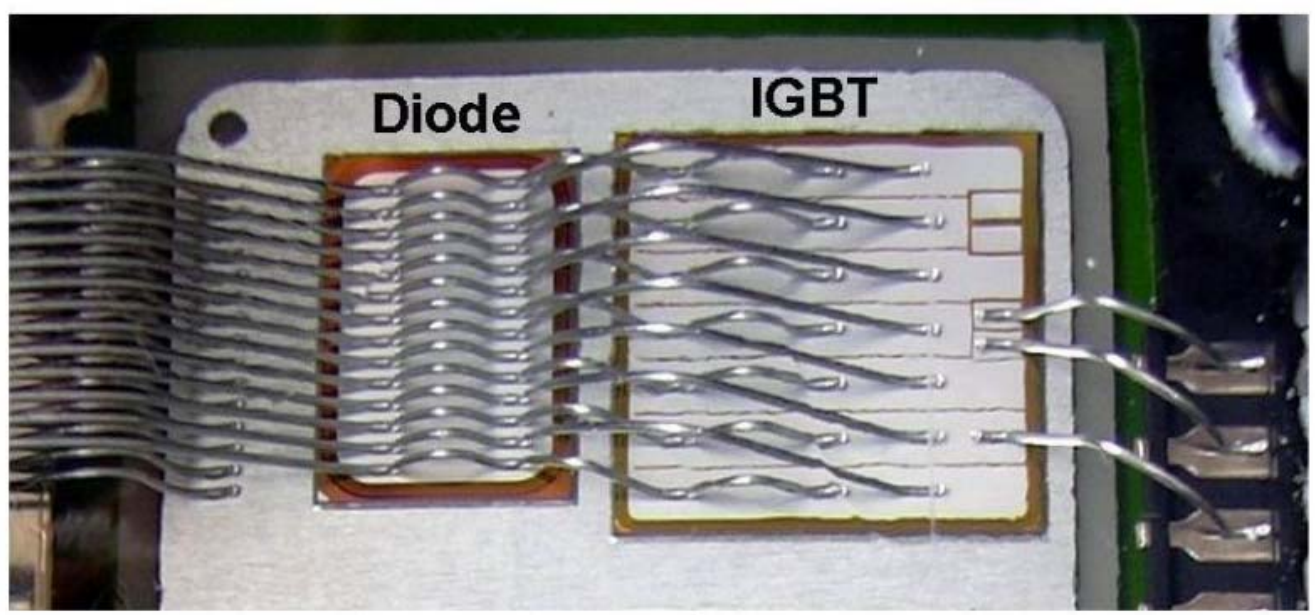

Prius Converter: 4 IGBTs and Diodes

Fig. 2.21. Close-up comparison of Camry converter IPM (upper) and Prius converter IPM (lower).

Table 2.5 summarizes the device count, wire-to-silicon ( $\mathrm{Si}$ ) bond count on the emitter surface, and amount of Si used in the Camry and Prius motor inverters and boost converters. The ratios of heat spreader area to total power electronic device Si area for the Camry motor inverter and boost converter are 10.1 and 4.3, respectively. The smaller ratio suggests a great success in size reduction (i.e., a small heat sink relative to the amount of Si). For comparison, the corresponding ratios for the Prius are 21.7 and 6.8. Again, these improvements are the result of the challenges of implementing the hybrid system into an already existing vehicle, whereas the Prius was strictly designed to be an HEV where volumetric constraints were not as restrictive. 
Table 2.5. Summary of power electronic device packaging

\begin{tabular}{|c|c|c|c|c|}
\hline \multirow{2}{*}{ Parameter } & \multicolumn{2}{|c|}{ Motor Inverter } & \multicolumn{2}{|c|}{ Buck/Boost Converter } \\
\hline & IGBTs & Diodes & IGBTs & Diodes \\
\hline \multicolumn{5}{|l|}{ Camry } \\
\hline Number of devices & 18 & 18 & 8 & 8 \\
\hline $\begin{array}{l}\text { Emitter wire bond count per } \\
\text { device. }\end{array}$ & 27 & 12 & 18 & 17 \\
\hline $\begin{array}{l}\text { Area of total Si die per device, } \\
\mathrm{mm}^{2} \text {. }\end{array}$ & 120.3 & 71 & 177 & 104 \\
\hline Summation of Si area, $\mathrm{mm}^{2}$. & 2165 & 1278 & 1400 & 830 \\
\hline Heat spreader area/Si area. & \multicolumn{2}{|c|}{$34800 / 3443=10.1$} & \multicolumn{2}{|c|}{$9530 / 2230=4.3$} \\
\hline \multicolumn{5}{|l|}{ Prius (for comparison) } \\
\hline Number of devices. & 12 & 12 & 4 & 4 \\
\hline $\begin{array}{l}\text { Emitter wire bond count per } \\
\text { device. }\end{array}$ & 20 & 5 & 21 & 28 \\
\hline $\begin{array}{l}\text { Area of total Si die per device, } \\
\mathrm{mm}^{2} \text {. }\end{array}$ & 131.9 & 40.7 & 228 & 119 \\
\hline Summation of Si area, $\mathrm{mm}^{2}$. & 1583 & 488 & 910 & 475 \\
\hline Heat spreader area/Si area. & \multicolumn{2}{|c|}{$45100 / 2071=21.7$} & \multicolumn{2}{|c|}{$9400 / 1385=6.8$} \\
\hline
\end{tabular}

\subsubsection{Capacitor Test Results}

As capacitor technologies mature, it is important to ascertain the capabilities and limitations of these new technologies by subjecting them to standardized tests to evaluate their characteristics. Test results will assist in benchmarking not only the capabilities and limitations of these technologies, but also to provide a baseline for comparison. All the capacitors studied are of the metallized plastic film type and were manufactured by Matsushita under the Panasonic brand name, except for the large Camry dc-link capacitor which was manufactured by Nichicon. As noted in Section 2.1, the capacitor modules are made up of several sub-capacitors. Tests were conducted upon the entire modules as well as the individual capacitors which were destructively removed from the entire module.

Capacitor tests were conducted both statically and dynamically. The former is a capacitor parameter assessment and the latter is a thermal characteristic assessment. The static test mode does not entail an externally applied dc-bias voltage and ripple current, but uses only signals supplied by an LCR meter. The capacitor parameters that are measured in the static mode are: (1) equivalent series resistance (ESR), (2) dissipation factor (DF), and (3) capacitance value. The capacitor is placed in an environmental chamber and the temperature is cycled through temperatures ranging from $-40^{\circ}$ to $140{ }^{\circ} \mathrm{C}$ using steps of $20^{\circ} \mathrm{C}$. These three parameters are measured at each temperature step.

The ESR is the real component of the equivalent impedance of the capacitor and corresponds directly with total energy loss which is dissipated as heat during operation. The DF is the ratio of the ESR over the capacitive reactance, which simplifies to $\omega R C$ and will be represented as the percentage of real power associated with a particular reactive power component. Both of these parameters were measured during static tests and the results were plotted over a wide frequency and temperature range.

In dynamic tests, a dc-bias voltage and ripple current is applied to the capacitor and the temperature of the capacitor is monitored. When a capacitor is used on a dc bus, the maximum ripple current capability is an important specification. The dynamic test determines the amount of heat generated by the capacitor as a function of ripple current at various ambient temperatures. 


\subsubsection{Static capacitor test results of the $2098 \mu \mathrm{F}$ dc-link smoothing capacitor module}

The data acquisition system (DAQ) consists of a Dell Precision 380 Workstation running LABView 8.5. In the static mode, the instruments used to log data are an Espec environmental chamber and an Agilent 4284 LCR meter. At the beginning of the static thermal cycling tests, after all temperature steps and test frequencies have been entered, the program turns on the environmental chamber and commands a target temperature to the chamber. After the target temperature has been reached and a pre-programmed delay time has been met, the program sends a command to the LCR meter to output the first test frequency and then begins to monitor the ESR from the capacitor under test. When that value is stable, the ESR is recorded and the next parameter is measured and recorded. After the values for ESR, DF, and capacitance are recorded at the first test frequency, the command is given to the LCR meter to output the next test frequency and the monitoring and recording process is repeated. After all data are recorded at all test frequencies, the next temperature step is commanded to the environmental chamber and the process is repeated.

The Camry capacitor module was tested in the static mode from -40 to $140^{\circ} \mathrm{C}$ over a frequency range of $100 \mathrm{~Hz}$ to $30 \mathrm{kHz}$. ESR, DF, and capacitance was measured and recorded. An interesting fact is observed in Fig. 2.22 as the capacitance approaches infinity beyond $16 \mathrm{kHz}$. The module can be represented as an RLC circuit with very small resistance and inductance. At high frequencies, even a small parasitic inductance component has a significant influence upon the entire equivalent reactance of the module. There is a certain resonant frequency where the capacitive (negative reactance) effect and inductive (positive reactance) effect are equal, and therefore the total reactance is zero and the imaginary admittance or susceptance is infinite. Thus, the equivalent capacitance approaches infinity as the frequency approaches resonant frequency. Just beyond the resonant frequency, the equivalent reactance is inductive and increases from zero as frequency increases. Figure 2.23 shows that the Prius capacitor module also has a similar effect near $15 \mathrm{kHz}$. As discussed shortly hereafter in Section 2.1.2.4, additional tests were conducted to investigate this matter further.

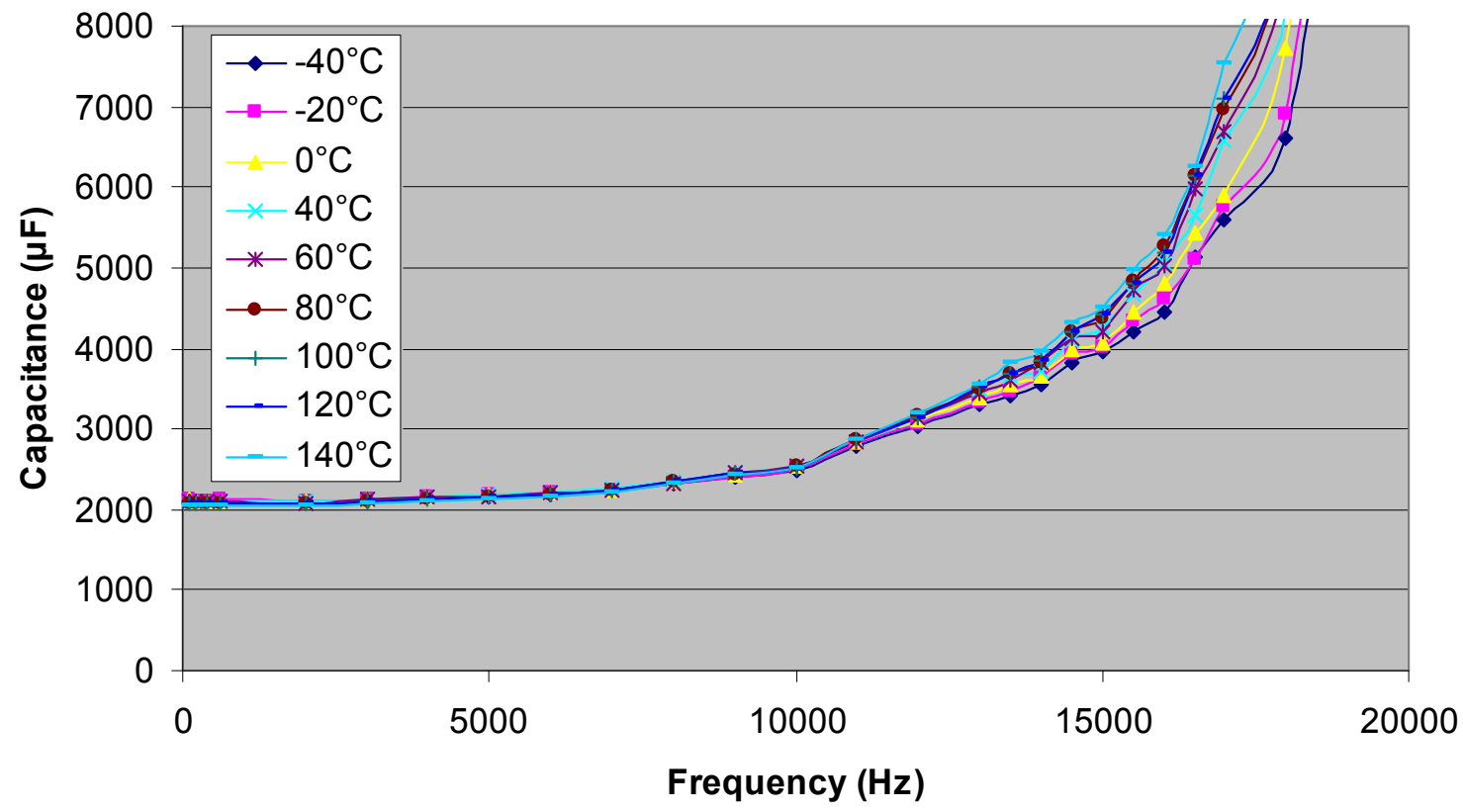

Fig. 2.22. Camry capacitor module equivalent capacitance vs. frequency. 


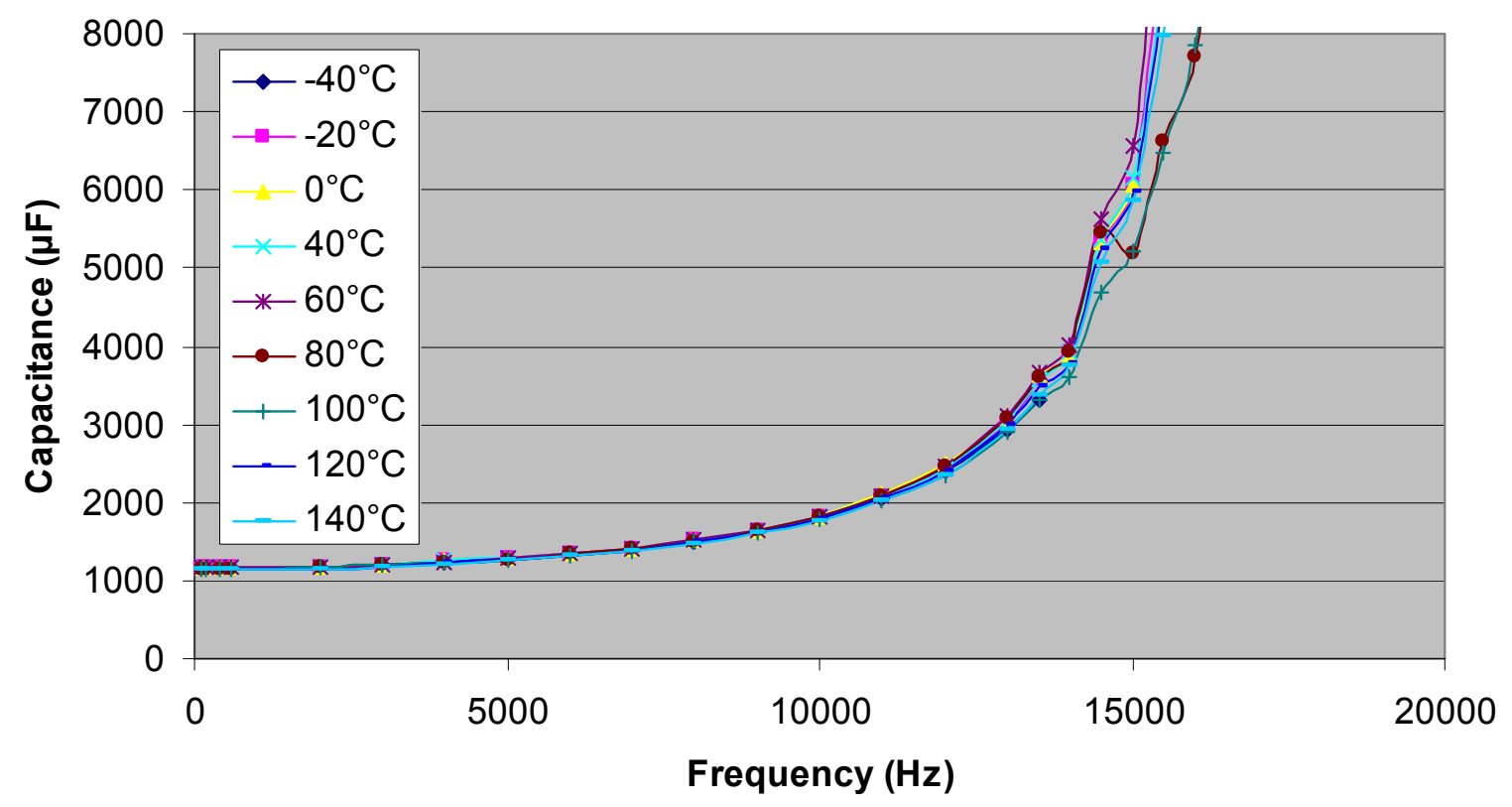

Fig. 2.23. Prius capacitor module equivalent capacitance vs. frequency.

As shown in Fig. 2.24, the response of the entire Camry module capacitance was very minimal over the full temperature range. The largest change in capacitance over the temperature range is observed at $15 \mathrm{kHz}$, which is also the frequency at which the highest capacitance was measured. For low frequencies, capacitance tended to increase with increasing temperature until peaking at a particular temperature and then the capacitance decreased slightly as temperature increased above this temperature. This peak capacitance temperature increased with increasing frequency. The Prius capacitor module showed similar effect and slight variation of capacitance with temperature.

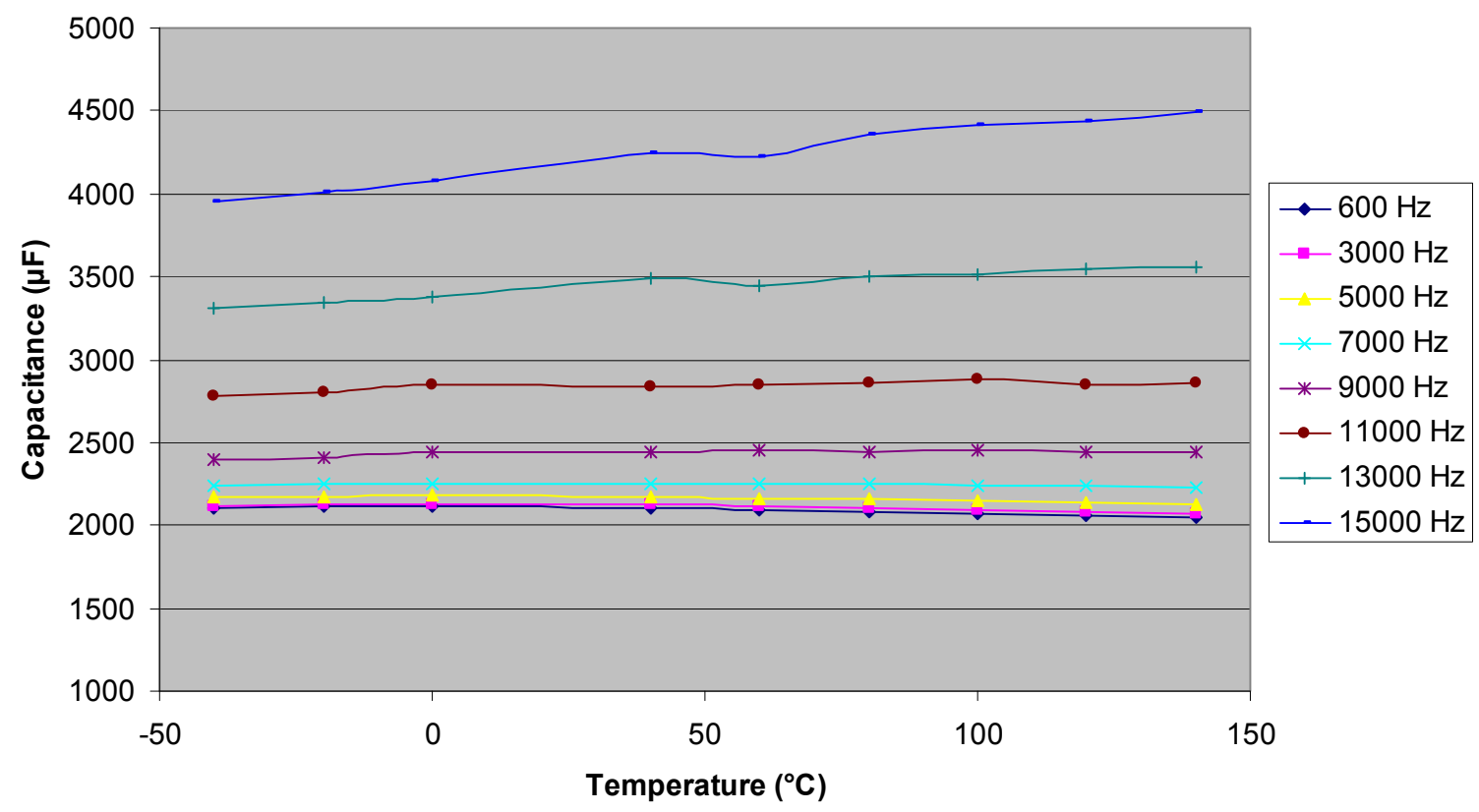

Fig. 2.24. Camry capacitor module equivalent capacitance variation with ambient temperature. 
Figures 2.25 and 2.26 show the ESR response to frequency for the Camry and the Prius module, respectively. Although the curve characteristics indicate that the influence of frequency upon the ESR of both modules is reasonably different, the ESR measurement is similar, particularly at low frequencies. Measurements indicate that ESR values generally increased with increasing temperature for both modules at all frequencies.

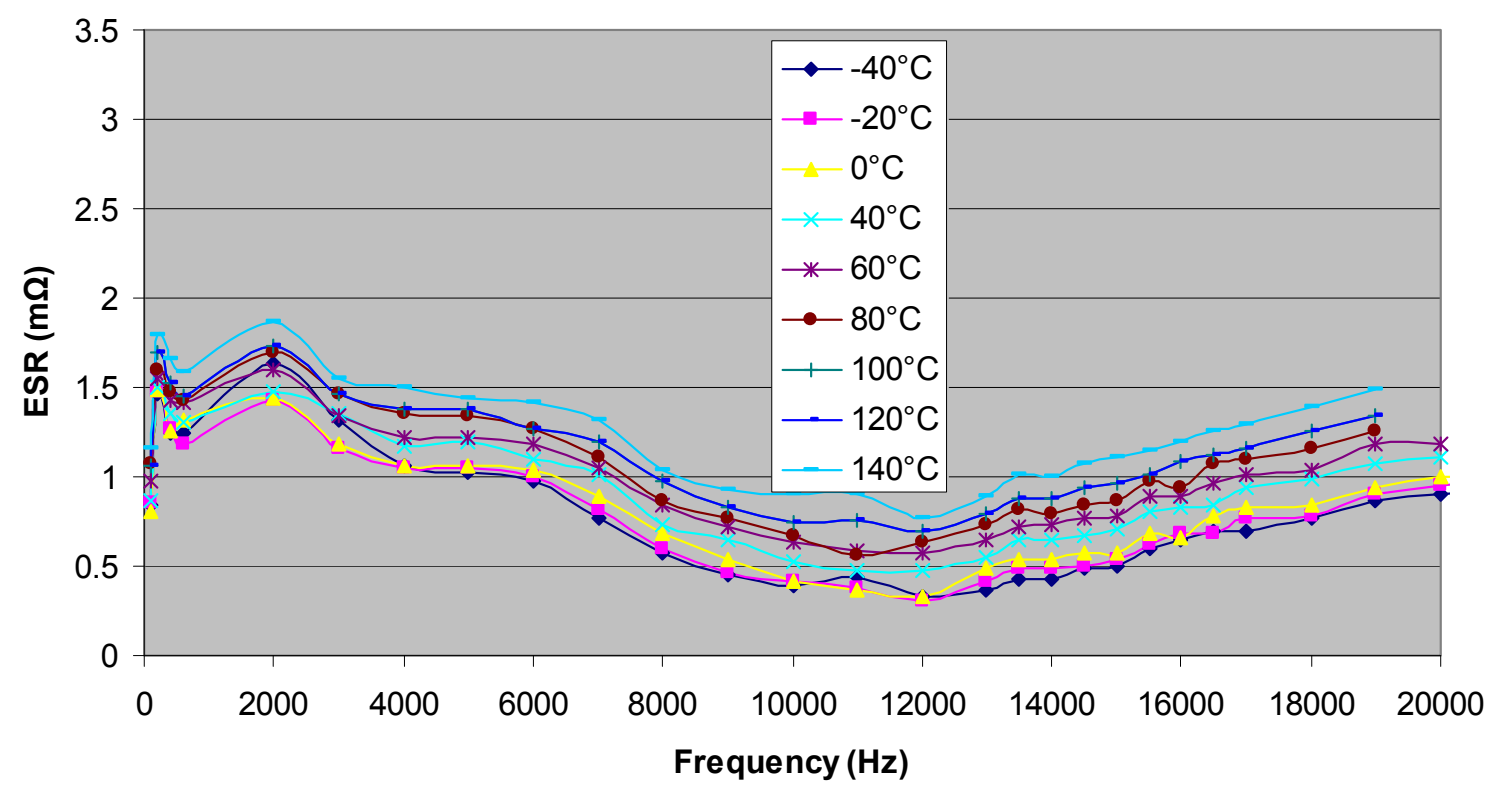

Fig. 2.25. Camry capacitor module ESR vs. frequency.

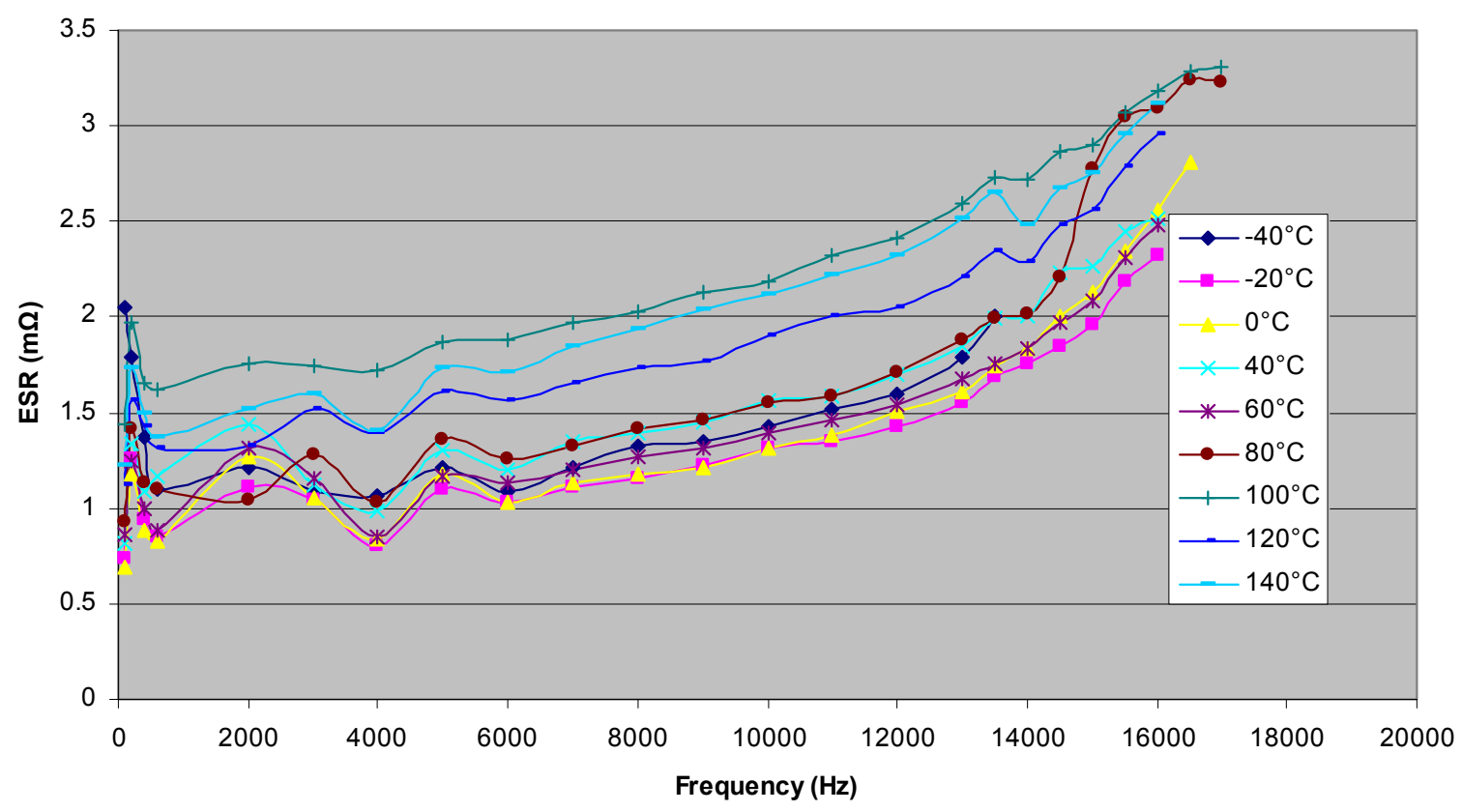

Fig. 2.26. Prius capacitor module ESR vs. frequency.

To obtain a clearer perspective of the impact of temperature upon ESR, Figs. 2.27 and 2.28 shows ESR plotted versus temperature for each frequency for the Camry and the Prius capacitor module, respectively. 


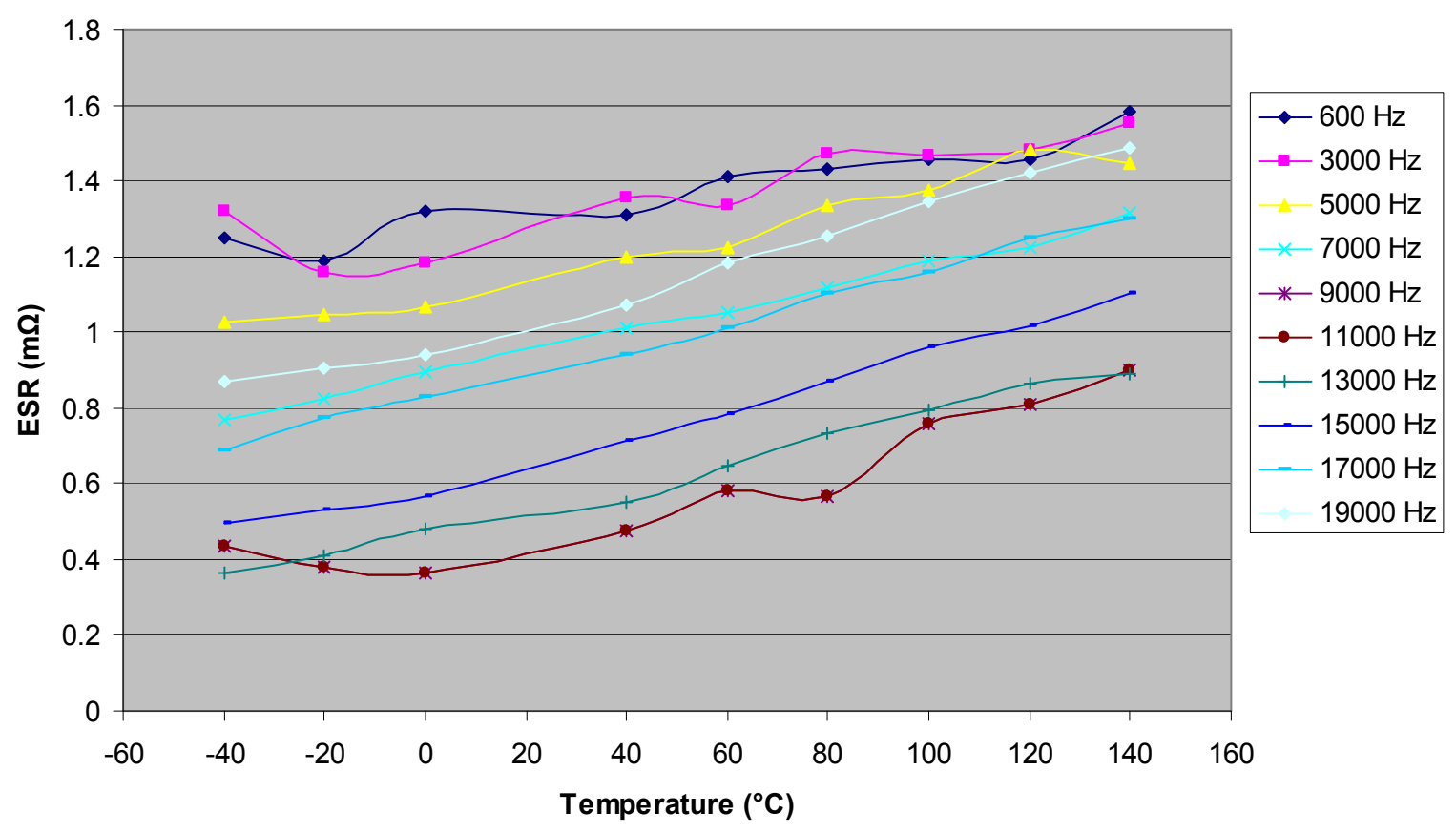

Fig. 2.27. Camry capacitor module ESR vs. temperature.

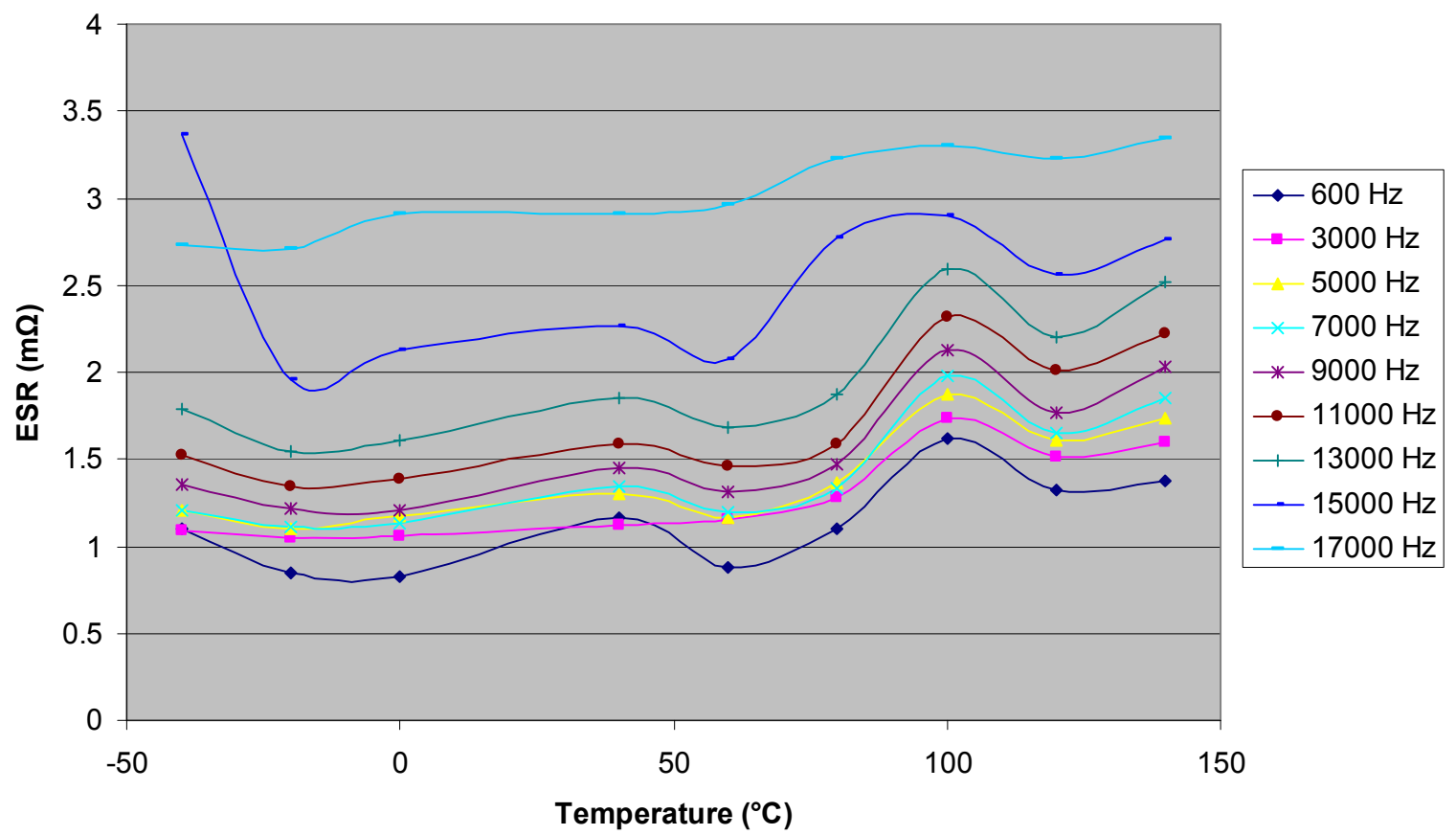

Fig. 2.28. Prius capacitor module ESR vs. temperature.

Again, the ESR of both modules generally increases with increasing temperature. Strangely, the ESR of the Prius module has a substantial lobe at $100^{\circ} \mathrm{C}$ for all frequencies as well as a high ESR measurement at $-40^{\circ} \mathrm{C}$ and $15 \mathrm{kHz}$.

The variations of DF with frequency for the Camry and Prius capacitor module are shown in Figs. 2.29 and 2.30, respectively. These graphs are similar to the capacitance versus frequency graphs in Figs. 2.22 
and 2.23. Since DF is the product of ESR, capacitance, and frequency, both graphs include curves which approach infinity near the resonant frequency. The behavior of the Camry capacitor module DF as a function of frequency is somewhat peculiar as the frequency increases beyond $6 \mathrm{kHz}$ and then resumes typical behavior beyond about $12 \mathrm{kHz}$.

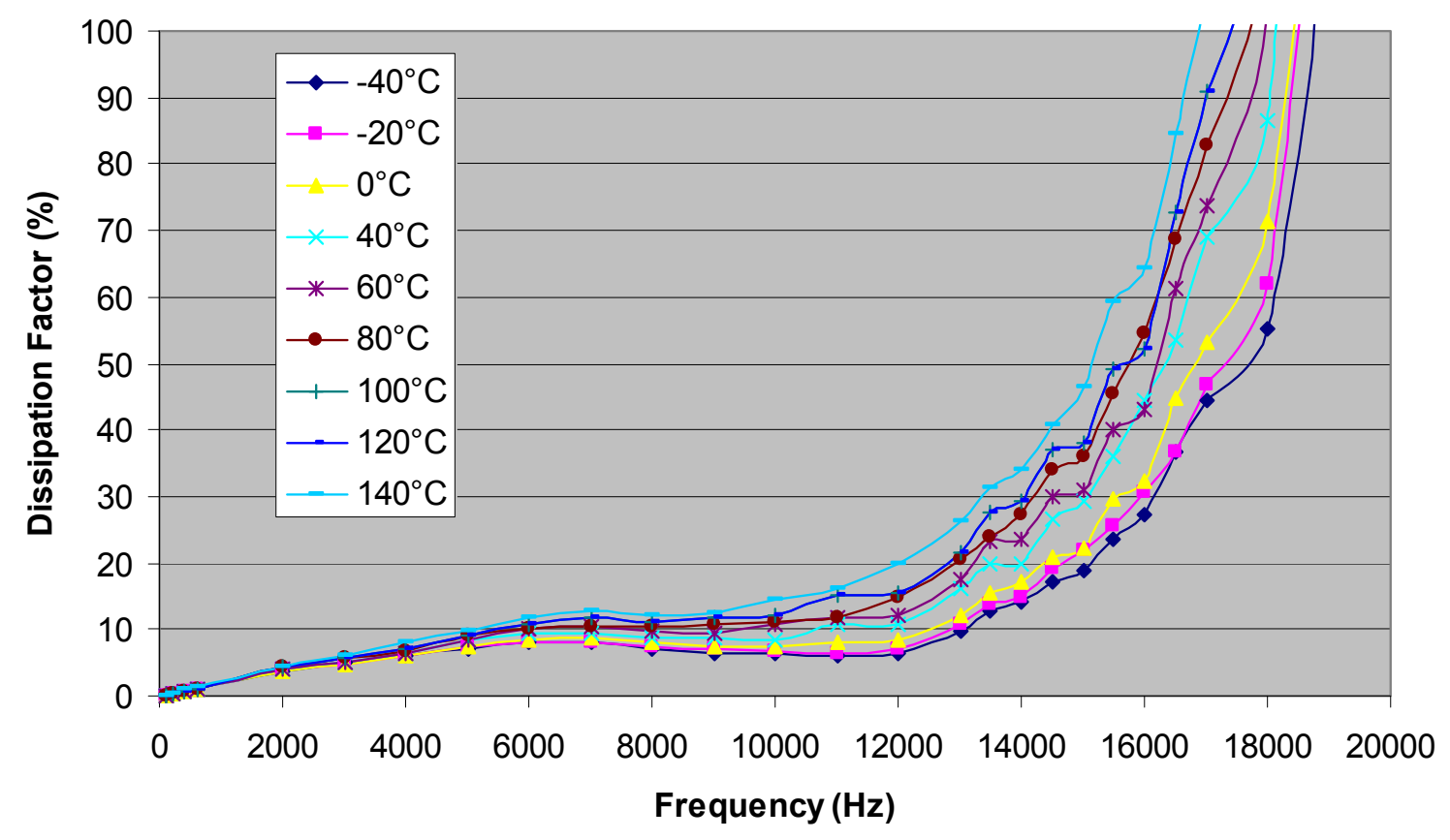

Fig. 2.29. Camry capacitor module DF frequency response.

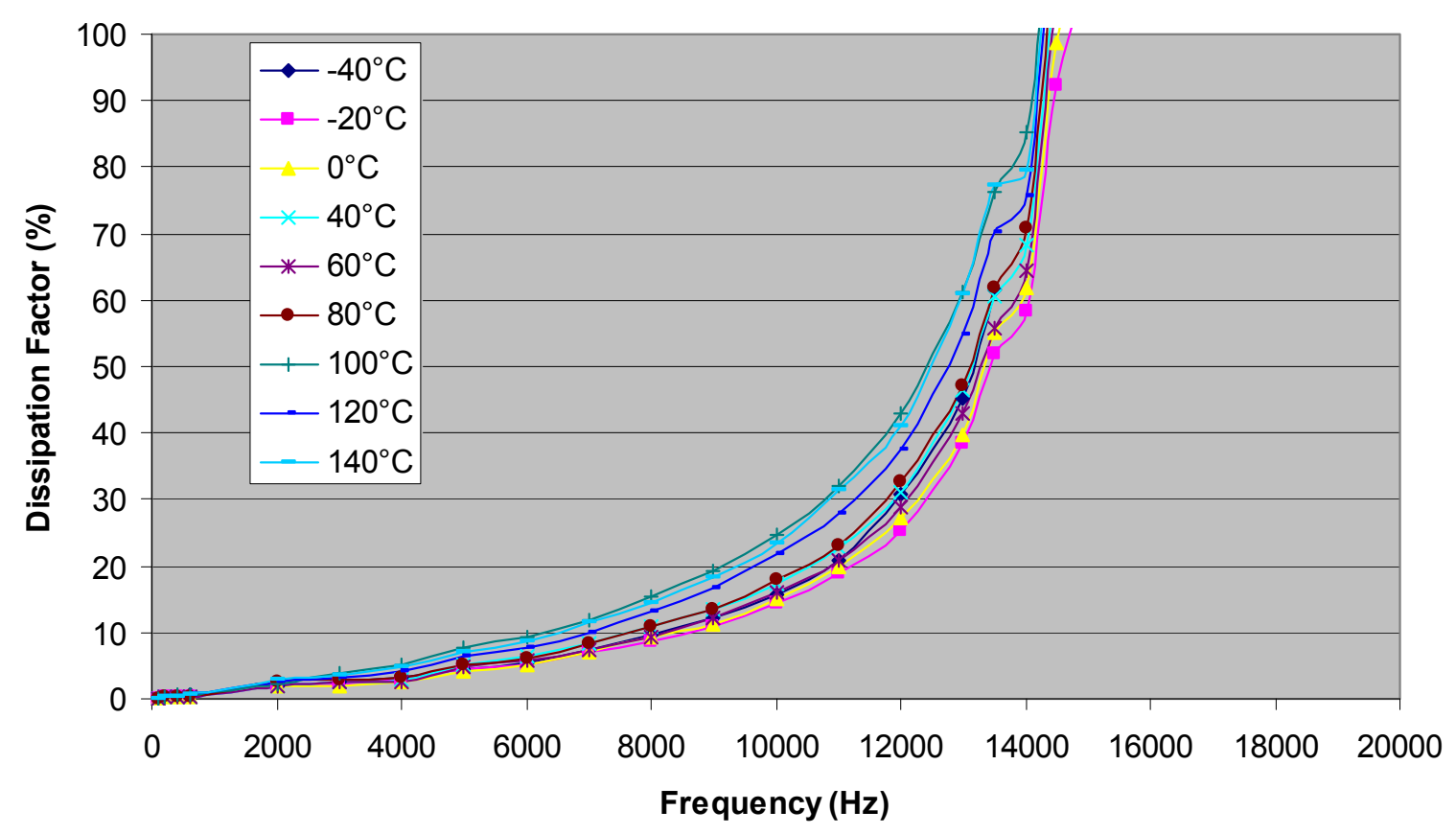

Fig. 2.30. Prius capacitor module DF frequency response. 
The impact of temperature on the DF of the Camry and Prius capacitor modules for each test frequency is observed in Figs. 2.31 and 2.32, respectively. Similar to the impact of temperature upon capacitance, the DF generally increases with increasing temperature. Additionally, temperature has a greater impact on DF at higher frequencies. Since the ESR naturally increases with increasing temperature, the amount of real power dissipated at a particular amount of reactive power increases as temperature increases.

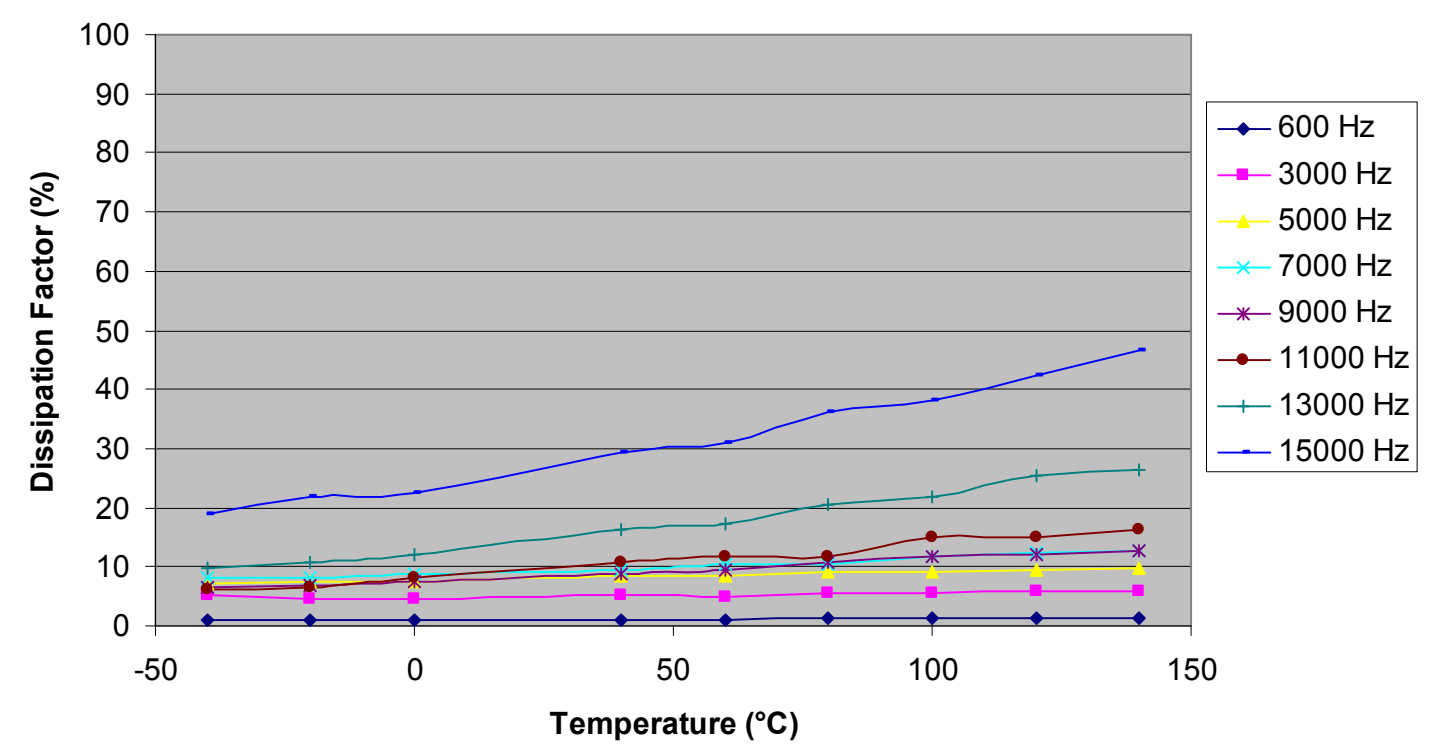

Fig. 2.31. Camry capacitor module DF temperature response.

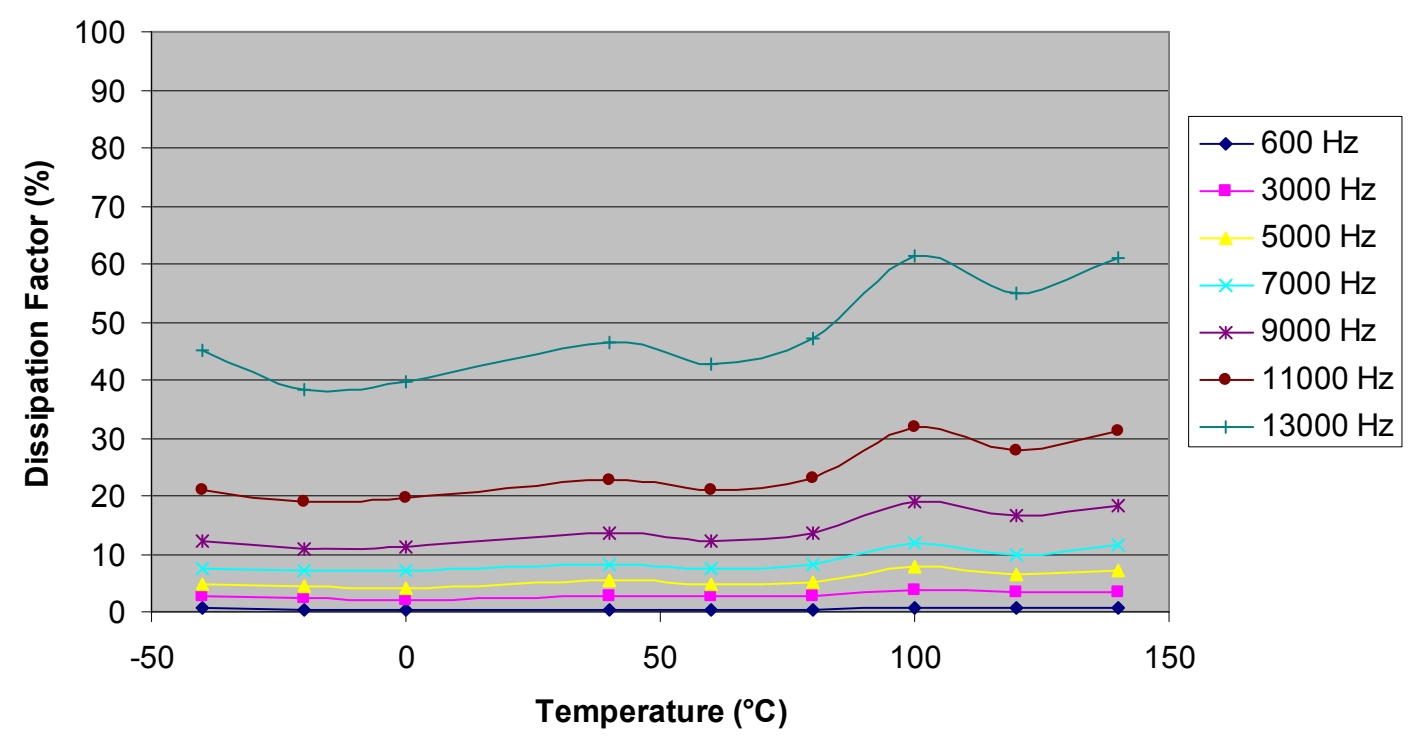

Fig. 2.32. Prius capacitor module DF temperature response.

\subsubsection{Dynamic capacitor test results from large dc-link capacitor module}

The Camry capacitor module was tested with a dc bias of $100 \mathrm{~V}$ and a maximum ripple current of $250 \mathrm{~A}$. Figure 2.33 shows the circuit used to apply a ripple current with a dc bias to the capacitor module under 
test. A capacitor was placed across the output of the dc power supply to decrease the potential of damaging the dc power supply with the high ripple currents generated during testing.

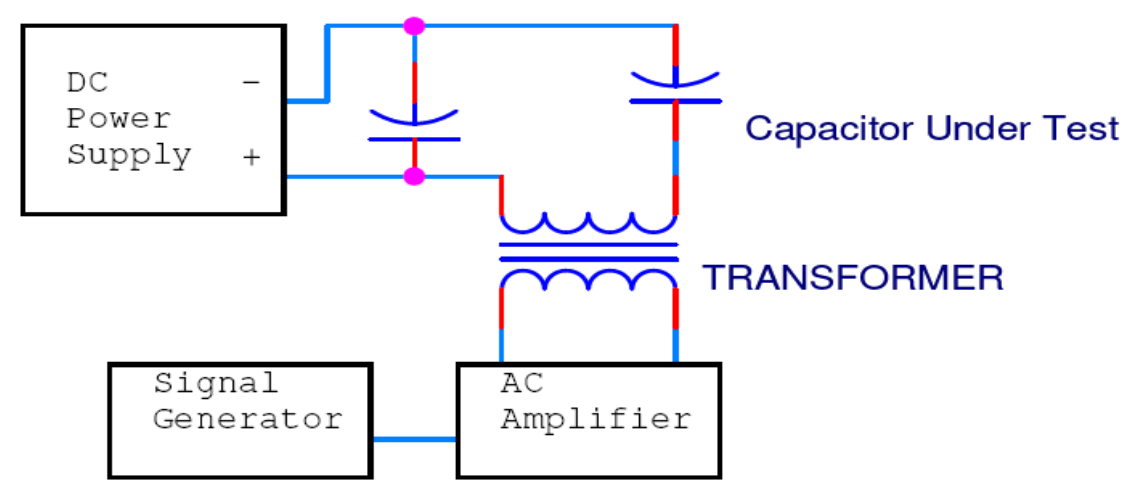

Fig. 2.33. Ripple current test schematic.

Thermocouples (TCs) were applied to the module in the center of both sides as shown in Fig. 2.34. Ripple current was applied in $50 \mathrm{~A}$ steps starting at $100 \mathrm{~A}$ and stopping at $250 \mathrm{~A}$ [root mean square (rms)]. The temperature was allowed to stabilize for 30 minutes before data was recorded. The two TC temperatures were averaged and plotted to determine the module's temperature response to high ripple current values. These data are shown in Fig. 2.35, which shows that the average temperature rise from $0-250 \mathrm{~A}$ was $11^{\circ} \mathrm{C}$ for the Camry capacitor module. The data for the $7.5 \mathrm{kHz}$ test stopped at $190 \mathrm{~A}$ due to the limitations of the alternating current (ac) amplifiers. Nonetheless, the test results indicate that the Camry is capable of withstanding high ripple currents without reaching excessive temperatures. Results from dynamic tests upon the Prius module at $4 \mathrm{kHz}$ are provided in Fig. 2.36, and indicate that the steady state temperature of the Prius module with a 200 A ripple current is about $52^{\circ} \mathrm{C}$, whereas the steady state temperature of the Camry module with a 200 A ripple current at $5 \mathrm{kHz}$ is only $28^{\circ} \mathrm{C}$.

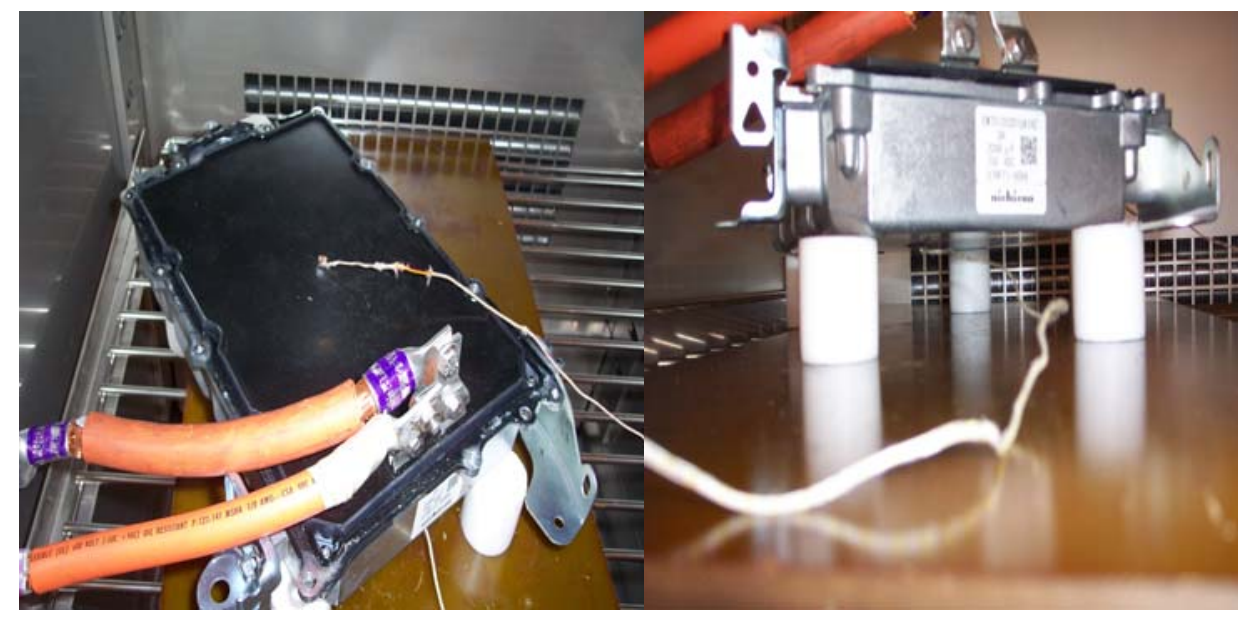

Fig. 2.34. TCs on the Camry capacitor module. 


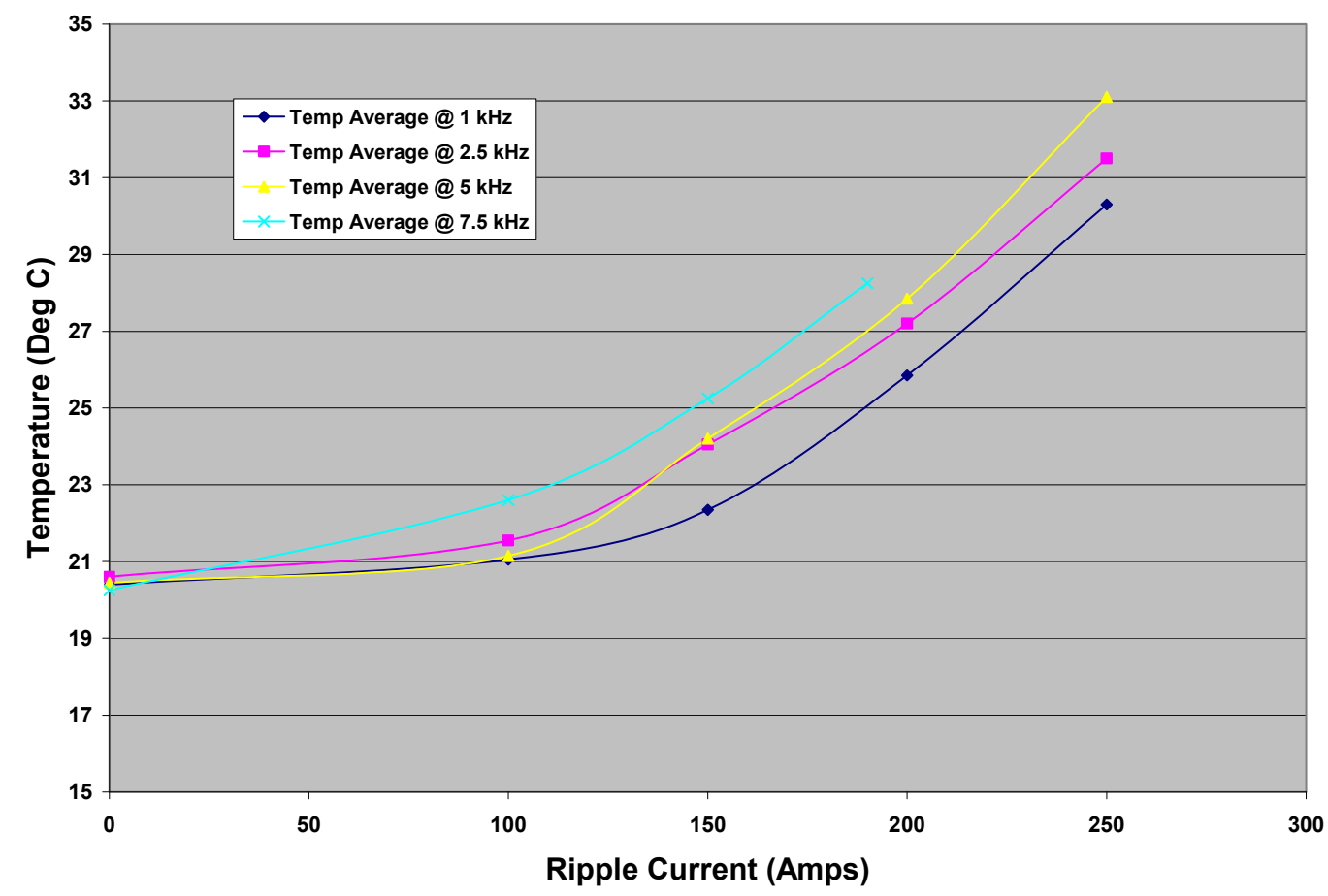

Fig. 2.35. Camry capacitor module steady-state temperature response vs. ripple current.

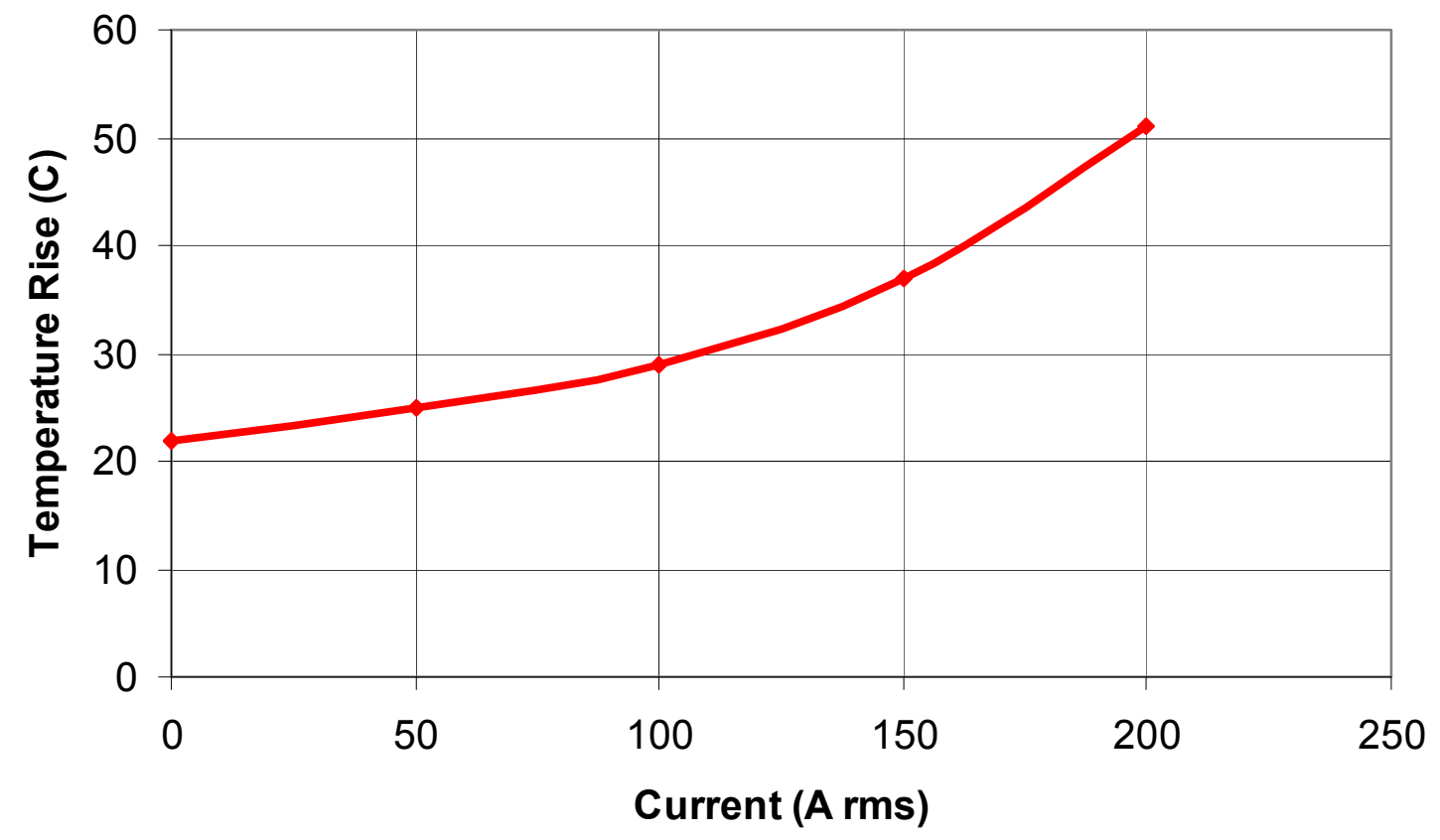

Fig. 2.36. Prius capacitor module steady-state temperature response vs. ripple current at $4 \mathrm{kHz}$. 


\subsubsection{Static capacitor test results of single sub-cell capacitor of smoothing capacitor module}

The Prius and Camry capacitor modules are composed of 8 and 24 sub-cells, respectively. A sub-cell was removed from the Camry module and tested under the same test conditions that the entire module was subjected to. Since the module architecture greatly influences the overall function of the module and the difference of the number of sub-cells is significant, the most informative comparison is between the entire modules and not the sub-cells. Therefore, a comparison is not made between the Camry and Prius subcells; yet the Prius sub-cell capacitor test results are provided in Appendix B. Additional Camry sub-cell capacitor test results are also provided in Appendix B.

The large Camry capacitor module contains $2486 \mu \mathrm{F}$ sub-cell in parallel to form a total capacitance of $2098 \mu \mathrm{F}$; whereas the large Prius capacitor module contains (8) $141 \mu \mathrm{F}$ sub-cell to form a total capacitance of 1,130 $\mu \mathrm{F}$. The capacitance, ESR, and DF were measured over temperatures ranging from $-40-140^{\circ} \mathrm{C}$ and frequencies from $1-35 \mathrm{kHz}$ and the results are shown in Figs. 2.37, 2.38, and 2.39, respectively. The capacitance increases only slightly until subjected to frequencies above $15 \mathrm{kHz}$. Figure 2.38 indicates that the ESR increases quickly with frequency at low frequencies and peaks at $5 \mathrm{kHz}$ and slowly decreases with increasing frequency. Note again that the most common switching frequency of the motor and generator inverters is $5 \mathrm{kHz}$. When compared to the test results from the Prius capacitor sub-cell provided in Appendix B, the capacitance of the Camry capacitor sub-cell increases much more slowly with frequency. The ESR of the Prius capacitor sub-cell is slightly lower than that of the Camry capacitor sub-cell. The DF is much lower for the Camry capacitor sub-cell. Again, these comparisons are not straightforward as the architectural discrepancies significantly impact the overall characteristics. Nonetheless, a broad comparison of the characteristics is informative.

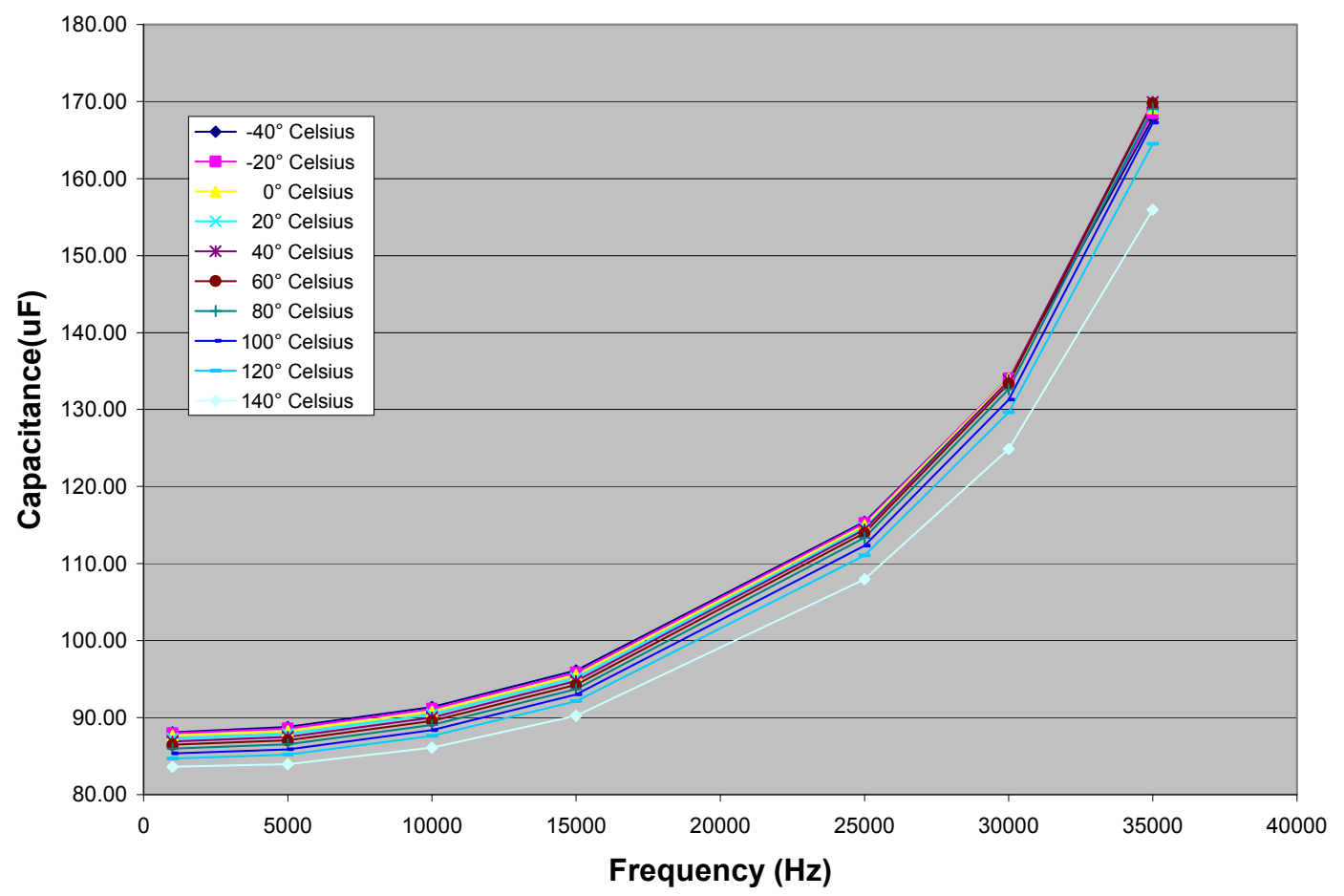

Fig. 2.37. Camry single $86 \mu \mathrm{F}$ capacitor, capacitance vs. frequency. 


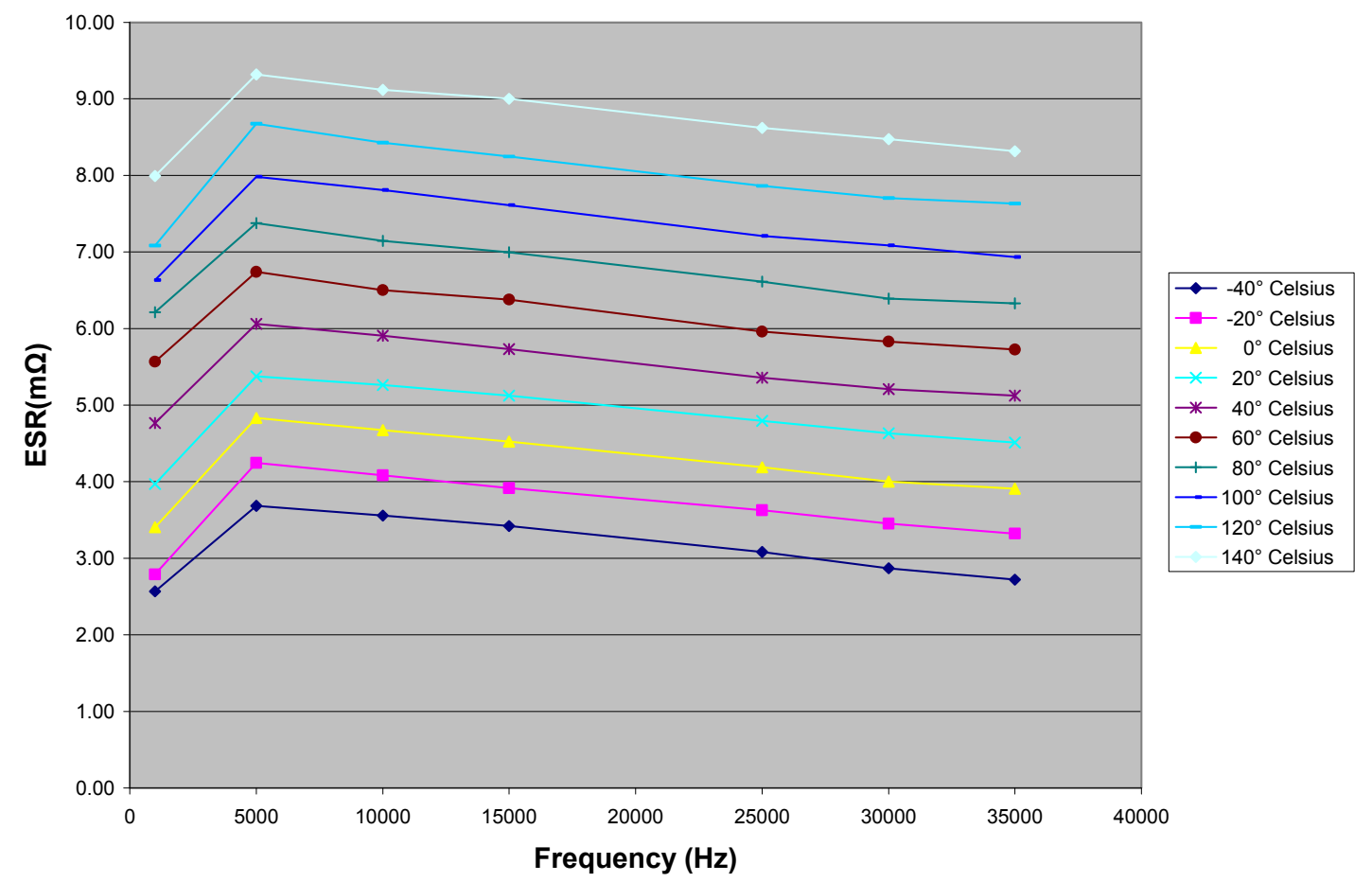

Fig. 2.38. Camry single $86 \mu \mathrm{F}$ capacitor, ESR vs. frequency.

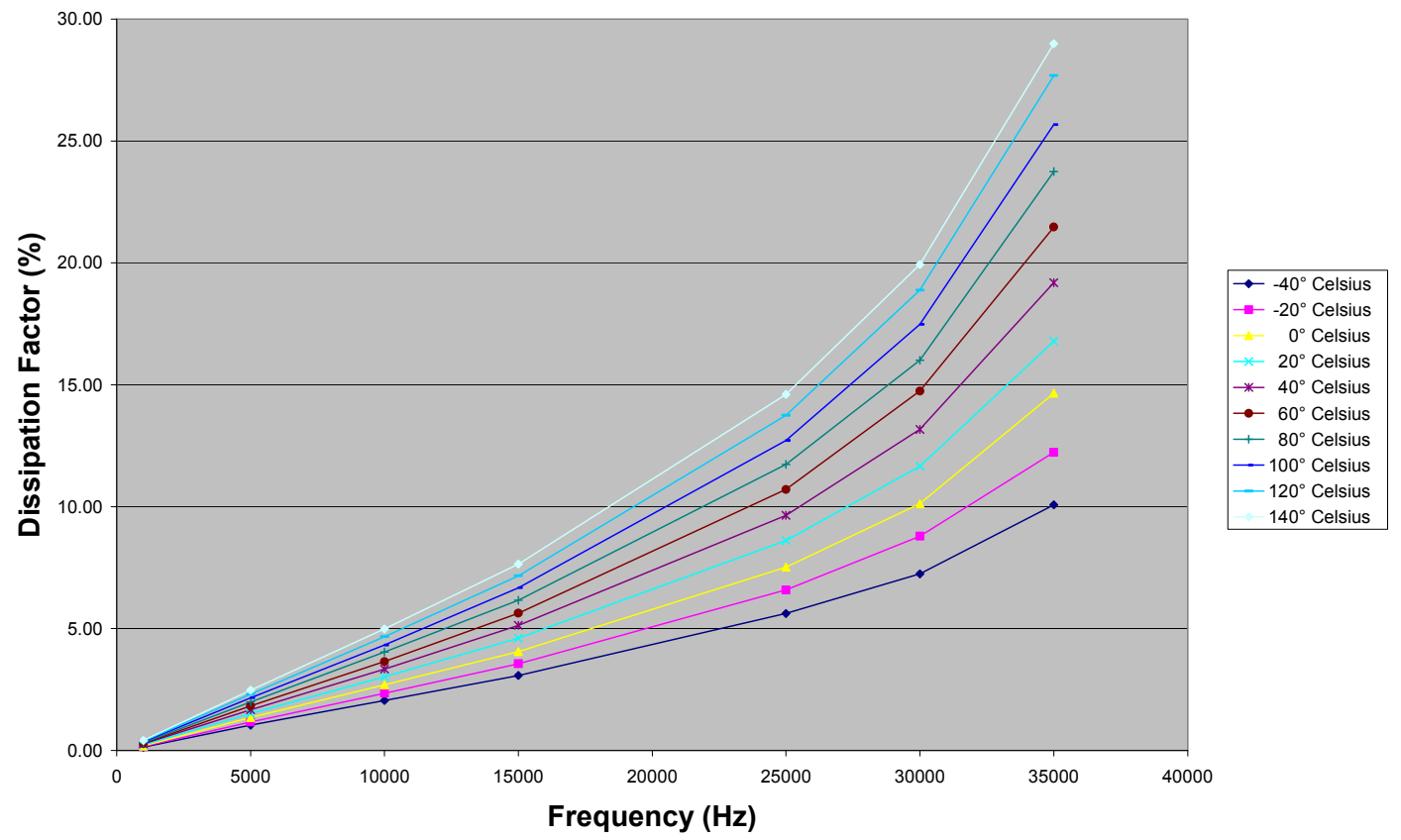

Fig. 2.39. Camry single $86 \mu \mathrm{F}$ capacitor, DF vs. frequency.

Figures 2.40, 2.41, 2.42, and 2.43 provide the combined capacitance, ESR, and DF responses versus temperature for frequencies of $1 \mathrm{kHz}, 5 \mathrm{kHz}, 15 \mathrm{kHz}$, and $35 \mathrm{kHz}$, respectively. In comparing these figures, it is apparent that the high temperatures have a significant effect on the capacitance, ESR, and DF, particularly at high frequencies. Even at relatively low frequencies, the DF varies significantly with 
temperature and frequency. Figures showing the results obtained while testing the Camry capacitor subcell at additional frequencies are provided in Appendix B. Furthermore, similar test results from the Prius capacitor sub-cell are provided in Appendix B.

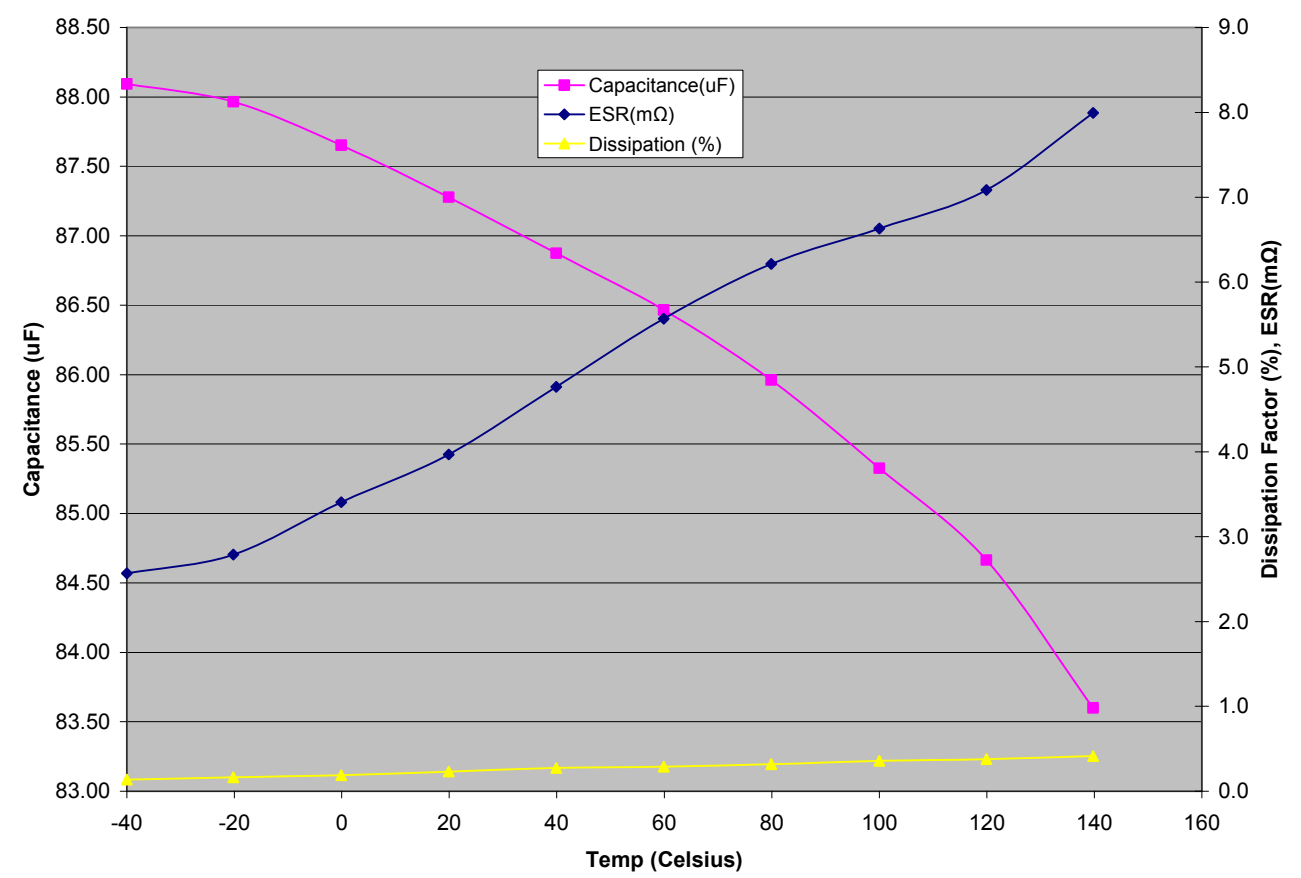

Fig. 2.40. Camry single $86 \mu \mathrm{F}$ capacitor, capacitance, ESR, and DF vs. temperature at $1 \mathrm{kHz}$.

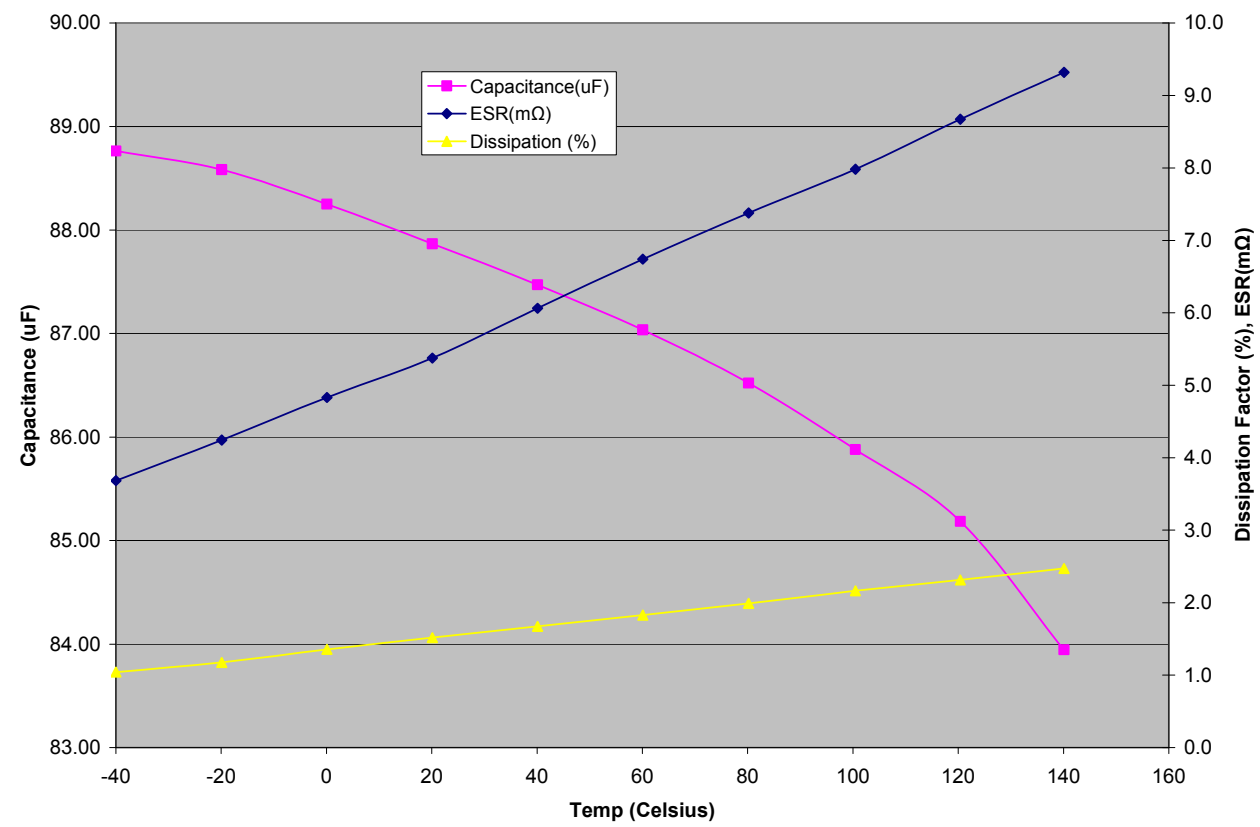

Fig. 2.41. Camry single $86 \mu \mathrm{F}$ capacitor, capacitance, ESR, and DF vs. temperature at $5 \mathrm{kHz}$. 


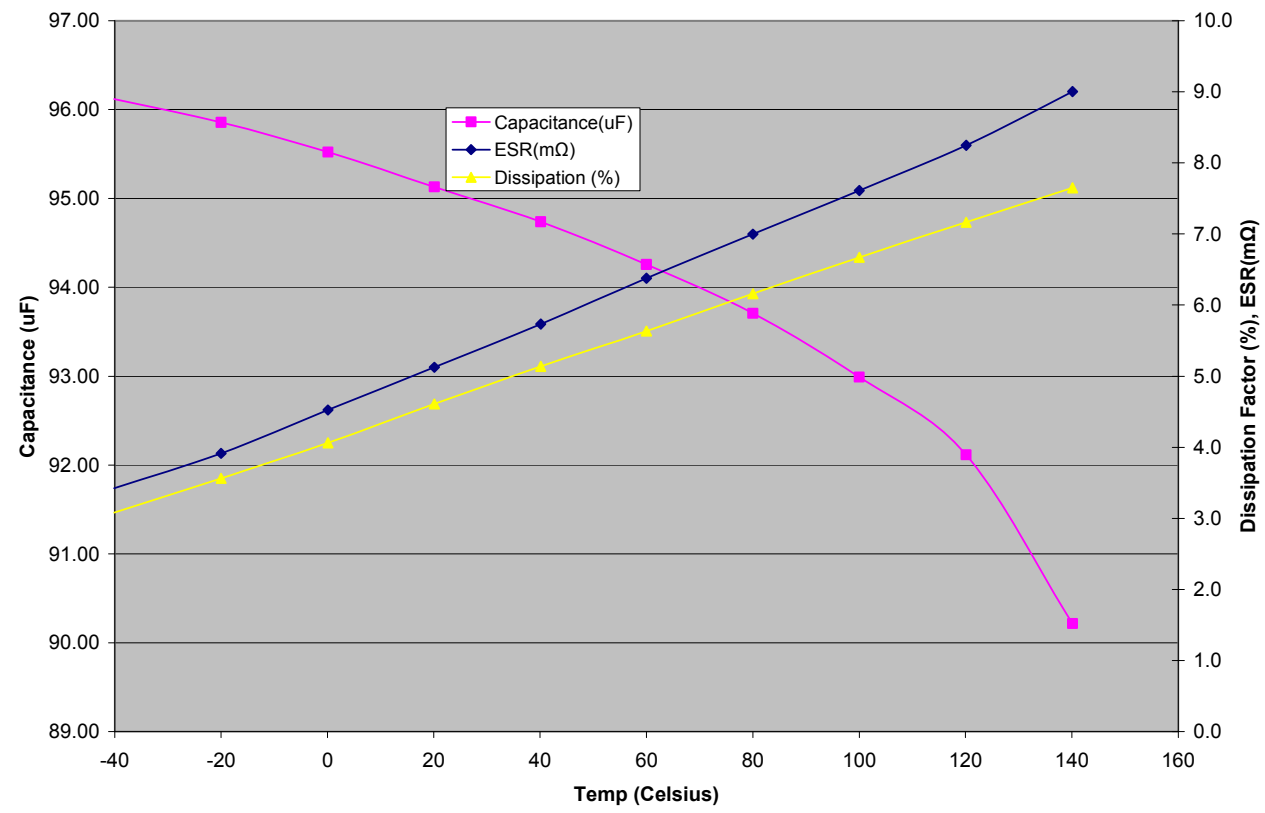

Fig. 2.42. Camry single $86 \mu \mathrm{F}$ capacitor, capacitance, ESR, and DF vs. temperature at $15 \mathrm{kHz}$.

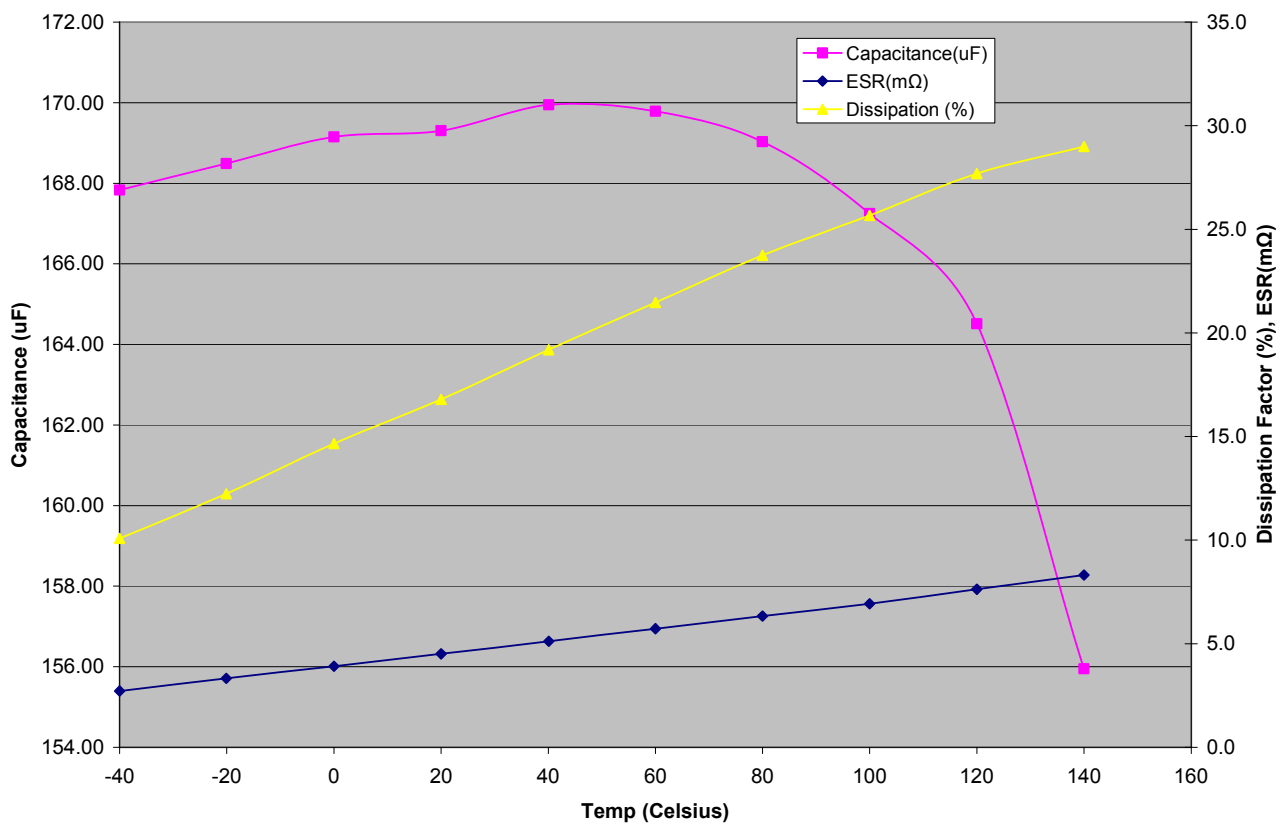

Fig. 2.43. Camry single $86 \mu \mathrm{F}$ capacitor, capacitance, ESR, and DF vs. temperature at $35 \mathrm{kHz}$.

Figures 2.44 and 2.45 provide the combined capacitance, ESR, and DF responses versus frequency for temperatures of $20^{\circ} \mathrm{C}$ and $140^{\circ} \mathrm{C}$, respectively. Although a quick comparison of the figures does not clearly reveal significant influences of temperature variation, notice the difference of scale between the figures. While the scale for capacitance remains the same, the scale for DF and ESR changes from 0-18 to 0-35 in Figs. 2.44 and 2.45, respectively. Thus, as indicated in the comparison of the previous figures, ESR and DF are significantly influenced by temperature variation. Since the unit is located within close proximity of the high operation temperatures of the ICE in addition to heat generated by components 
within the PCU (including the capacitor itself), the capacitor module is often subject to high temperatures. Similar figures for the Camry and Prius capacitor sub-cells are provided in Appendix B.

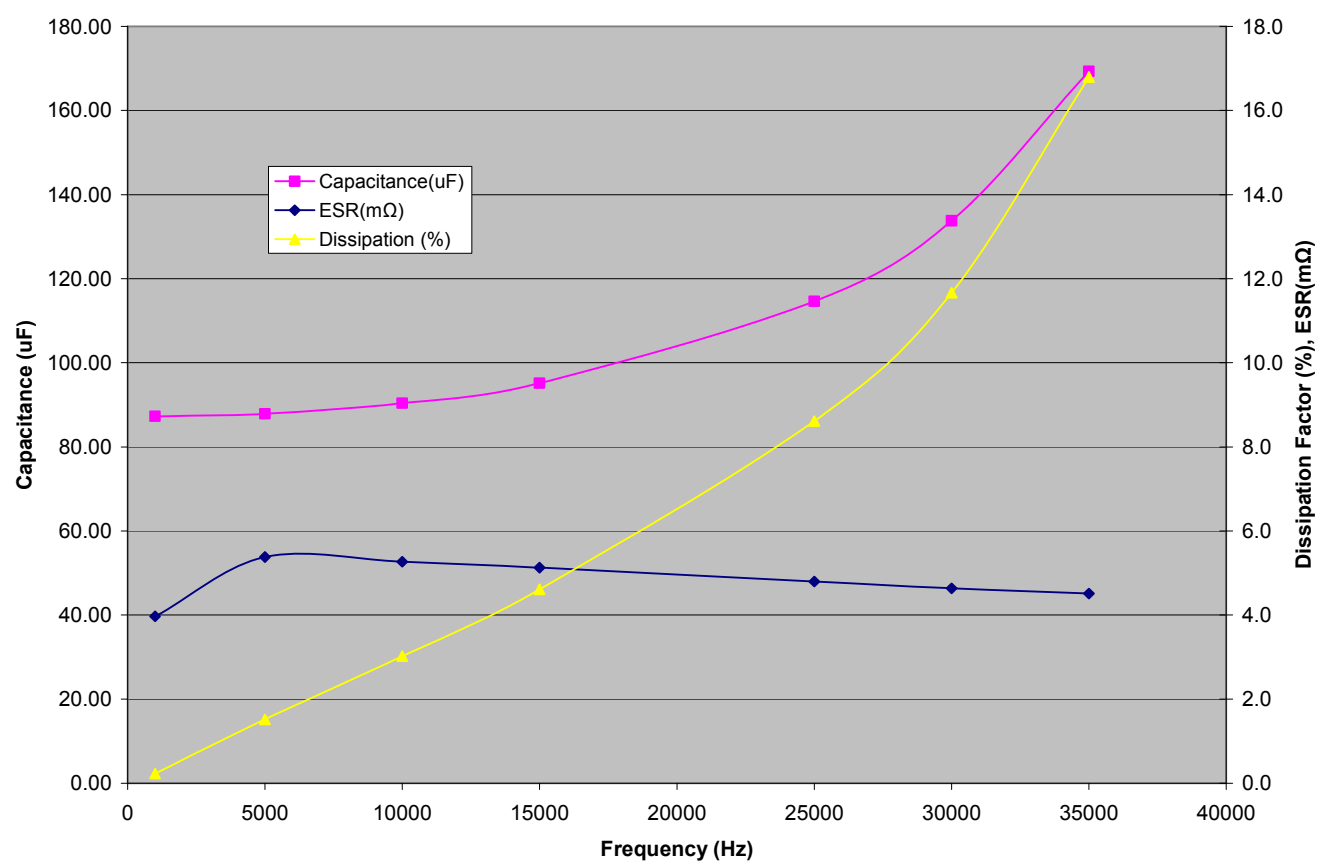

Fig. 2.44. Camry single $86 \mu \mathrm{F}$ capacitor, capacitance, ESR, and DF vs. frequency at $20^{\circ} \mathrm{C}$.

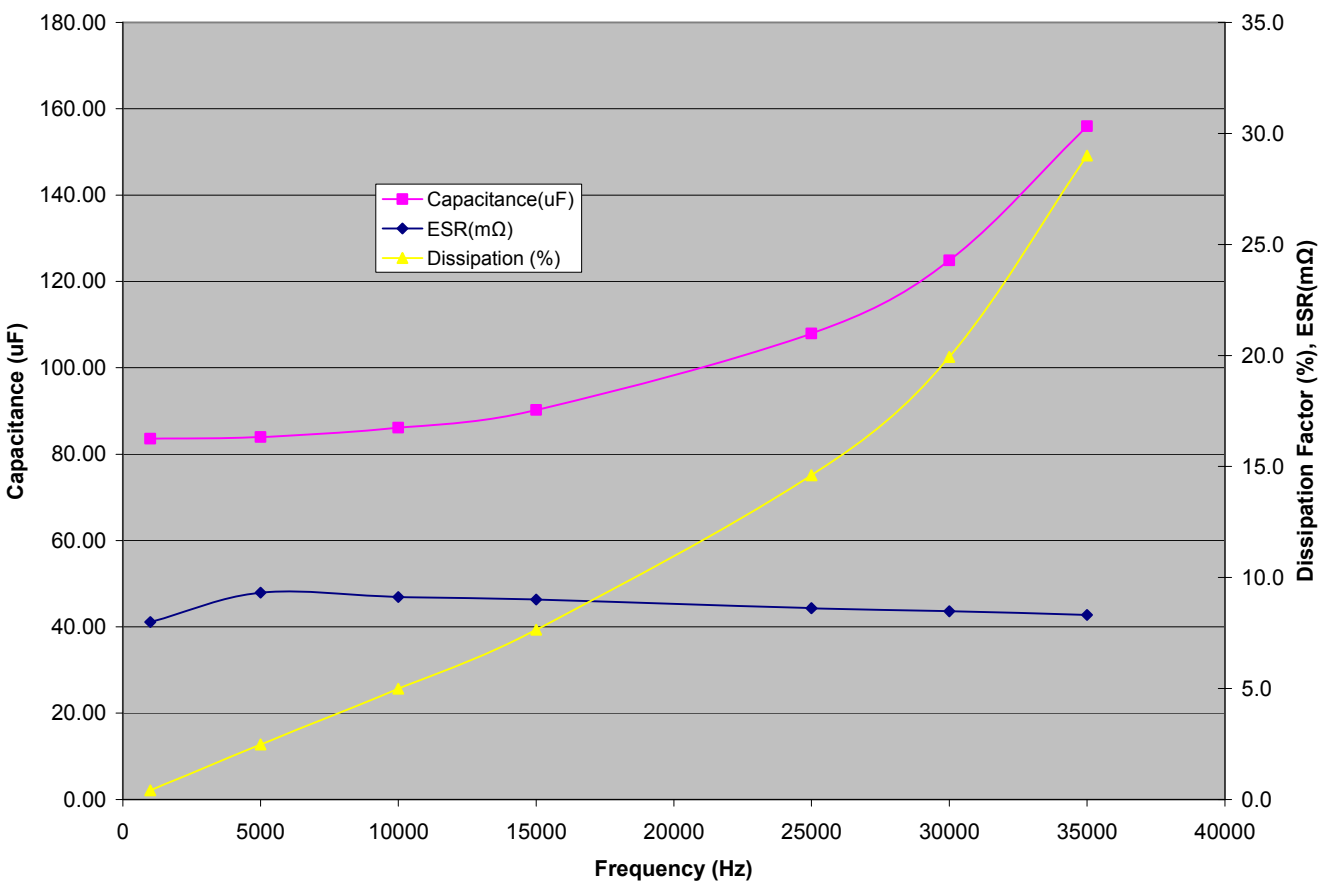

Fig. 2.45. Camry single $86 \mu \mathrm{F}$ capacitor, capacitance, ESR, and DF vs. frequency at $140^{\circ} \mathrm{C}$. 


\subsubsection{Inspection into positive reactance measurement of large dc-link capacitor module}

Further inspections into the influence of frequency upon characteristics of the Camry and Prius capacitor modules were conducted using the dynamic test setup described above. A Yokogawa PZ4000 power analyzer was used to monitor the current and voltage waveforms in order to determine the respective rms values and phase differences between the two. No dc bias was applied during these tests, and all currents and voltages discussed hereon are sinusoidal in nature and the corresponding signal levels are given in terms of rms values.

The primary intent of these tests was to evaluate the voltage and current phase angle for various ripple current frequencies, as well as obtain general information regarding the voltage response of the capacitor module to a particular ripple current amplitude for various ripple current frequencies. Figures 2.46, 2.47, and 2.48 show the phase angles between the current and voltage of the Camry and Prius capacitor modules at various frequencies. These tests were conducted with about $25 \mathrm{~A}$ of current applied to the modules at frequencies from 5-20 kHz and all signals were measured with a Yokogawa PZ4000 wattmeter. These figures are screenshots of the Yokogawa PZ4000 measurements and they include Uac1, the rms of the ripple voltage (with no dc component), and Iac1, the rms of the ripple current, as well as the frequency, which is shown in the upper left corner of the display. The phase angle between the current and voltage was also measured, but the value is not shown in these figures. A leading phase angle is obtained when the current leads the voltage, which is typical for a capacitive reactance. A lagging phase angle is associated with an inductive reactance, in which the current lags the voltage.
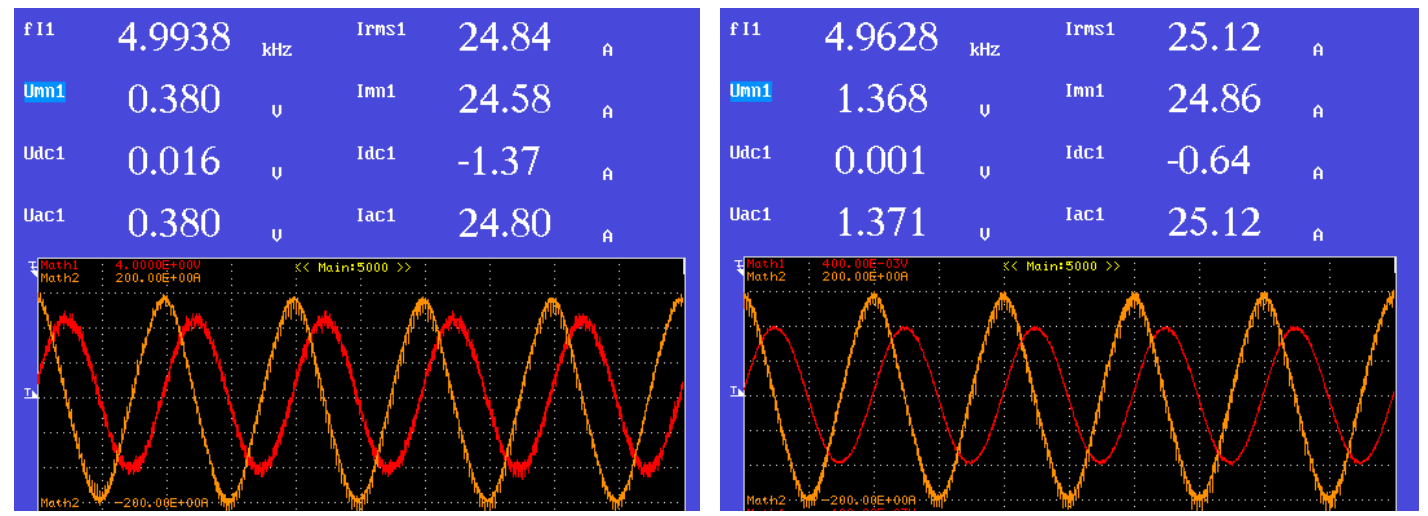

Fig. 2.46. Waveforms of the Camry (left) and Prius (right) capacitor module at $5 \mathrm{kHz}$.
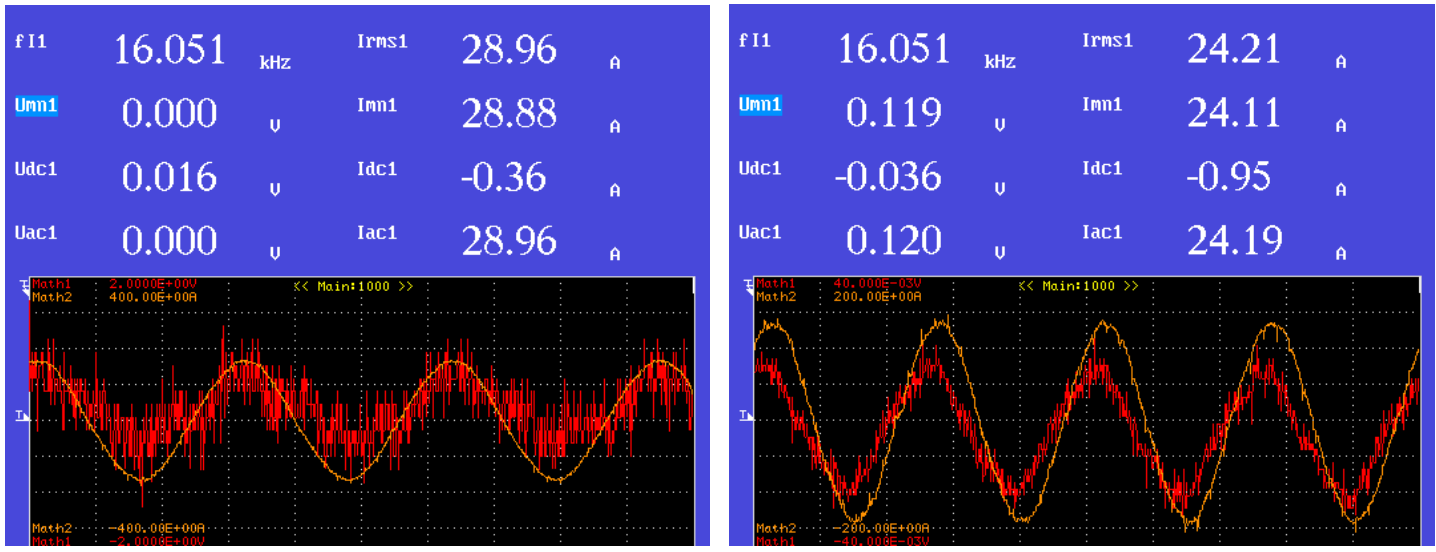

Fig. 2.47. Camry (left) and Prius (right) capacitor module waveforms at $16 \mathrm{kHz}$. 

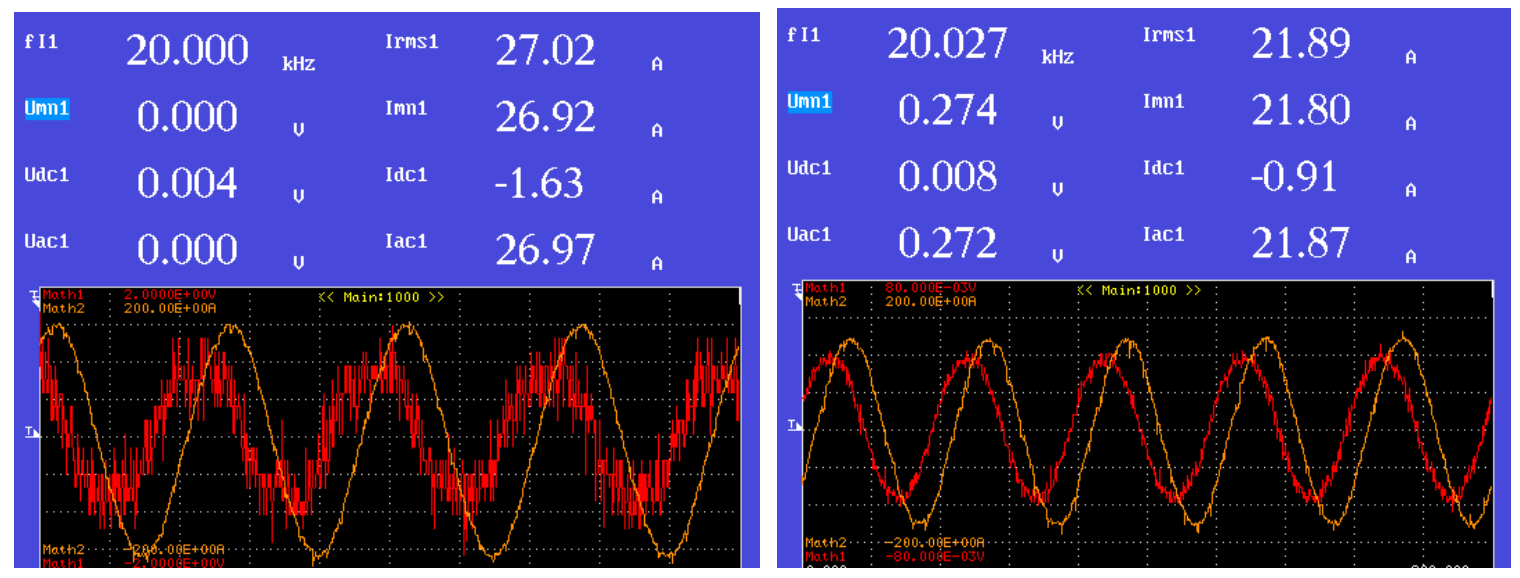

Fig. 2.48. Waveforms of the Camry (left) and Prius (right) capacitor module at $20 \mathrm{kHz}$.

Figure 2.46 shows the phase angles between the current and voltage at $5 \mathrm{kHz}$ for the Camry and Prius capacitor module with the current waveform being the orange trace and having the highest amplitude. For both modules, the current is leading the voltage by an angle which is close to $90^{\circ}$ indicating a typical capacitive response at $5 \mathrm{kHz}$. The voltage ripple of the Prius module at $25 \mathrm{~A}$ is higher than that of the Camry module as the capacitance of the Camry is higher than that of the Prius at this frequency.

Figure 2.47 shows screenshots obtained during a similar test with a frequency of $16 \mathrm{kHz}$ for the Camry and Prius capacitor modules. The voltage waveforms contain significant noise levels as the amplitude is very low for these frequencies. The phase angle between the voltage and current of the Camry module at $16 \mathrm{kHz}$ is nearly zero, and the current is lagging the voltage of the Prius module at $16 \mathrm{kHz}$ indicating that the reactance is positive and the module behaves like an inductor at this frequency.

In Fig. 2.48, the frequency of the ripple current applied to both modules is $20 \mathrm{kHz}$. The phase difference between the current and voltage is large enough to easily concur that the current is lagging the voltage significantly.

A second series of tests were conducted with the Camry and Prius capacitor modules. The overall test procedures were similar to those just discussed, yet the amplitude of the signal generator (shown in Fig. 2.33) waveform was kept constant. Conditions were similar but not identical between the tests on the Camry and Prius capacitor modules and a comparison of the test results provides only general information regarding the frequencies at which the resonance and phase angle changes occur.

Figures 2.49 and 2.50 compare the responses of the Camry and Prius capacitor modules to various frequencies. In Fig. 2.49, as the applied frequency on the Camry module increases from $1 \mathrm{kHz}$, the current increases and peaks at a frequency of about $2 \mathrm{kHz}$. A similar characteristic is noticed for the Prius module and the current peaks between 2 and $3 \mathrm{kHz}$. As indicated by both figures, the current leads the voltage for low frequencies indicating a dominant capacitive effect until a frequency of about $16 \mathrm{kHz}$ for the Camry and $15 \mathrm{kHz}$ for the Prius. Leading phase measurements are indicated by the yellow traces, which end just prior to these resonance frequencies where the capacitive and inductive effects are equal and the corresponding reactance is zero. As the frequency increases beyond the resonant frequency, the module behaves as an inductive load as the parasitic inductance has a greater effect on the reactance than the capacitance does, even though the parasitic inductance is very low. These characteristics re-affirm that the large dc-link capacitor is used for smoothing of low machine level ripple frequencies associated with the operation the motor and generator, as opposed to being used primarily for attenuation of switching transients. 


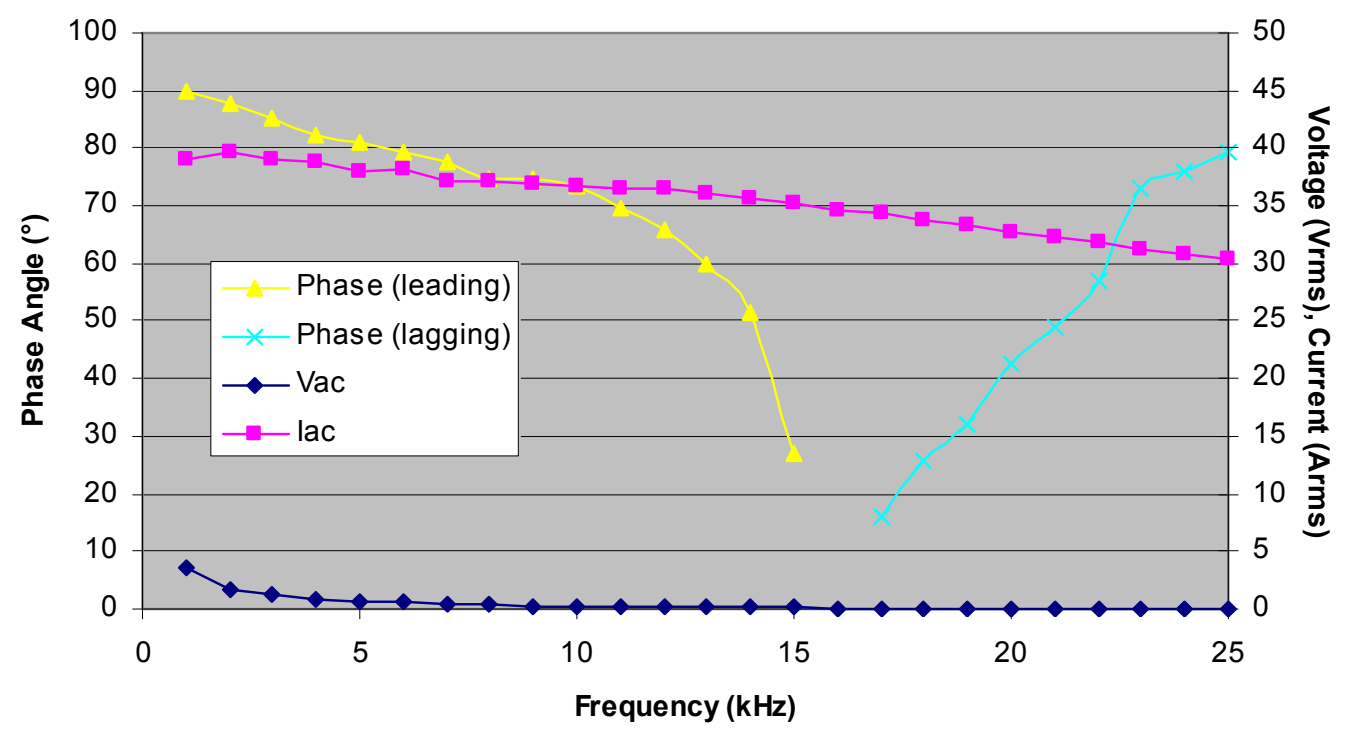

Fig. 2.49. Camry capacitor module voltage and current response to frequency.

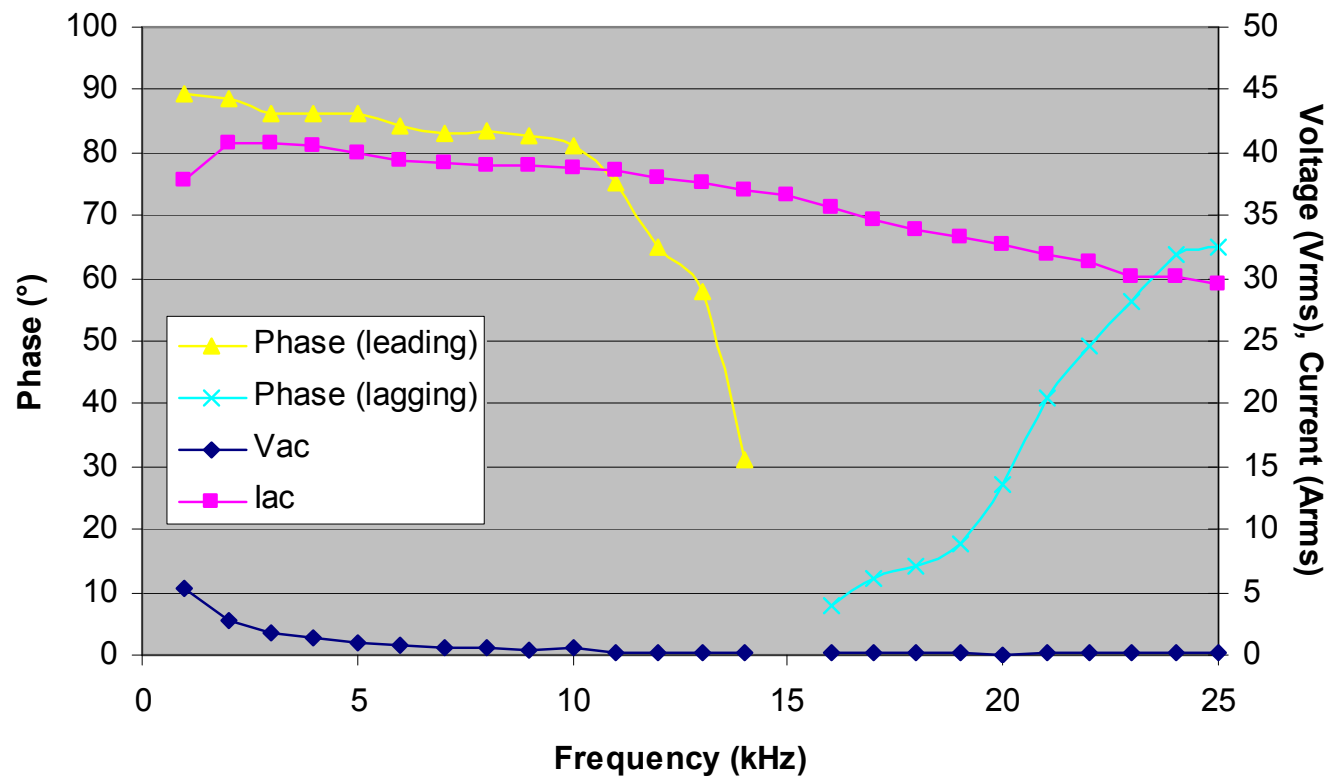

Fig. 2.50. Prius capacitor module voltage and current response to frequency.

\subsubsection{Static capacitor test results of battery level filter capacitor evaluations}

Figures 2.51 and 2.52 compare the capacitor test results of the $500 \mathrm{~V}, 378 \mu \mathrm{F}$ capacitor of the Camry and the $600 \mathrm{~V}, 282 \mu \mathrm{F}$ capacitor of the Prius, respectively. Each capacitor resides between the battery and the boost converter and is located within the PCU. Significant differences are noticed between the characteristics of the two capacitors, particular when comparing the influence of frequency upon capacitance and DF. The equivalent capacitance of the Prius begins to approach infinity near about $22 \mathrm{kHz}$, whereas the equivalent capacitance of the Camry capacitor only increased slightly as the maximum test frequency of $30 \mathrm{kHz}$ was reached. Since DF is a product of ESR, capacitance, and frequency, the DF curves have characteristics similar to those of the capacitance curves. 


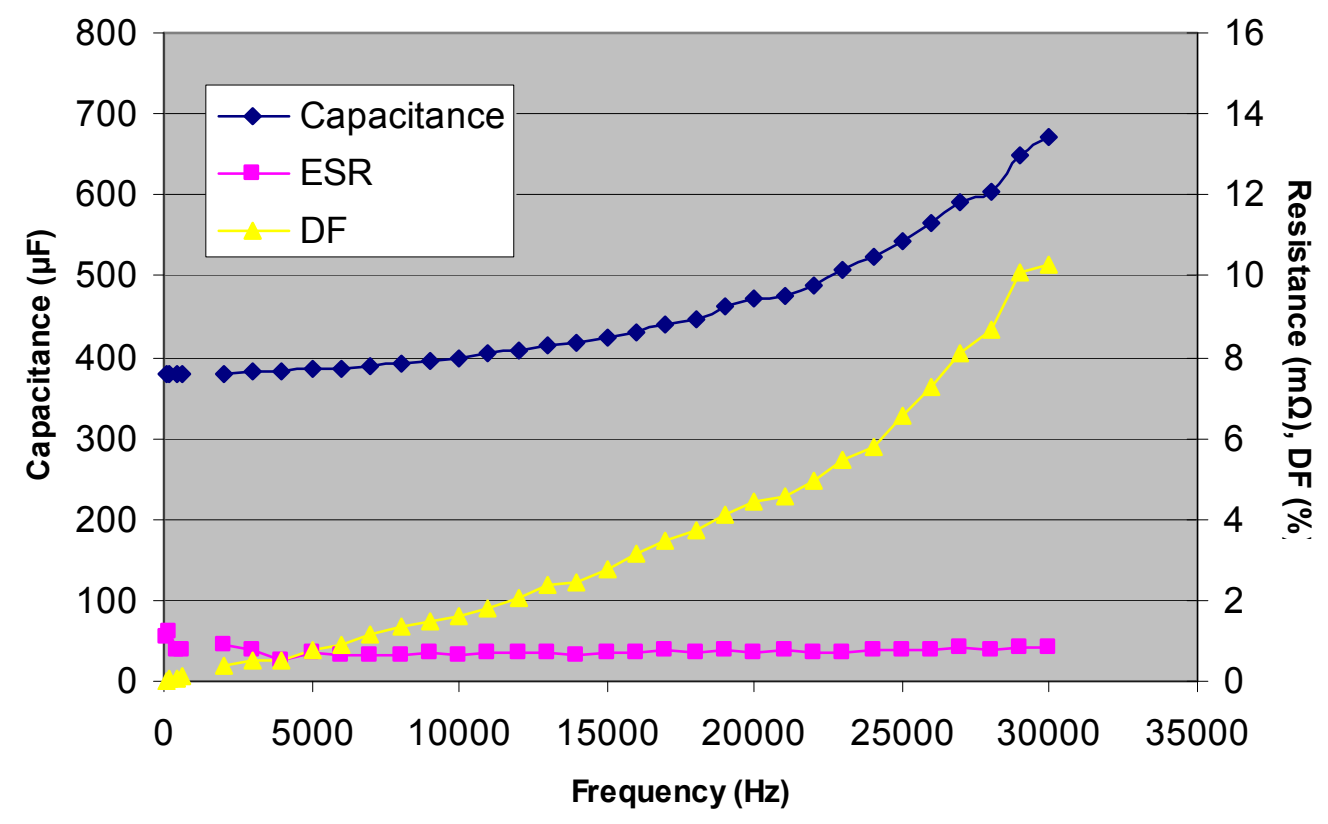

Fig. 2.51. Camry battery level $378 \mu \mathrm{F}$ capacitor, capacitance, ESR, and DF vs. frequency.

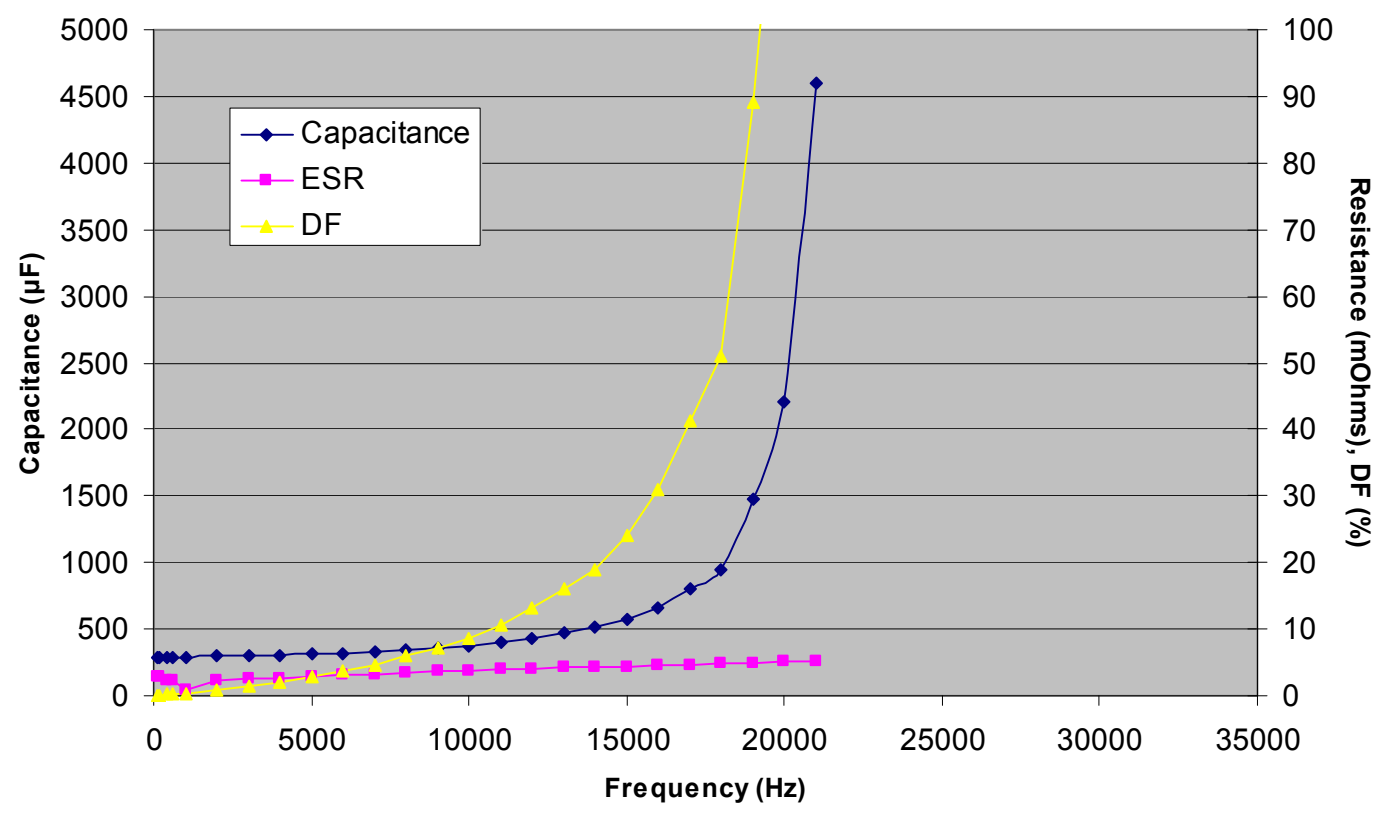

Fig. 2.52. Prius battery level $282 \mu \mathrm{F}$ capacitor, capacitance, ESR, and DF vs. frequency.

\subsubsection{Static capacitor test results of small dc-link capacitor evaluations}

Figures 2.53 and 2.54 compare the capacitor test results of the dc-link $750 \mathrm{~V}, 0.9 \mu \mathrm{F}$ capacitor of the Camry and the $750 \mathrm{~V}, 0.1 \mu \mathrm{F}$ capacitor of the Prius, respectively. Although the equivalent capacitance of the small Camry capacitor appears to decrease significantly, a closer look at the capacitance axis limits indicates that frequency has a small effect on the equivalent capacitance of the small Camry and Prius capacitors. Unlike the ESR of the other capacitors, the ESR of both small capacitors is much higher for 
low frequencies and decreases quickly with increasing frequency. All data points were taken at room temperature. The DF is relatively low even at high frequencies. These characteristics indicate the high frequency filtering capabilities of the small capacitors.

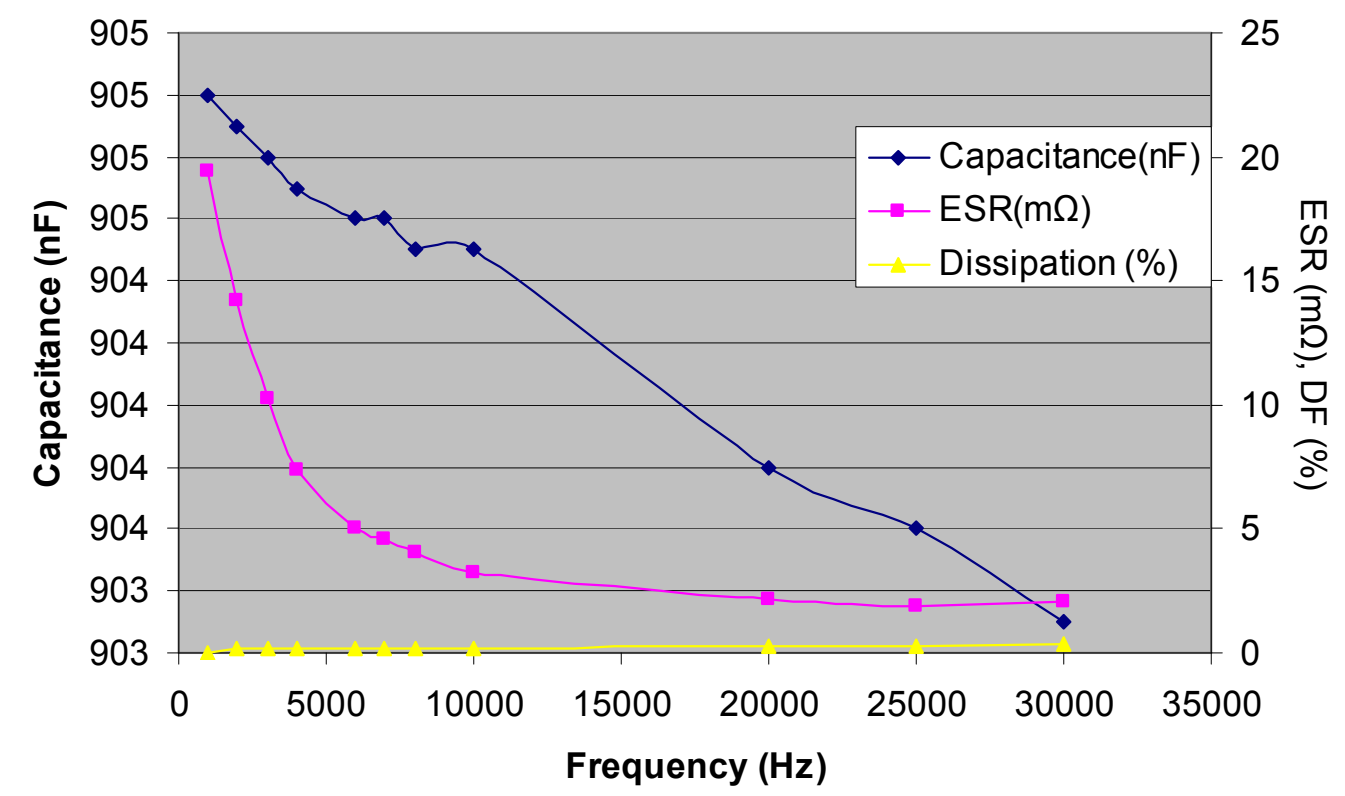

Fig. 2.53. Camry dc-link $0.9 \mu \mathrm{F}$ capacitor, capacitance, ESR, and DF vs. frequency.

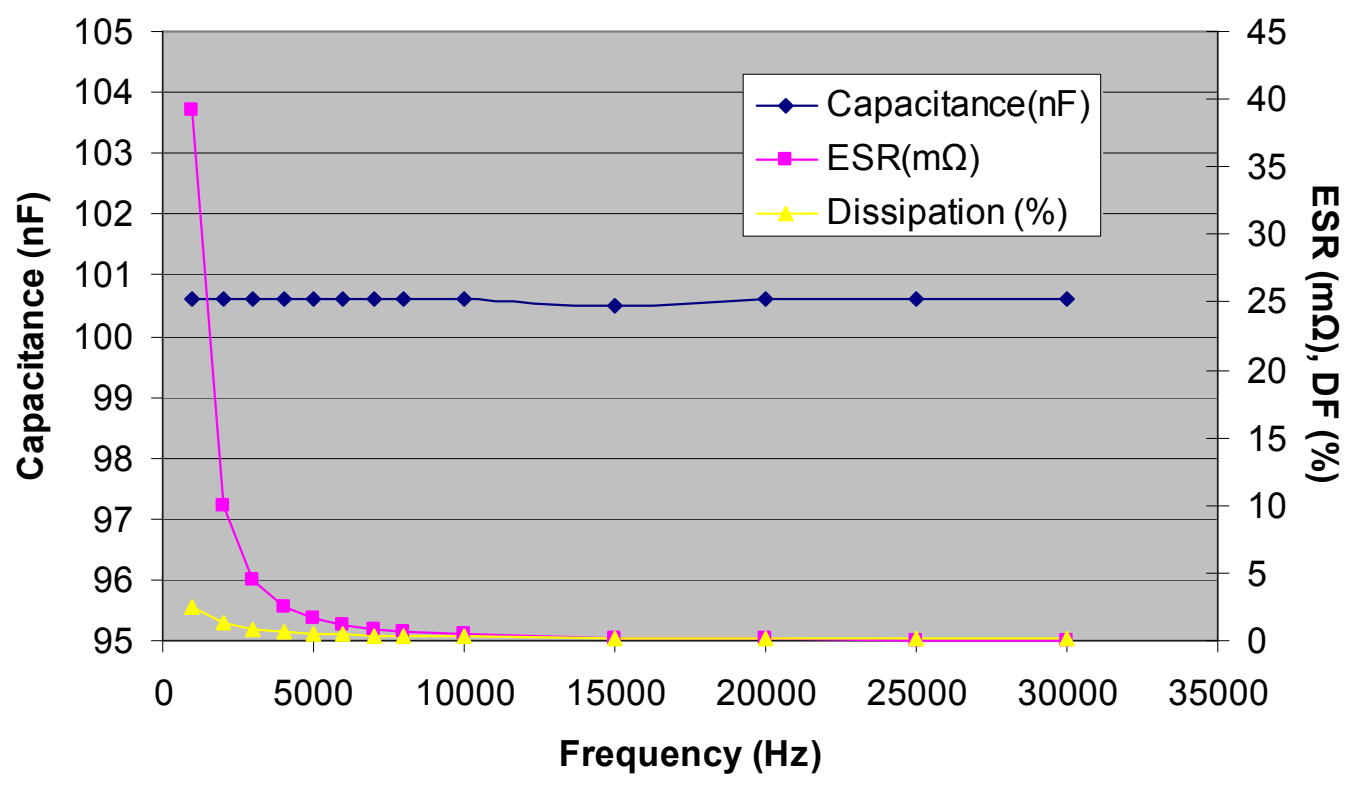

Fig. 2.54. Prius dc-link 0.1 $\mu$ F capacitor, capacitance, ESR, and DF vs. frequency.

\subsection{TRANSAXLE}

The 2007 hybrid Camry transaxle assembly is comprised of motor, generator, and gear box subassemblies. The mass of the entire unit is $108 \mathrm{~kg}$, which is shown in Fig. 2.55. An ICE mounts to the transaxle and a mechanical interface is established with spline shaft, which is slightly visible in the figure. 
The electric motor and generator outputs are not directly accessible yet through a combination of various gear configurations, the total motive force output of the hybrid system is supplied to the drive shafts by the differential gear outputs which are indicated in the figure. The generator is located adjacent to the ICE input (referred to as front end) and the motor is located in the rear portion of the transaxle, as shown in Fig. 2.56. The gear section of the transaxle is located between the generator and motor sections, as shown in Fig. 2.57.
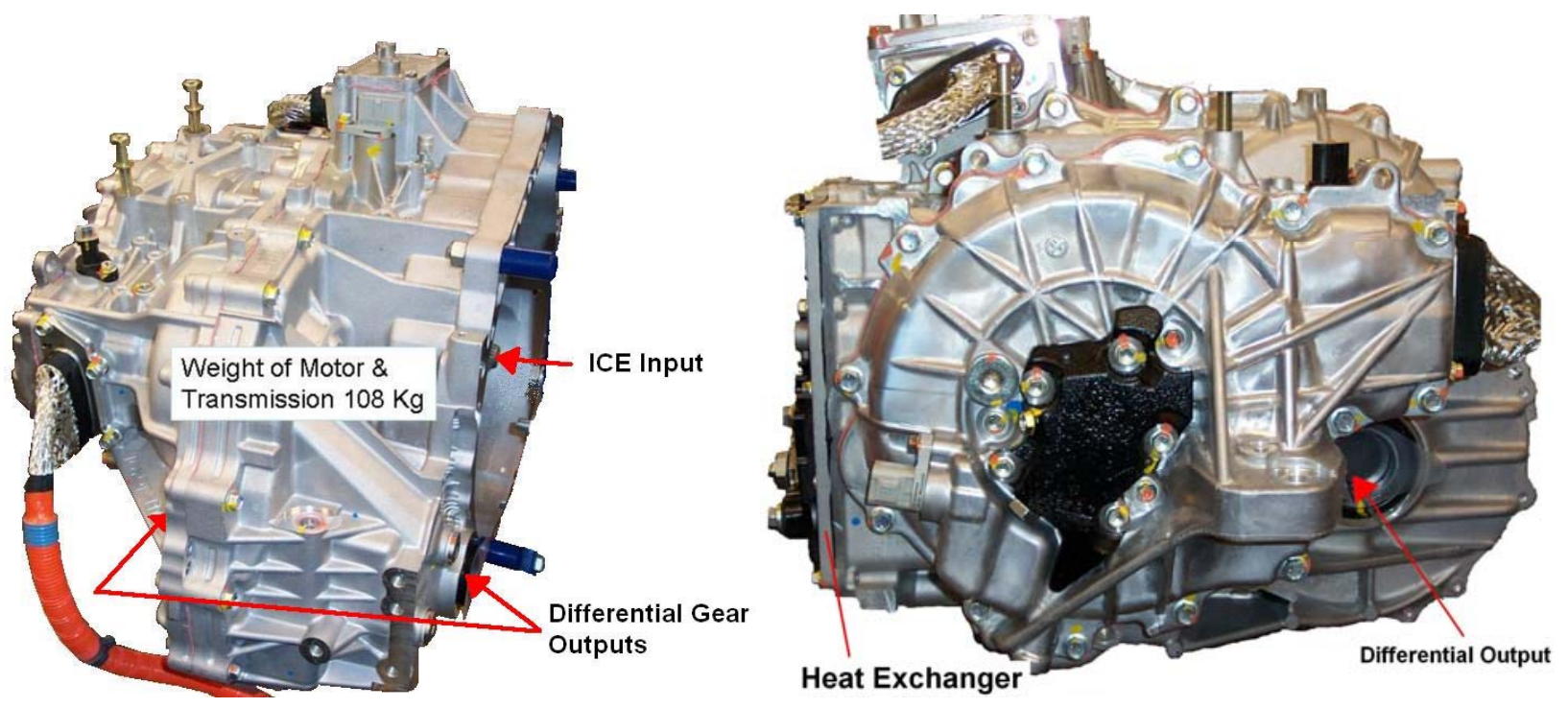

Fig. 2.55. Hybrid Camry transaxle isometric view (left) and rear view (right).
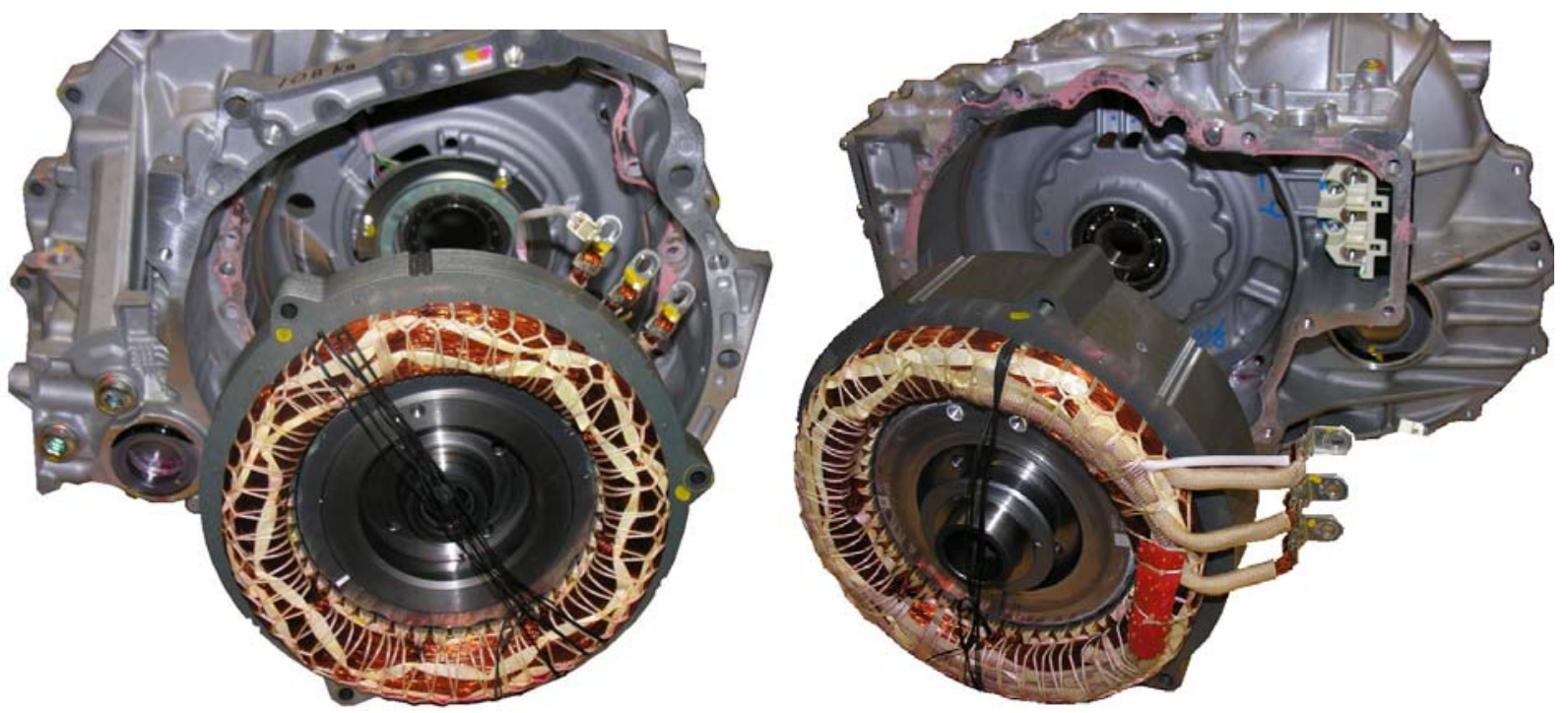

Fig. 2.56. Camry generator front view with ICE spline removed (left) and motor rear view (right). 


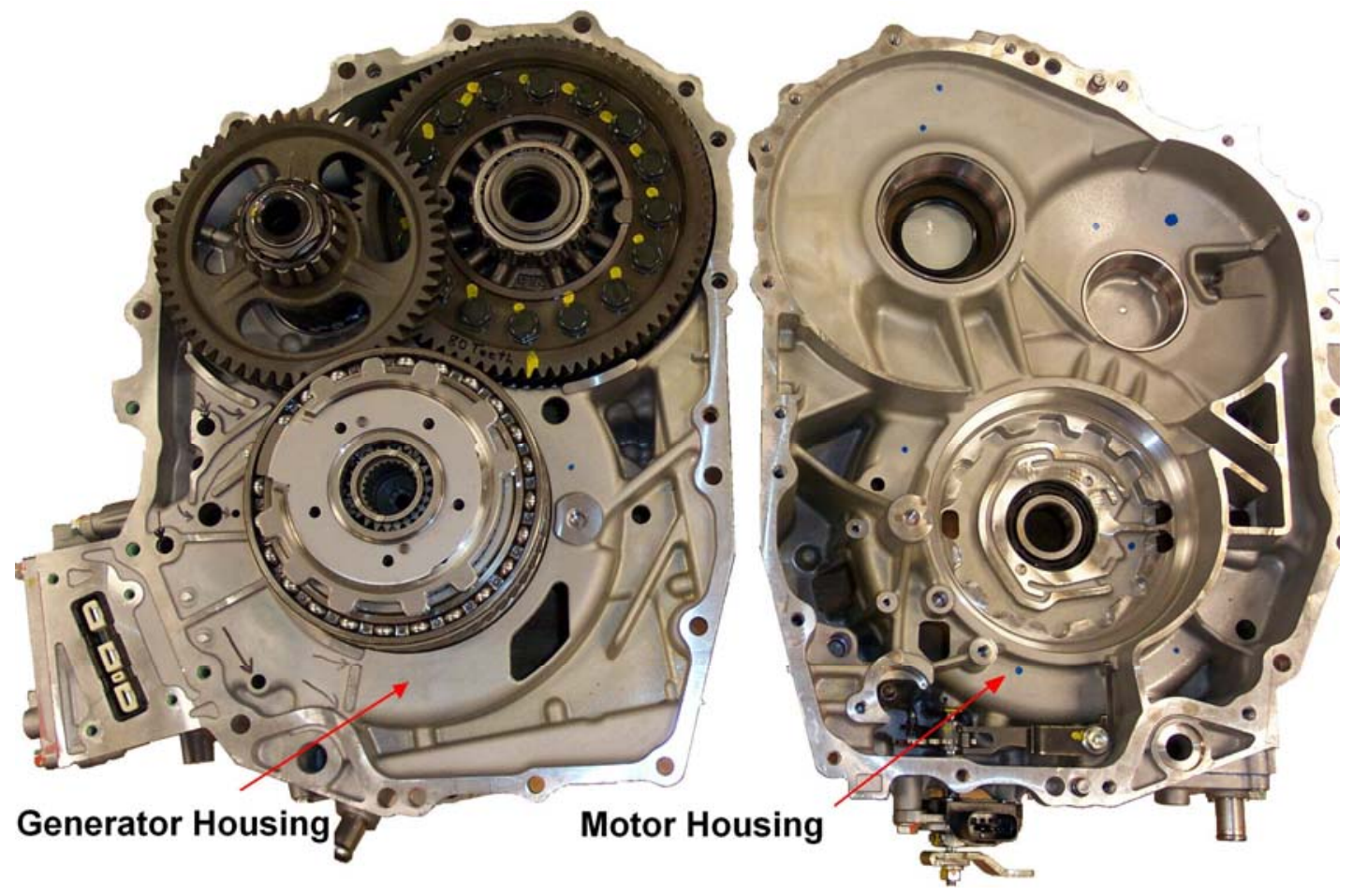

Fig. 2.57. Camry transaxle gear section open sandwich view.

\subsubsection{Thermal Management and Lubrication System}

The thermal management and lubrication system of the transaxle utilizes a mechanically driven trochoid oil pump as well as oil slinging movement by the drive gears to circulate oil throughout the transaxle. As shown in Fig. 2.58, the trochoid shaft is driven by the planetary carrier, which is connected directly to and rotates at the same speed as the ICE. The black plate was removed from the rear of the trochoid system to provide a view of the interior of the trochoid pump. An oil pickup is located near the bottom of the motor section which serves as an input to the trochoid pump. The central component of the trochoid pump resembles a gear and is machined such that the oil collects in the gaps of the pump teeth and forces the oil through the trochoid shaft shortly thereafter. The motor rotor shaft is hollow and the trochoid pump shaft extends through the hollow shaft of the motor rotor. A portion of the oil is dispensed to the motor bearing which is located next to the toothed central component of the trochoid pump. Small holes are located along the side of the trochoid pump shaft to supply oil to another motor bearing on the opposite end of the motor rotor. The tip of the trochoid pump shaft supplies oil to the power split and speed reduction gear through the same interface in which the shaft is driven. The 2004 Prius contains a similar trochoid pump mechanism.

Note that oil is not circulated by the trochoid pump if the ICE is not active. Therefore, if the vehicle is operating in electric mode only, then the system fully depends on the oil slinging action of the gear train for oil circulation. A general diagram of the oil flow paths is provided in Fig. 2.59. Oil that has settled in the bottom portion of the gear section is picked up by the differential gear teeth and is then slung to the driver gear, to reservoirs in the upper portion of the gear section, and to the power split planetary gear unit. The oil reservoirs are flooded if the differential gear is rotating above $900 \mathrm{rpm}$. A large reservoir is adjacent to a heat exchanger in order to transfer heat to the cooling system. Weep holes and oil ports distribute oil to the motor and generator stator as well as several bearings throughout the system. Note that the circulation due to gear slinging is dependent upon vehicle speed. 


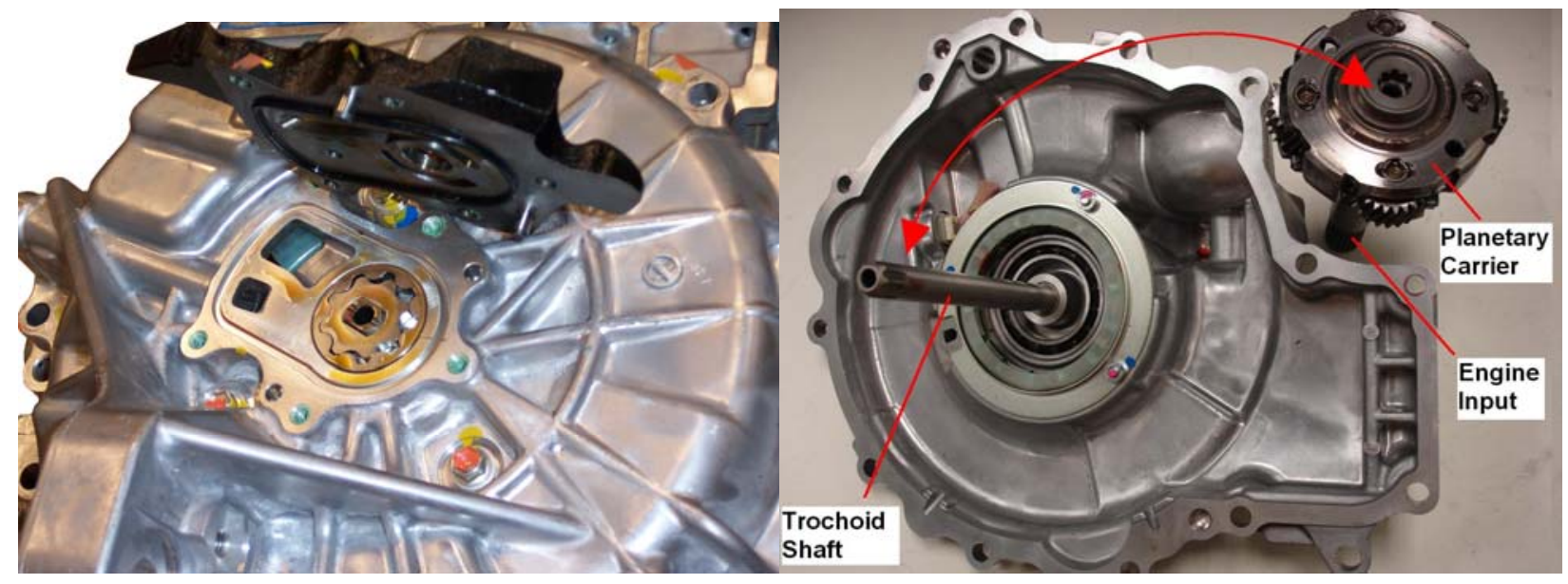

Fig. 2.58. Trochoid oil pump view from outside rear (left) and from inside motor section (right).

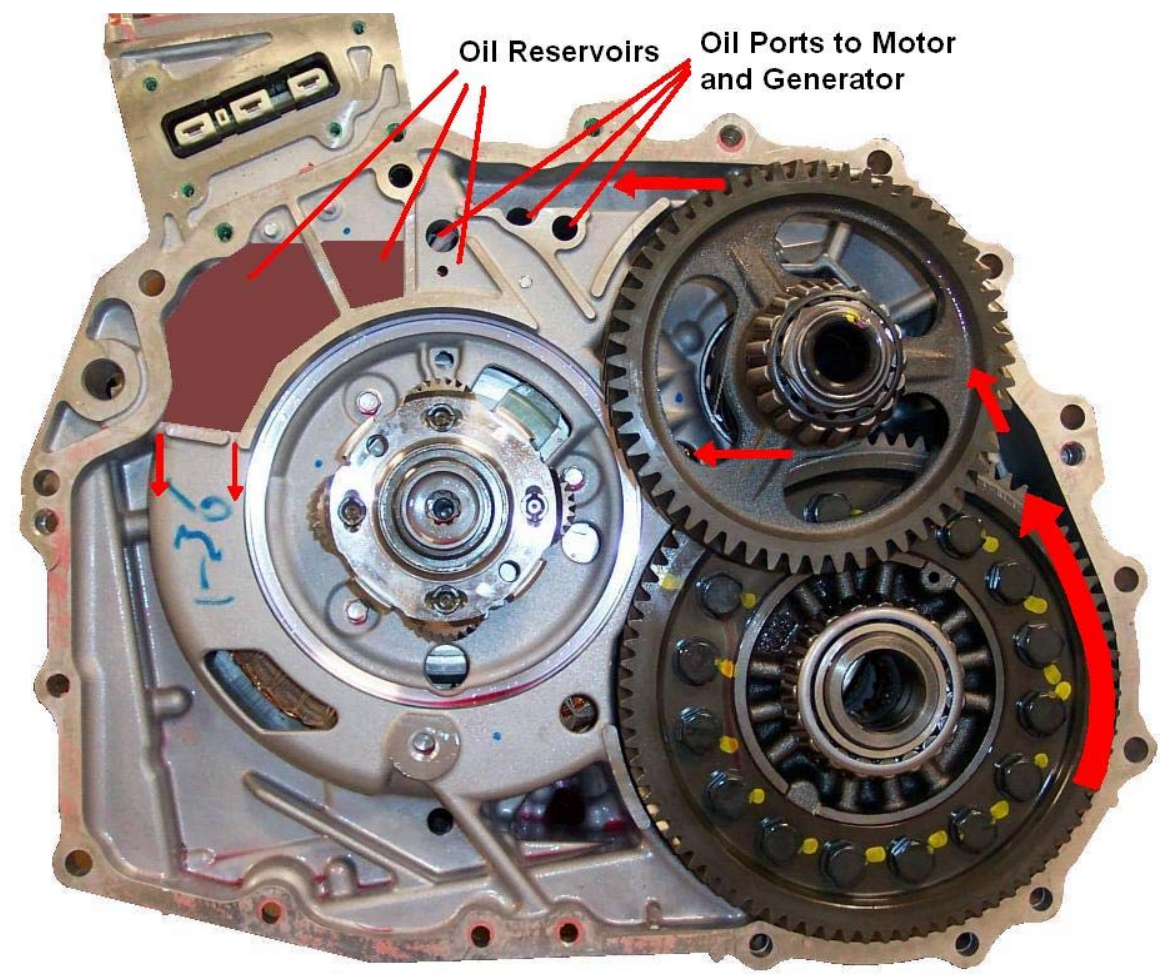

Fig. 2.59. Oil slinging paths formed by gear train.

A heat exchanger is located on the one side of the motor periphery and the generator also has a small heat exchanger which is part of a series coolant loop with the motor heat exchanger as well as the PCU heat exchanger. According to specifications in the Camry repair manual, the coolant loop consists of a standard 50\% ethlyene glycol and 50\% water mixture which flows at $10 \mathrm{~L}$ per minute and has an average operation temperature of $65^{\circ} \mathrm{C}$. Vehicle tests at Argonne National Laboratory (ANL) indicate the average coolant temperature may be considerably lower depending on operation conditions. The coolant capacity is listed as $2.9 \mathrm{~L}$. A separate radiator is dedicated to the THS coolant loop which is isolated from the ICE coolant loop that operates at much higher temperatures. 


\subsubsection{Transaxle Gear Train}

The Camry transaxle has three primary gear systems which are designed to carry out power split, speed reduction, and drive functions. A general comparison of the 2004 Prius gear train and the 2007 Camry gear train is provided in Fig. 2.60. The number of teeth on each gear is noted in black text on a white background. There are several noticeable differences between the two designs. The Prius transaxle design has a chain coupling between the power split planetary ring and the counter drive gear, whereas the planetary ring and counter drive gears mesh directly within the Camry transaxle. Additionally, the Camry transaxle has only three separate axes about which gear systems rotate, compared to four axes in the Prius transaxle. The number of teeth on the planetary gear components does not differ between the two designs. The total gear ratio from the Camry power split planetary ring to the differential output is $(80 / 23) \times(55 / 54)=3.542$, where the equivalent gear ratio for the Prius is $(75 / 26) \times(44 / 30) \times(35 / 36)=$ 4.113 .
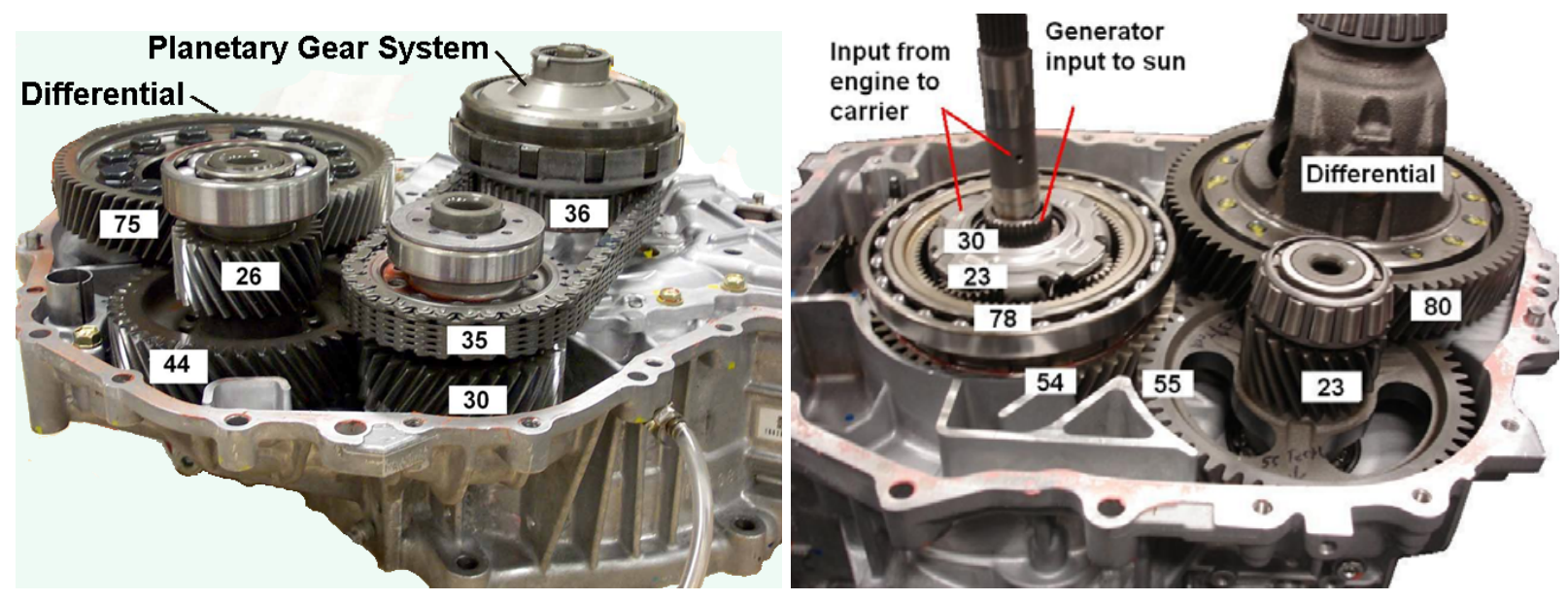

Fig. 2.60. 2004 Prius gear train (left) and 2007 Camry gear train (right).

Another significant difference between the designs is that the Camry has a speed reduction gear, which is comprised of a planetary gear unit. The speed reduction planetary gear assembly is shown along with the power split planetary gear unit in Fig. 2.61. The planetary gear units share the ring gear in which the electric motor, MG2, is connected to the ring gear through the speed reduction gears. The number of teeth is shown for each gear and the planetary carrier is fixed to the chassis. Thus, the gear ratio between the electric motor shaft is $(57 / 18) \times(18 / 23)=2.478$, where the MG2 spins 2.478 times faster than the ring gear and therefore the torque output of MG2 is effectively multiplied by 2.478 prior to reaching the ring gear. Gear teeth on the outer periphery of the ring gear, collectively referred to as the counter drive gear, mesh with the counter driven gear which supplies motive force to the drive shafts though the final and differential gear units. Consequently, the speed of MG2 is directly proportional to the speed of the vehicle. The generator rotor shaft is hollow and connects to the sun gear of power split planetary and the input shaft from the ICE is fed through the hollow generator shaft and connects to the planetary carrier. A locking gear mechanism is adjacent to the counter drive gear which is engaged when the vehicle gear selector is placed in park. A summary of the number of gear teeth for each gear is provided in Table 2.6. Since the Prius drive gear train is moderately different from the Camry drive train, a comparison is not easily made between each component of the drive train, but is more meaningful if the overall gear ratio is compared, as provided previously. 


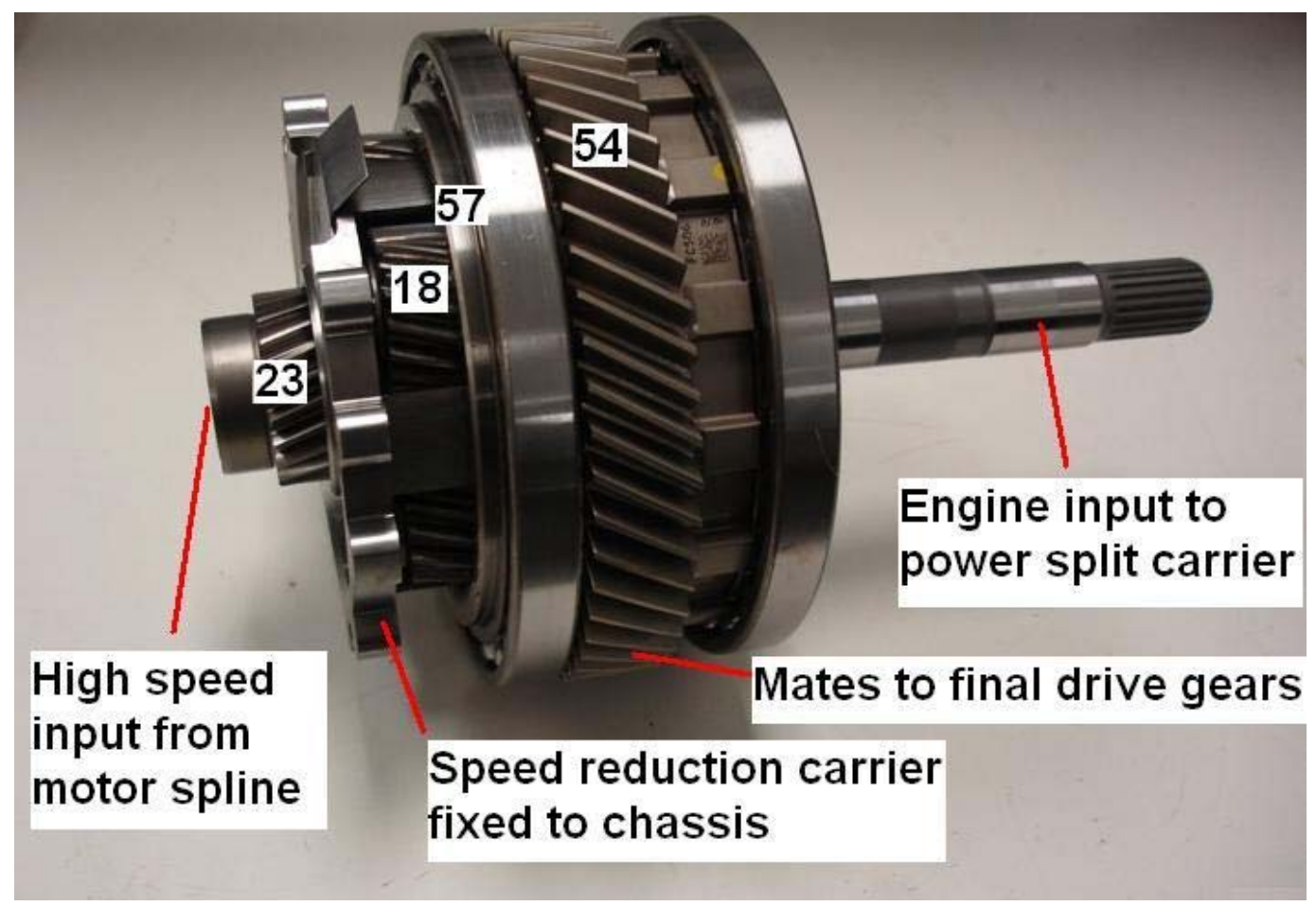

Fig. 2.61. Camry speed reduction planetary and power split planetary.

Table 2.6. Camry transaxle gear information

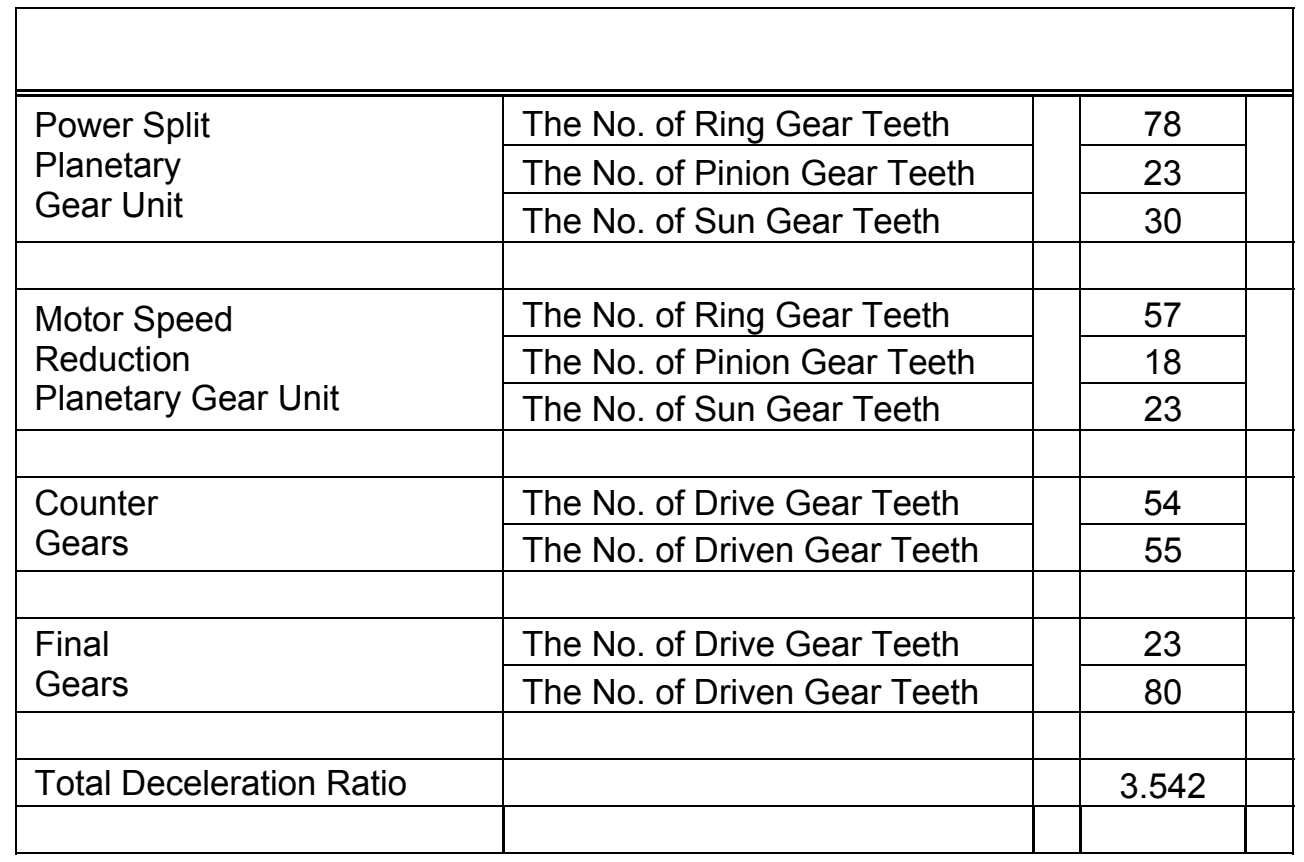

\subsubsection{Motor Mass and Volumetric Assessments}

When comparing the Camry and Prius electric drive characteristics, the mass and volume of the primary electric drive motor, MG2, was decreased although the peak and continuous power capabilities of the motor increased. This was primarily accomplished by increasing the rated speed of the motor from about 
$6,000-14,000 \mathrm{rpm}$. To clarify the benefit of increasing the speed rating, the torque and power rating of the Prius motor is given in Fig. 2.62. These are shown to present the general speed, torque, and power relationship of any motor as power is equal to torque times speed. Therefore, a much lower torque is required to produce a certain power level at a higher speed than for a lower speed. For example, a torque of $382 \mathrm{Nm}$ is required to produce $40 \mathrm{~kW}$ at $1000 \mathrm{rpm}$, whereas only $38.2 \mathrm{Nm}$ is required to produce $40 \mathrm{~kW}$ at 10,000 rpm. Additionally, torque is proportional to current and, roughly speaking, the amount of current required to produce a consistent power level decreases with increasing speed. While this is not entirely an accurate statement as there are many factors to consider when making such a comparison, the concept generally holds true.
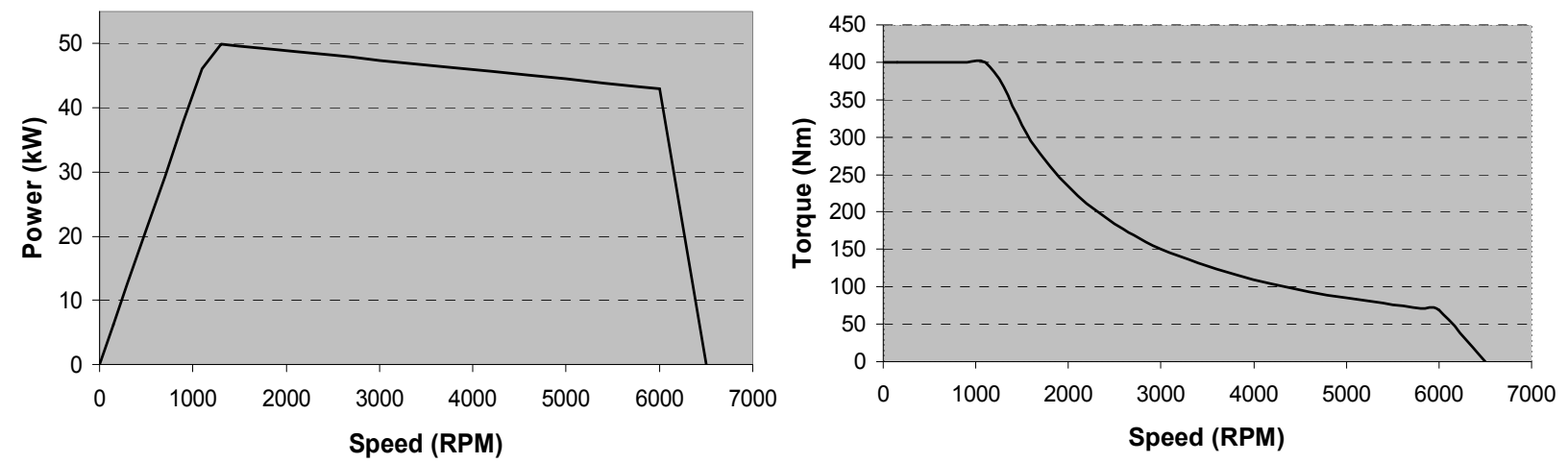

Fig. 2.62. Speed, torque, and power relationship.

There are a few negative aspects of moving to higher motor speed ratings however. Typically, the low speed torque rating of the motor is compromised when the speed rating is increased. Therefore, the lowest speed at which rated power can be developed, namely base speed, increases. Again, these relationships depend upon various motor design parameters such as rotor diameter, lamination stack length, magnet strength, and winding configuration, yet these relationships are typically pertinent. As rotor speed ratings increase, additional mechanical design aspects must be considered. Improved support must be provided by the rotor laminations to retain the PMs which are subjected to forces which are directly proportion to the square of the rotor speed. Additionally, bearings must be designed to withstand the high speeds of the rotor shaft. Depending on the characteristics of the PMs, rotor, and stator, core losses and induced backemf voltages typically increase with increasing rotor speed. The high speed reduction gear used in the Camry design is required to convert the high speed of the motor to properly match the remaining transaxle design. Although the torque rating of the Camry is only $270 \mathrm{Nm}$, the maximum torque is converted to about $670 \mathrm{Nm}$ through the speed reduction gear.

Figures 2.63 and 2.64 provide various views of the Camry transaxle and the volume associated with the primary drive motor. Certain key dimensions are shown, but several others are needed to determine volume since the motor terminal box, and especially the heat exchanger shown in Fig. 2.64 have complex geometries. Since the motor casing also houses some of the gear box, the motor casing had to be well defined to arrive at the mass and volume, excluding areas unrelated to the motor. For example, in Figs. 2.63(a) and 2.63(b), the surface chosen for the end of the motor housing is indicated. 


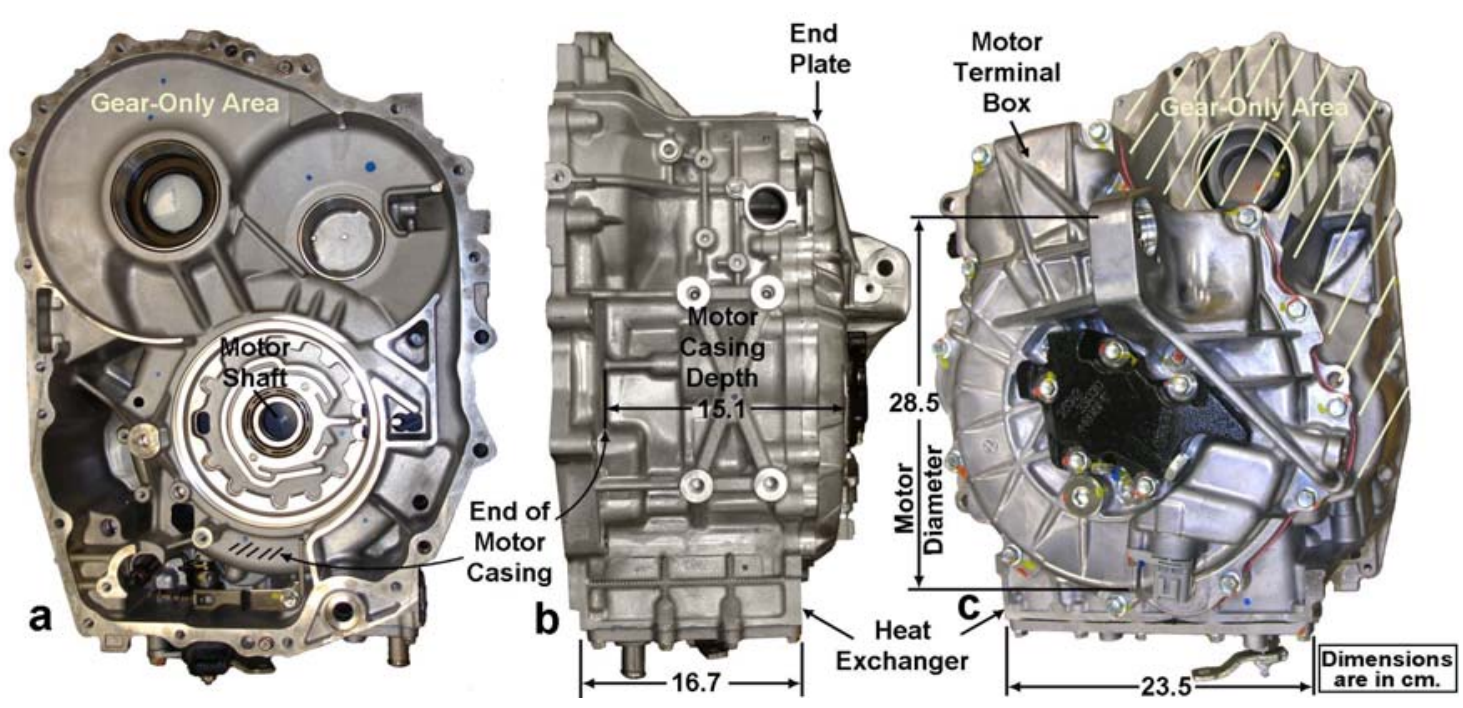

Fig. 2.63. Camry motor assembly after separation from generator assembly.

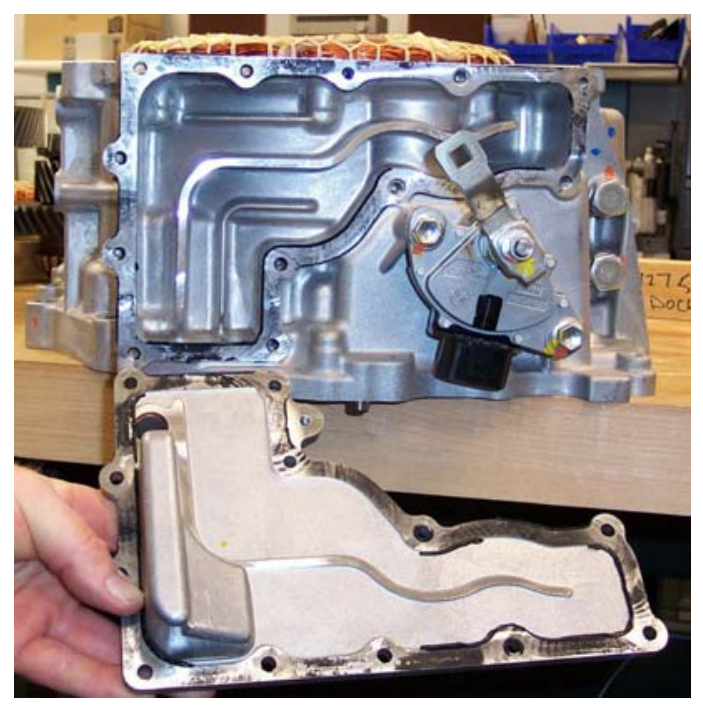

Fig. 2.64. Coolant channel at bottom of motor casing.

The results of the packaging assessment were used to generate estimates of peak specific power and peak power density as summarized and compared to the Prius specs in Table 2.7. Because of advantages gained by increasing the maximum speed from $6,000-14,000 \mathrm{rpm}$, Toyota was able to optimize the Camry design such that motor volume and mass were both lower than for the Prius in spite of a higher published peak power rating. It is appropriate to include the mass and volume of the Camry speed reduction planetary gear in this comparison with the Prius and doing so mitigates the perceived improvement upon the Prius design.

Table 2.7. Specific power and power density estimates for the PMSM

\begin{tabular}{|l|c|c|}
\hline \multicolumn{1}{|c|}{ Parameter } & Camry & Prius \\
\hline $\begin{array}{l}\text { Motor peak specific power (without } \\
\text { converter), } \mathrm{kW} / \mathrm{kg}\end{array}$ & $70 / \sim 41.7=\sim \mathbf{1 . 6 8}$ & $50 / 45.0=\mathbf{1 . 1 1}$ \\
\hline Motor peak power density, kW/L & $70 / \sim 14.8=\sim \mathbf{4 . 7 3}$ & $50 / 15.4=\mathbf{3 . 2 5}$ \\
\hline
\end{tabular}


Figure 2.65 shows the stator assembly that was removed from the Camry transaxle assembly. The entire Camry stator assembly mass is $18.0 \mathrm{~kg}$, whereas the Prius stator assembly mass is $25.9 \mathrm{~kg}$, with $5.7 \mathrm{~kg}$ and $6.8 \mathrm{~kg}$ of copper within each stator, respectively. The three-phase power input ("output" during regenerative braking) leads are clearly evident. A thermistor is embedded in the stator windings and the corresponding leads are routed adjacently to the motor leads. There are 18 wires bundled in each motor lead which splits in half to form a parallel winding configuration. The Camry stator windings have 9 strands of copper with 14 turns per pole and the Prius stator windings have 13 stands of copper with 9 turns per pole in parallel and series configurations, respectively. Notice that the product of the number of strands and the number of turns has a comparable result between the Camry and the Prius.

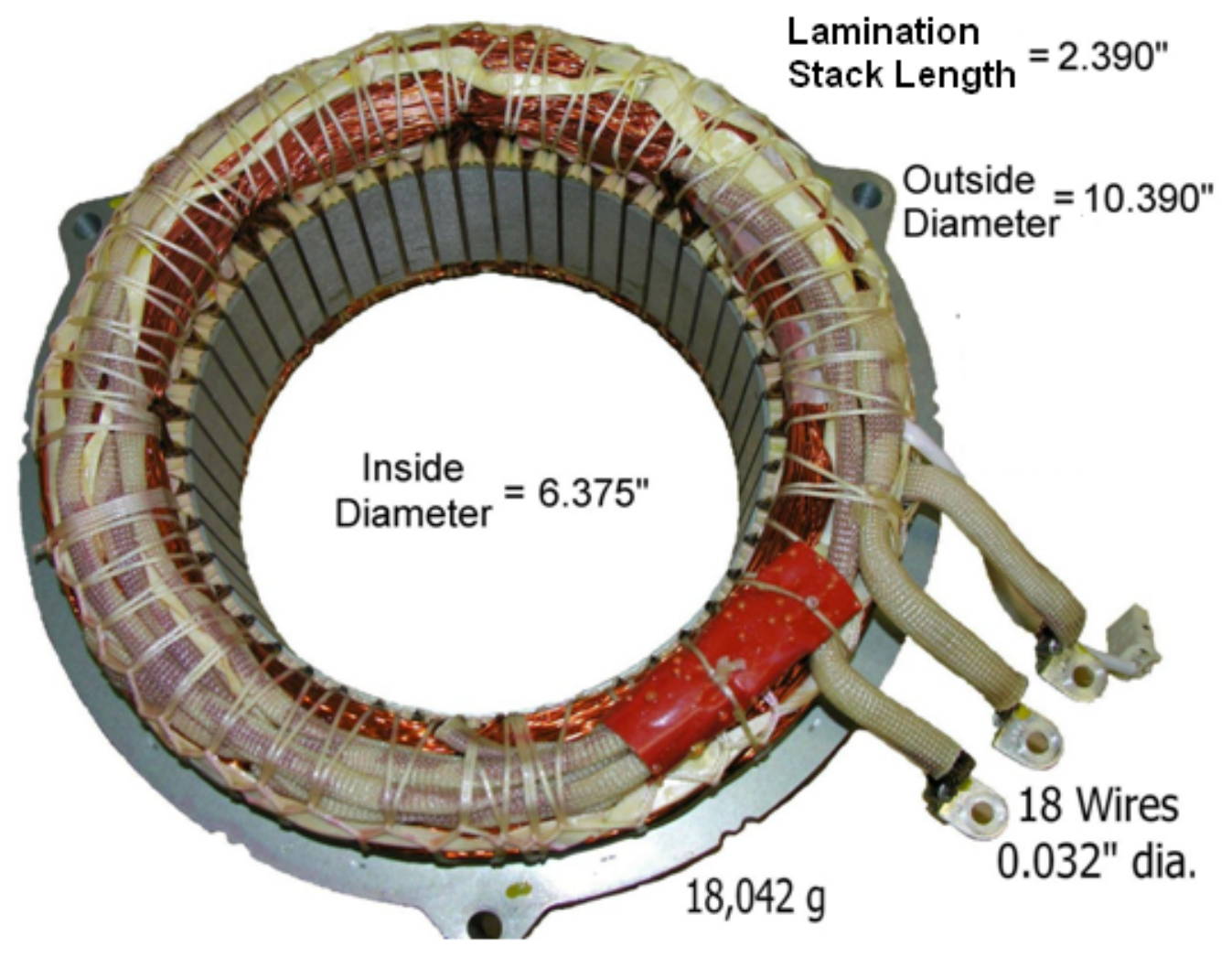

Fig. 2.65. Camry motor stator.

A comparison of the Camry and Prius laminations is provided in Fig. 2.66. In Fig. 2.66(a), a Camry motor stator lamination is placed on top of a Prius motor stator lamination, showing that the outer diameter (OD) of the Camry lamination is slightly smaller than that of the Prius. Through both Figs. 2.66(a) and 2.66(b) it is shown that the Camry motor stator slots are somewhat shorter, yet they are wider than the slots on the Prius motor stator laminations. The Camry generator stator laminations are identical to the Camry motor stator laminations. The motor lamination stack thickness has reduced from 3.29" on the Prius to 2.39 " on the Camry. The Camry generator lamination stack thickness is 1.41 ". The inner diameters (IDs) of the Camry motor, Camry generator, and Prius motor stator laminations are equal. The stack lengths and outer diameters of the rotors have corresponding similarities. 


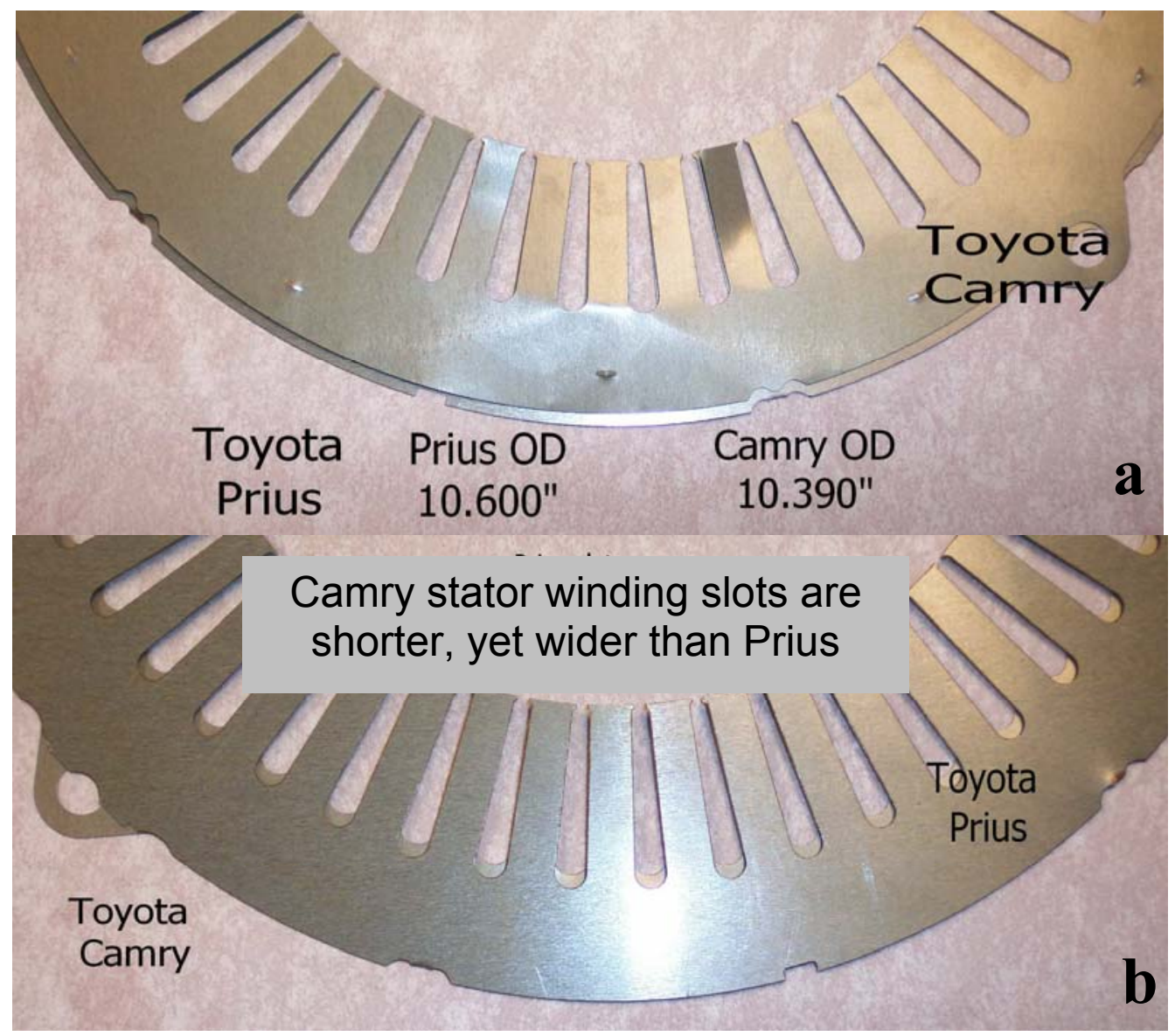

Fig. 2.66. Camry and Prius motor stator laminations.

Figure 2.67 shows details of the Camry rotor assembly and the "V" orientation of the neodymium iron boron $(\mathrm{NdFeB})$ interior PM. Looking at the pair of magnets in the foreground, it is possible to see the narrow support bar that passes between them. This support bar, missing from the Prius motor laminations, helps to enable the motor to operate at much higher rotational speeds.
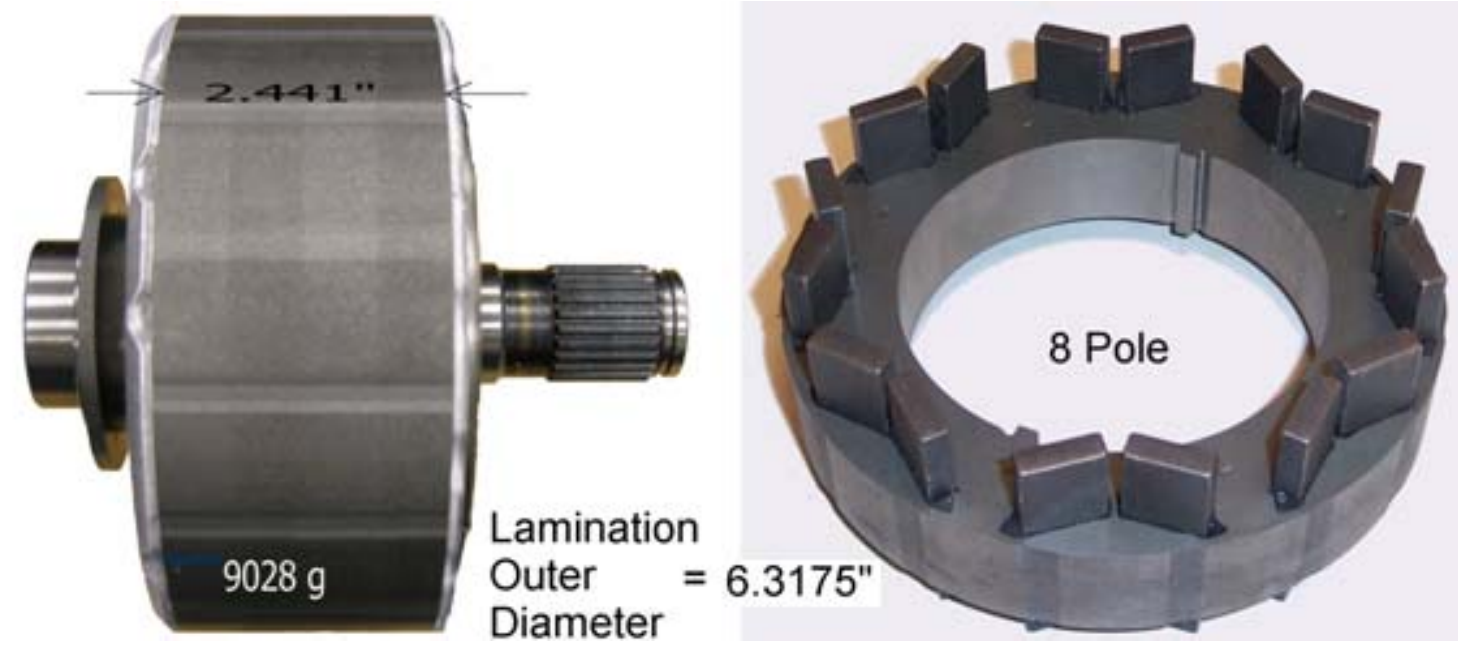

Fig. 2.67. Camry rotor assembled (left) and partially disassembled (right). 
In making various comparisons between the Camry and Prius motor components, the highlights shown in Table 2.8 were generated. The table summarizes the general motor design, rotor and stator dimensions/mass, and the wiring and slot details of the stator. Because the rotor and stator lamination geometries are difficult to fully describe in a table, Figs. 2.68 and 2.69 provide this information. The length of the magnets decreased along with the decrease in the stator and rotor lamination stack length. However, the thickness and width of the Camry and Prius motor PMs are very similar. Details regarding the magnet characteristics are provided in Section 2.2.4. Various motor characteristics were experimentally measured and the results are presented in Section 3.

Table 2.8. 2007 Camry/2004 Prius motor design comparison highlights

\begin{tabular}{|c|c|c|c|}
\hline Parameter & Camry & Prius & Comments \\
\hline \multicolumn{4}{|l|}{ Lamination Dimensions } \\
\hline Stator OD, mm & 264 & 269 & OD \\
\hline Stator ID, mm & 161.93 & 161.93 & ID \\
\hline Stator stack length, $\mathrm{cm}$ & 6.07 & 8.4 & \\
\hline Rotor OD, mm & 160.47 & 160.47 & OD \\
\hline Rotor lamination ID, mm & 105 & 111 & ID \\
\hline Rotor stack length, $\mathrm{cm}$ & 6.2 & 8.36 & \\
\hline Air gap, mm & 0.73025 & 0.73025 & \\
\hline Lamination thickness, $\mathrm{mm}$ & 0.31 & 0.33 & \\
\hline \multicolumn{4}{|l|}{ Mass of Assemblies } \\
\hline Rotor mass, $\mathrm{kg}$ & 9.03 & 10.2 & Including rotor shaft. \\
\hline Stator mass, $\mathrm{kg}$ & 18.0 & 25.9 & \\
\hline Stator core mass, $\mathrm{kg}$ & 12.38 & 19.05 & Laminations only. \\
\hline \multicolumn{4}{|l|}{ Stator Wiring } \\
\hline Number of stator slots & 48 & 48 & \\
\hline Stator turns per coil & 14 & 9 & \\
\hline Parallel circuits per phase & 2 legs & 0 & \\
\hline Turns in series per phase & 4 per leg & 8 & \\
\hline Number of wires in parallel & 9 per leg & 13 & \\
\hline $\begin{array}{l}\text { Wire size, American wire gauge } \\
\text { (AWG) }\end{array}$ & 20 & 19 & \\
\hline Phase resistance at $21^{\circ} \mathrm{C}, \mathrm{ohm}$ & 0.023 & 0.069 & $\begin{array}{l}\text { Average of phase-to-phase } \\
\text { divided by two. }\end{array}$ \\
\hline Total mass of stator copper, $\mathrm{kg}$ & 5.6 & 6.8 & \\
\hline Slot depth, mm & 30.9 & 33.5 & \\
\hline Slot opening, $\mathrm{mm}$ & 1.88 & 1.93 & \\
\hline \multicolumn{4}{|l|}{ Casing } \\
\hline Motor casing mass, $\mathrm{kg}$ & 9.5 & 8.9 & $\begin{array}{l}\text { Camry has thicker walls, larger } \\
\text { heat exchanger, speed reduction } \\
\text { gear casing and bearings }\end{array}$ \\
\hline Motor casing diameter, $\mathrm{cm}$ & 30.2 & 29.9 & \\
\hline Motor casing axial length, $\mathrm{cm}$ & 17.0 & 20.5 & \\
\hline \multicolumn{4}{|l|}{ Magnets (NdFeB) } \\
\hline Magnet dimensions, $\mathrm{mm}$ & $60.6 \times 19.1 \times 6.6$ & $83.1 \times 18.9 \times 6.5$ & One magnet ( $1 / 2$ of "V" or pole). \\
\hline Magnet volume, $\mathrm{cm}^{3}$ & 7.63 & 10.2 & One magnet ( $1 / 2$ of "V" or pole). \\
\hline Magnet mass, grams & 58 & 77 & One magnet ( $1 / 2$ of "V" or pole). \\
\hline Total mass of magnets, $\mathrm{kg}$ & 0.928 & 1.232 & Entire magnet mass in rotor. \\
\hline
\end{tabular}




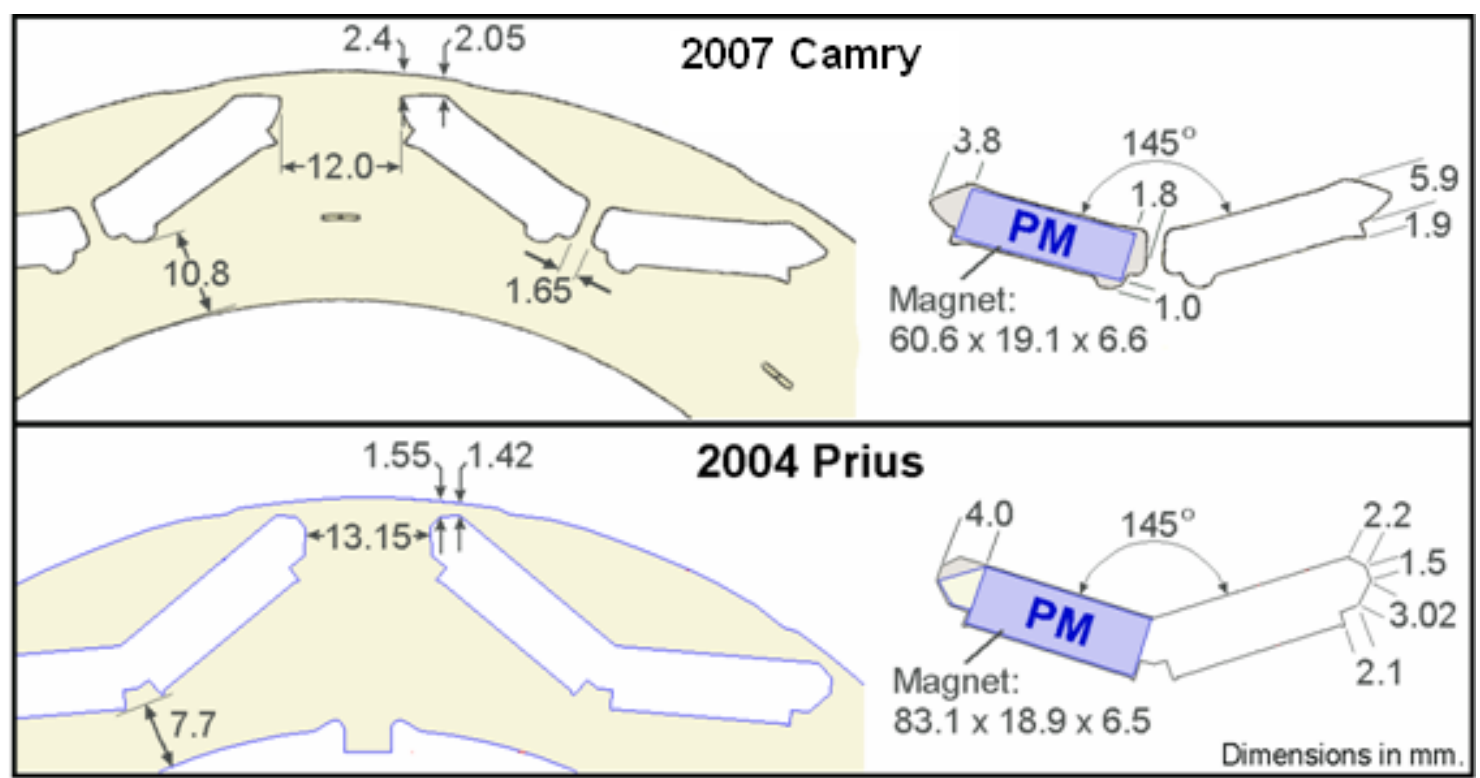

Fig. 2.68. Camry and Prius motor rotor lamination/PM design.

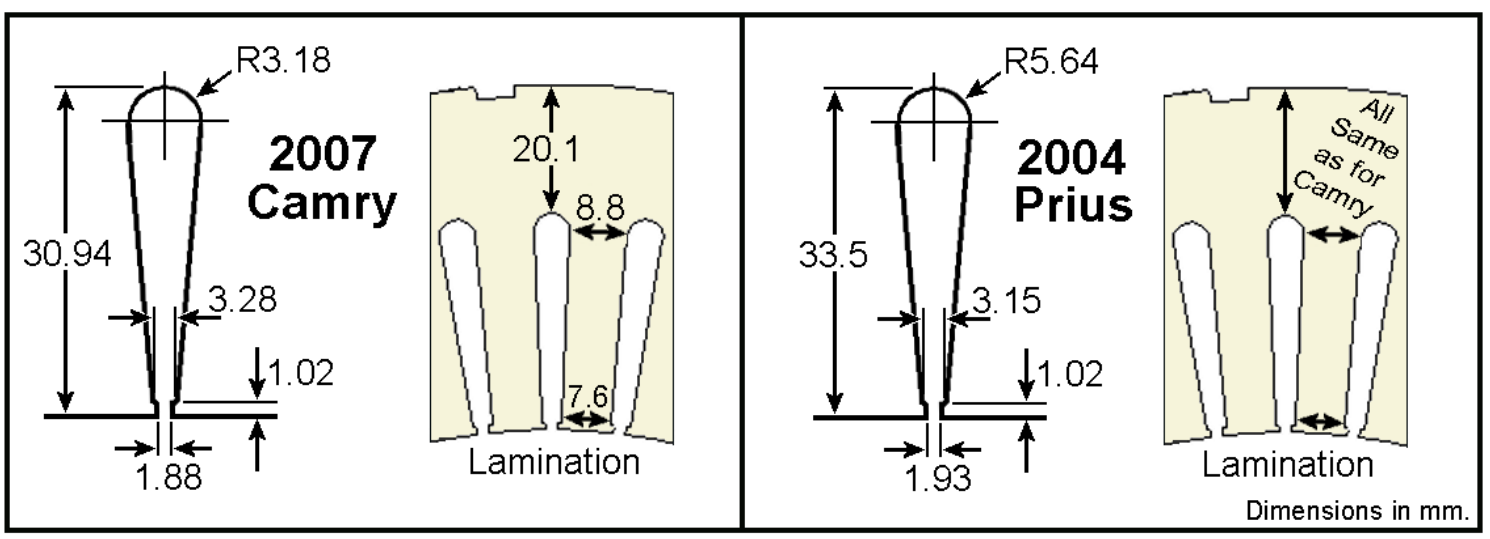

Fig. 2.69. Camry and Prius motor stator lamination/slot design.

Volume assessments of the Camry generator housing were conducted with the general approach and calculations shown in Fig. 2.70. The total volume of the Camry generator housing is about $11 \mathrm{~L}$ and the total mass is about $28 \mathrm{~kg}$. The power rating of the Camry generator is approximately $40 \mathrm{~kW}$ compared to the $33 \mathrm{~kW}$ rating of the Prius generator. Comparisons of the Camry and Prius generator stators and rotors are provided in Figs. 2.71 and 2.72, respectively. It is evident that the generator has increased in both diameter and stack length by about $14 \%$ and $17.5 \%$, respectively. The size of the Camry generator is more suited for continuous operation. A thermistor is embedded within the stator windings to provide temperature feedback and the MG ECU will discontinue operation of the generator upon reaching an over-temperature condition. A summary and comparison of the Camry and Prius generator specifications is provided in Table 2.9 . 

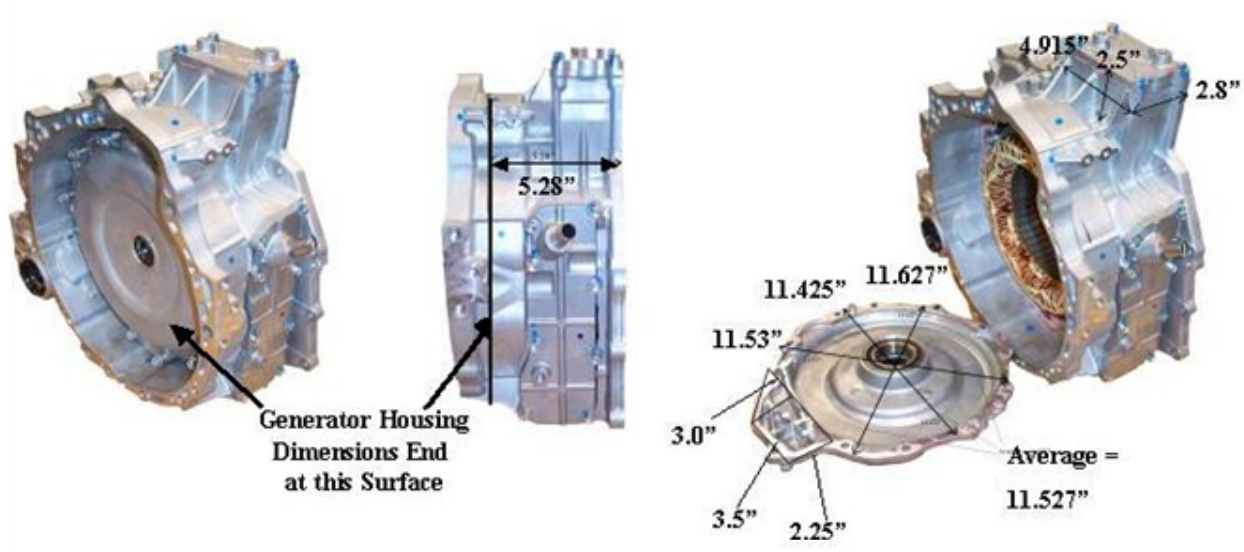

\begin{tabular}{|c|}
\hline Approximate Volume of \\
Camry Generator Minus \\
Cooling Channels and \\
Terminal Block Housing = \\
\\
$\left(5.28^{\prime \prime}\right)(\pi)\left(11.527^{\prime \prime} / 2\right)^{2}=$ \\
$551 \mathrm{in}^{3}=9,029 \mathrm{~cm}^{3}=9.03 \mathrm{~L}$ \\
\hline Volume of Cooling Passages = \\
$0.5 \mathrm{~L}$ \\
\hline Volume of Terminal \\
Block Housing = \\
$(1 / 2)\left(3^{\prime \prime}\right)(2.25 ")\left(5.28^{\prime \prime}\right)+$ \\
$\left(3.5^{\prime \prime}\right)(2.25 ")\left(5.28^{\prime \prime}\right)+$ \\
$\left(4.915^{\prime \prime}\right)\left(2.5^{\prime \prime}\right)\left(2.8^{\prime \prime}\right)=$ \\
$93 . \sin ^{3}=1540 \mathrm{~cm}^{3}=1.54 \mathrm{~L}$ \\
\hline
\end{tabular}

Fig. 2.70. Camry generator volume assessment.

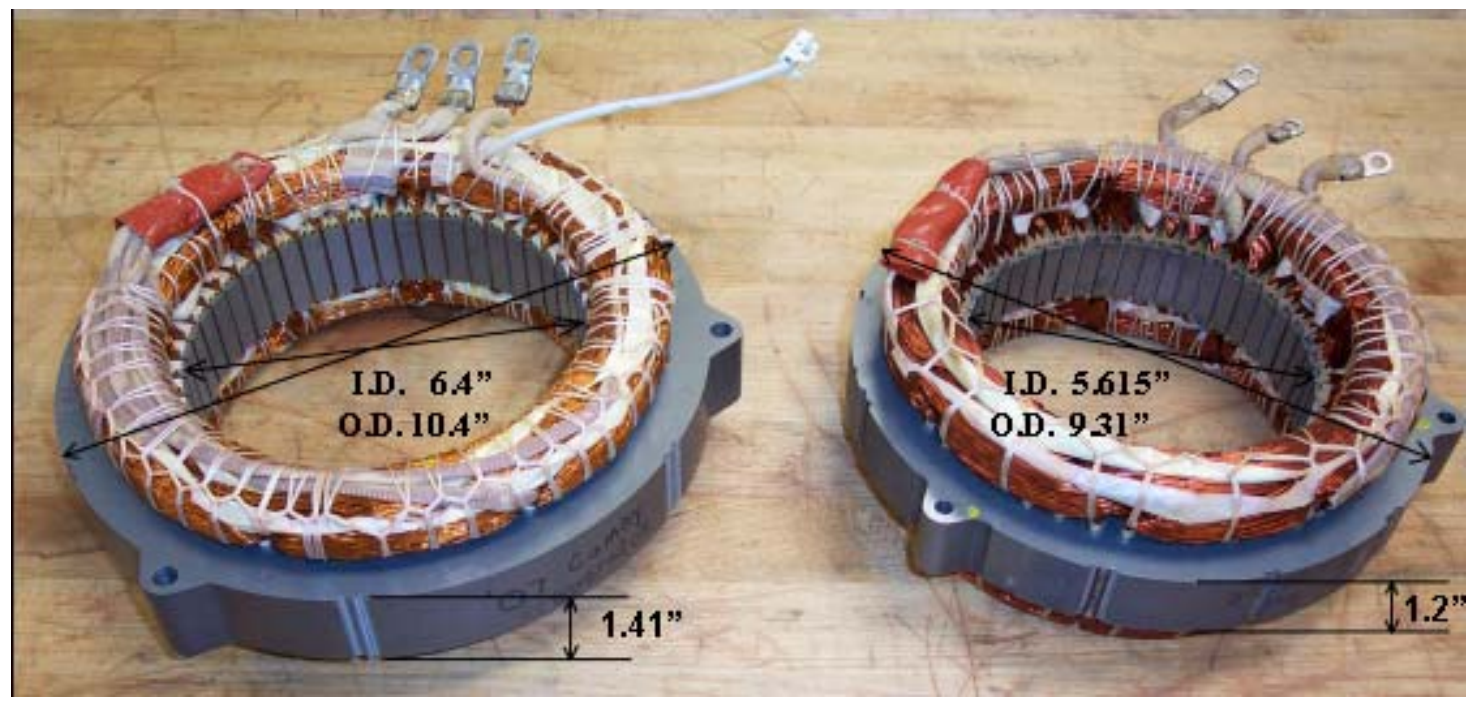

Fig. 2.71. Camry (left) and Prius (right) generator stator comparison.

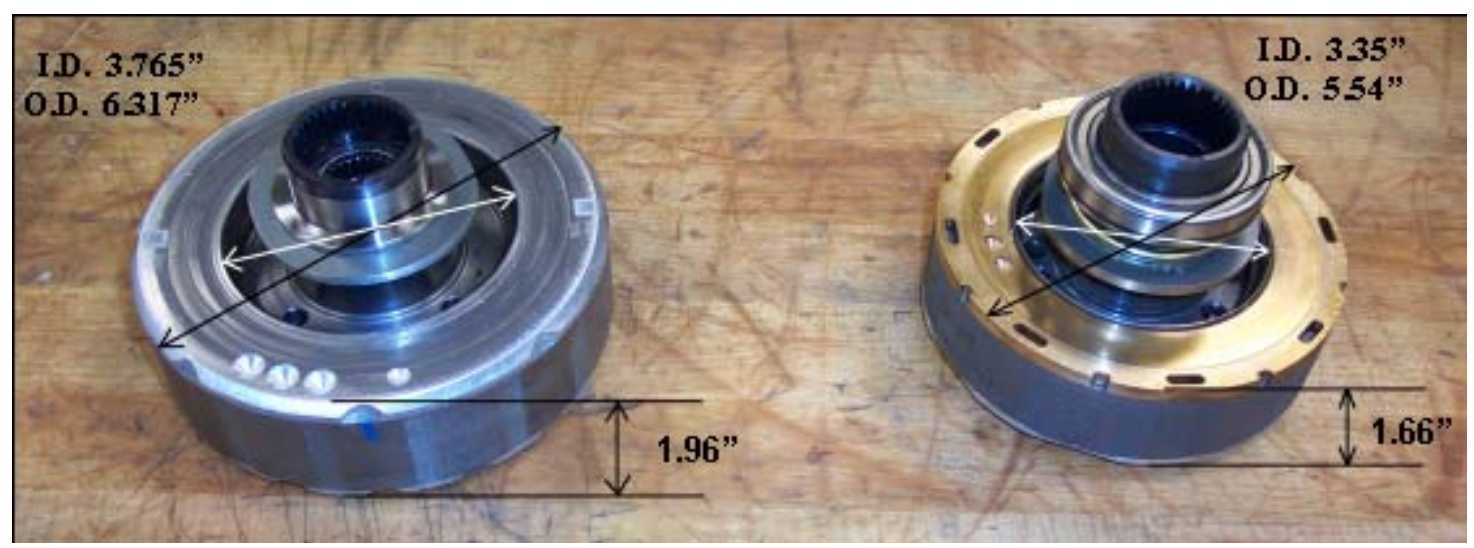

Fig. 2.72. Camry (left) and Prius (right) generator rotor comparison. 
Table 2.9. 2007 Camry/2004 Prius generator design comparison highlights

\begin{tabular}{|l|c|c|c|}
\hline \multicolumn{1}{|c|}{ Parameter } & Camry & Prius & Comments \\
\hline Lamination Dimensions & 264.16 & 236.2 & \\
\hline Stator OD, mm & 162.6 & 142.6 & \\
\hline Stator ID, mm & 3.58 & 3.05 & \\
\hline Stator stack length, cm & 160.46 & 140.72 & \\
\hline Rotor OD, mm & 95.63 & 85.09 & \\
\hline Rotor lamination ID, mm & 0.31 & 0.33 & \\
\hline Lamination thickness, mm & 5.188 & 4.01 & Including rotor shaft \\
\hline Mass of Assemblies & 12.09 & 9.16 & \\
\hline Rotor mass, kg & 48 & 48 & \\
\hline Stator mass, kg & 18 & 12 & \\
\hline Stator Wiring & 20 & 20 & \\
\hline Number of stator slots & & & \\
\hline Number of wires in parallel & \multicolumn{5}{|l|}{} \\
\hline Wire size, AWG &
\end{tabular}

\subsubsection{PM Characteristic Assessments}

Hysteresis tests were conducted on the Camry motor PMs using the Walker Scientific AMH-40 hysteresisgraph (shown in Fig. 2.73), which is capable of producing 30,000 Oersteds of magnetic field strength. A hysteresis test provides information regarding the remanent flux density and coercivity of a magnet and these tests are often conducted over a wide range of temperatures. The remanent flux density, $\mathrm{B}_{\mathrm{r}}$, is the remaining flux density created by the magnet with no external field applied. Or simply stated the remanent flux density represents the strength of the magnet. The remanent flux density decreases to some extent with increasing temperature. The coercivity of a magnet is defined to be the intensity of the magnetic field required to reduce the magnetization of the magnet, and the coercivity of a magnet decreases with increasing temperature. Coercivity is an especially important characteristic of PMs that are used in HEV applications, which often involve high temperature and high field weakening operation conditions.

During hysteresis tests, the magnet is subjected to positive and negative magnetic fields while the impact of the externally applied magnetic field on the magnet is observed. A graph from hysteresis tests conducted on a magnet from the Camry motor rotor at $110^{\circ} \mathrm{C}$ is shown in Fig. 2.74. Two curves are shown on the graph with the burgundy trace being the normal, or total magnetic flux density, and the turquoise trace representing the intrinsic magnetic flux density. The intrinsic flux density is the flux density solely created by the magnet, which is obtained by subtracting the applied flux density from the total flux density. The remanent flux density is the value at which both curves intersect with the y-axis, which is at $\mathrm{y}=11.86 \mathrm{kG}$ in this case. The value of coercivity is found at the point where the intrinsic curve crosses the $\mathrm{x}$-axis, which is $\mathrm{x}=14.46 \mathrm{kOe}$ in this case. A similar graph is provided in Fig. 2.75, with the hysteresis evaluation conducted at an ambient temperature of $198^{\circ} \mathrm{C}$. Notice that the curves are much closer to the origin when compared to Fig. 2.74 . As the temperature increased from $110-198^{\circ} \mathrm{C}$, the remanent flux density and coercivity decreased from $11.86-10.29 \mathrm{kG}$ and $14.46-5.757 \mathrm{kOe}$, respectively. The drastic decrease of the coercivity indicates that the magnet is much more susceptible to demagnetization at high temperatures. 


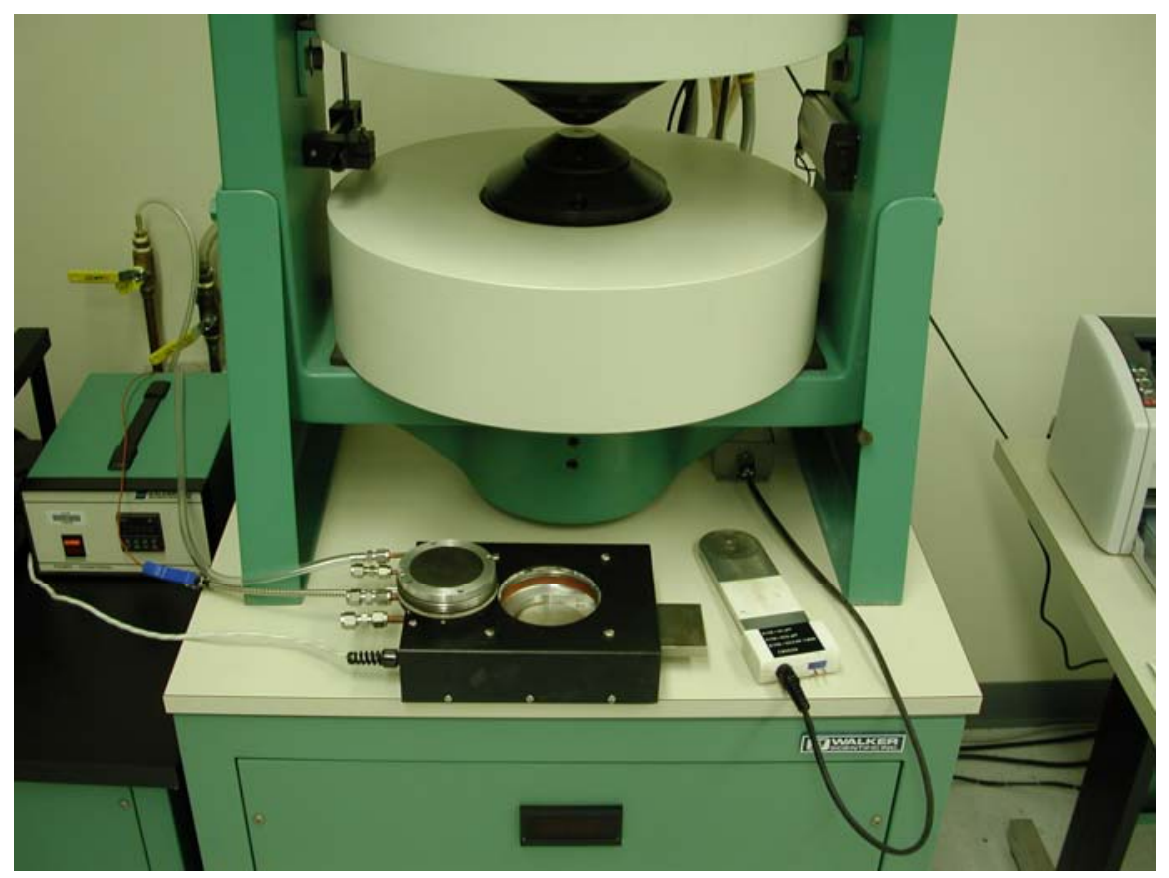

Fig. 2.73. Walker Scientific hysteresis graph.

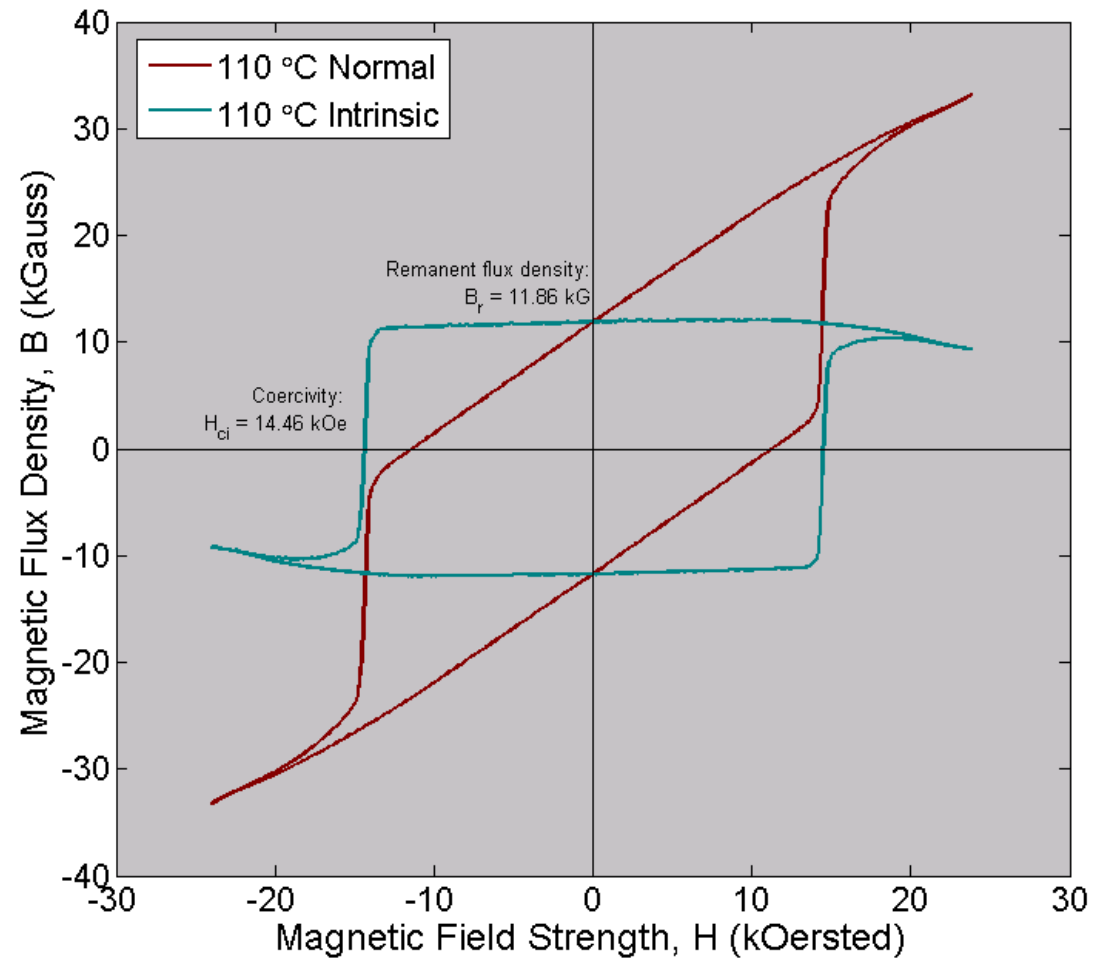

Fig. 2.74. Hysteresis graph for Camry motor magnet at $110^{\circ} \mathrm{C}$. 


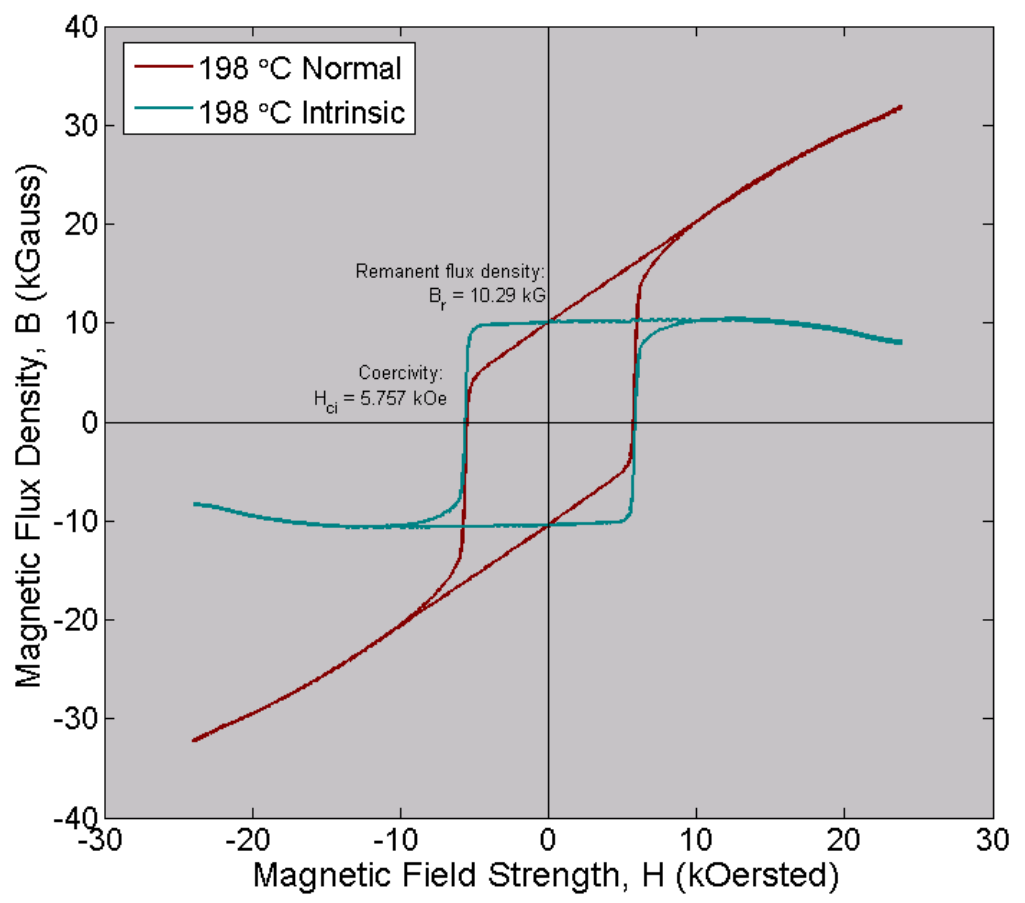

Fig. 2.75. Hysteresis graph for Camry motor magnet at $198^{\circ} \mathrm{C}$.

Intrinsic curves from hysteresis tests conducted with a Camry motor magnet at various temperatures have been combined onto one plot in Fig. 2.76. These curves further exemplify the diminishing nature of the remanent flux density and coercivity with increasing temperature. A similar graph containing the intrinsic curves obtained from the Prius motor magnet hysteresis tests is provided in Fig. 2.77. Although it is difficult to make a detailed comparison using these figures, a general comparison indicates that the coercivity of the Camry magnet is significantly lower than that of the Prius.

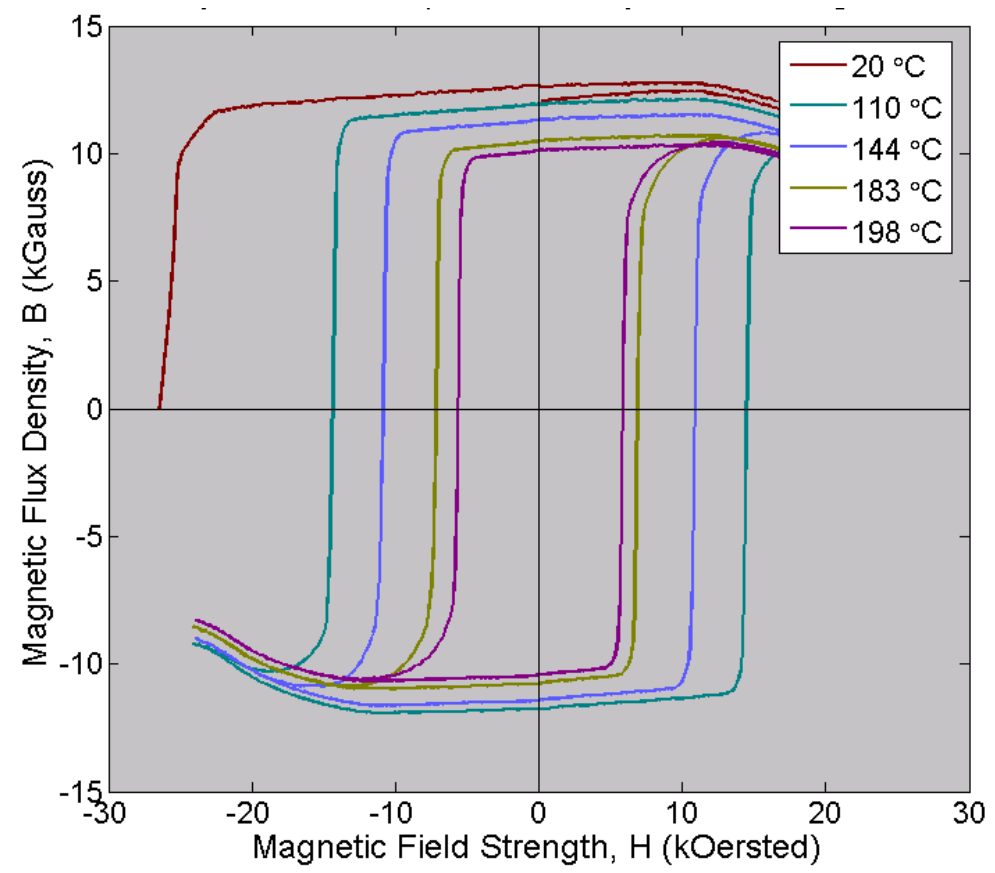

Fig. 2.76. Intrinsic hysteresis graphs for Camry motor magnet at various temperatures. 


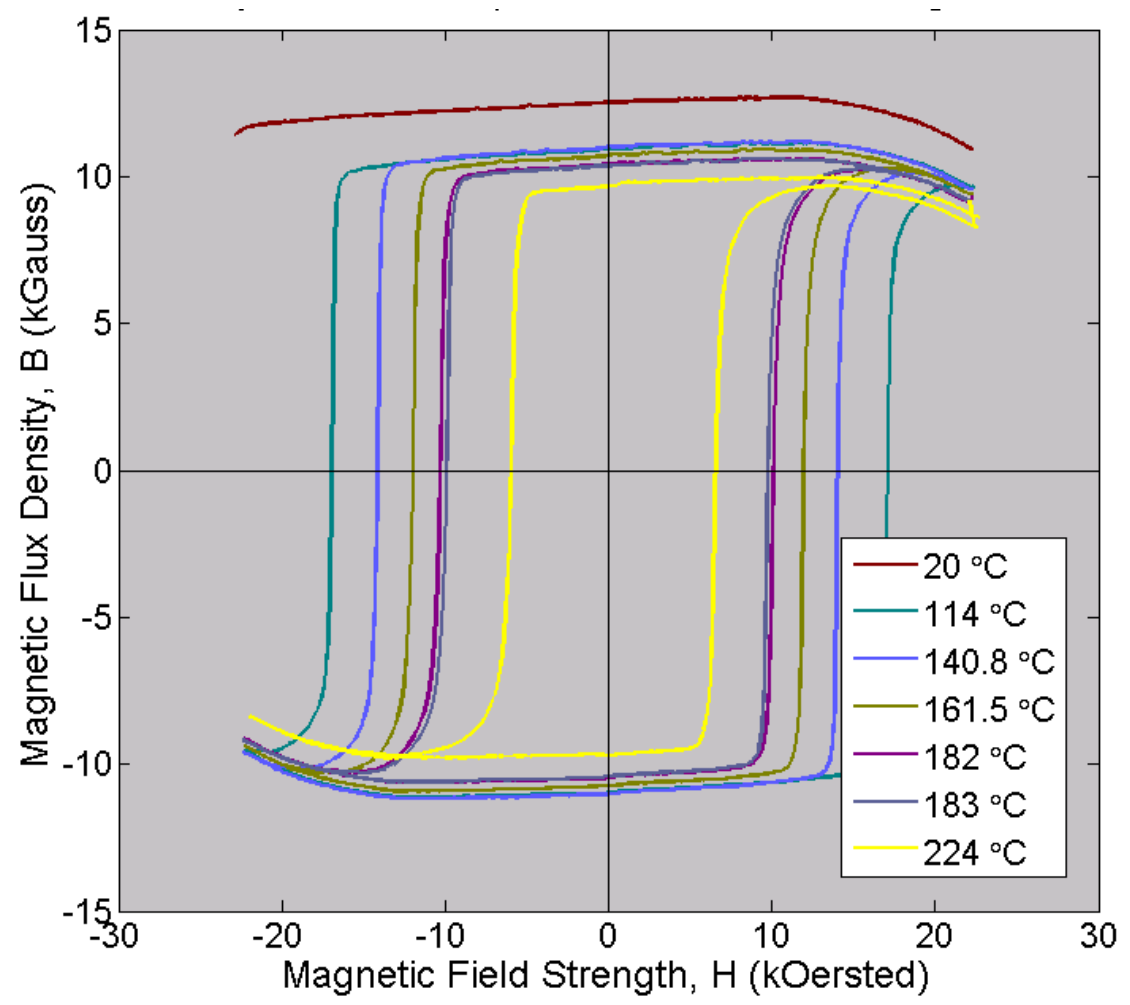

Fig. 2.77. Intrinsic hysteresis graphs for Prius motor magnet at various temperatures.

To provide a more straight forward comparison of the remanent flux density characteristics of the Camry and Prius motor magnets, the values were plotted versus temperature in Fig. 2.78. The strength of the Camry motor magnet is marginally higher than the strength of the Prius motor magnet, except for temperatures beyond about $215^{\circ} \mathrm{C}$. A similar plot is shown in Fig. 2.79 for the coercivity versus temperature relationship of the Camry and Prius motor magnets. The coercivity of the Camry motor magnet is about $70 \%$ of the coercivity of the Prius magnet, except for temperatures above about $200^{\circ} \mathrm{C}$ where the coercivity values are a bit closer.

Although the Camry motor magnet is slightly stronger than the Prius magnet, the coercivity is much lower and, therefore, is much more susceptible to demagnetization when subjected to high temperatures and/or high strength magnetic fields which oppose the direction of the magnetic field of the magnet. It is common to apply opposing magnetic fields to the magnets when operating at high speeds, wherein high back-emf voltages are subdued to enable high speed operation within the voltage constraints. It is very likely that the cost of the Camry motor magnet is lower than the cost of the Prius magnet and although it has a lower coercivity, demagnetization can be avoided using preventative control techniques. 


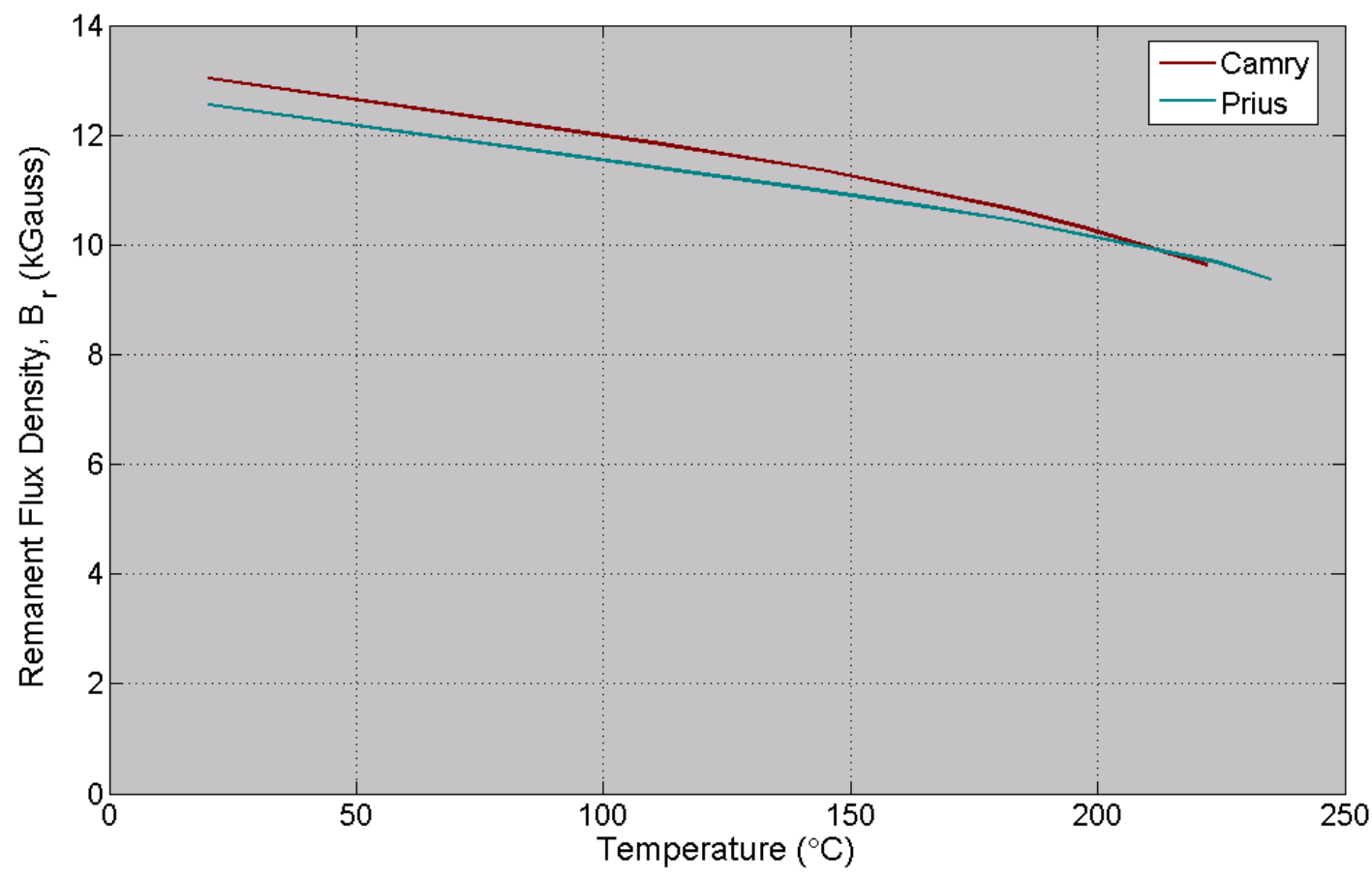

Fig. 2.78. Remanent flux density for Camry and Prius motor magnet.

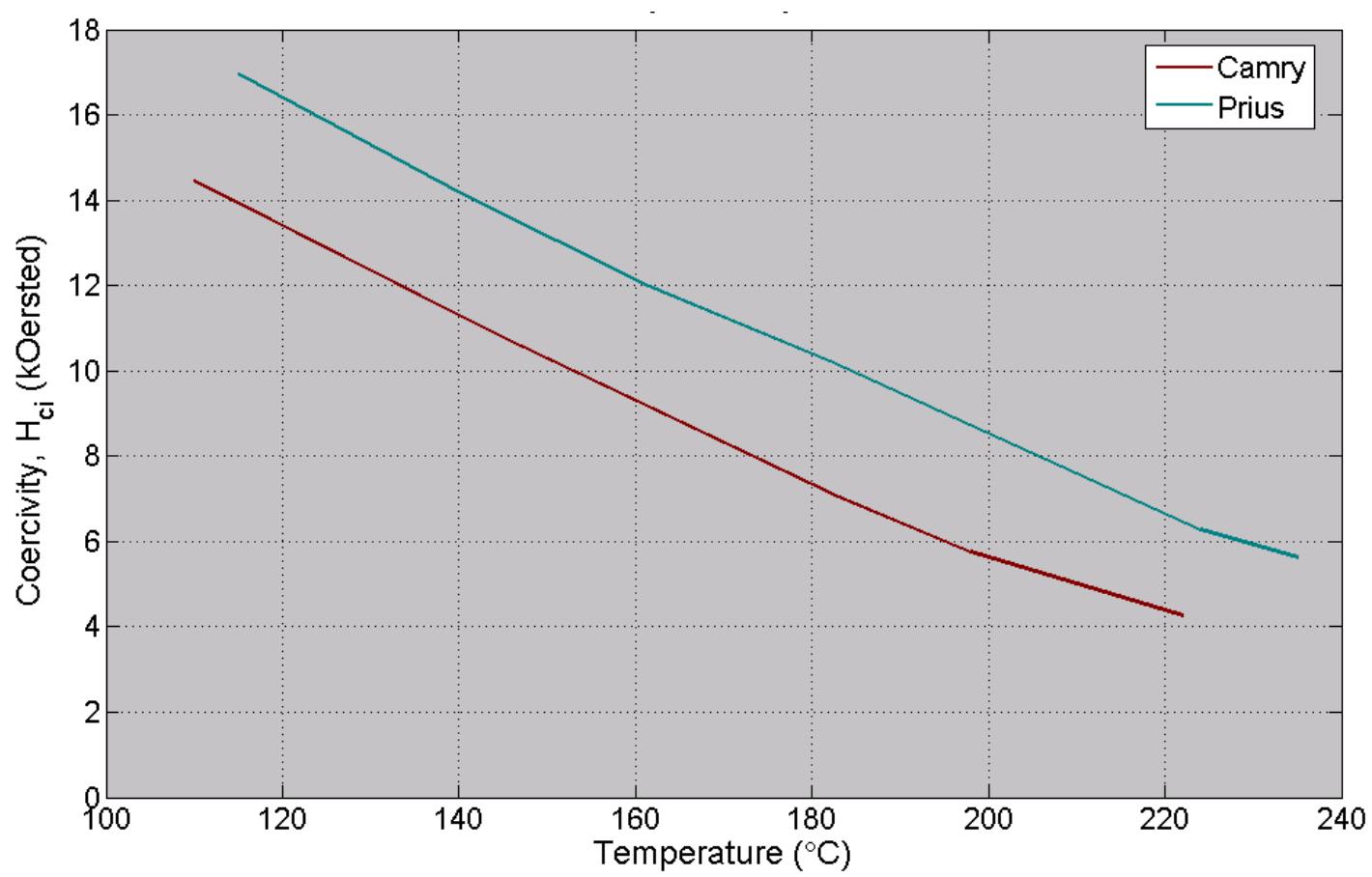

Fig. 2.79. Coercivity of Camry and Prius motor magnet. 


\section{BENCHMARKING TESTS OF CAMRY PMSM AND INVERTER}

This section describes the hybrid Camry subassembly preparation and the back-emf, rotational loss, locked-rotor, performance/efficiency, and continuous load duration tests. With the exception of the backemf, rotational loss, and locked-rotor tests which did not require inverter operation, each was performed using both the PMSM and inverter subsystems.

\subsection{SUBSYSTEM PREPARATION FOR TESTING}

As design and packaging assessments of the transaxle and PCU were being conducted, preparation for testing of the subsystems was commenced, including hardware design and fabrication, controller/interface development, and instrumentation for the DAQ. Two separate approaches were taken to adapt the Camry PMSM to separate dynamometer setups as each provided a benefit in terms of implementation time versus unmitigated testing capability. Although basic framework was available from previous benchmarking efforts, a large portion of the efforts devoted to controller/interface and DAQ development required innovation.

\subsubsection{Hardware Preparation}

The first test setup approach provided a quick resolution and means to initiate testing, yet it did not provide testability throughout the entire operation range of the PMSM. Therefore, while the initial tests were being conducted with the first test setup, a second approach was instituted. Additionally, the dynamometer test cell was upgraded to suit the high speed and power demands of the Camry PMSM.

Similar to the approach taken with the Prius transaxle hardware setup, the first approach involved welding the power split planetary gear as shown in Fig. 3.1. This causes the ICE input shaft, which is easily accessible, to rotate at the same speed as the ring gear of the power split planetary gear unit. For the Prius design, the ring gear rotates at the same speed of the primary drive motor, MG2. However, the MG2 of the Camry is connected to the ring gear through the speed reduction planetary gear unit. Thus, although the first approach provided a quick means to access the motive force of the motor, uncertainties were associated with the influence of speed reduction gear losses upon power and efficiency measurements. To obtain accurate motor efficiency measurements, it is crucial to accurately measure the mechanical power produced directly by the motor. Nonetheless, the setup provided a quick means of test initiation and valuable insights, such as controller development aspects. Additionally, the setup eliminated the immediate need for equipment with high speed testing capabilities, which was not installed until a later time during the project duration.

The second approach involved design and fabrication of a shaft and faceplate (shown in Fig. 3.2) which adapts to the Camry motor rotor, transaxle mounting pattern, and the high speed torque cell face mount and spline shaft. Design considerations were carefully surmised to ensure that no part of the system operation was hindered or enhanced. Particularly, intense focus was placed on maintaining the operational characteristics of the thermal management and lubrication system mostly by ensuring that the oil flow pattern throughout the transaxle remained unchanged. This approach avoids uncertainties associated with the losses of the high speed reduction gear, thereby providing accurate measurements of motor power output. 


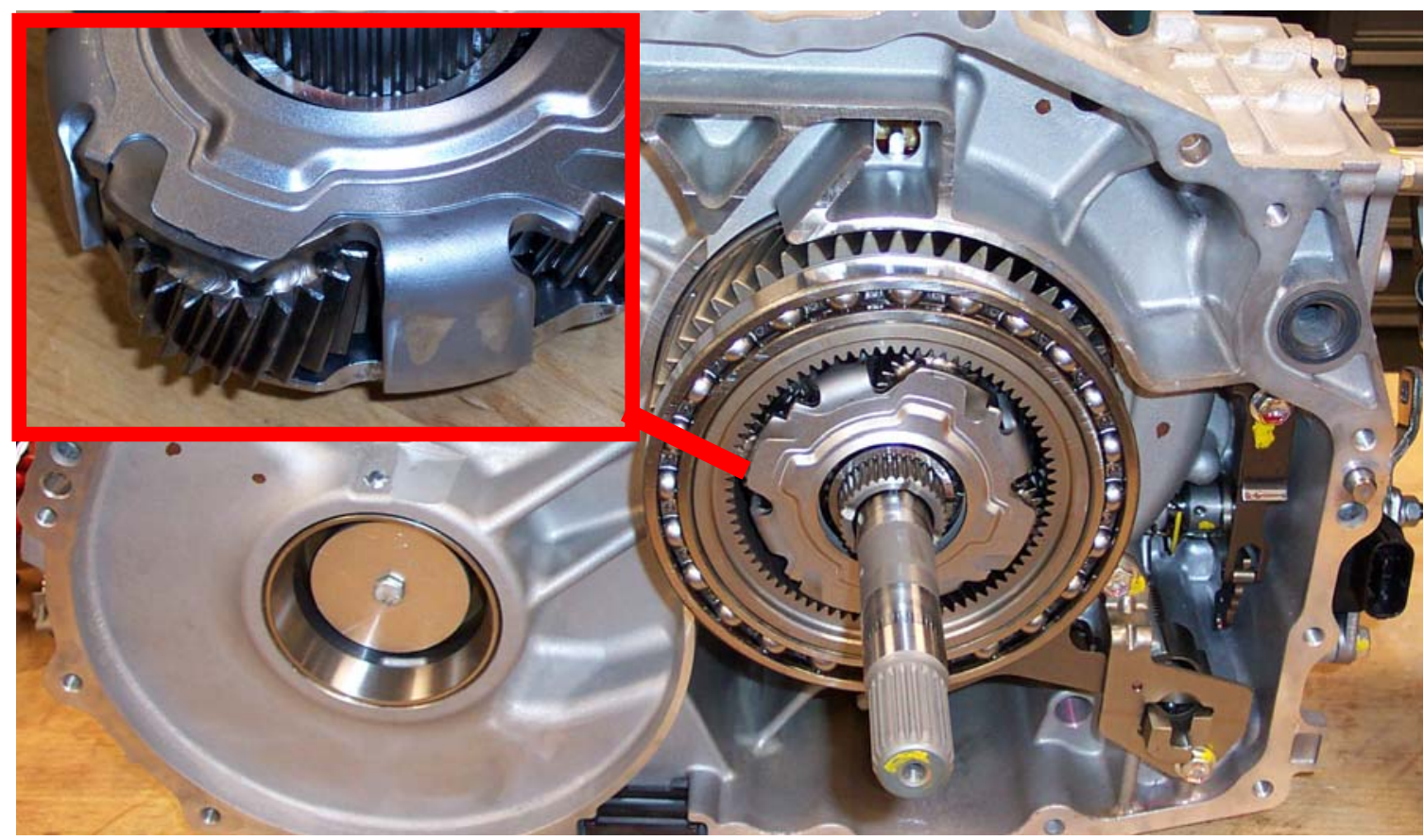

Fig. 3.1. First test setup approach with welded Camry planetary gear.

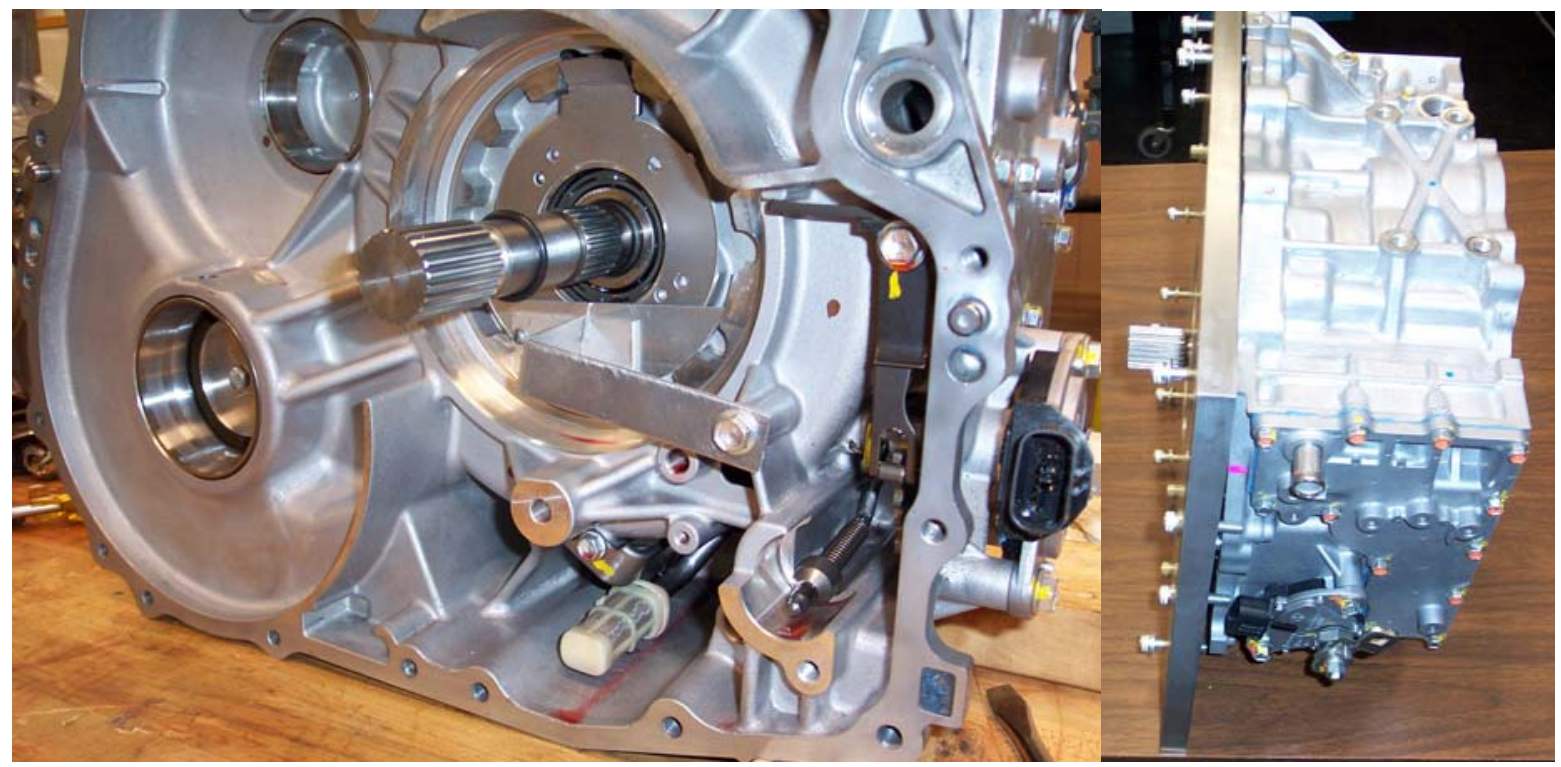

Fig. 3.2. Second test setup approach with modified motor rotor shaft.

To accommodate the high speed and power testing requirements of the Camry PMSM, the test cell was upgraded with a $400 \mathrm{hp}$ dynamomter and speed reduction gearbox, as shown in Fig. 3.3. The speed reduction gearbox was required to match the speed range of the dynamometer to a speed of up to $18,000 \mathrm{rpm}$ on the high speed input shaft. A high speed torque transducer (not shown) attaches to the high speed input shaft of the gearbox via a face mount support. The spline shaft output of the modified Camry rotor shaft and the fabricated faceplate mates with the input of the high speed torque transducer. 


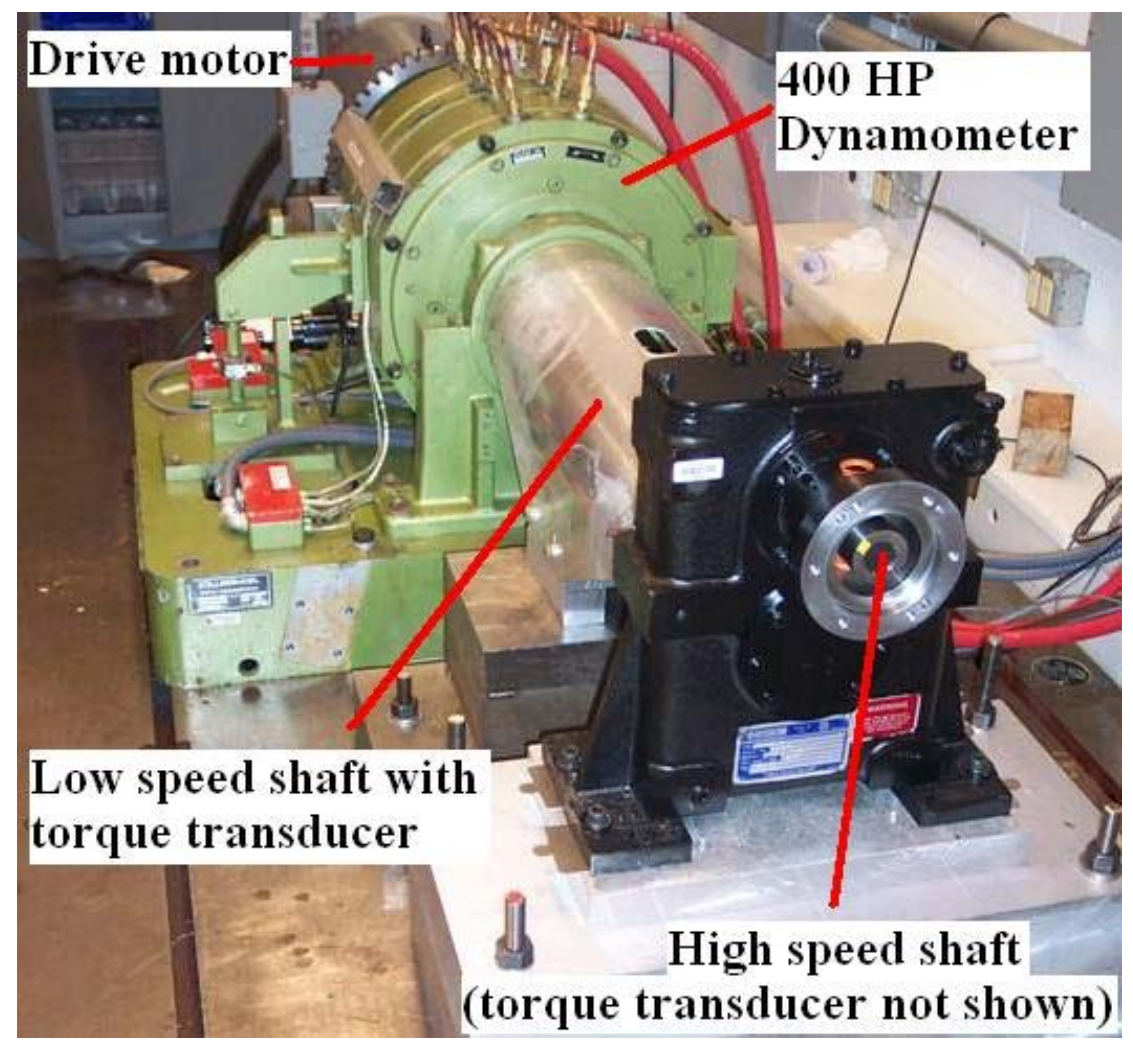

Fig. 3.3. Upgraded dynamometer test cell.

\subsubsection{Instrumentation and DAQ Development}

The PCU, PMSM, and transaxle were instrumented with thermistors and TCs in order to monitor and record thermal conditions and characteristics of the subsystem during various operation conditions. In preparation for performance, efficiency, and continuous duration tests in the ORNL laboratory, the motor inverter was instrumented with three TCs placed in the edges of the three power electronics heat spreaders as shown in Fig. 3.4. Two other TCs were placed in the (1) aluminum wall against the potted inductor of the buck/boost converter, and (2) edge of the heat spreader for the buck/boost converter power electronics module.

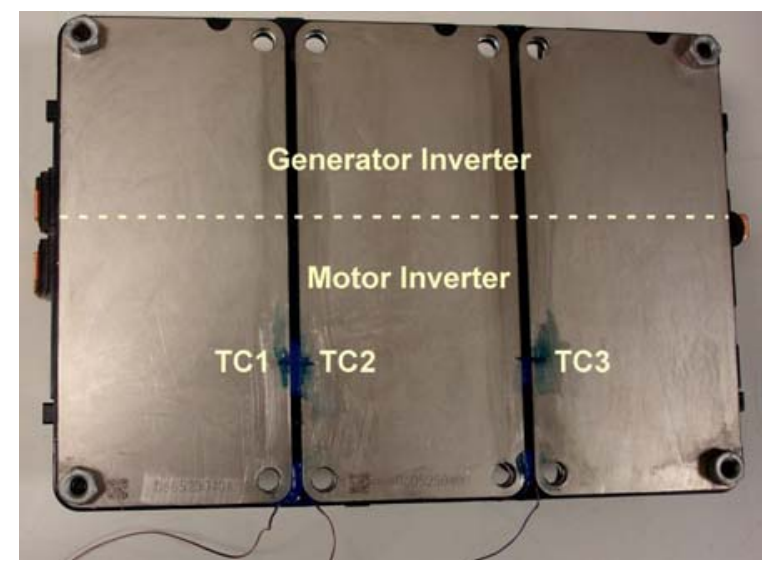

Fig. 3.4. TCs in the inverter power electronics heat spreaders. 
Thermistors were installed in various locations on the stator windings and transaxle housing, as indicated in Fig. 3.5. Each location has a unique letter identifier and additional location information. For example, thermistor "D: ML 1" is located on the motor lead side of the stator at the 1 o'clock position indicated by the red circle. All thermistor locations on the front side of the stator are indicated by red circles and thermistor locations on the rear of the stator are marked with cyan circles. Case thermistor locations are indicated by light green circles and oil thermistor locations are indicated by orange circles. Note that thermistor "E: ML 2" is the original factory installed thermistor. The resistance of an identical thermistor was evaluated over a wide range of temperatures in order to generate a lookup table to be used with the DAQ software.
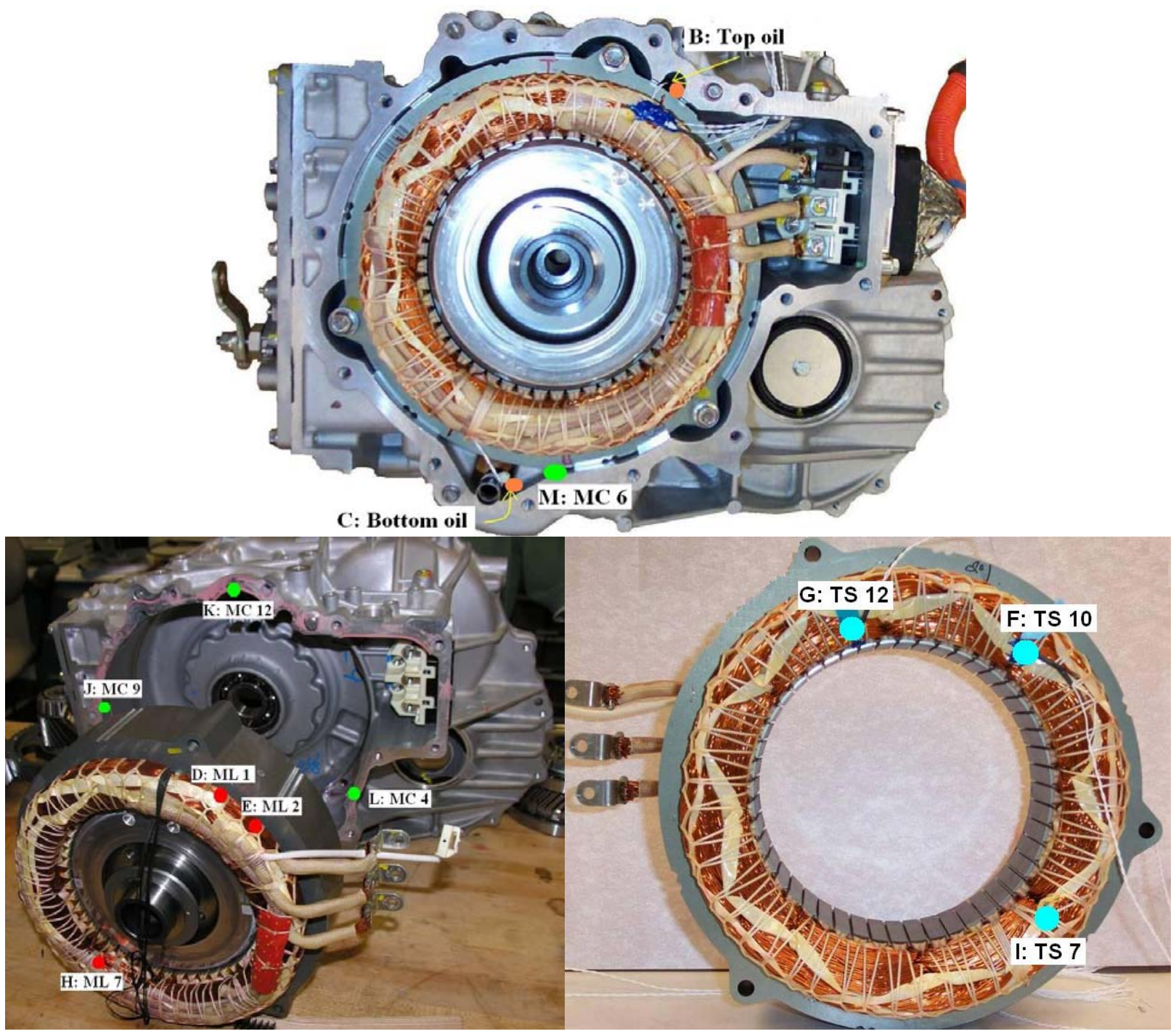

Fig. 3.5. Thermistor locations on PMSM and transaxle.

The Camry transaxle was modified to include windows and temporary viewports in the locations shown in Fig. 3.6 to facilitate observations of the oil system characteristics. These observations provided useful information regarding oil circulation and oil levels in various locations throughout the transaxle. It was especially necessary to assess these characteristics as the design, fabrication, and implementation of the second test setup approach was carried out and that these characteristics remained unchanged during 
operation. It was determined that the oil reservoirs as well as the upper oil channels are nearly full when the ring gear is rotating at speeds near 1,000 rpm.

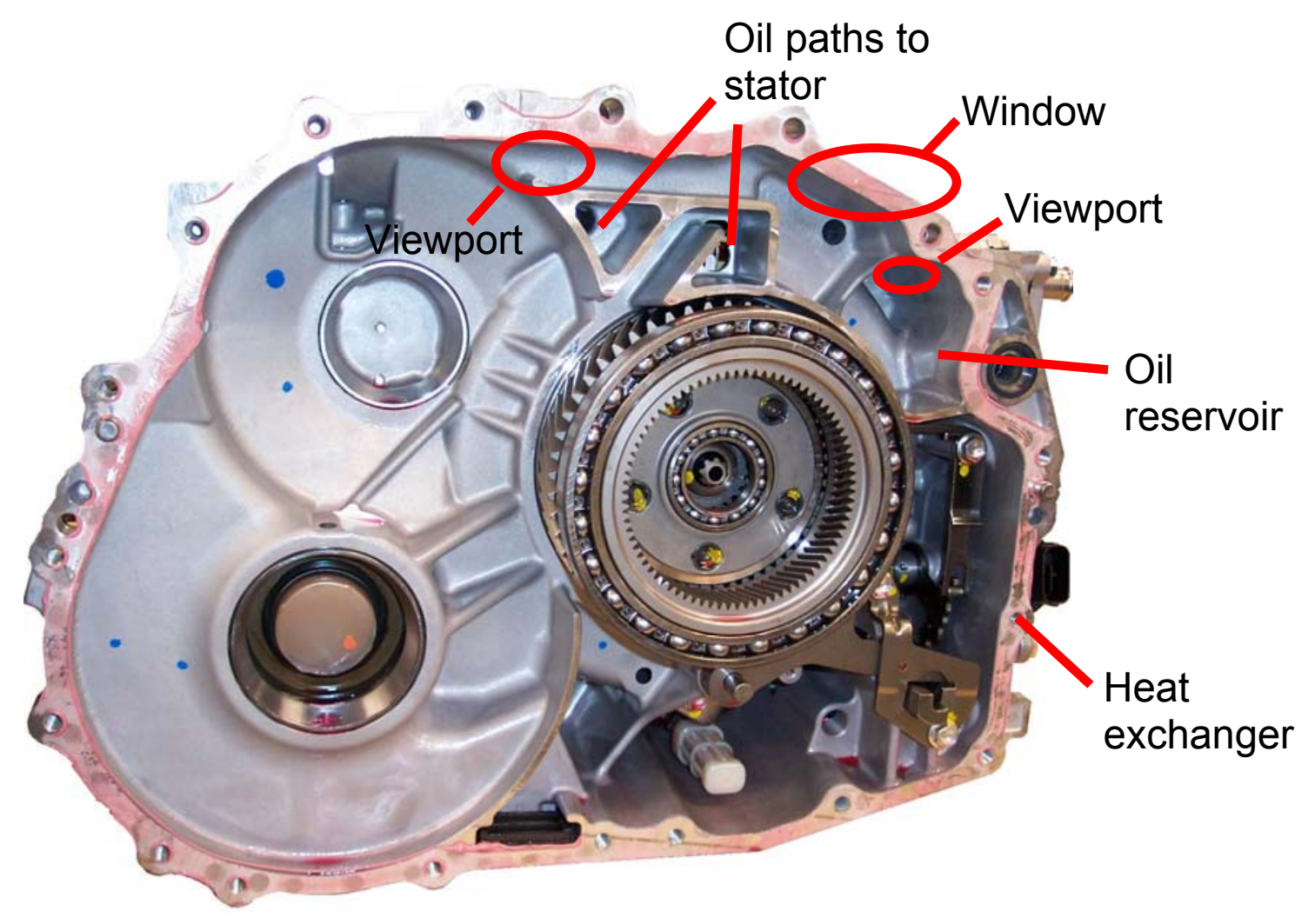

Fig. 3.6. Viewport and window locations implemented on transaxle.

A program written in the Visual Basic programming language was developed to collect data from various measurement instruments and merge the data into a convenient spreadsheet format. Torque, speed, and mechanical power were obtained using a Himmelstein torque and speed transducer. Temperature measurement signals from thermistors and TCs were collected with a Keithly 2700 acquisition unit. A Yokogawa PZ4000 power analyzer was used to carry out electrical measurements such as ac and dc rms voltage, rms current, real power, and many other properties of the waveforms.

The DAQ system was important not only for data logging, but it also served as a real time feedback system in which system conditions were monitored to ensure that operational limitations were not violated and to ensure that the system was being operated in an optimal manner. Temperature and current constraints were the primary limitations of the entire drive system. Efficiencies were calculated using the mechanical and electrical data and were used to verify that the controller operation was optimized. 


\subsubsection{Controller and Interface Development}

The hybrid subsystems of the 2007 Toyota Camry were evaluated for performance and efficiency characteristics such as peak and continuous power ratings and motor/inverter efficiency. Continuous operational capabilities are greatly affected by the heat transfer characteristics of the motor, which is cooled through oil circulation and an ethylene-glycol coolant loop. The hybrid subsystems were operated over a broad torque-speed range in order to collect and analyze thermal and electrical data at a multitude of operation points. For each operation point during efficiency evaluations, the system was held in steady state for at least 20 seconds as a minimum of 5 data samples were taken.

ORNL's dynamometer test cell and Opal-RT-based speed and current feedback controller were adapted to provide the torque needed at each reference speed. Thus, as the applied torque from the dynamometer was varied manually, the controller regulated the torque producing current appropriately. The current controller consists of two standard proportional-integral (PI) controllers for the direct and quadrature currents, $i_{d}$ and $i_{q}$, respectively. These $d-q$ components are obtained by applying the $d-q$ transformation to the three-phase currents which have a fixed reference. The transformation converts the three-phase currents into two-phase vectors, which have a reference that rotates with the rotor. Therefore, precise rotor position feedback is used during this transformation.

The steady state torque equation for the salient PM machine is expressed by:

$$
\tau_{L}=n_{p}\left(L_{d}-L_{q}\right) i_{d} i_{q}+n_{p} K i_{q}
$$

where

$n_{p}$ is the number of pole pairs,

$L_{d}$ is the $d$-axis inductance,

$L_{q}$ is the $q$-axis inductance, and

$K$ is the back-emf and torque-current factor.

The total torque given by Eq. (1) consists of two torque terms which are reluctance torque and PM torque, respectively. PM torque is produced only by the current component along the q-axis. If current is applied which results with a negative component along the $d$-axis, positive reluctance torque is developed since the difference, $L_{d}-L_{q}$, in the first term is negative and all remaining variables and constants are positive in the motoring region. In theory, there is an infinite amount of $d-q$ current combinations that will satisfy a particular operation condition. There is an optimal $d-q$ current combination in which the motor efficiency is maximized for each particular torque. It is difficult to determine the optimal current trajectories for the entire torque-speed range, as complex factors such as effects of saturation and harmonics must be considered. Therefore, the DAQ was used to monitor the system efficiency to ensure that the controller is operating optimally.

A high level diagram of the Opal-RT controller and interface system is shown in Fig. 3.7. A console personal computer (PC) is used to develop and modify control schemes in a block diagram format, which is converted and compiled to traditional programming languages (mostly $\mathrm{C}$ ) and sent to the target nodes through an ethernet network. The target nodes execute the controller code in real time and the console PC is used to control the mode of the controller operation as well as to update various parameters if desired. While the development process is more straightforward than microprocessor programming, the PC based architecture of the target nodes introduces a significant degradation in terms of control sampling frequency. Therefore, the system resources must be utilized in an efficient manner. 


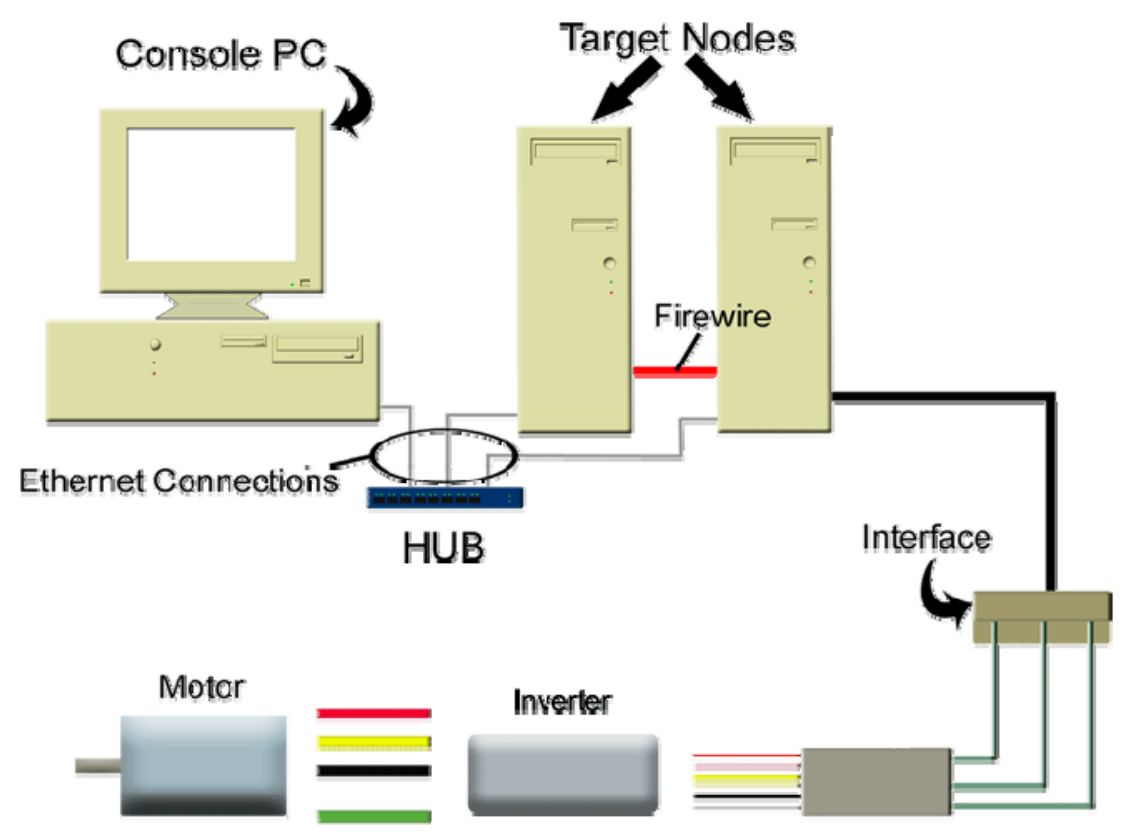

Fig. 3.7. Opal-RT controller and interface system.

\subsection{BACK-EMF TEST RESULTS}

The non-energized Camry PMSM was spun at various speeds over its full design range to obtain backemf data. The shaft speed and back-emf data (line-to-neutral rms averaged for the three phases) is plotted in Fig. 3.8. This test was repeated after the performance/efficiency mapping test to verify that no magnetic strength was lost in the rotor during performance tests or extended periods of high-temperature testing. As expected, there were no significant differences in the data obtained from the second back-emf test.

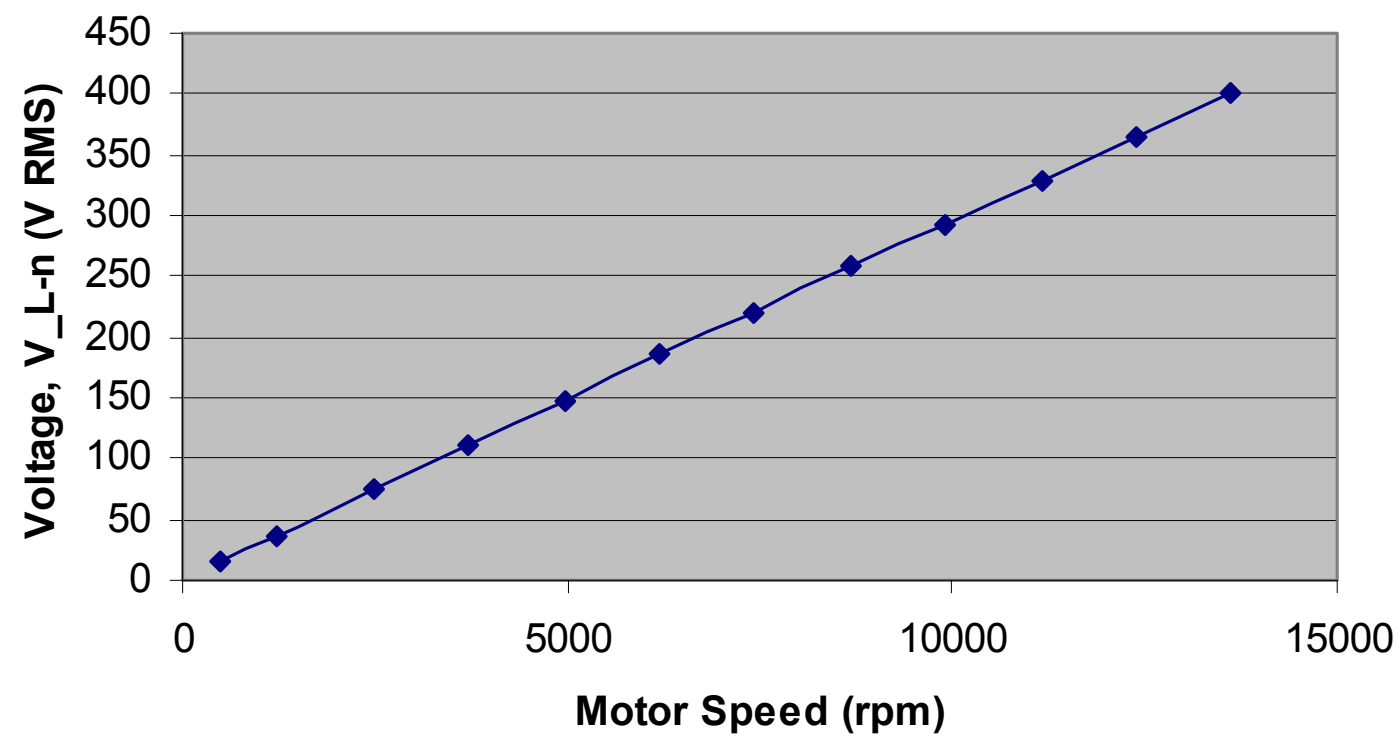

Fig. 3.8. 2007 Camry motor back-emf test results. 
A plot containing the line-to-neutral back-emf voltage measurements observed during benchmarking evaluations of the Prius is shown in Fig. 3.9. A comparison of Figs. 3.8 and 3.9 indicates that the voltsper-hertz ratio of the Prius back-emf is higher. However, the maximum back-emf voltage of the Camry, observed at a shaft speed of 14,000 rpm is much higher than the maximum back-emf voltage of the Prius at $6,000 \mathrm{rpm}$. Note that the ratio of these maximum voltages is approximately equal to the ratio of the maximum dc-link voltages, which is 650/500.

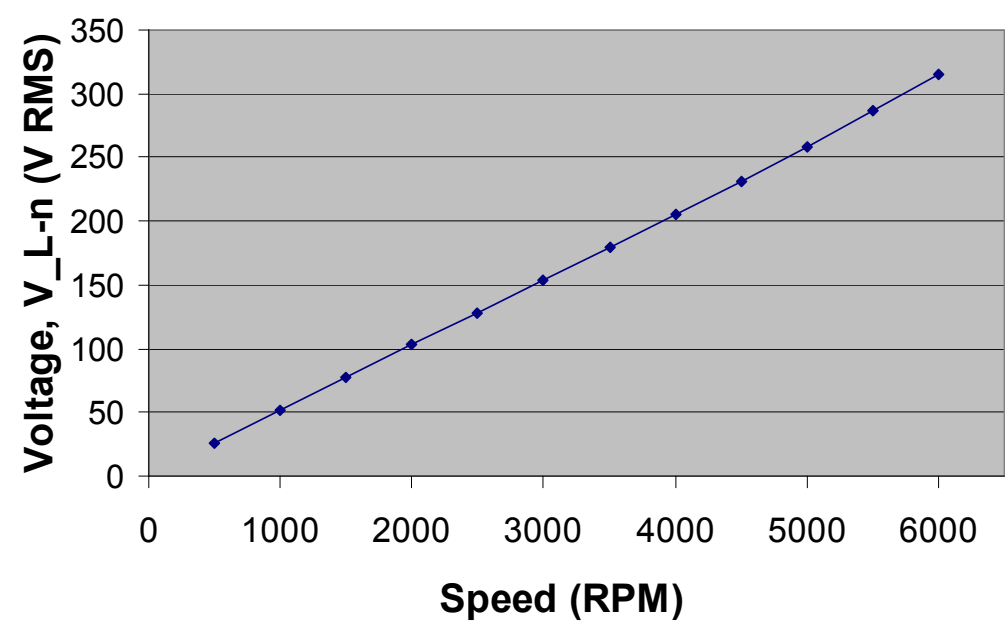

Fig. 3.9. 2004 Prius motor back-emf test results.

\subsection{ROTATIONAL LOSS ASSESSMENTS}

The rotational losses of the entire gear train and the Camry motor alone were evaluated by rotating the input shafts with an external drive motor. Gear train loss assessments began with the entire gear system installed, which includes the drive gears and planetary gears. The generator and motor rotor were removed in order to assess only the gear losses and motor core loss assessments were conducted at a later time. Torque and power measurements were measured and plotted versus ring gear speed as shown in Figs. 3.10 and 3.11, respectively. The average oil temperature was slightly higher than room temperature during these tests. Note the maximum speed shown in this plot is 5,500 rpm and since the speed reduction gear ratio is 2.47 , the corresponding motor speed is $13,585 \mathrm{rpm}$ and the vehicle speed associated with this extreme condition is approximately 113 miles per hour.

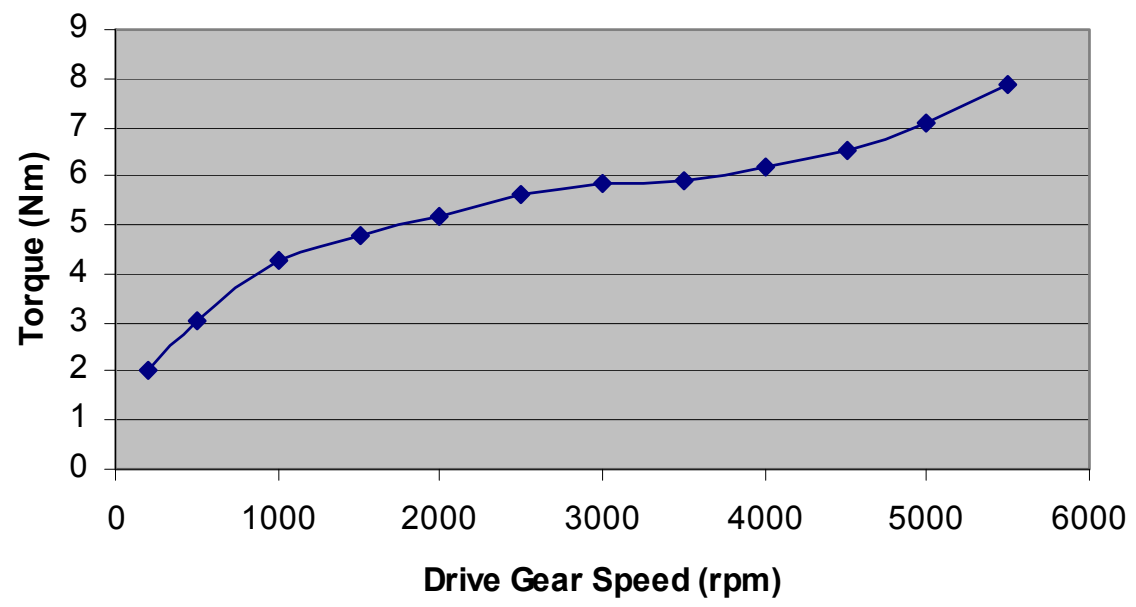

Fig. 3.10. 2007 Camry gear train rotational torque. 


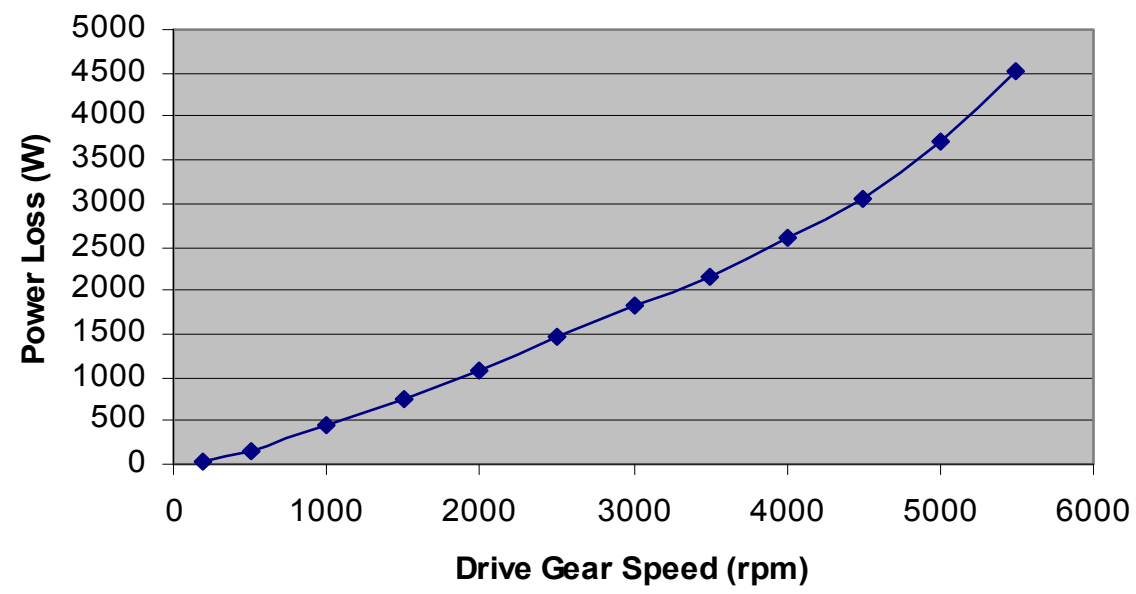

Fig. 3.11. 2007 Camry gear train rotational losses.

Results from the rotational loss tests conducted with the shaft connected directly to the motor rotor are shown in Fig. 3.12. These losses are mostly comprised of core (or iron) losses, which are associated with eddy currents and hysteresis effects. In combining the gear losses shown in Fig. 3.11 and the core losses shown in Fig. 3.12, it is inferred that a significant amount of losses are associated with the rotational motion of the drive system. Nonetheless, these losses are exceptionally low when compared to that of a conventional automatic transmission, which includes multiple planetary gears and clutching mechanisms.

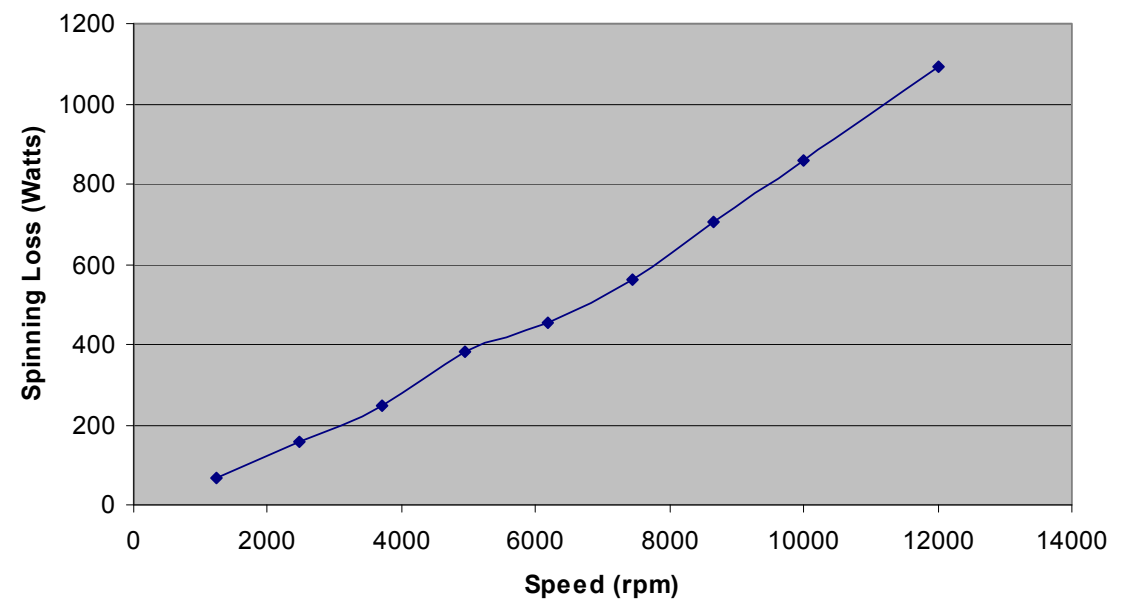

Fig. 3.12. 2007 Camry motor rotational losses.

Further gear loss assessments were conducted to obtain information which more specifically describes the losses associated with each component, as well as the influence of oil temperature upon the gear losses. The first test was conducted with all gears installed and the motor rotor removed and the oil temperature initially low. The Bay-Voltex external coolant temperature regulator was used to increase the oil temperature in order to observe the effects of increasing oil temperature as the rotor speed was held constant. These tests were conducted at ring gear speeds of 2000, 3500, and $5000 \mathrm{rpm}$. A gear system was removed after each test was conducted, and therefore the associated losses of the removed gear system can be assessed. The results from these tests are shown in Fig. 3.13, with the 2000, 3500, and $5000 \mathrm{rpm}$ traces shown in shades of blue, green, and red, respectively. After tests were conducted with no motor rotor, the drive gears were removed, then the planetary gears were removed. Losses of the entire gear train tend to decrease with increasing oil temperature due to deceasing oil viscosity and losses are minimal near the common operation temperatures of the transaxle, namely $50-80^{\circ} \mathrm{C}$. Extended tests at 
$3500 \mathrm{rpm}$ reveal that the gear losses increase beyond a temperature of $90^{\circ} \mathrm{C}$. In comparing the loss difference of each of the tests, the drive gears have the highest amount of losses associated with spinning motor and the planetary gears contribute only a small amount.

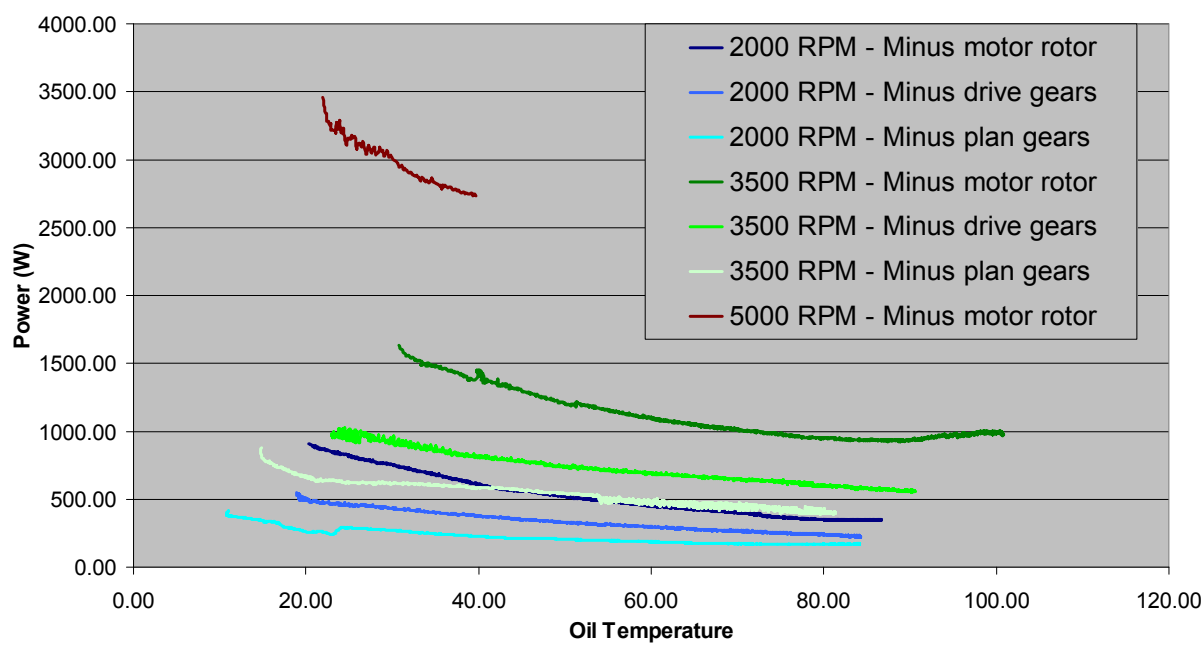

Fig. 3.13. 2007 Camry gear losses vs. oil temperature at various ring gear speeds.

\subsection{LOCKED ROTOR TEST}

A series of locked rotor tests were performed to determine the torque-producing behavior of the PMSM motor. During locked rotor tests, the rotor is rotated throughout an electrical cycle and the shaft is rigidly locked at each position as dc current is applied. Torque values were obtained from an in-line shaft torque sensor when the motor windings were energized. The resulting data was used to produce torque versus electrical position plots, which are shown in Fig. 3.14 for various current levels. These tests were not conducted at extremely high dc currents to avoid high temperatures which could potentially damage the stator windings or rotor magnets. The peak torque for each current level was chosen and is indicated by the blue trace in Fig. 3.15. Peak locked rotor torques for the Prius are also included in the figure, and are much larger than that of the Camry. However, the equivalent torque of the Camry motor on the low speed side of the speed reduction gear is much higher, as indicated by the yellow trace in Fig. 3.15.

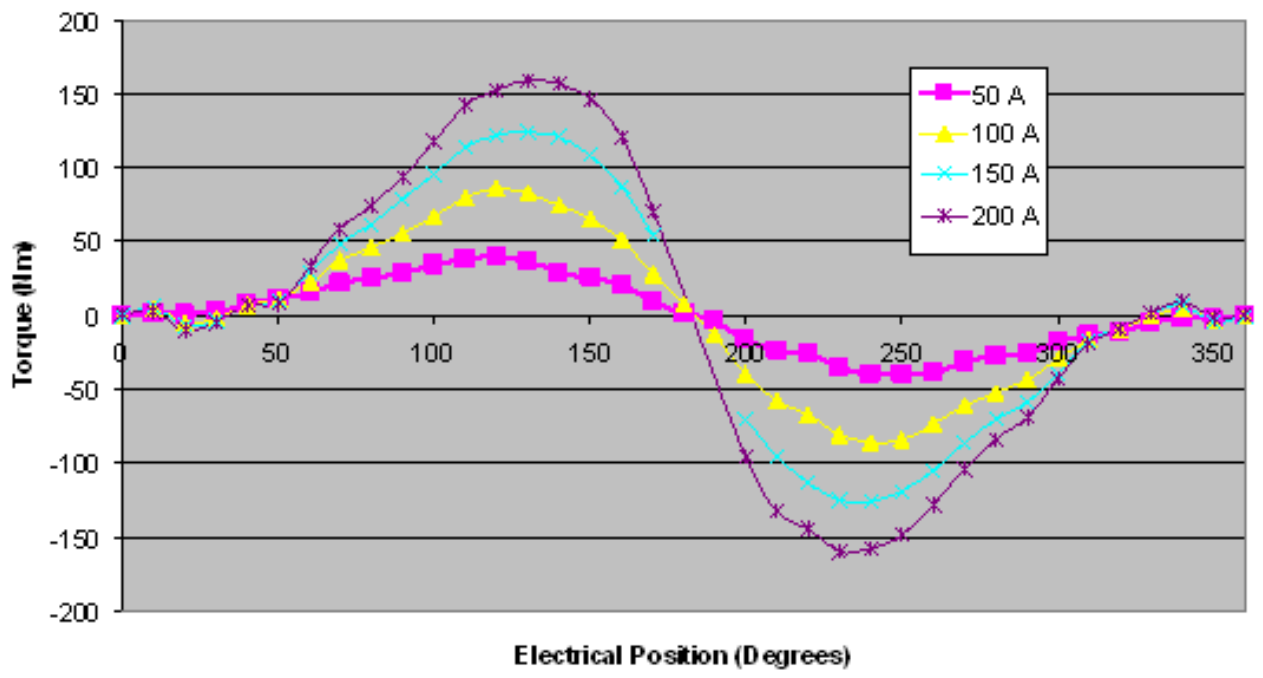

Fig. 3.14. 2007 Camry locked rotor torque vs. position for various de currents. 


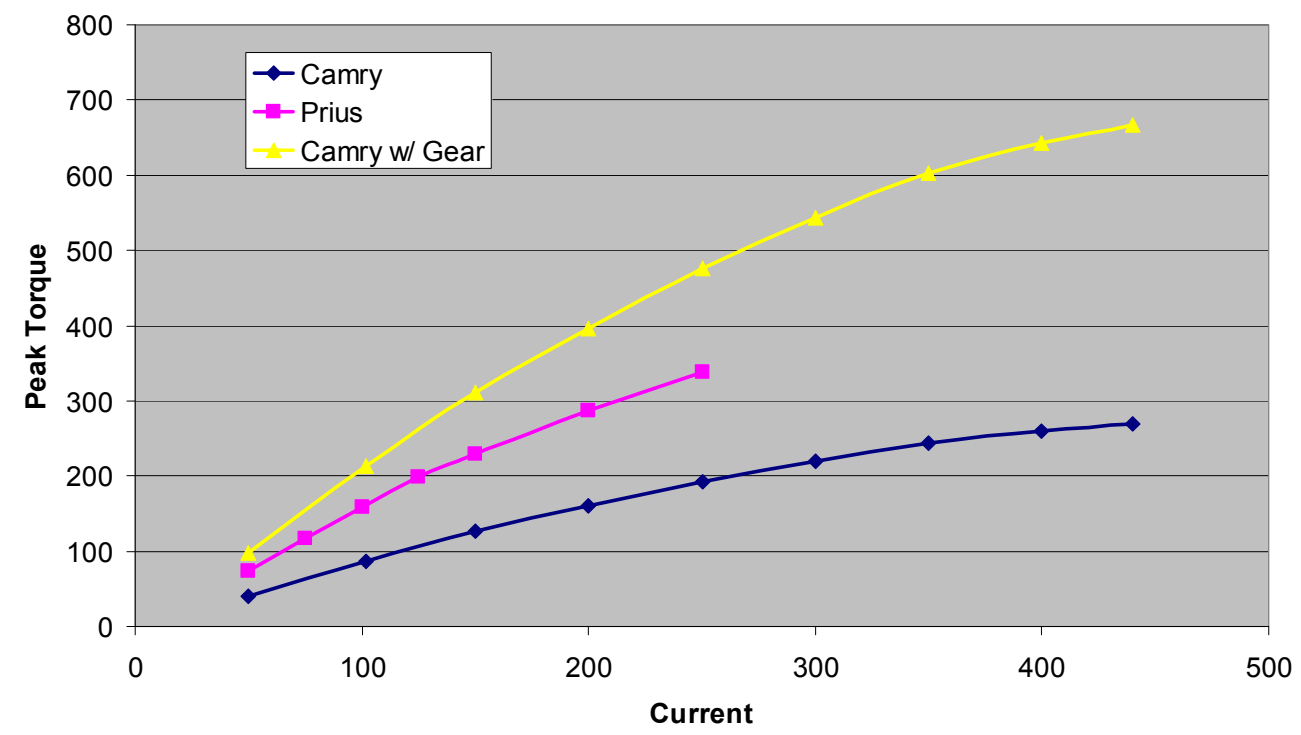

Fig. 3.15. 2007 Camry and Prius peak locked rotor torque vs. dc current.

Interior PM motors have two torque components and there is an optimal current angle at which the two torque components produce the maximum torque per current. Figure 3.16 shows the PM torque, reluctance torque, and the total sum of the two torque components for a constant exemplar current magnitude. Although the maximum PM torque is produced at a current angle of zero electrical degrees and the maximum reluctance torque is produced at 45 electrical degrees, the maximum total torque is produced at about 35 electrical degrees. This optimal current angle varies with many conditions such as current magnitude and speed.

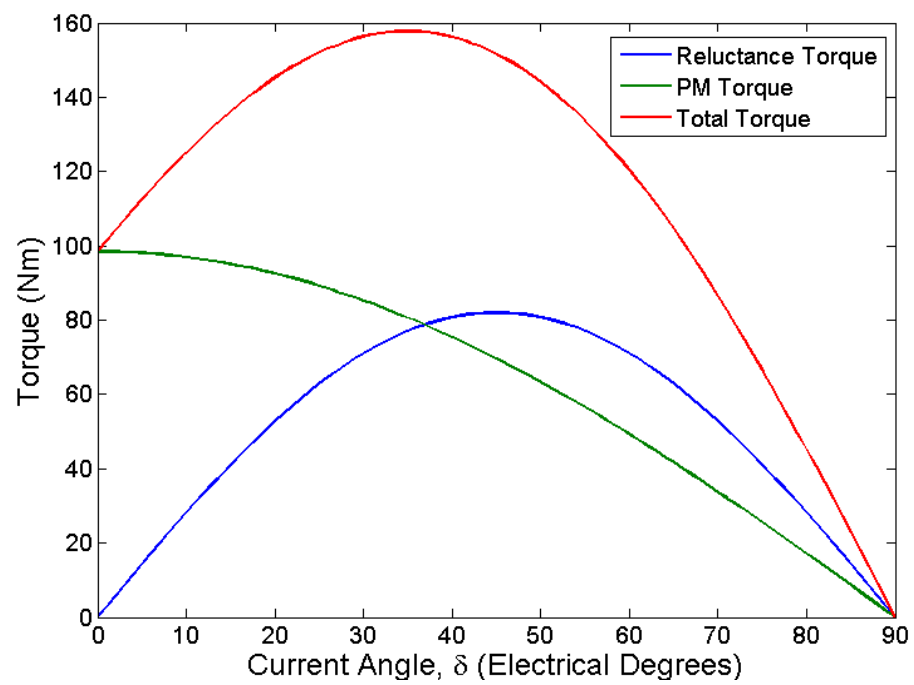

Fig. 3.16. 2007 Camry and Prius peak locked rotor torque vs. dc current.

\subsection{PERFORMANCE AND EFFICIENCY EVALUATIONS}

This section provides information about the performance and efficiency evaluations of the 2007 Camry hybrid subsystem components. The motor and inverter characteristics were evaluated simultaneously with power provided directly to the de link as opposed to the power being supplied through the boost converter. Therefore, the $33 \mathrm{~kW}$ power rating of the inverter did not limit the capabilities of the motor and 
inverter during the performance and efficiency assessment process. The dc-link voltage was maintained at $650 \mathrm{Vdc}$ and a switching frequency of $10 \mathrm{kHz}$ was used. Motor efficiency was measured throughout most of the entire torque-speed range in which the motor is capable of operating. For each operation point, the motor was controlled in steady state for at least 20 seconds and at least 5 data points were averaged to generate the efficiency map in Fig. 3.17.

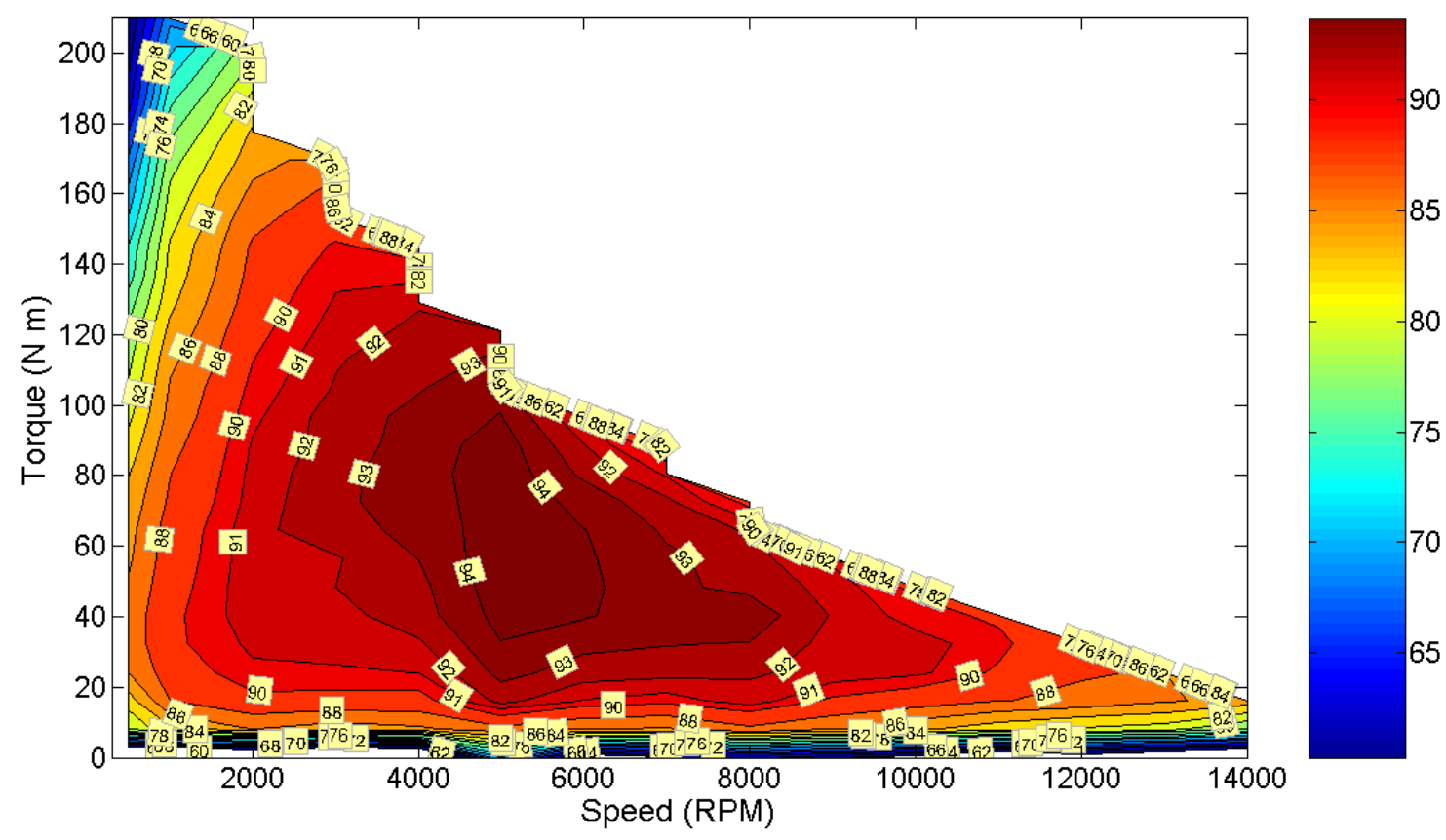

Fig. 3.17. 2007 Camry motor efficiency contours.

Efficiencies of the Camry motor are above $90 \%$ for a large portion of the torque-speed operation region. The high speed or high torque regions tend to incorporate lower operation efficiencies. To provide a straightforward comparison with the Prius motor efficiency map, the torque and speeds were scaled by 2.47 appropriately, as shown in Fig. 3.18. A comparison of the scaled Camry efficiency map and the Prius efficiency map in Fig. 3.19 reveals that the Camry has higher efficiencies for much of the map. Similar scales, axis limitations, percentage ranges, and color schemes are used to further ease the comparison. Note that a portion of the Camry high torque region is not visible. The most significant improvement over the Prius is observed at low speeds, where the Prius efficiencies drop quickly as torque increases and speed approaches zero. This region is frequented often since the electric motor is utilized to develop the torque required to accelerate the vehicle at low speeds or from standstill. 


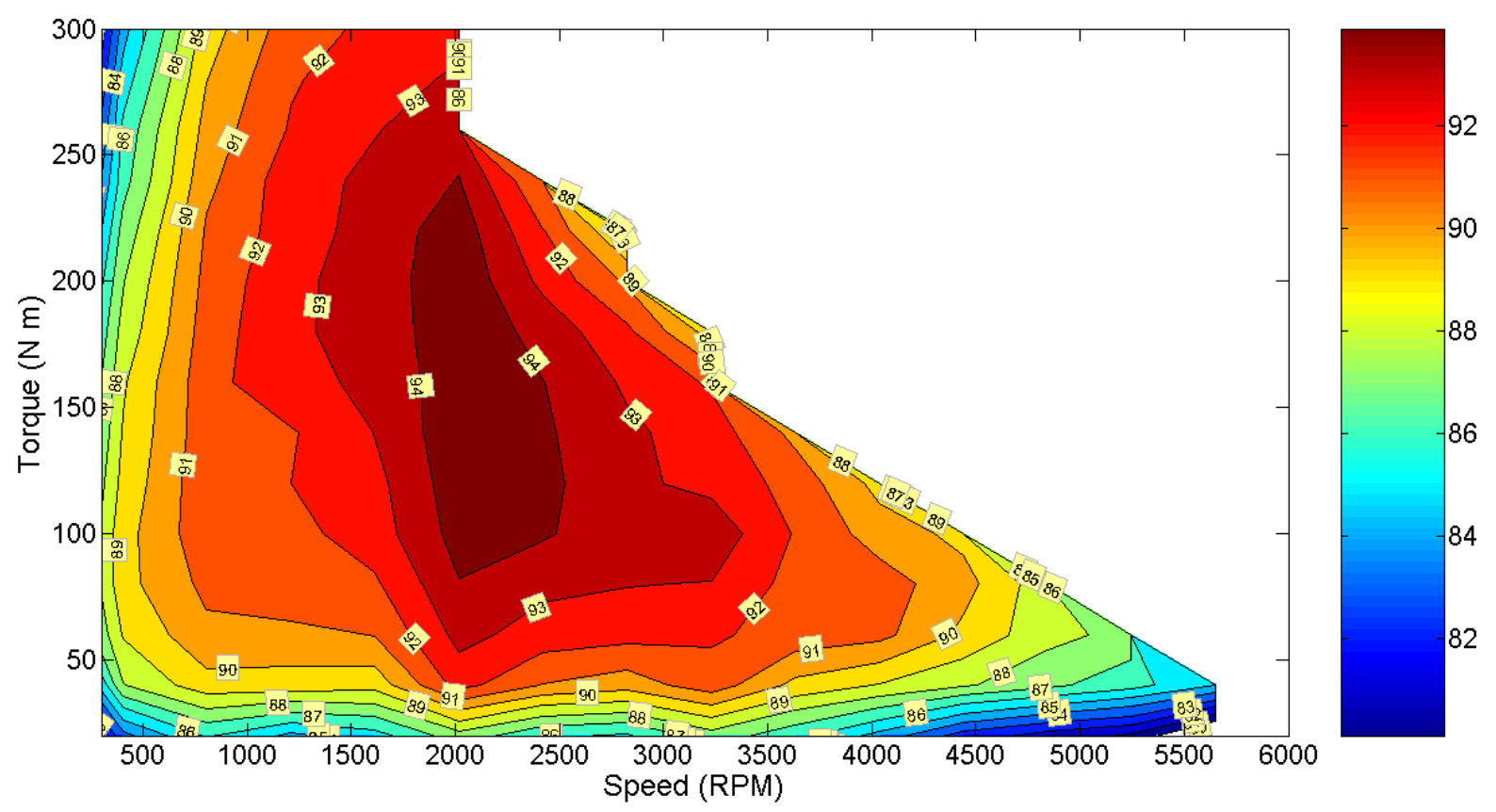

Fig. 3.18. 2007 Camry motor efficiency contours scaled by 2.47 .

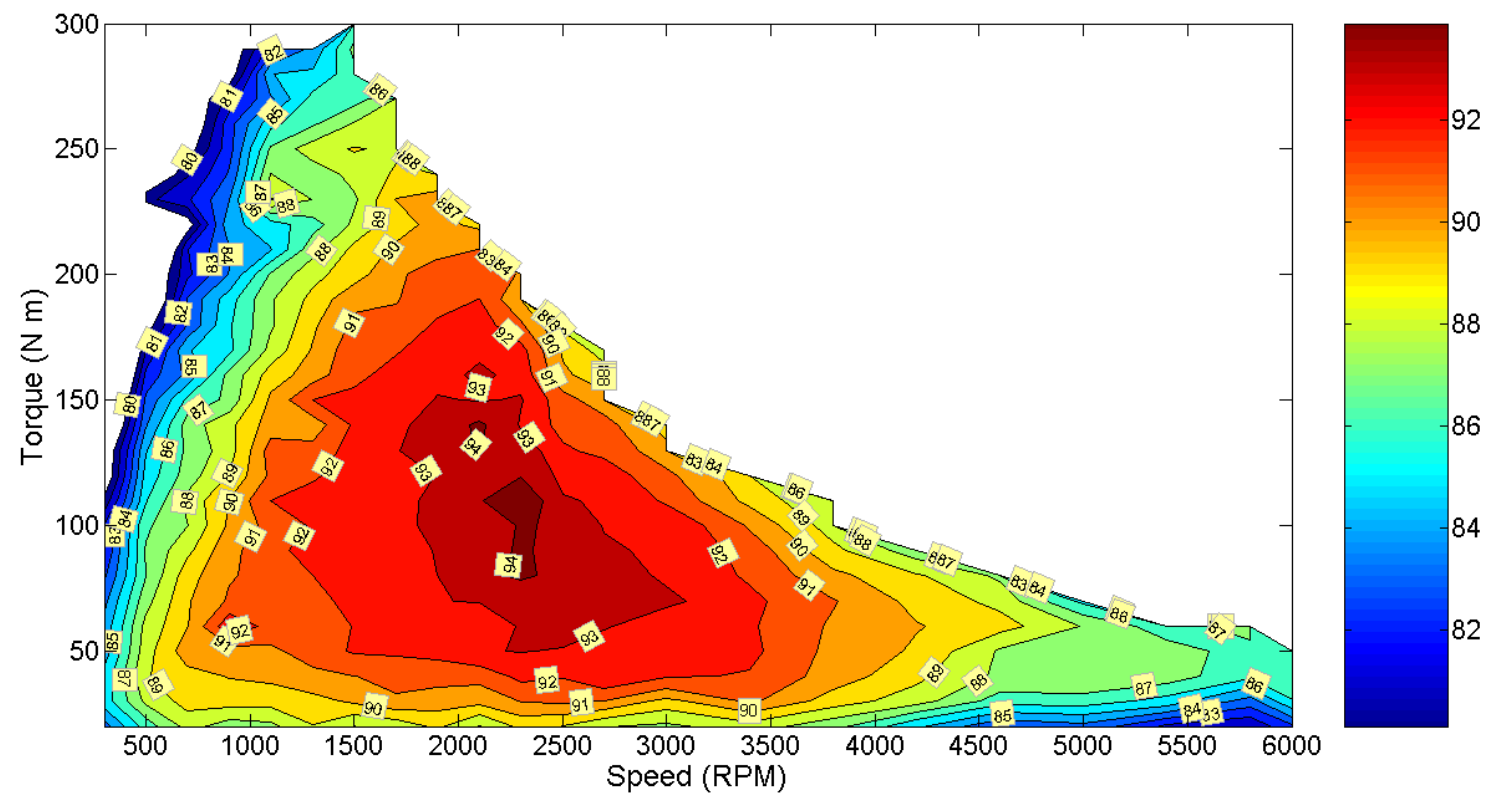

Fig. 3.19. 2004 Prius motor efficiency contours.

Thermal limitations hindered the extent of the Camry motor evaluations at low speeds and high torques, where steady state testing was limited to about $210 \mathrm{Nm}$ in order to prevent over-temperature conditions. It has been verified through dynamic, short duration tests that the motor is capable of producing the published rated torque of $270 \mathrm{Nm}$, yet for only a very short time duration of a few seconds. According to the Camry service manual, the operation temperature of the motor is typically below $90^{\circ} \mathrm{C}$. With this limitation, the extent of maximum torque of $270 \mathrm{Nm}$ is much shorter as temperature limitations were set at about $150^{\circ} \mathrm{C}$ during the tests. The maximum power capability is limited by voltage constraints to about 
$70 \mathrm{~kW}$ at $4500 \mathrm{rpm}$. This matches the expected power rating based on the size of the generator inverter and boost converter. Estimated power rating techniques based on properties such as the mass, volume, speed, and thermal characteristics also result in similar power ratings for this motor. It is assumed that the published $105 \mathrm{~kW}$ power rating of the transaxle is the sum of the motor and generator power ratings as no rating is published for the generator.

Similar to the process used with the Camry motor efficiency contours, the Camry inverter efficiency contours were generated and scaled by the high speed gear ratio of 2.47 in order to provide a straightforward comparison with the Prius. A comparison of the inverter efficiency maps, shown in Figs. 3.20 and 3.21, indicates that the efficiency of the Camry inverter is somewhat lower than the efficiency of the Prius inverter for speeds below $2000 \mathrm{rpm}$. Similar scales, axis limitations, percentage ranges, and color schemes are used in these efficiency maps to further ease the comparison. The low speed, high torque capabilities of the Camry inverter appear to be greater than that of the Prius inverter as the speed reduction gear facilitates the use of a much lower current to generate the same amount of equivalent torque on the low speed side of the speed reduction gear. For low torques above $2000 \mathrm{rpm}$, the Camry inverter efficiency contours indicate that the efficiency decreases slightly as the torque approaches zero, whereas the Prius inverter efficiency remains consistent beyond $2000 \mathrm{pm}$. Higher losses of the Camry inverter is possibly due to the $30 \%$ increase of the dc-link voltage and the $50 \%$ increase in the number of power electronic devices when compared to that of the Prius.

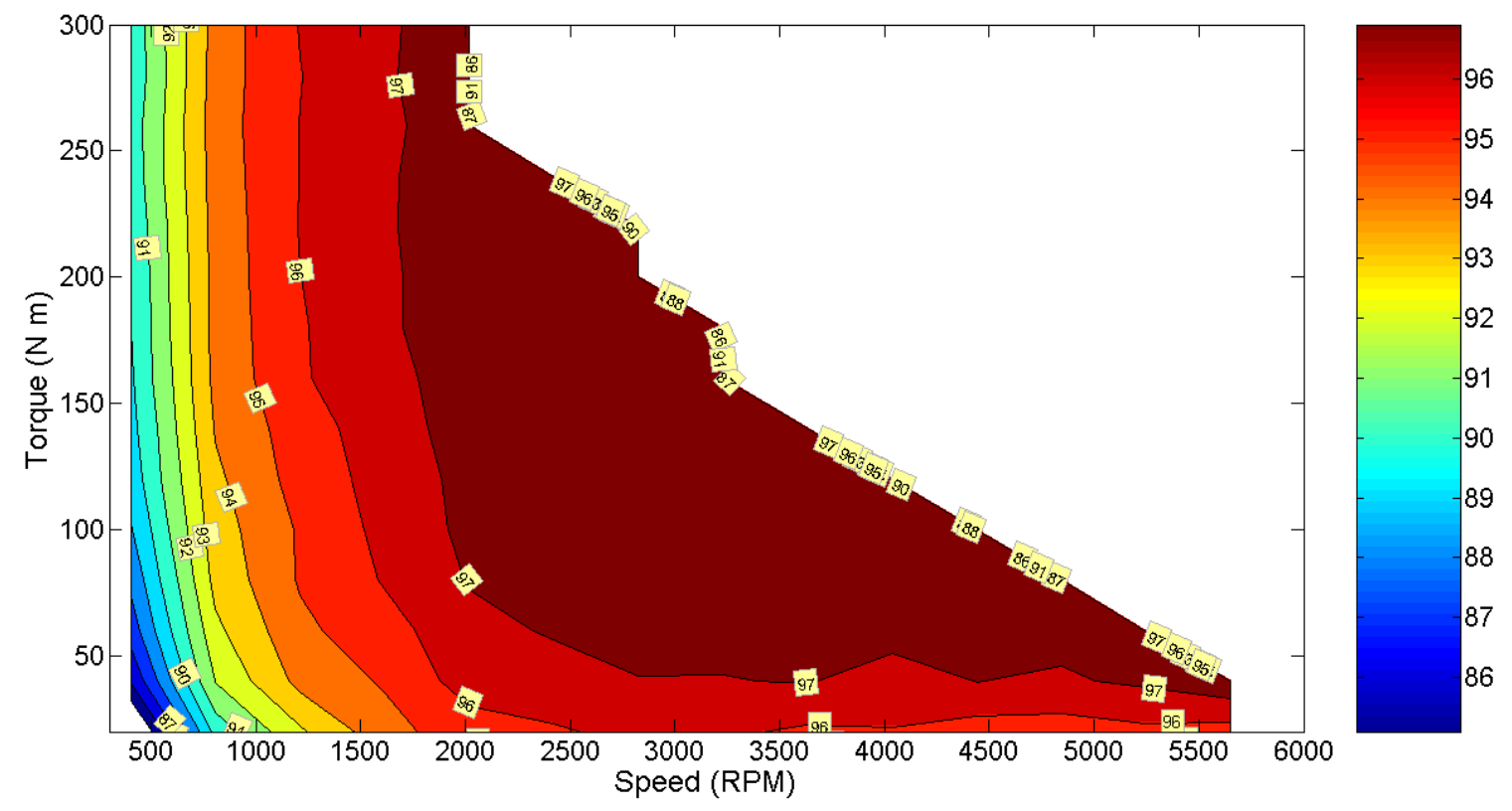

Fig. 3.20. 2007 Camry inverter efficiency contours scaled by 2.47. 


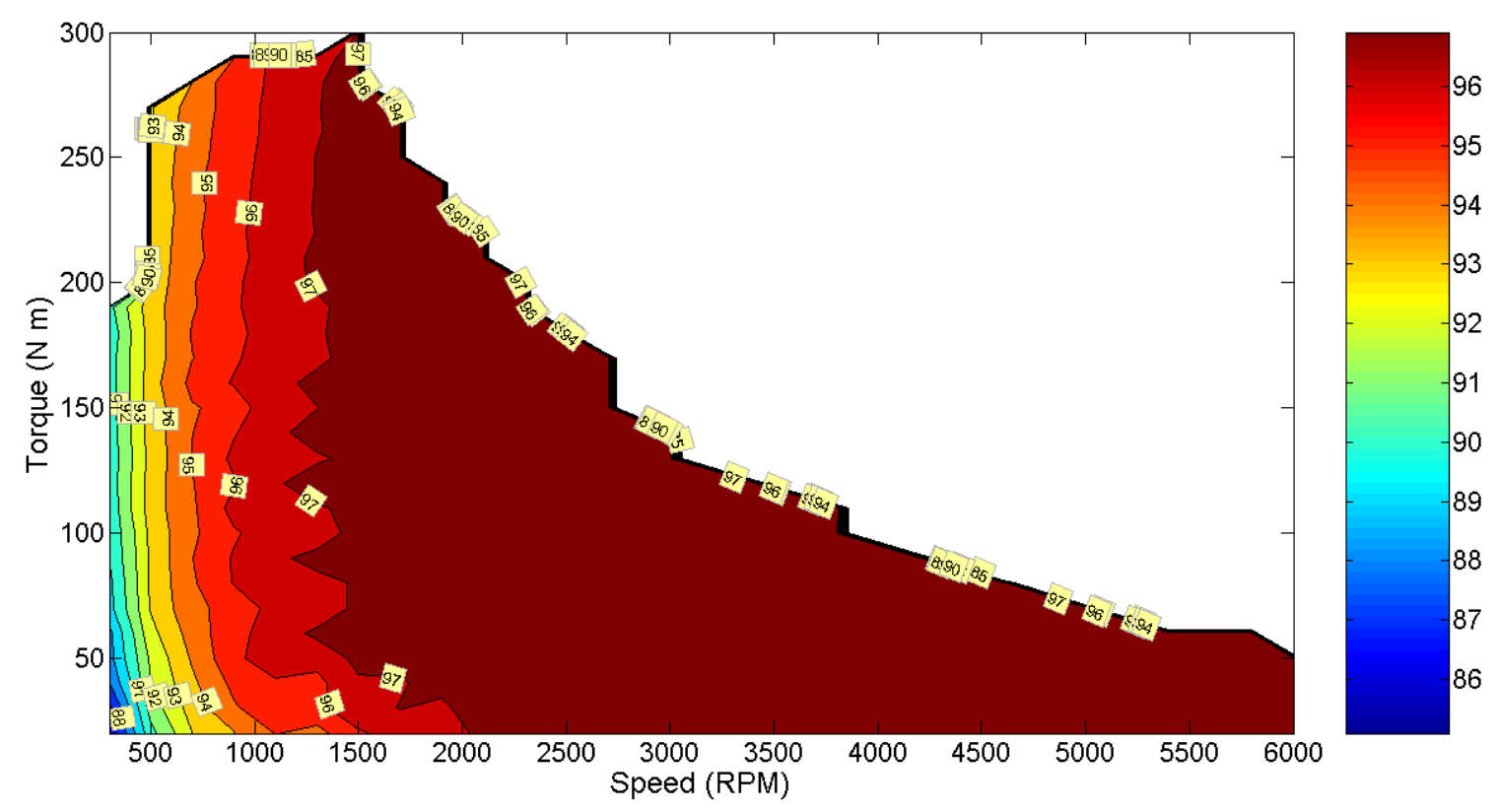

Fig. 3.21. 2004 Prius inverter efficiency contours.

The lower inverter efficiencies of the Camry cause the combined motor/inverter efficiencies to be somewhat closer than the motor efficiencies alone, as indicated in Figs. 3.22 and 3.23. Although there are striking similarities between the two efficiency contour maps, benefits of the high speed motor in the Camry are evident for the low speed, high torque regions.

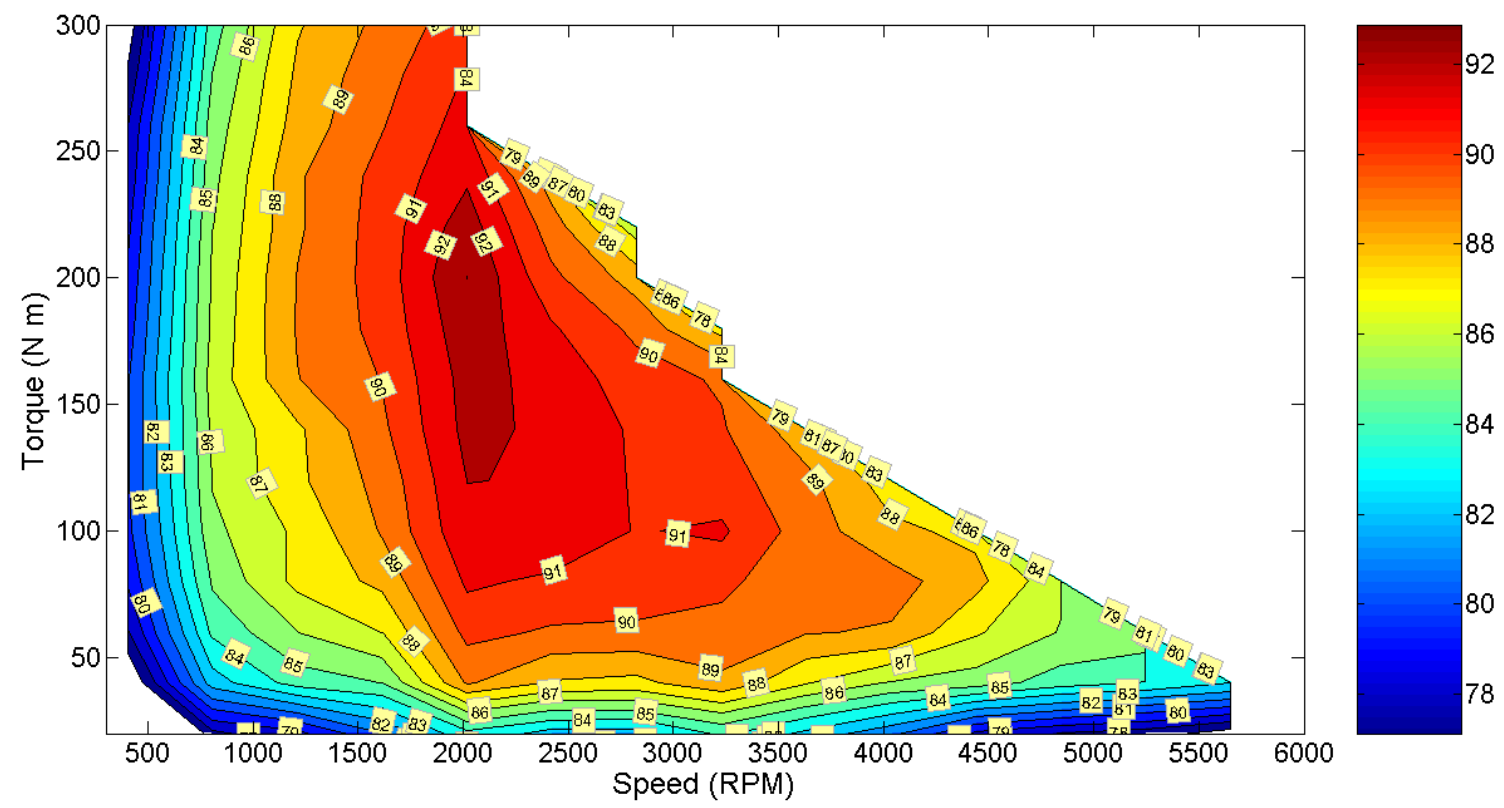

Fig. 3.22. 2007 Camry motor/inverter efficiency contours. 


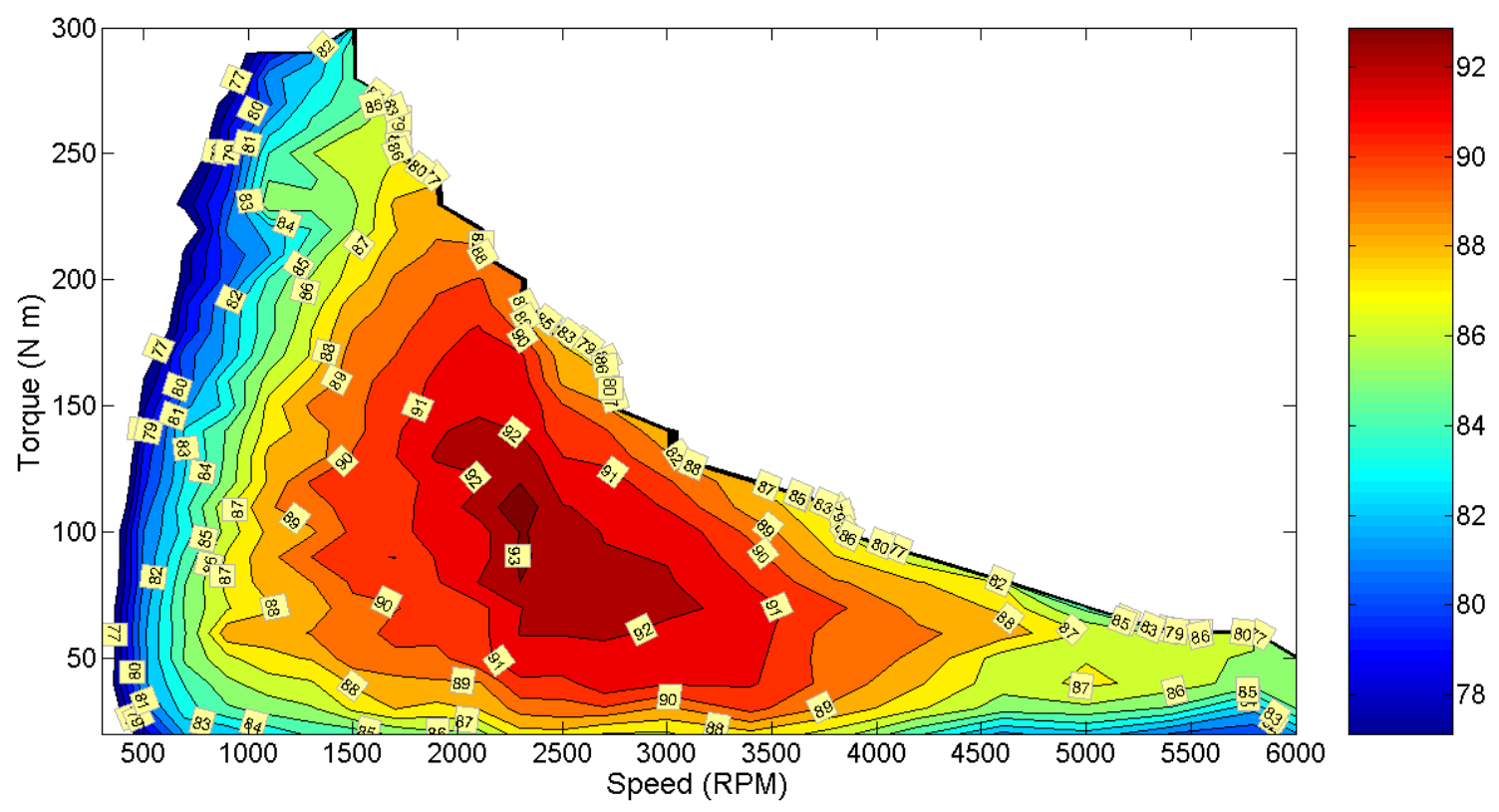

Fig. 3.23. 2004 Prius motor/inverter efficiency contours.

To further explore the various influences on inverter efficiency, tests were conducted with various dc-link voltages and inverter switching frequencies. In Fig. 3.24, a constant operation condition at $1000 \mathrm{rpm}$ and $80 \mathrm{Nm}$ was maintained throughout the tests. As expected, the inverter efficiency decreases with increasing dc-link voltage and increasing switching frequency. The Camry controller can operate at switching frequencies of $1.25 \mathrm{kHz}, 2.5 \mathrm{kHz}, 5 \mathrm{kHz}$, and $10 \mathrm{kHz}$, yet it operates at $5 \mathrm{kHz}$ for much of the time when controlled by the MG ECU in vehicle. The impact of these parameters is lower for some operation conditions and high dc-link voltages are unavoidable at high speed, high torque conditions wherein back-emf voltages demand a high supply voltage.

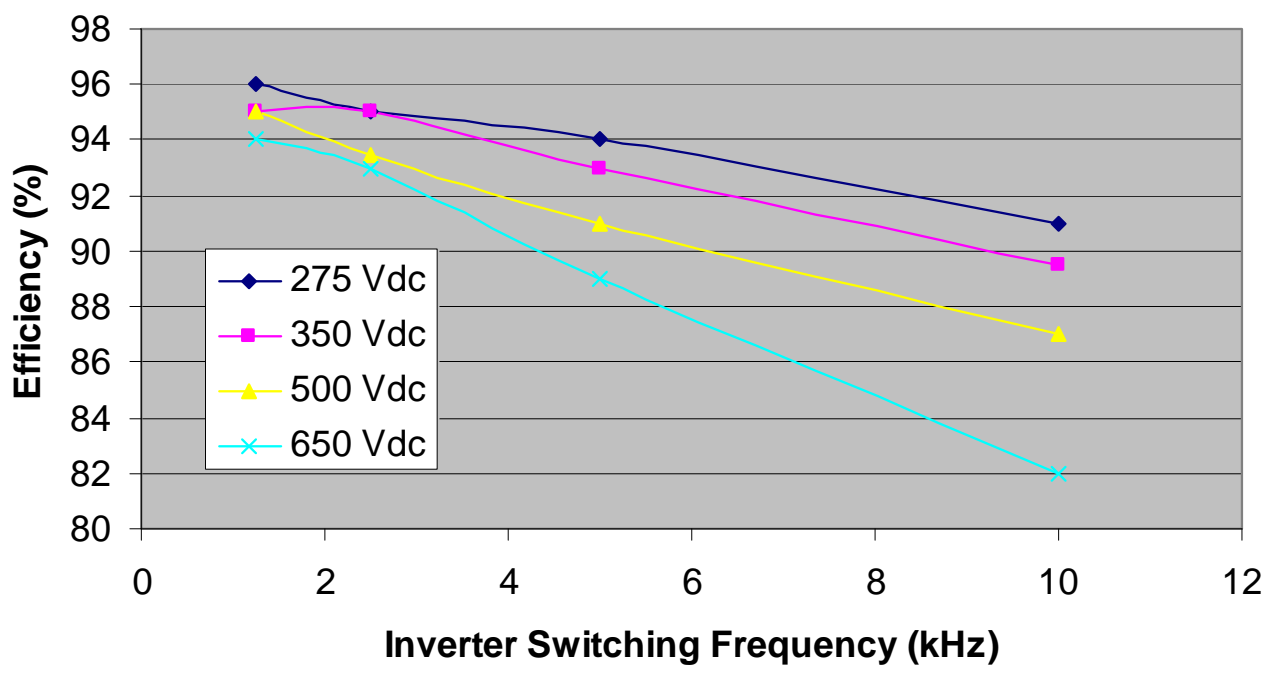

Fig. 3.24. 2007 Camry inverter efficiency vs. switching frequency for various dc-link voltages.

Boost converter efficiency assessments were conducted with various dc-link voltage and current output levels. The evaluations were conducted as the boost converter supplied the motor inverter, both of which 
were operated at $5 \mathrm{kHz}$. The motor speed was maintained at $1000 \mathrm{rpm}$ as the torque was increased to increase the boost converter current. According to the data from full vehicle tests conducted at ANL, the input voltage to the boost converter is commonly near $275 \mathrm{Vdc}$. Camry and Prius boost converter efficiencies are plotted versus boost converter input current in Figs. 3.25 and 3.26. Curve characteristics are undoubtedly different between the two, and the Prius boost converter has a slightly higher efficiency for much of the operation range. Low dc-current limitations were set for initial tests to prevent potential failures from preventing completion of general tests. Nonetheless, a failure occurred with an output voltage of $500 \mathrm{Vdc}$ and input current of about $70 \mathrm{~A}$ and anticipated tests at $650 \mathrm{Vdc}$ as well as a second series of tests at $10 \mathrm{kHz}$ were not conducted. The failure was associated with an extremely high ripple current and the Toyota controller likely uses a switching frequency of $10 \mathrm{kHz}$ in these conditions.

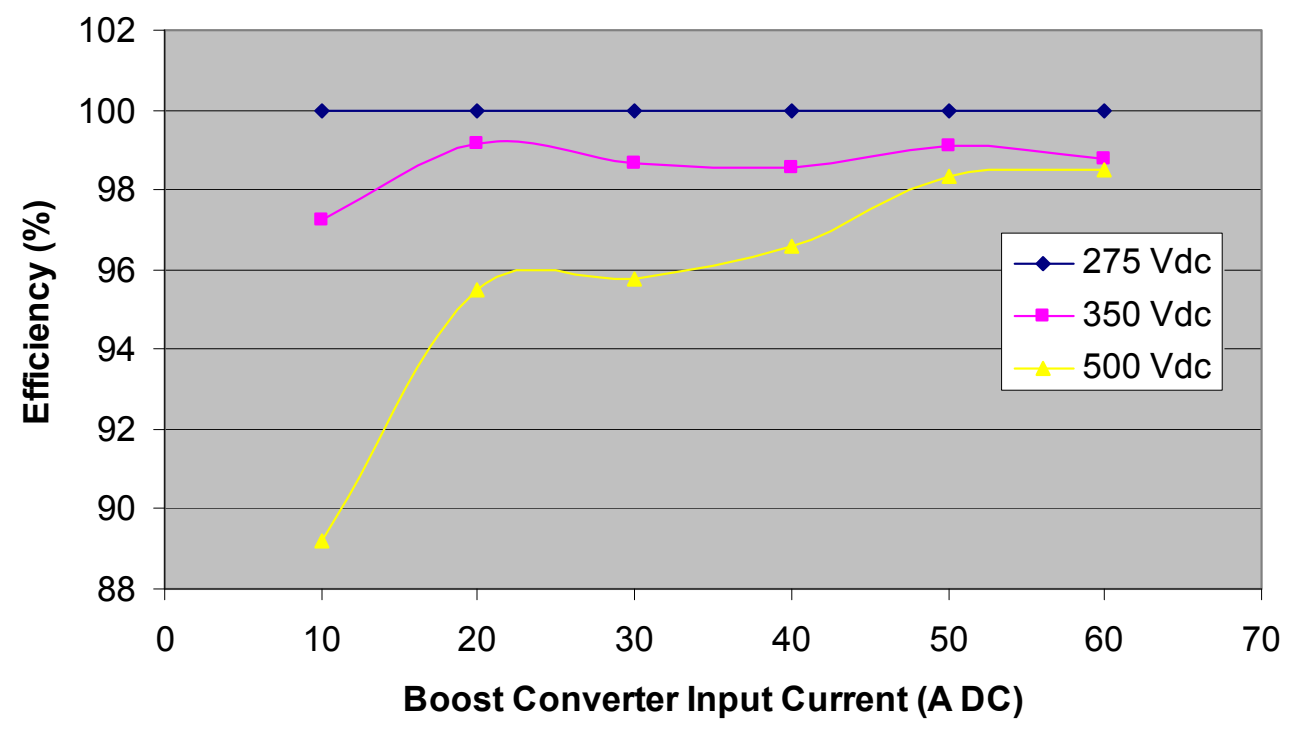

Fig. 3.25. 2007 Camry boost converter efficiency vs. input current for various dc-link voltages.

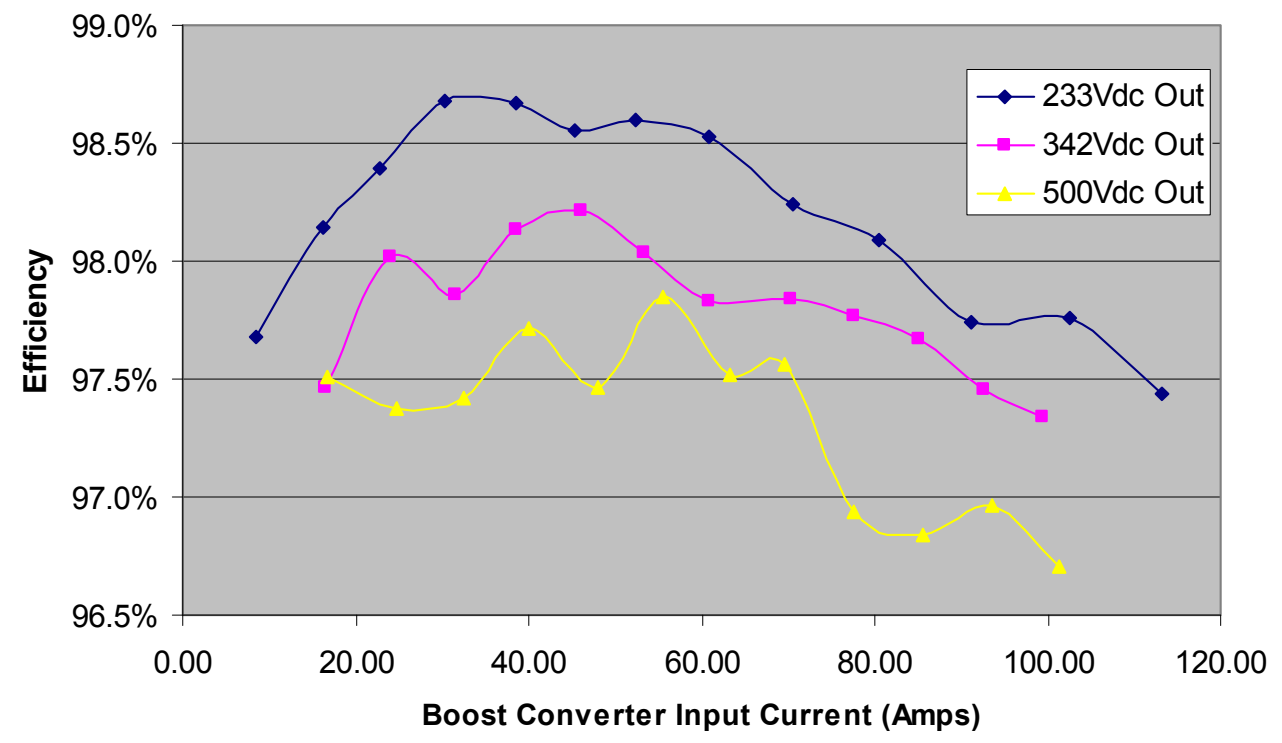

Fig. 3.26. Prius boost converter efficiency vs. input current for various dc-link voltages. 


\subsection{CONTINOUS LOAD DURATION TESTS}

The Camry motor was operated at continuous power levels for different speeds and coolant temperatures to observe the continuous capability of the motor under various conditions. Continuous tests were conducted at 25, 33.5, and $50 \mathrm{~kW}$ at 3000,5000 , and $7000 \mathrm{rpm}$ with coolant temperatures of 20, 25, 50, and $65^{\circ} \mathrm{C}$. For each case, motor temperatures were allowed to stabilize prior to initiating the continuous tests and the Bay-Voltex coolant temperature regulation unit was used to regulate the coolant at a desired temperature.

TCs and thermistors were installed in various locations throughout the transaxle and PCU with locations indicated in Fig. 3.5. Coolant temperatures are indicated by the traces labeled "To Camry" and "From Cam." A thermistor labeled "D: ML 1" was installed within close proximity of the factory thermistor of the Camry, which is labeled "E: ML 2". Additionally stator, internal/external case, and inverter temperatures were monitored and recorded.

Figure 3.27 shows the continuous test results conducted at a power level of $50 \mathrm{~kW}$, a motor speed of $5000 \mathrm{rpm}$, and a coolant temperature of $50^{\circ} \mathrm{C}$. The traces are labeled and identified by color in the key provided on the left. Mechanical power, "Pmech," is represented by a blue trace. The symbol at each datapoint is not distinguishable in the figure since the time scale is so large and the datapoints are close together. A table indicates the time duration for the associated stator temperature limitation in the upper left corner of the figure. For example, with a coolant temperature of $50^{\circ} \mathrm{C}$, the motor can operate at $50 \mathrm{~kW}$ for about 8:05 (minutes:seconds) prior to reaching a stator temperature of $130^{\circ} \mathrm{C}$. If the stator temperature limit is raised to $140^{\circ} \mathrm{C}$, the motor can operate for about 10:18 under these conditions. Thus, the extent of continuous operation capabilities depends greatly upon stator temperature limitations.

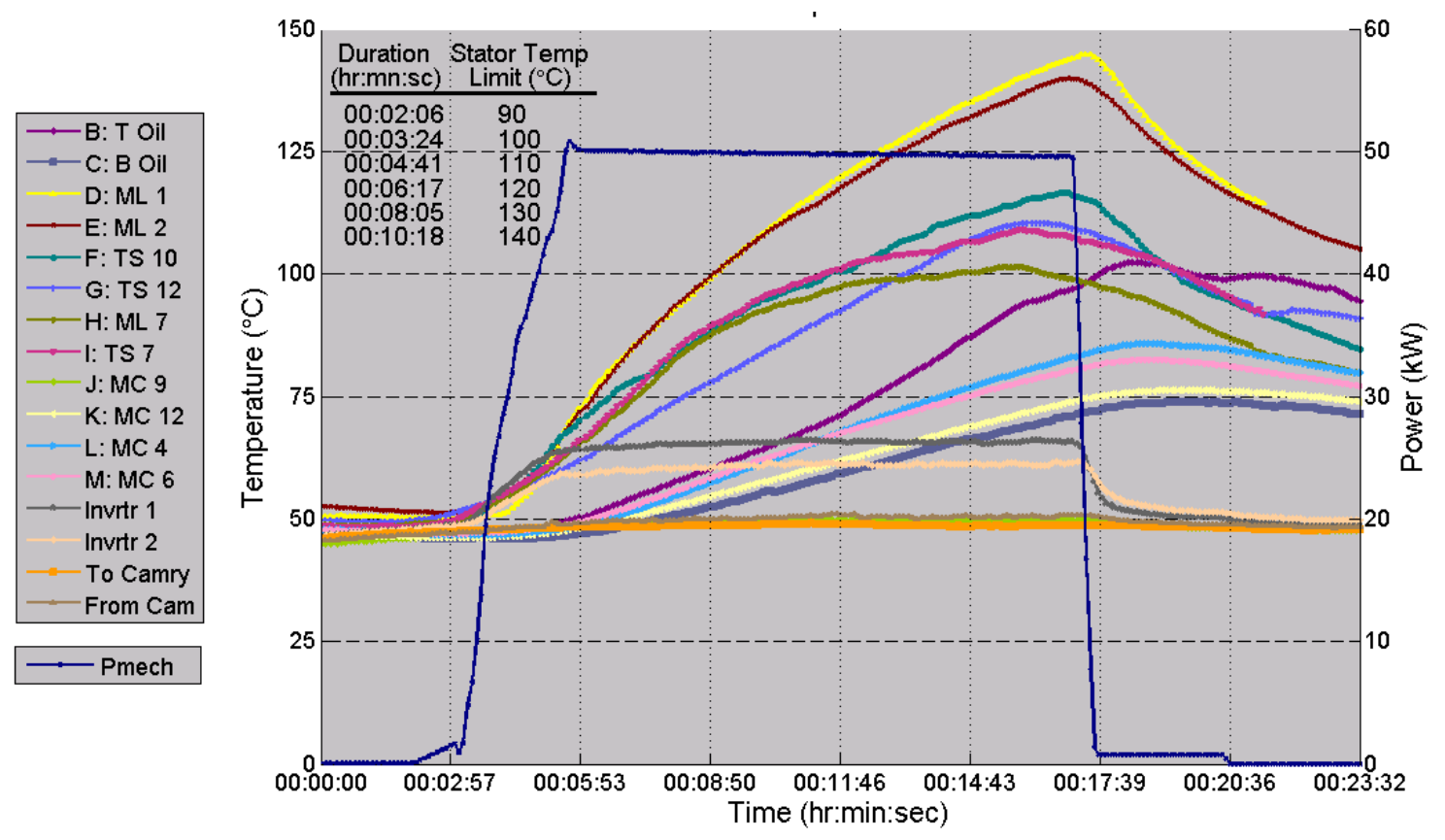

Fig. 3.27. Camry $50 \mathrm{~kW}$ continuous duration test at $5000 \mathrm{rpm}$ with $50^{\circ} \mathrm{C}$ coolant.

Stator temperature limitations are set to prevent potential damage within the stator windings and to prevent demagnetization of the PMs. Long term effects which affect the life of the PMSM must also be considered when choosing a stator temperature limitation. According to full vehicle tests at ANL, the Camry stator temperature is generally kept well below $90^{\circ} \mathrm{C}$. The temperatures of the original Camry 
thermistor and the installed thermistor remained close during the continuous duration tests. Results show that the original Camry thermistor, "E: ML 2," is placed in one of the hottest locations of the motor. Figures 3.28 and 3.29 show the plots from tests conducted with a coolant temperature of $65^{\circ} \mathrm{C}$ at power levels of $50 \mathrm{~kW}$ and $25 \mathrm{~kW}$ and $7000 \mathrm{rpm}$ and $5000 \mathrm{rpm}$, respectively. Note that in the latter test the coolant temperature was reduced after thermal steady state was reached, as indicated in Fig. 3.29.

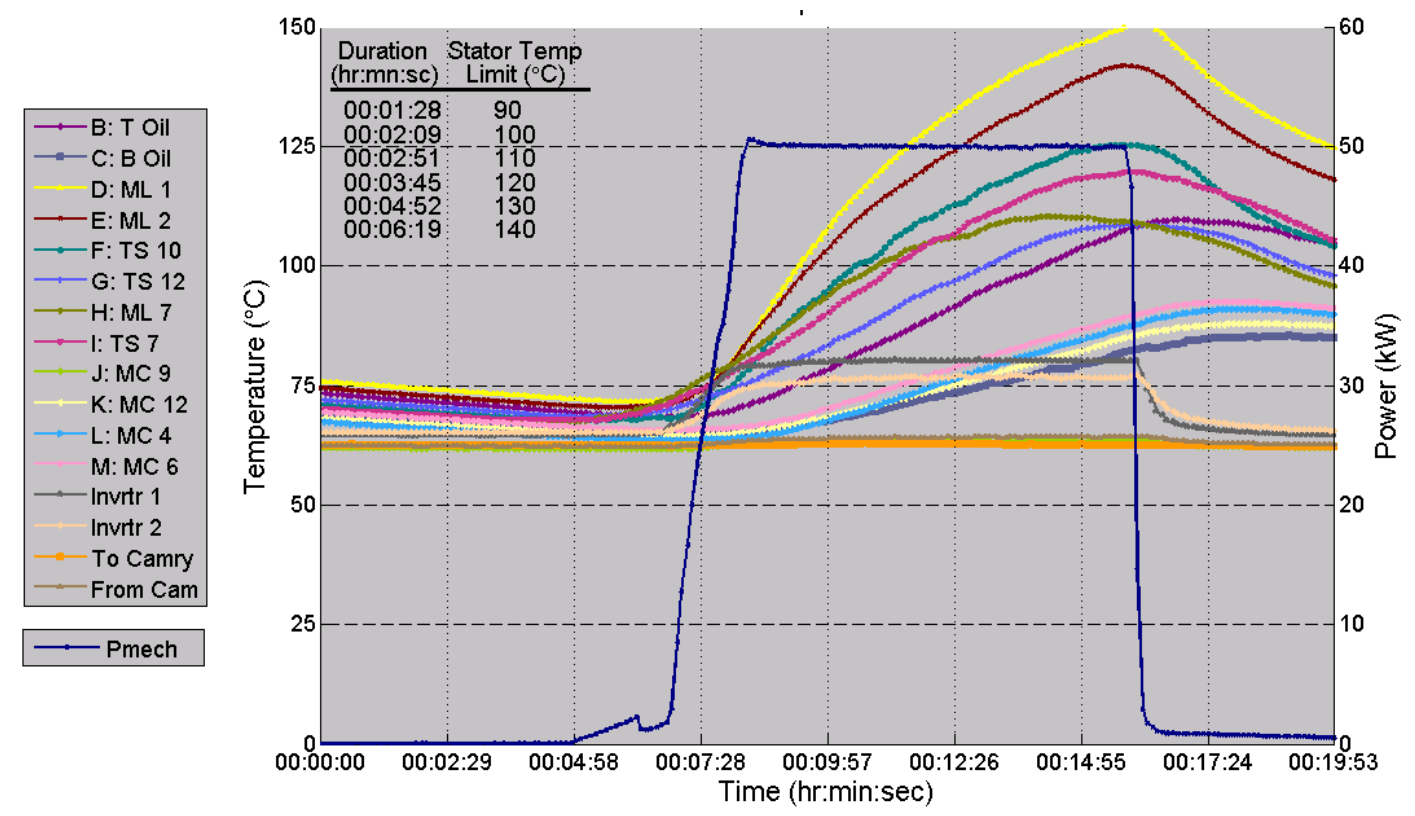

Fig. 3.28. Camry $50 \mathrm{~kW}$ continuous duration test at $7000 \mathrm{rpm}$ with $65^{\circ} \mathrm{C}$ coolant.

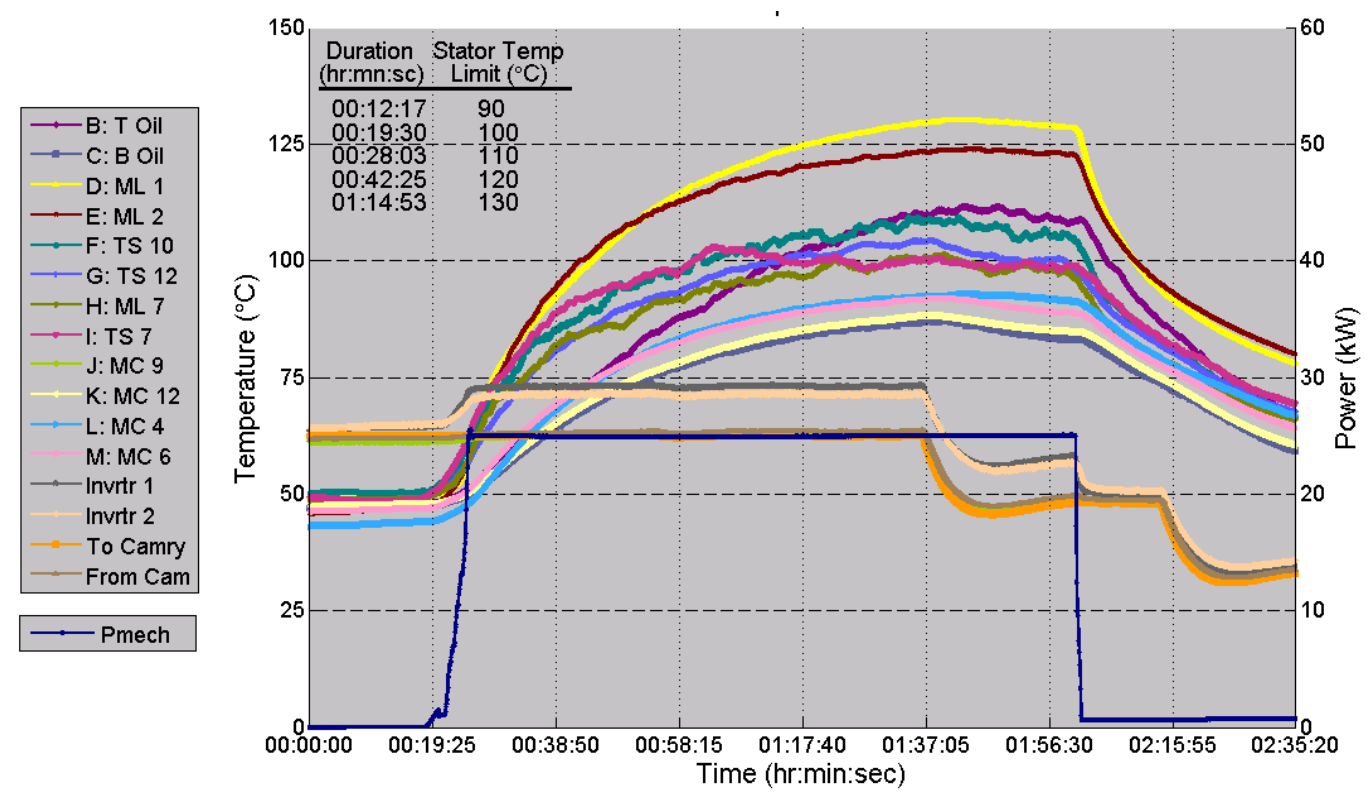

Fig. 3.29. Camry $25 \mathrm{~kW}$ continuous duration test at $5000 \mathrm{rpm}$ with $65^{\circ} \mathrm{C}$ coolant.

As expected, a comparison of Figs. 3.27 and 3.28 shows that the time extent of operation at $50 \mathrm{~kW}$ decreases as the test speed changes from 5000-7000 rpm and coolant temperature increases from $50-65^{\circ} \mathrm{C}$. All tests conducted at $5000 \mathrm{rpm}$ produced the most efficient operation and thus the longest duration of operation at any power level when compared to test results obtained while operating at other 
speeds and a similar coolant temperature. The highest temperatures stabilized near $130^{\circ} \mathrm{C}$ in Fig. 3.29 at $5000 \mathrm{rpm}$ and $25 \mathrm{~kW}$. Note that it took over an hour to reach this temperature. Another continuous duration graph from tests conducted at $3000 \mathrm{rpm}$ and $33.5 \mathrm{~kW}$ with a coolant temperature of $65^{\circ} \mathrm{C}$ is shown in Fig. 3.30.

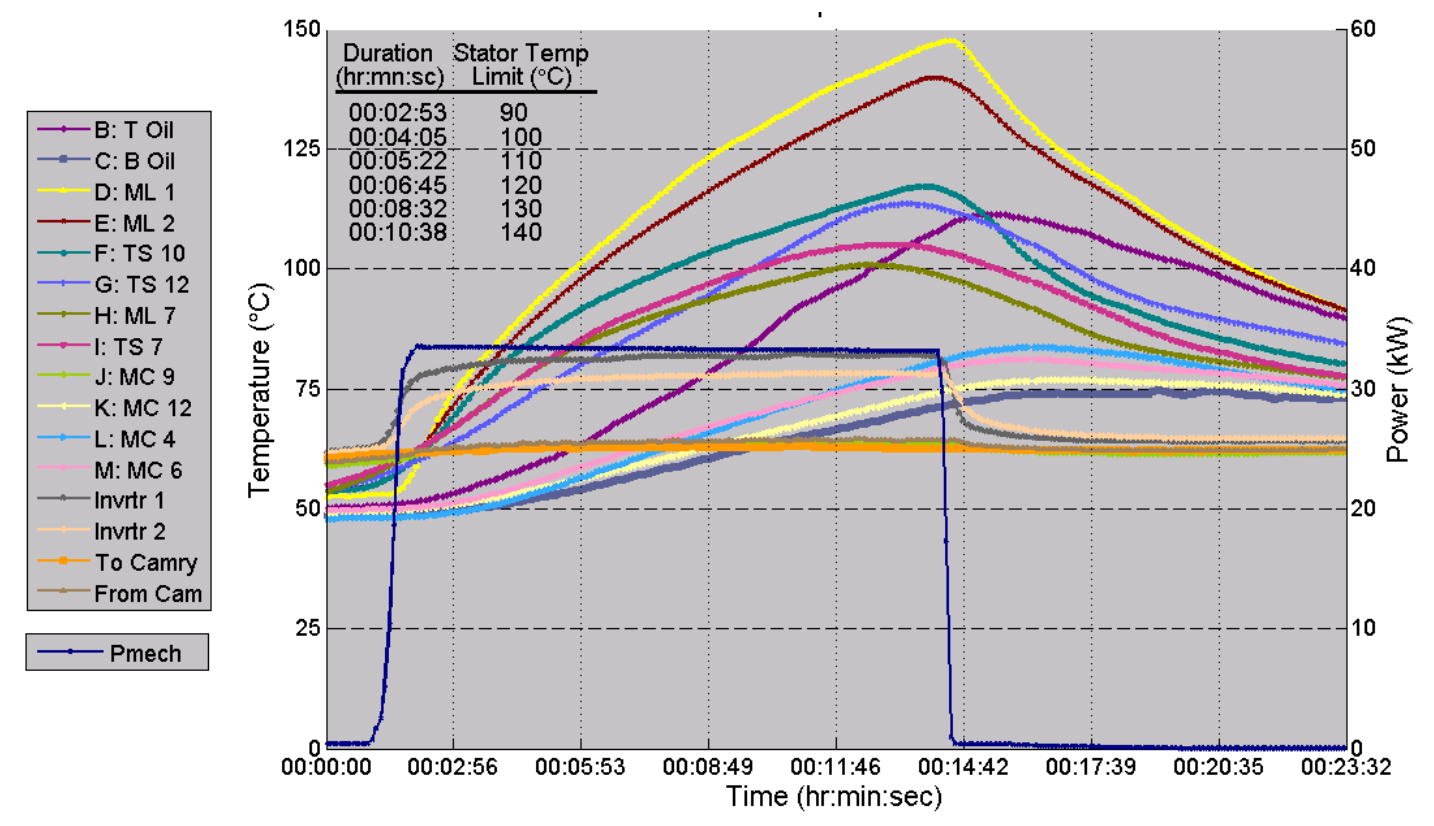

Fig. 3.30. Camry $33.5 \mathrm{~kW}$ continuous duration test at $3000 \mathrm{rpm}$ with $65^{\circ} \mathrm{C}$ coolant.

Graphs similar to Fig. 3.30 were generated for each test condition and while they are informative, it is difficult to fully study the impact of various power levels, motor speeds, coolant temperatures, and stator temperature limitations upon the extent of time at which the motor can operate under these conditions. Therefore, the duration times shown in the upper left corner of the previous figures were used to produce graphs which provide more meaningful comparisons. In Fig. 3.31, the time durations associated with operation at $25 \mathrm{~kW}$ with a $65^{\circ} \mathrm{C}$ coolant temperature is graphed versus speed. Each trace represents the time durations which correlate to a particular stator temperature limit. Through inspection of this graph, it is more evident that the duration of operation is greater at $5000 \mathrm{rpm}$ than for any other speed. Note again that in this case, the stator temperature stabilized near $130^{\circ} \mathrm{C}$ at $5000 \mathrm{rpm}$, which is represented by the upper most trace. Thus, the trace for a temperature of $150^{\circ} \mathrm{C}$ would theoretically have a data point that approaches infinity. Also note that tests under these conditions were discontinued after 30 minutes of operation at $7000 \mathrm{rpm}$ and therefore stator temperatures did not reach higher than $120^{\circ} \mathrm{C}$.

Similar graphs are shown in Fig. 3.32 for a power level of $33.5 \mathrm{~kW}$ and a coolant temperature of $35^{\circ} \mathrm{C}$. At $5000 \mathrm{rpm}$, the motor operated for over 30 minutes before reaching a stator temperature of $125^{\circ} \mathrm{C}$. For low stator temperature limits, the duration capability does not change significantly as the motor speed increases from 5000-7000 rpm. 


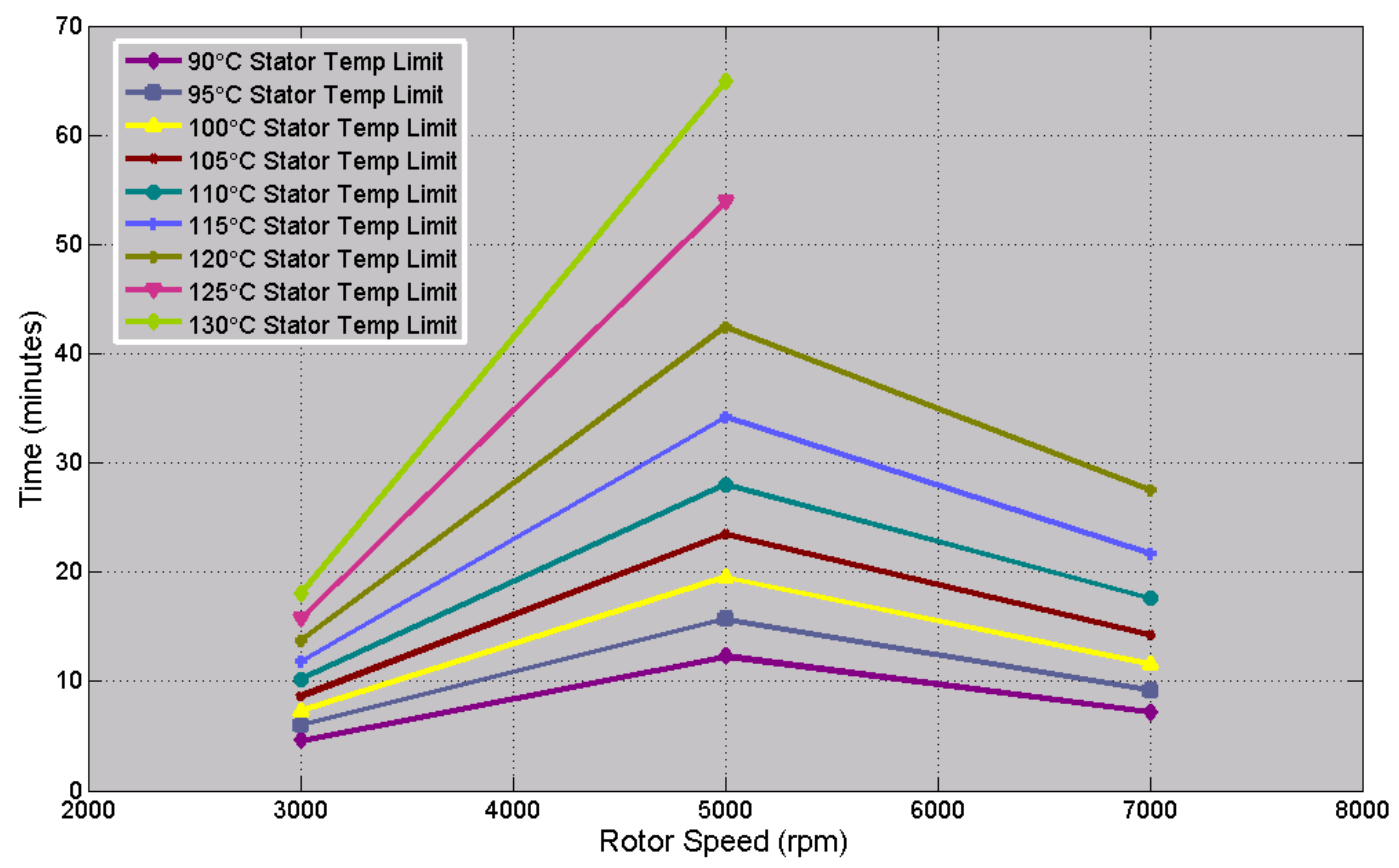

Fig. 3.31. Camry $25 \mathrm{~kW}$ continuous duration vs. speed with $65^{\circ} \mathrm{C}$ coolant.

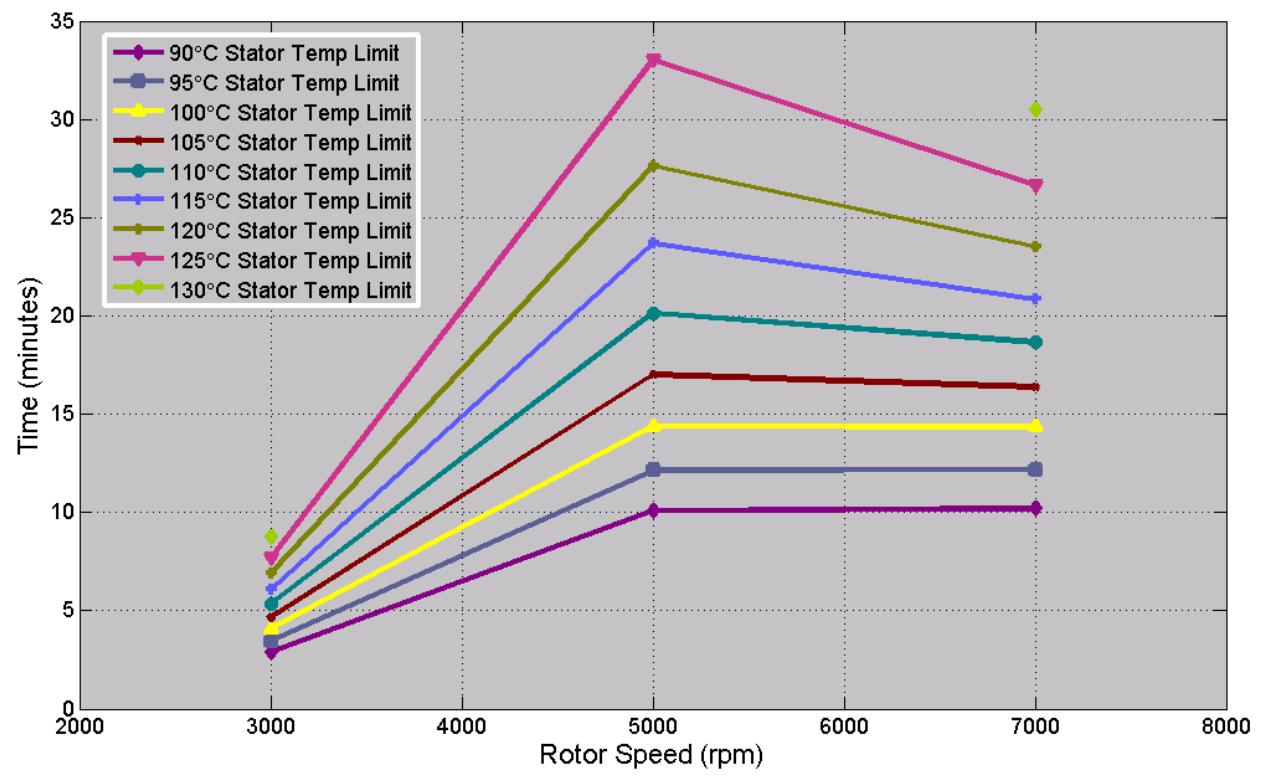

Fig. 3.32. Camry $33.5 \mathrm{~kW}$ continuous duration vs. speed with $35^{\circ} \mathrm{C}$ coolant.

Similar graphs are shown in Figs. 3.33 and 3.34 for continuous tests conducted at $50 \mathrm{~kW}$ with coolant temperatures of $35^{\circ} \mathrm{C}$ and $65^{\circ} \mathrm{C}$, respectively. The trace color and stator temperature limitation correlations are consistent for all of the graphs to provide ease in comparisons. The impact of coolant temperature is quite visible as the time for stator temperatures to reach $135^{\circ} \mathrm{C}$ at $5000 \mathrm{rpm}$ is about 13 minutes with a $35^{\circ} \mathrm{C}$ coolant temperature versus about 8 minutes with a $65^{\circ} \mathrm{C}$ coolant temperature. 


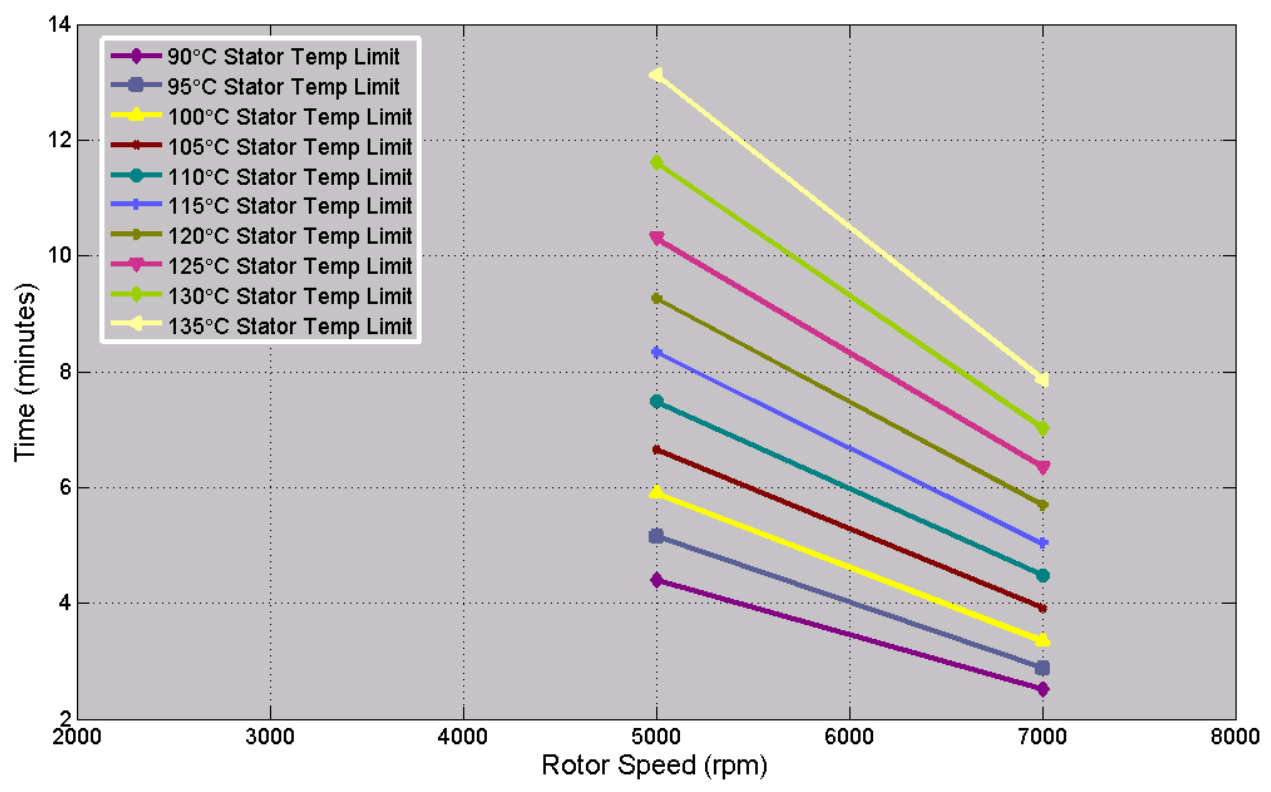

Fig. 3.33. Camry $50 \mathrm{~kW}$ continuous duration vs. speed with $35^{\circ} \mathrm{C}$ coolant.

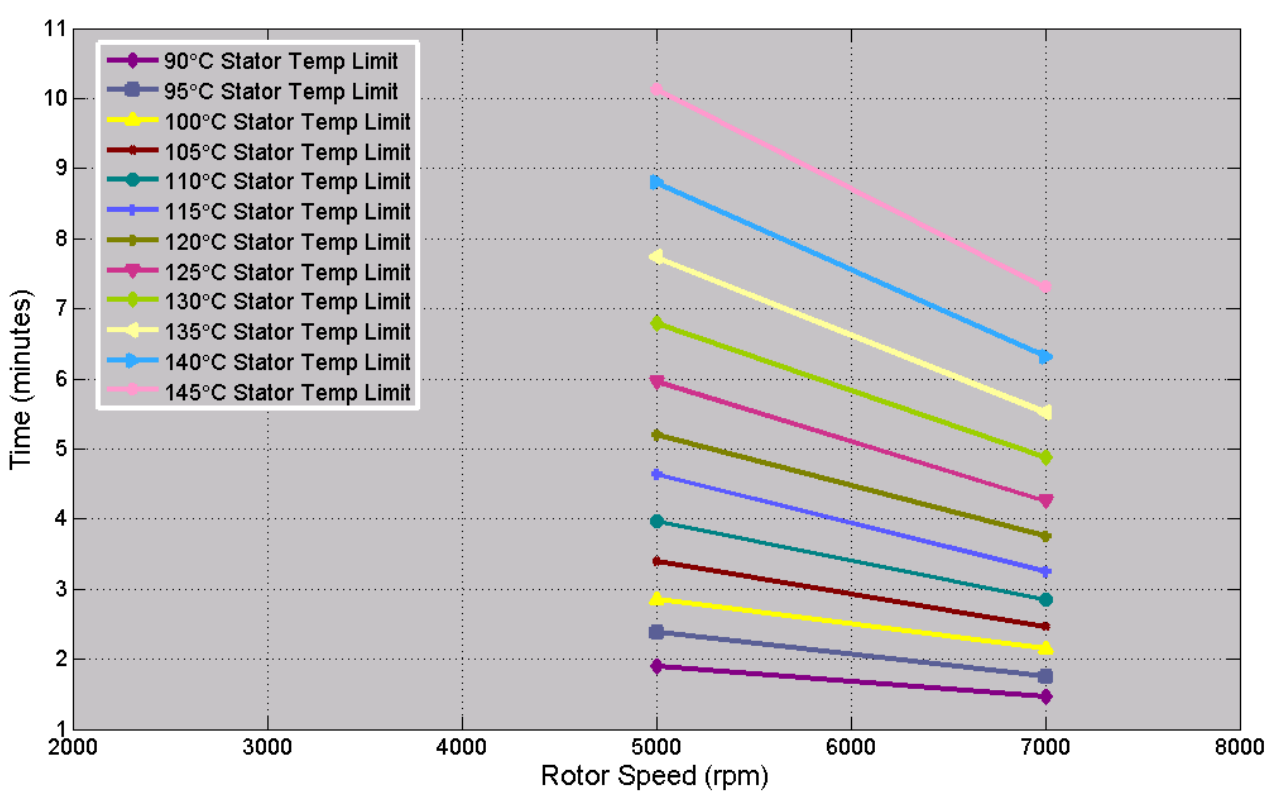

Fig. 3.34. Camry $50 \mathrm{~kW}$ continuous duration vs. speed with $65^{\circ} \mathrm{C}$ coolant.

The previous graphs provided a clear indication of the influence of speed and coolant temperature upon duration capabilities. To provide a more clear assessment of the impact of stator temperature limitations and coolant temperature upon duration capability, duration time is plotted versus the stator temperature limit in Fig. 3.35 for operations at $3000 \mathrm{rpm}$. Each trace represents a particular power level and coolant temperature combination. In studying the figure, it is evident that coolant temperature does not affect operation duration greatly at $33.5 \mathrm{~kW}$, yet coolant temperature greatly affects operation duration at a power level of $25 \mathrm{~kW}$. 


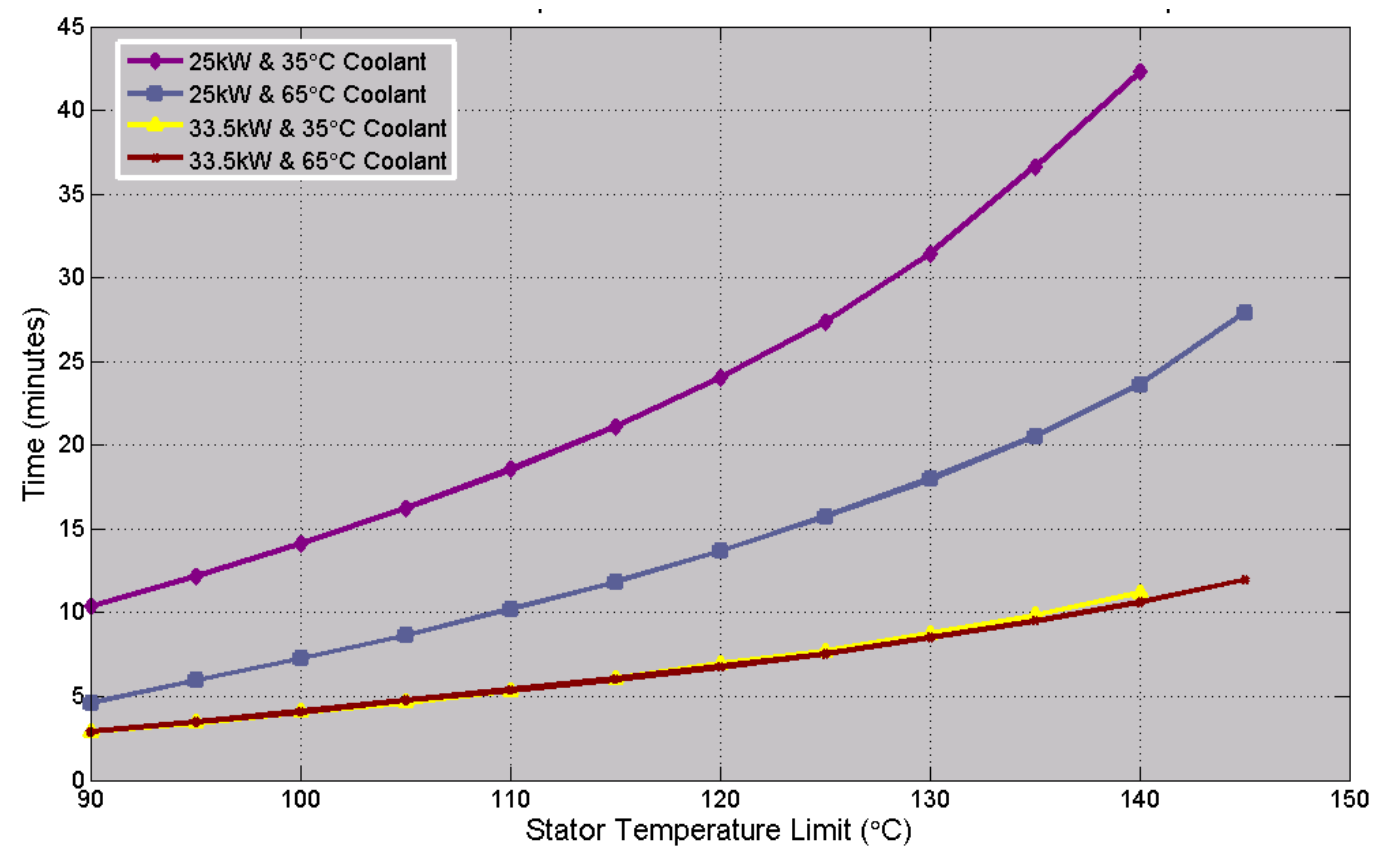

Fig. 3.35. Camry continuous duration at $3000 \mathrm{rpm}$ with various power levels and coolant temperatures.

Characteristics similar to what are observed in Fig. 3.35 are observed in Fig. 3.36 where duration time is plotted versus stator temperature limit at $5000 \mathrm{rpm}$ for various power and coolant temperature combinations. As the power level increases, the impact of coolant temperature upon duration decreases. For tests wherein thermal steady state was nearly reached, the curves approach a vertical asymptote which is located at the steady state stator temperature.

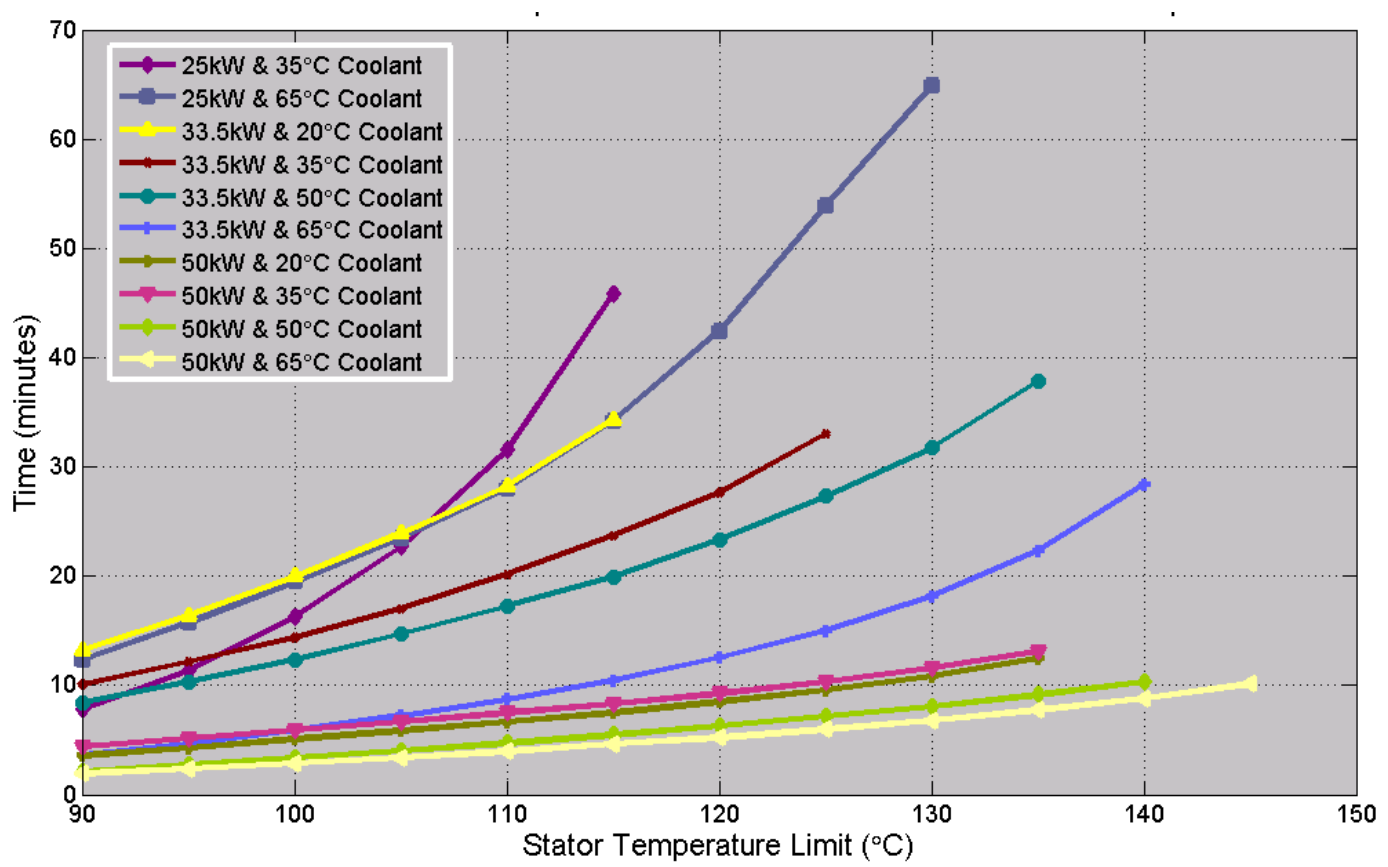

Fig. 3.36. Camry continuous duration at $5000 \mathrm{rpm}$ with various power levels and coolant temperatures. 
A graph of duration versus stator temperature limit at $7000 \mathrm{rpm}$ with various power and coolant temperature combinations is shown in Fig. 3.37. Again, with increasing power, coolant temperature has a decreasing effect upon the duration of motor operation under these conditions. Note that all powercoolant temperature combinations and color correlations do not remain the same among Figs. 3.35, 3.36, and 3.37. A comparison of these figures indicates that coolant temperature has a greater impact upon the duration of operation at higher speeds. For example, the duration of operation is influenced more by coolant temperature at $7000 \mathrm{rpm}$ and $25 \mathrm{~kW}$ than it is for $25 \mathrm{~kW}$ power levels at $3000 \mathrm{rpm}$ and $5000 \mathrm{rpm}$.

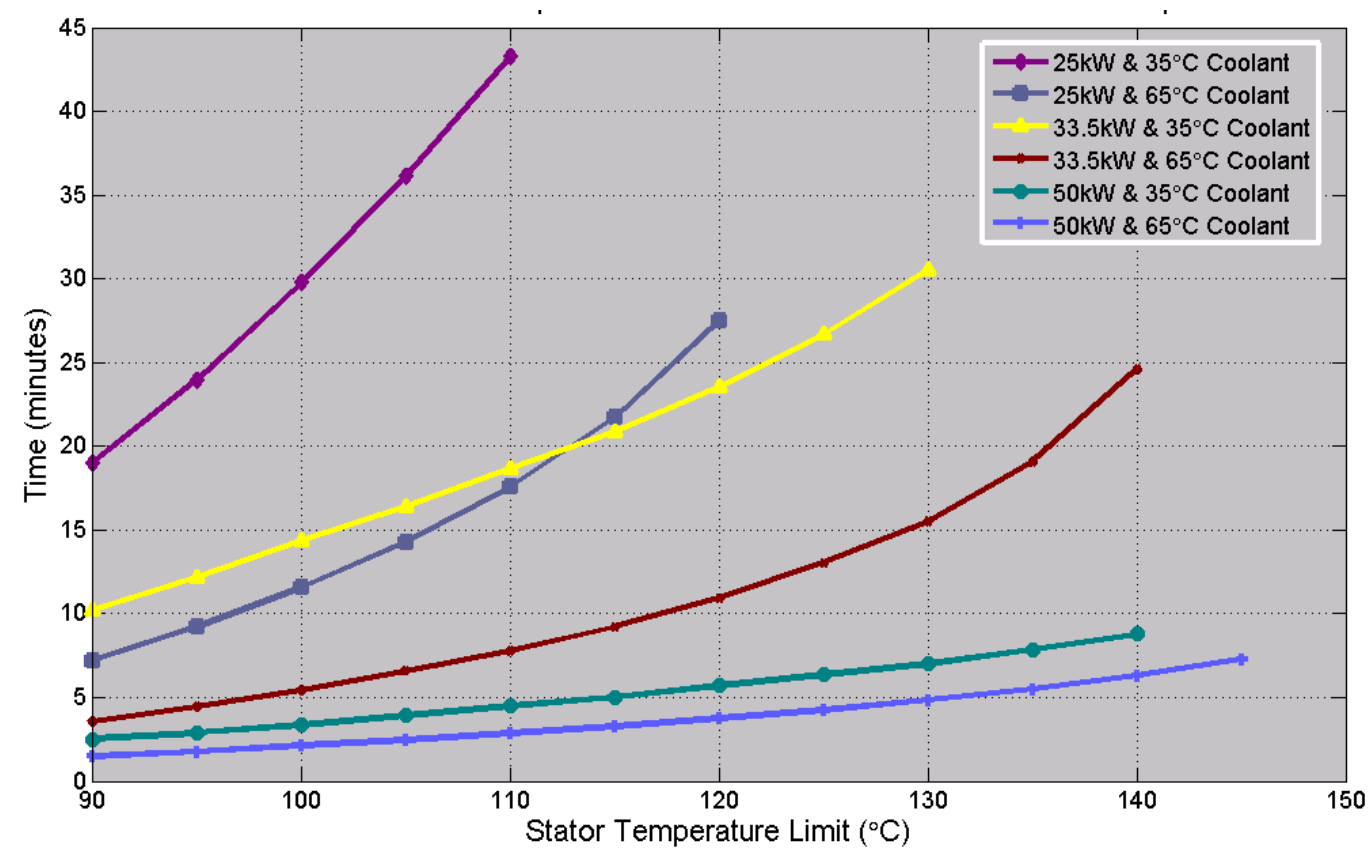

Fig. 3.37. Camry continuous duration at $7000 \mathrm{rpm}$ with various power levels and coolant temperatures.

Note that in some of the tests in which lower coolant temperatures were used, the duration of operation was longer than that of a lower power level with a higher coolant level. This occurred because system temperatures were allowed to stabilize at each coolant temperature. For example, the duration of the $33.5 \mathrm{~kW}$ and $35^{\circ} \mathrm{C}$ coolant temperature test condition is longer than that with the $25 \mathrm{~kW}$ and $65^{\circ} \mathrm{C}$ coolant temperature test conditions if the stator temperature limitation is set at a low temperature. However, if the stator temperature limitation is set at a high level, the motor can operate longer at the $25 \mathrm{~kW}$ and $65^{\circ} \mathrm{C}$ coolant temperature test condition. Thus, with $33.5 \mathrm{~kW}$ operation and a $35^{\circ} \mathrm{C}$ coolant temperature, the entire system begins at a cooler temperature, yet the entire system temperature increases more quickly and eventually becomes hotter than if the system were operating at $25 \mathrm{~kW}$ operation with $65^{\circ} \mathrm{C}$, even though the system begins at a higher temperature $\left(65^{\circ} \mathrm{C}\right)$.

It is clear that defining the continuous operation capability of a motor depends on many variables, which even includes the definition of continuous operation. For example, continuous operation could be defined to be operation at a particular power level for an infinite amount of time, or a particular time restraint could be included in the definition. For some HEV applications, it is crucial that the motor is capable of operating continuously within particular power levels. For example, the Camry hybrid system requires torque from the motor and generator for the engine to supply power to the drive wheels. Many aspects must be considered for these conditions, and if properly designed, the volume and mass of the electric drive system can be optimized to match the demands of the system. 


\section{SUMMARY AND CONCLUSIONS}

The 2007 Camry HEV subsystem assemblies were physically evaluated and comprehensively tested in the laboratory to fully assess their performance, efficiency, design, and packaging characteristics. The laboratory evaluations included back-emf, rotational loss, locked rotor, efficiency mapping, and extendedduration load tests. Overall, the Camry motor outperformed the Prius motor in terms of efficiency and equivalent torque and power, while the mass and volume of the system decreased significantly. Increased operation speed of the motor is the primary factor which provides the enhanced characteristics of the hybrid system. Additionally, the improved packaging and trench gate structure used in the PCU IGBTs led to a higher power density of the PCU components. The Camry inverter efficiencies are slightly lower than those of the Prius, yet the combined motor and inverter efficiencies of the Camry are still higher, especially for the low speed, high torque operation region. The lower motor efficiencies of the Prius have a much higher impact on the combined motor and inverter efficiencies than the impact of the slightly lower efficiencies of the Camry inverter.

Evaluations illustrate the benefits of moving to a high speed motor through improved packaging, higher efficiencies, increased performance, and improved continuous operation test results. Motor efficiencies are above $90 \%$ for a great portion of the operation range. Low speed efficiencies of the Camry are much higher than those of the Prius, which is particularly noticeable when the speed reduction gear ratio of 2.47 is applied to the efficiency map, and therefore the resulting torque is increased significantly. The peak power of the primary Camry motor is about $70 \mathrm{~kW}$ at $5000 \mathrm{rpm}$, which is much lower that the published rating of $105 \mathrm{~kW}$. There are no specifications published for the generator and the published power rating may be for both the motor and generator. Simulations of this motor and a comparison of specific power characteristics with other high speed motors also suggest that the power rating is near $70 \mathrm{~kW}$.

Continuous duration varies significantly with speed, specified stator temperature limit, and coolant temperature. A power level of $33.5 \mathrm{~kW}$ was maintained at $5000 \mathrm{rpm}$ for about 30 minutes with $65^{\circ} \mathrm{C}$ coolant, at which a stator temperature of $140^{\circ} \mathrm{C}$ was reached. There is no standard for establishing continuous or peak power rating specifications for motors designed for HEV applications such as the hybrid Camry and Prius motors. For example, the Camry PMSM is able to sustain a power level of $50 \mathrm{~kW}$ at $5000 \mathrm{rpm}$ for about 13 minutes with a stator temperature limit of $135^{\circ} \mathrm{C}$ and coolant temperature of $35^{\circ} \mathrm{C}$; however, the duration is only about 8 minutes if a coolant temperature of $65^{\circ} \mathrm{C}$ is applied. In addition to the unexpectedly low motor power rating, this highlights a very important reason for performing benchmarking tests on HEV subsystems - current technology must be verified objectively under consistent operating parameters before the results are used by the FCVT program and researchers. The influence of HEV specifications on technical goals and program planning would be drastically different if unclear published specifications of HEV systems were used as a baseline.

Among the vast amount of information obtained during benchmarking efforts, the significant findings are summarized in Table 4.1. Some of the information obtained from the Prius and Camry benchmarking studies has been and will be used by researchers to improve/verify analytical models. As a next step in the benchmarking efforts at ORNL, focus will be placed on an HEV system with improved power capabilities. These efforts are expected to be performed in FY2008 and will focus on the Lexus LS 600h hybrid subsystems, which are expected to include significant design improvements. Technological advances which facilitate higher power capability, power density, specific power, efficiency, and cost effectiveness of HEV components are essential as HEVs become increasingly dependant upon the electrical portion of the drive system and as the electric vehicle (EV) and HEV market continues to expand in the future. 
Table 4.1. 2007 Camry/2004 Prius design comparison highlights

\begin{tabular}{|c|c|c|c|}
\hline Parameter & Camry & Prius & Comments \\
\hline \multicolumn{4}{|l|}{ Transaxle } \\
\hline Motor power rating. & $70 \mathrm{~kW}$ & $50 \mathrm{~kW}$ & $\begin{array}{l}\text { Published Camry power rating } \\
\text { is likely a combination of motor } \\
\text { and generator ratings. }\end{array}$ \\
\hline Motor lamination stack length. & $6.07 \mathrm{~cm}\left(2.39^{\prime \prime}\right)$ & $8.40 \mathrm{~cm}\left(3.3^{\prime \prime}\right)$ & Reduced by $2.33 \mathrm{~cm}\left(0.91^{\prime \prime}\right)$. \\
\hline Motor mass. & $41.7 \mathrm{~kg}$ & $45.0 \mathrm{~kg}$ & $7.3 \%$ reduction. \\
\hline Motor volume. & $14.8 \mathrm{~L}$ & $15.4 \mathrm{~L}$ & $3.9 \%$ reduction. \\
\hline Motor specific power. & $1.68 \mathrm{~kW} / \mathrm{kg}$ & $1.11 \mathrm{~kW} / \mathrm{kg}$ & Improved by a factor of 1.5 . \\
\hline Motor power density. & $4.73 \mathrm{~kW} / \mathrm{L}$ & $3.25 \mathrm{~kW} / \mathrm{L}$ & Improved by a factor of 1.5 . \\
\hline Equivalent torque rating. & $667 \mathrm{Nm}$ & $400 \mathrm{Nm}$ & $\begin{array}{l}\text { Camry torque value from speed } \\
\text { reduction gear (short duration). }\end{array}$ \\
\hline Motor speed rating. & $14,000 \mathrm{rpm}$ & $6,000 \mathrm{rpm}$ & \\
\hline Motor winding configuration. & Parallel & Series & \\
\hline \multirow{2}{*}{\multicolumn{4}{|c|}{$\begin{array}{l}\text { Power split. } \\
\text { PCU }\end{array}$}} \\
\hline & & & \\
\hline Nominal battery voltage. & $244.8 \mathrm{~V}$ & $201.6 \mathrm{~V}$ & $\begin{array}{l}\text { Up to } 20 \% \text { higher during } \\
\text { operation. }\end{array}$ \\
\hline Maximum dc-link voltage. & $650 \mathrm{Vdc}$ & $500 \mathrm{Vdc}$ & \\
\hline Boost converter power rating. & $30 \mathrm{~kW}$ & $20 \mathrm{~kW}$ & \\
\hline Filter capacitor (battery level). & $\begin{array}{c}500 \mathrm{Vdc}, \\
378 \mu \mathrm{F}\end{array}$ & $\begin{array}{l}600 \mathrm{Vdc}, \\
282 \mu \mathrm{F}\end{array}$ & \\
\hline $\begin{array}{l}\text { Smoothing capacitor } \\
\text { (boosted level). }\end{array}$ & $\begin{array}{l}750 \mathrm{Vdc} \\
2098 \mu \mathrm{F}\end{array}$ & $\begin{array}{l}600 \mathrm{Vdc}, \\
1,130 \mu \mathrm{F}\end{array}$ & \\
\hline Entire PCU mass. & $17.86 \mathrm{~kg}$ & $21.2 \mathrm{~kg}$ & $15.8 \%$ reduction. \\
\hline Entire PCU volume. & $11.7 \mathrm{~L}$ & $17.8 \mathrm{~L}$ & $\begin{array}{l}\text { Prius PCU includes } 12 \mathrm{~V} \mathrm{dc-dc} \\
\text { and compressor inverter, Camry } \\
\text { PCU does not. }\end{array}$ \\
\hline Motor inverter mass. & $7.5 \mathrm{~kg}$ & $8.8 \mathrm{~kg}$ & $14.7 \%$ reduction. \\
\hline Motor inverter volume. & $\sim 6 \mathrm{~L}$ & $8.7 \mathrm{~L}$ & $31 \%$ reduction. \\
\hline Motor inverter specific power. & $9.3 \mathrm{~kW} / \mathrm{kg}$ & $5.7 \mathrm{~kW} / \mathrm{kg}$ & Improved by a factor of 1.6 . \\
\hline Motor inverter power density. & $11.7 \mathrm{~kW} / \mathrm{L}$ & $5.7 \mathrm{~kW} / \mathrm{L}$ & Improved by a factor of 2.1 . \\
\hline Boost converter mass. & $6.6 \mathrm{~kg}$ & $4.8 \mathrm{~kg}$ & $37.5 \%$ increase. \\
\hline Boost converter volume. & $3.5 \mathrm{~L}$ & $5.1 \mathrm{~L}$ & $31.3 \%$ reduction. \\
\hline $\begin{array}{l}\text { Boost converter specific } \\
\text { power. }\end{array}$ & $4.5 \mathrm{~kW} / \mathrm{kg}$ & $4.2 \mathrm{~kW} / \mathrm{kg}$ & Improved by $7 \%$. \\
\hline Boost converter power density. & $8.6 \mathrm{~kW} / \mathrm{L}$ & $3.9 \mathrm{~kW} / \mathrm{L}$ & Improved by a factor of 2.21 . \\
\hline
\end{tabular}




\section{REFERENCES}

1. Source: http://www.eere.energy.gov/vehiclesandfuels/technologies/systems/index.shtml.

2. J. S. Hsu, S. C. Nelson, P. A. Jallouk, C. W. Ayers, R. H. Wiles, S. L. Campbell, C. L. Coomer, K. T. Lowe, and T. A. Burress, Report on Toyota Prius Motor Thermal Management, ORNL/TM2005/33, UT-Battelle, LLC, Oak Ridge National Laboratory, Oak Ridge, Tennessee, February 2005.

3. R. H. Staunton, C. W. Ayers, J. Chiasson, T. A. Burress, and L. D. Marlino, Evaluation of 2004 Toyota Prius Hybrid Electric Drive System, ORNL/TM-2006-423, UT-Battelle, LLC, Oak Ridge National Laboratory, Oak Ridge, Tennessee, May 16, 2006.

4. R. H. Staunton, T. A. Burress, and L. D. Marlino, Evaluation of 2005 Honda Accord Hybrid Electric Drive System, ORNL/TM-2006-535, UT-Battelle, LLC, Oak Ridge National Laboratory, Oak Ridge, Tennessee, September 2006.

5. Camry Hybrid Vehicle New Car Features 2007, Toyota Motor Corporation, March 2006. 


\section{APPENDIX A: 2004 PRIUS POWER CONVERTER UNIT PACKAGING ASSESSMENTS}

\section{Prius Motor Inverter Mass and Volume Assessment}

Total Volume of PCU casing is $\mathbf{1 7 . 8} \mathbf{~ L}$ as depicted in Fig. A.1.
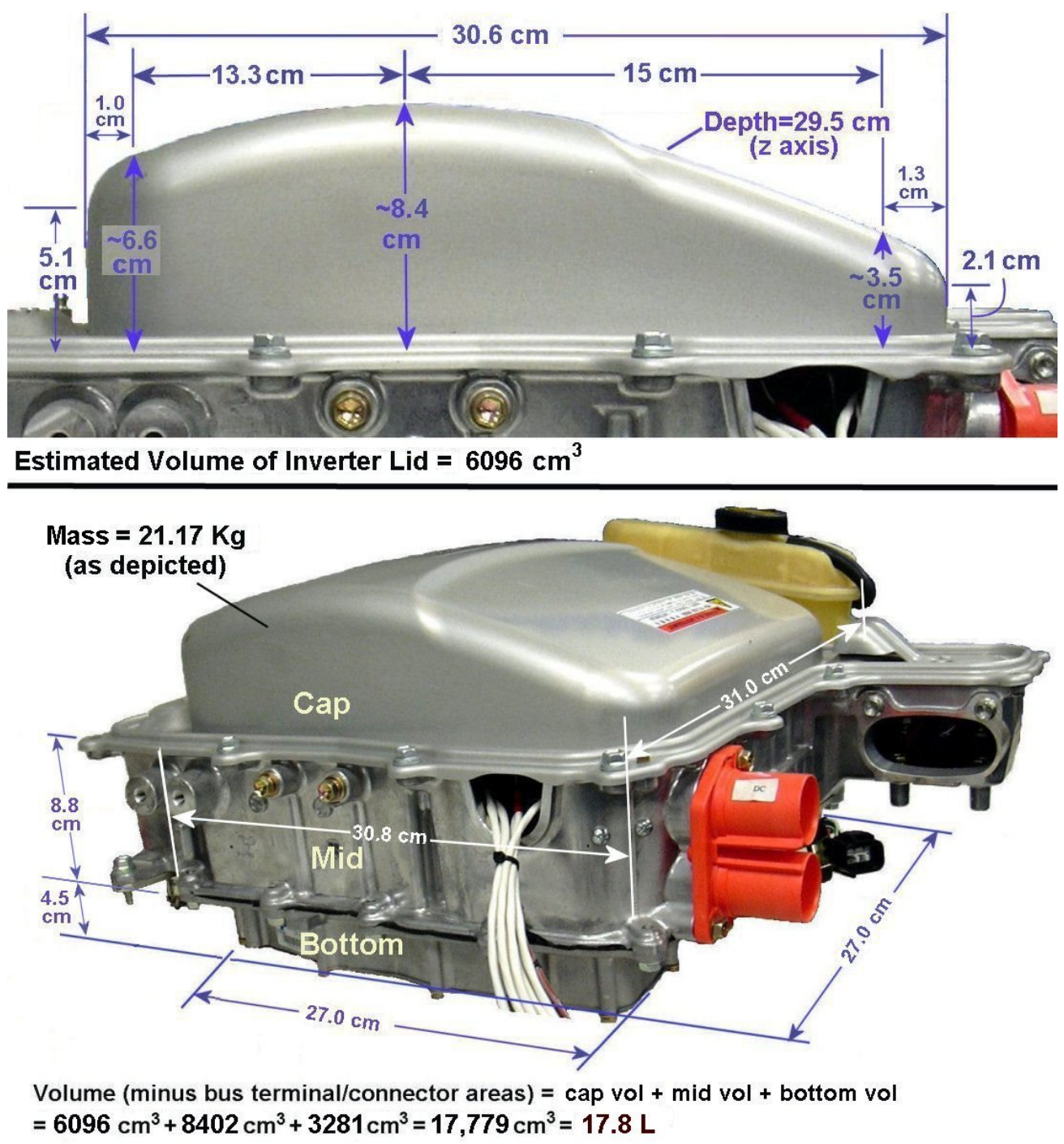

Fig. A.1. Volume of entire Prius PCU assembly.

Total volume of "inverter only" is $\mathbf{8 . 7} \mathbf{~ L}$ and is derived as follows:

- Mid section volume is reduced by $55 \%$ after the exclusion of the volume associated with the converter components, the generator portion of the inverter board (a $1 / 2$ reduction), the generator portion of the power module (a $1 / 3$ reduction) and the corresponding portion of the cold plate (a $60 \%$ reduction). See Fig. A.2 as an aid in visualization. 


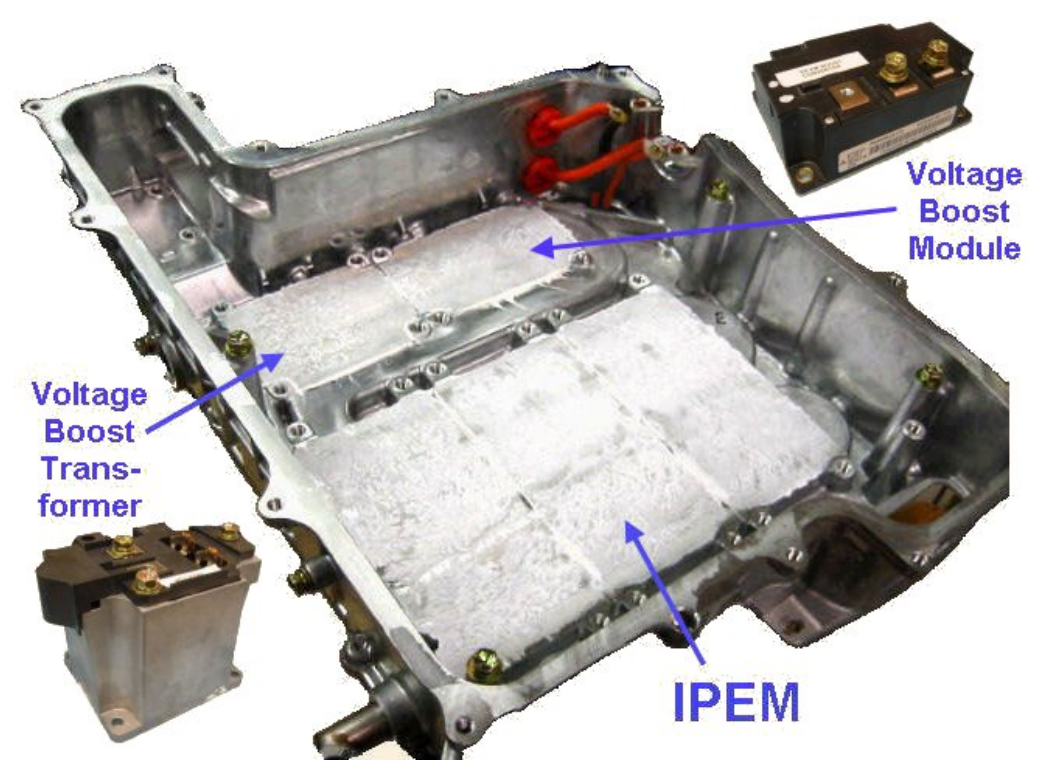

Fig. A.2. Empty inverter/converter housing showing cold plate surfaces.

- It is also reduced by the deletion of the bottom compartment (unrelated circuitry).

- The lid and capacitor volume, although not optimized, is scaled by a factor of $1130 \mu \mathrm{F} /(282 \mu \mathrm{F}+$ $1130 \mu \mathrm{F})=4 / 5$ to account for the separation of the boost converter and inverter capacitors.

Total mass of PCU casing as depicted in Fig. A.1 is $\mathbf{2 1 . 2} \mathbf{~ k g}$.

Total mass of "inverter only" is $\mathbf{8 . 8} \mathbf{~ k g}$ and is derived in a similar manner that volume was derived $(80 \%$ of capacitor mass, $45 \%$ of mid-section mass, and $0 \%$ of bottom section mass). The reduction of midsection mass is actually more severe than the " $45 \%$ " suggests since the high-mass converter transformer and converter power module were first fully excluded.

\section{Prius Bi-Directional Boost Converter Mass and Volume Assessment}

The general circuit diagram for the converter is shown in Fig. A.3, showing that the converter topology is that of a conventional bidirectional boost converter. The figure also supplies mass and volume figures of the inductor and IPM.

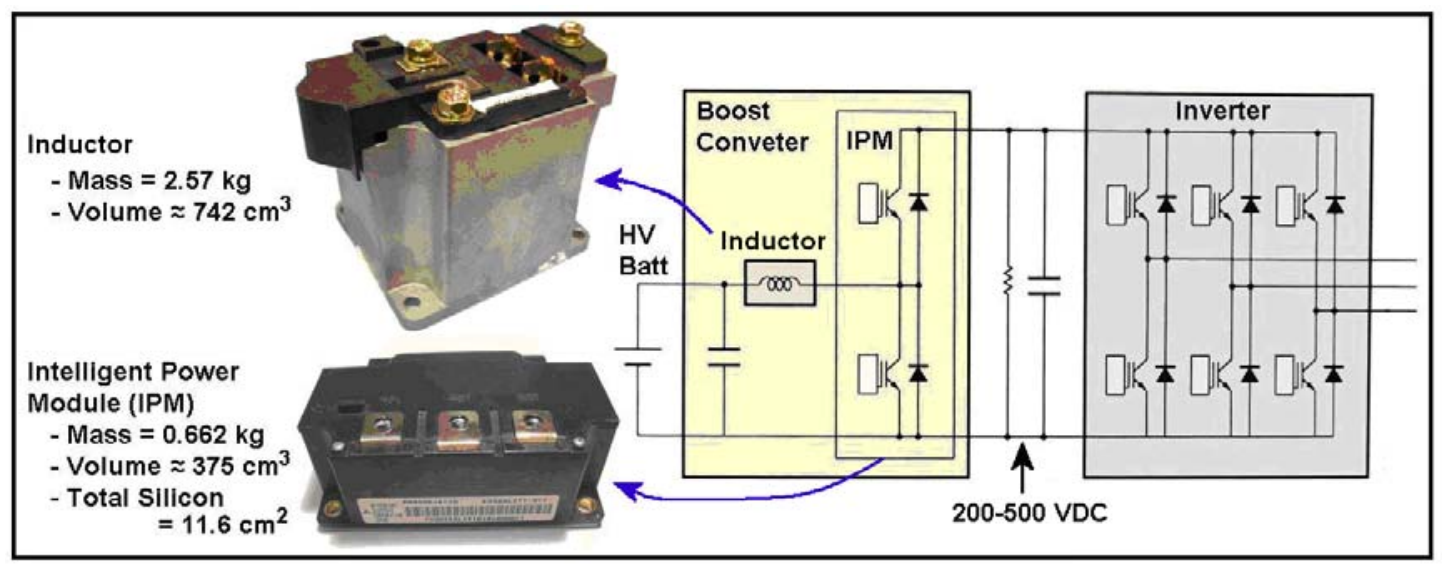

Fig. A.3. General circuit schematic of the Prius inverter. 
During periods of maximum power demand from the driver, the converter provides up to $\sim 20 \mathrm{~kW}$ to the inverter/motor system and the vehicle generator supplies up to $\sim 30 \mathrm{~kW}$. This power split allows a reduction in size of the high-cost HV battery and the converter, while the extent of fully electric operation is compromised.

Excluding the cold plate, the volume and mass totals for the $\sim 20 \mathrm{~kW}$ boost converter IPM and inductor are $\sim 1.12 \mathrm{~L}$ and $3.23 \mathrm{~kg}$, respectively.

Volume calculation approach A: The volume of the cold plate under the 2 converter components (including adjacent mounting holes) is $19 \mathrm{~mm} \times 100 \mathrm{~mm} \times 250 \mathrm{~mm}=0.48 \mathrm{~L}$. However, this approach ignores the space enclosed by the converter portion of the casing.

Volume calculation approach B: It is more pertinent to consider the entire volume that includes the cold plate, items mounted on it, and surrounding space enclosed in the casing. This volume is $335 \mathrm{~mm} \times$ $100 \mathrm{~mm} \times 140 \mathrm{~mm}=4.7 \mathrm{~L}$.

It is estimated that $15 \%$ of the casing mass is dedicated to the bidirectional converter. Since the casing shell is $6.45 \mathrm{~kg}$, the mass reduction is $\sim 1 \mathrm{~kg}$.

Capcitor: The entire capacitor volume is $1.8 \mathrm{~L}$. The volume associated with the boost converter is approximately $1.8 \times 282 \mu \mathrm{F} /(282 \mu \mathrm{F}+1130 \mu \mathrm{F})=1.8 / 5=0.36 \mathrm{~L}$. The capacitor mass is approximately $2.79 \mathrm{~kg} / 5=0.56 \mathrm{~kg}$.

Conclusions: Accounting for the inductor, IPM, casing, and capacitor the converter system volume is $5.1 \mathrm{~L}$ and the mass is $4.8 \mathrm{~kg}$. 


\section{APPENDIX B: PRIUS AND CAMRY CAPACITOR TEST RESULTS}

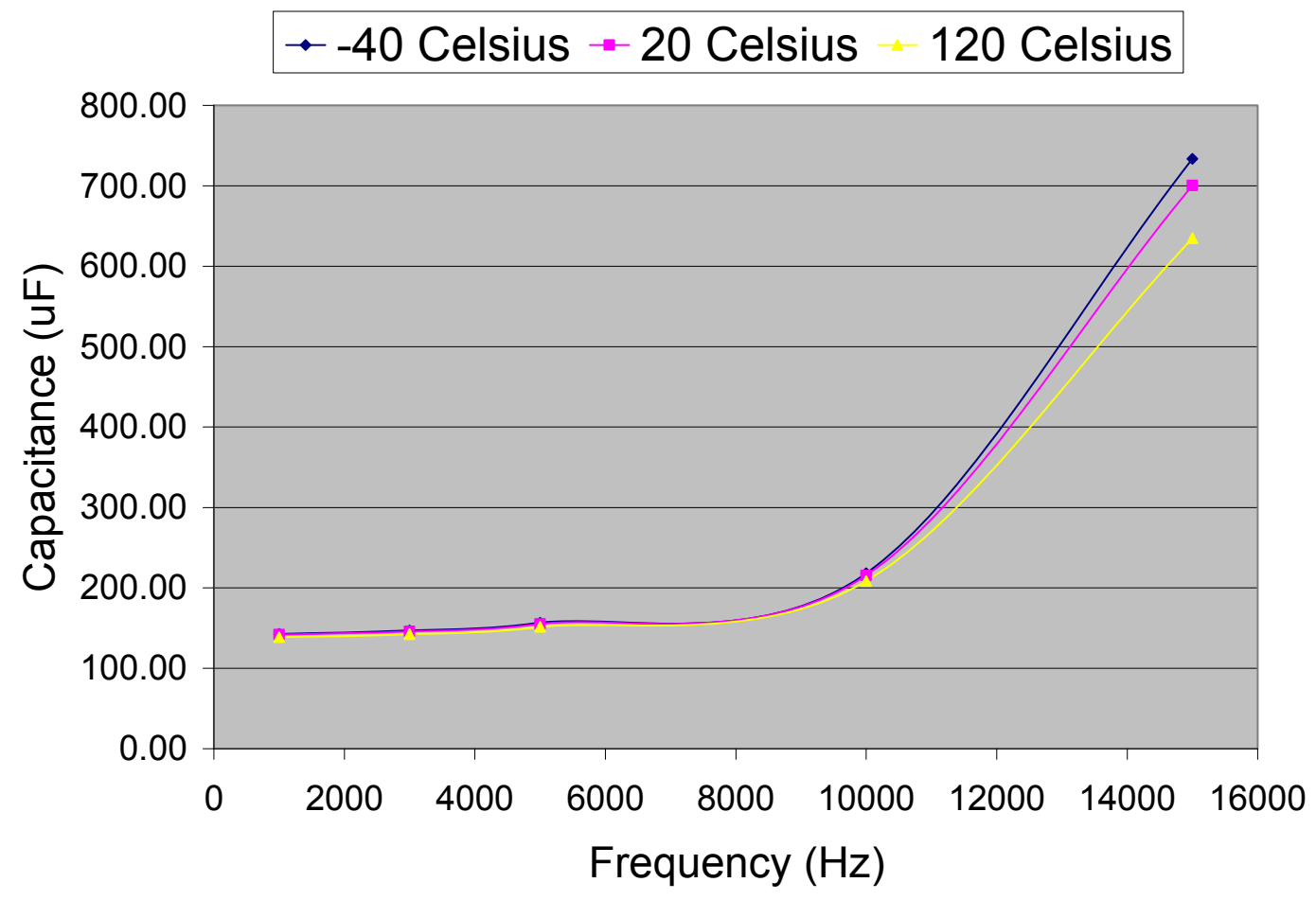

Fig. B.1. Prius single $141 \mu \mathrm{F}$ capacitor from $1,130 \mu \mathrm{F}$ module, capacitance vs. frequency.

$$
\rightarrow-40 \text { Celsius } \rightarrow-20 \text { Celsius } \rightarrow 120 \text { Celsius }
$$

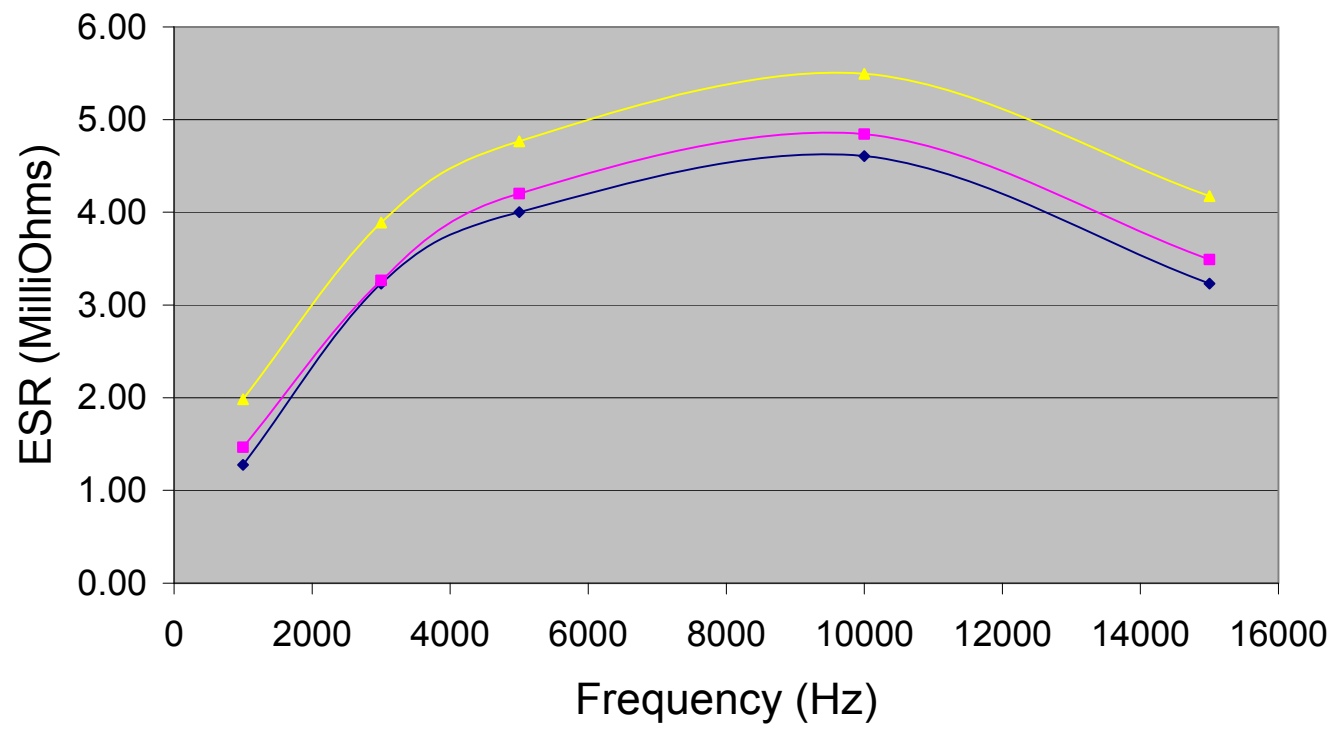

Fig. B.2. Prius single $141 \mu \mathrm{F}$ capacitor from $1,130 \mu \mathrm{F}$ module, ESR vs. frequency. 


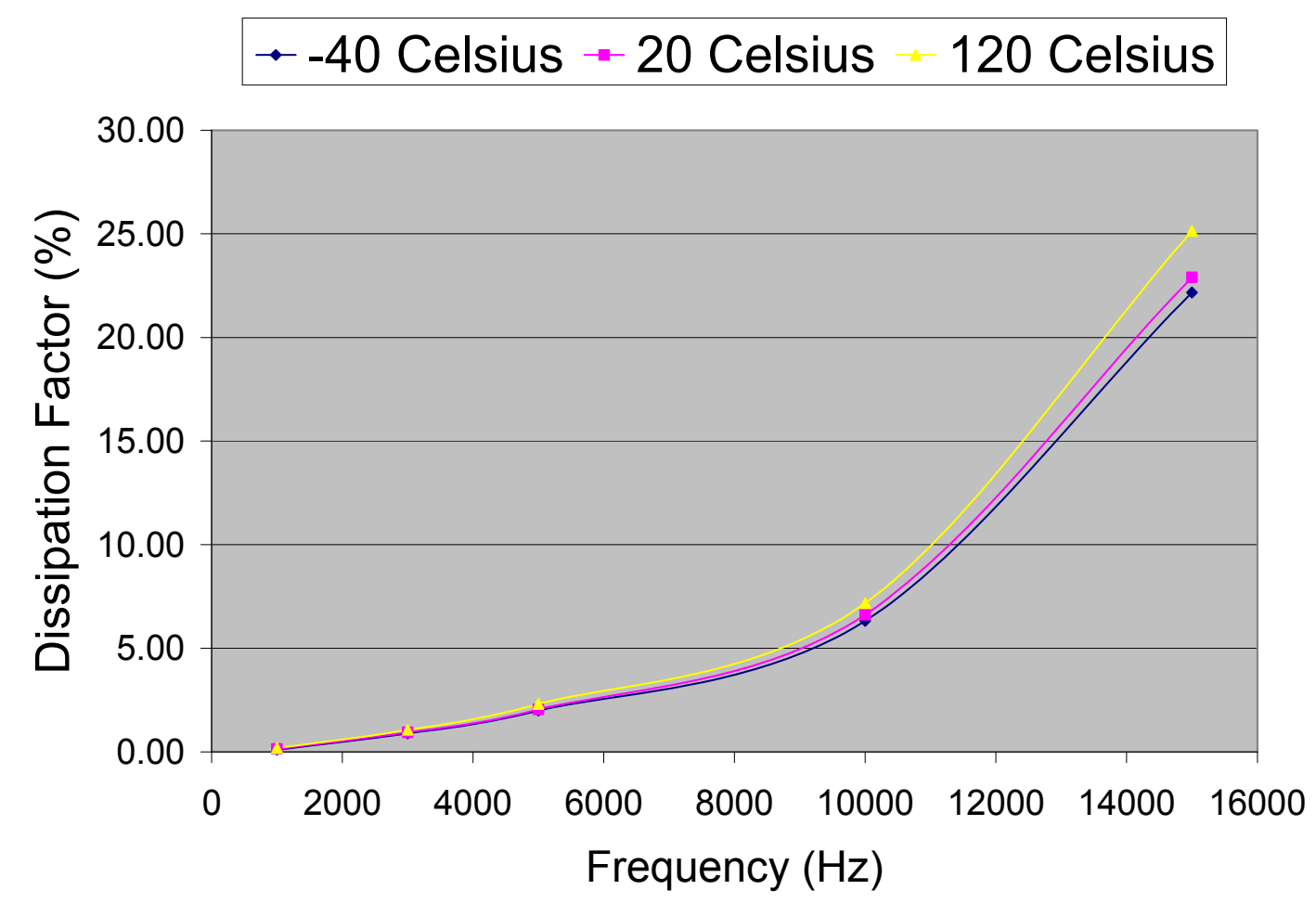

Fig. B.3. Prius single $141 \mu \mathrm{F}$ capacitor from $1,130 \mu \mathrm{F}$ module, DF vs. frequency.

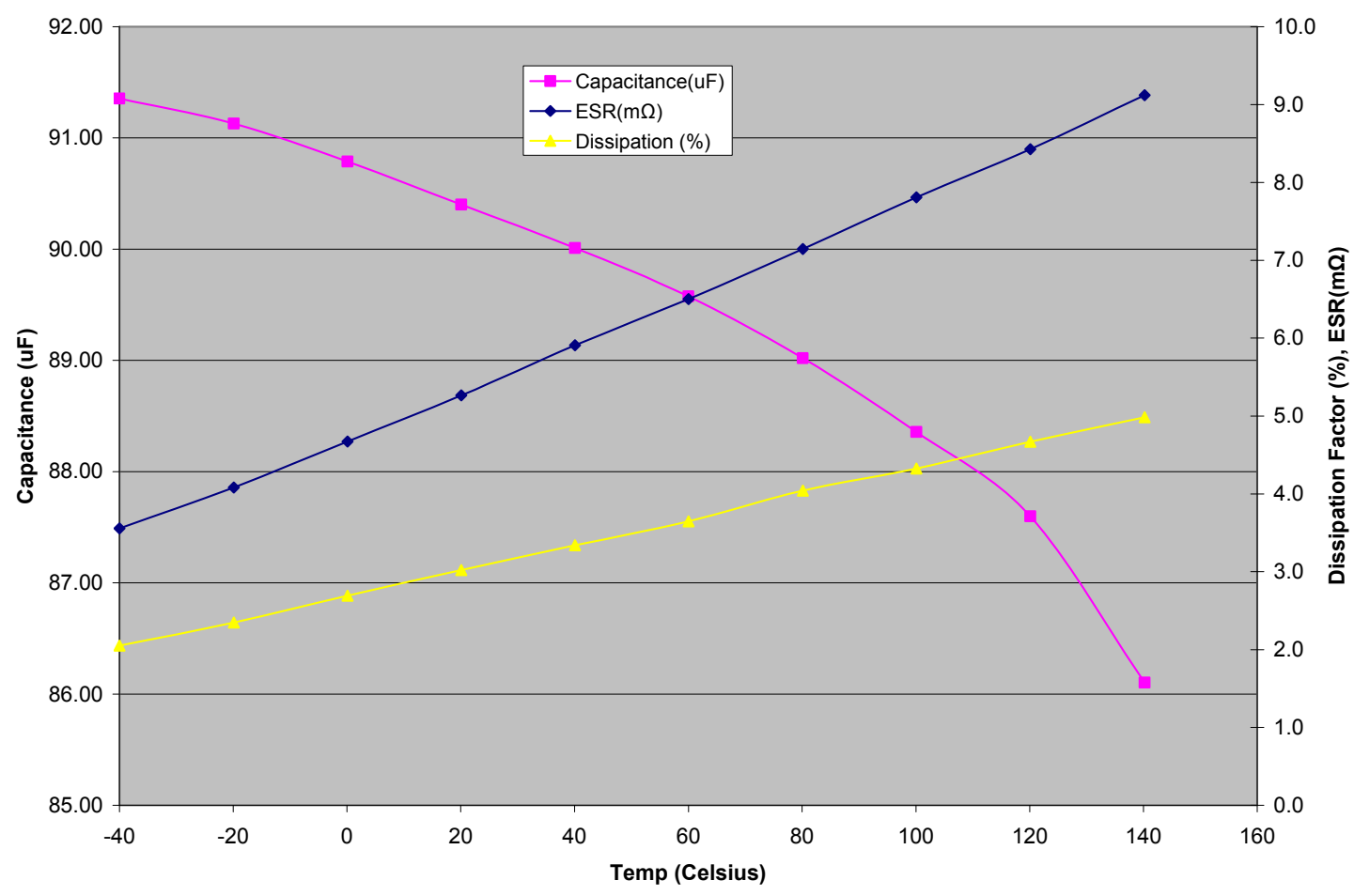

Fig. B.4. Camry single $86 \mu$ F capacitor, capacitance, ESR, and DF vs. temperature at $10 \mathrm{kHz}$. 


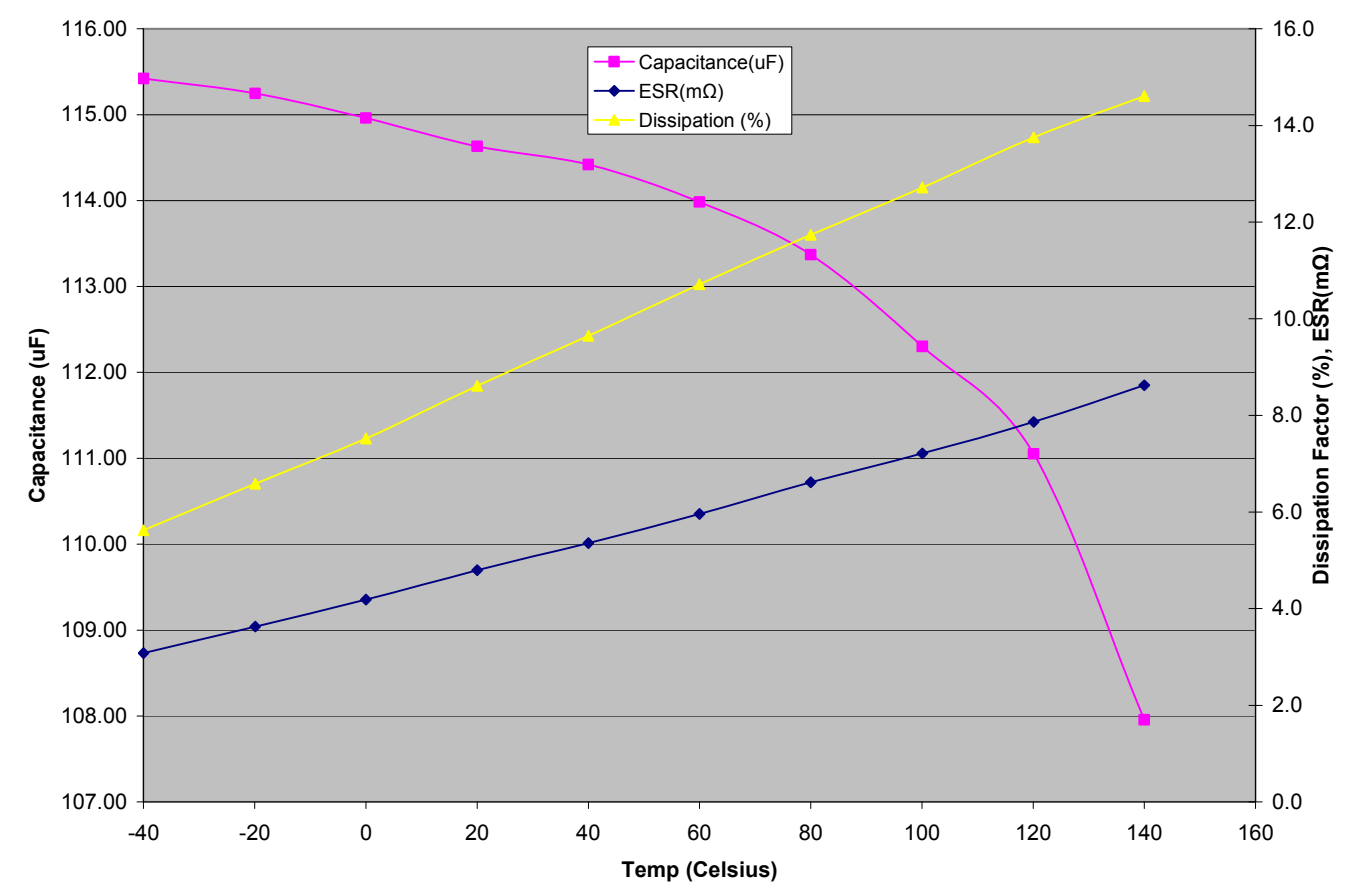

Fig. B.5. Camry single $86 \mu$ F capacitor, capacitance, ESR, and DF vs. temperature at $25 \mathrm{kHz}$.

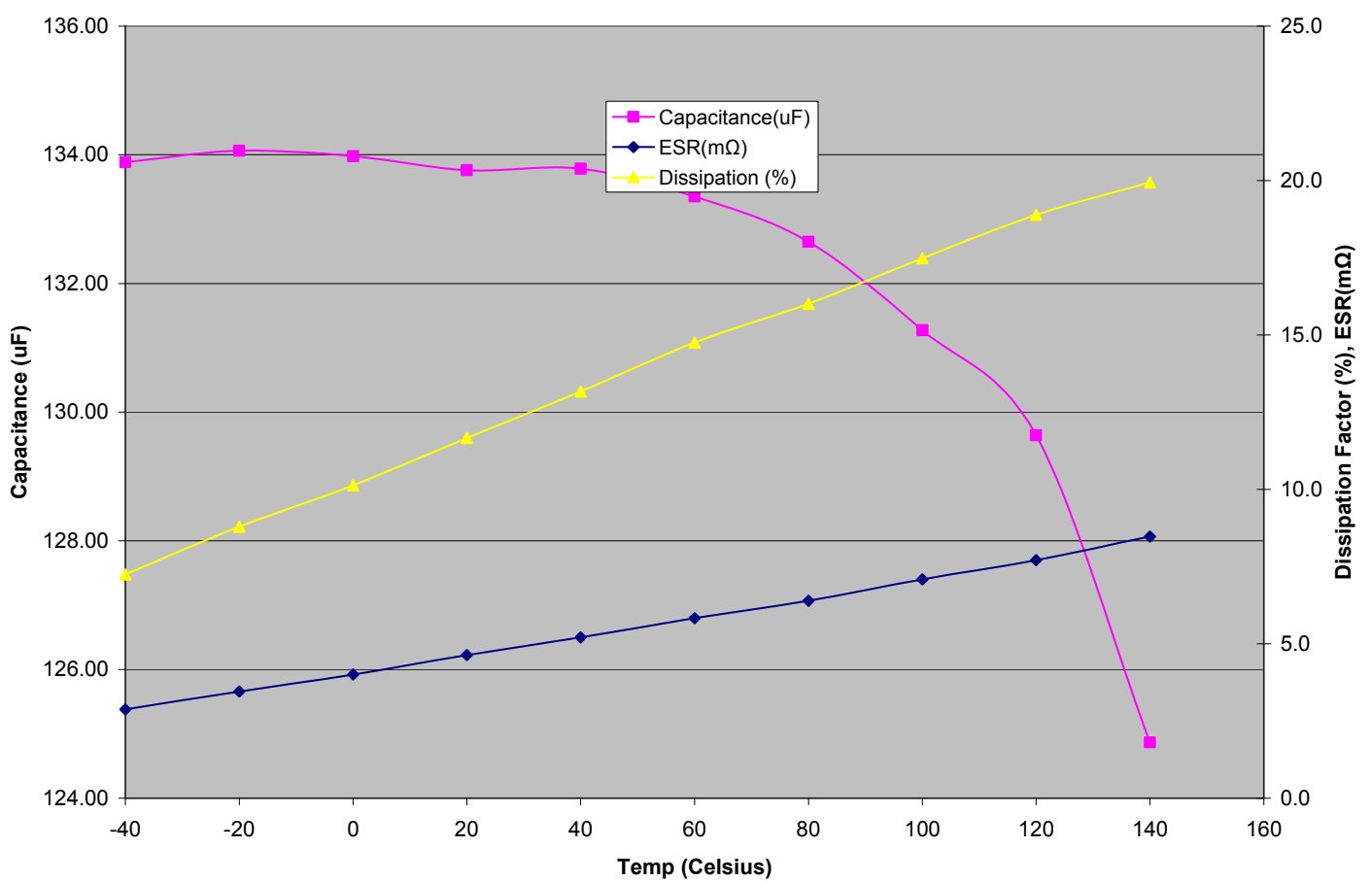

Fig. B.6. Camry single $86 \mu$ F capacitor, capacitance, ESR, and DF vs. temperature at $30 \mathrm{kHz}$. 


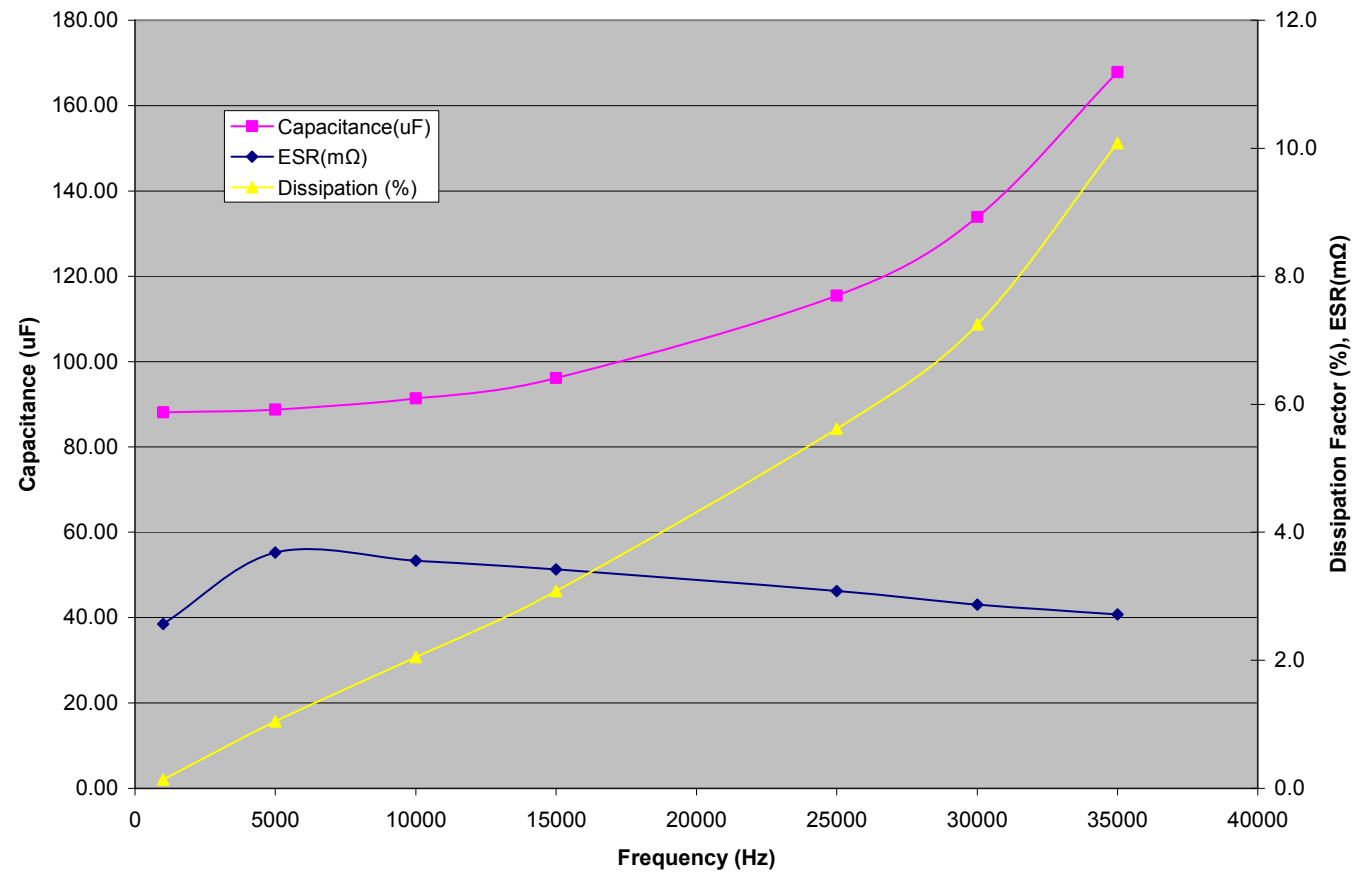

Fig. B.7. Camry single $86 \mu \mathrm{F}$ capacitor, capacitance, ESR, and DF vs. frequency at $-40^{\circ} \mathrm{C}$.

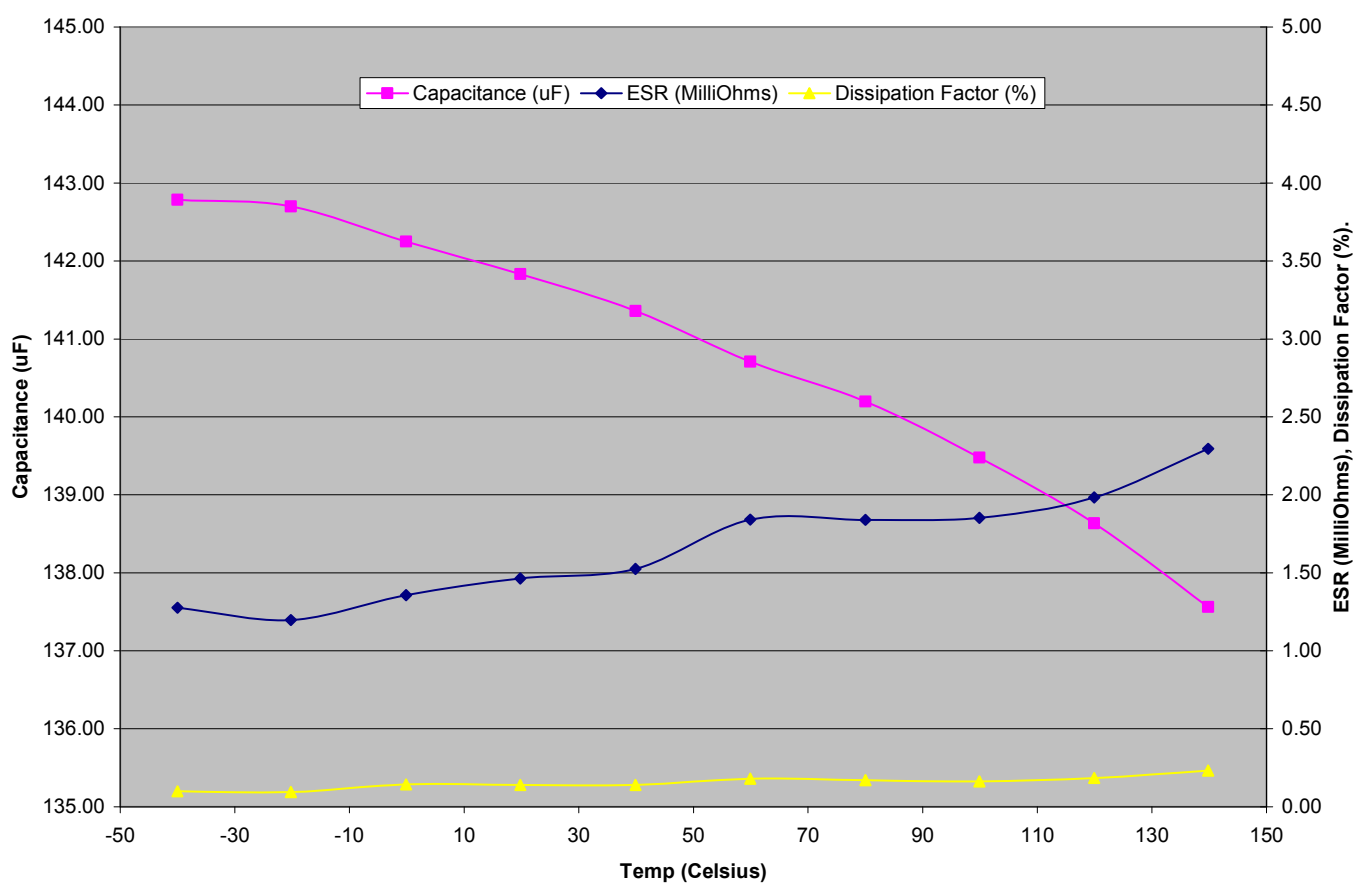

Fig. B.8. Prius single $141 \mu$ F capacitor, capacitance, ESR, and DF vs. temperature at $1 \mathrm{kHz}$. 


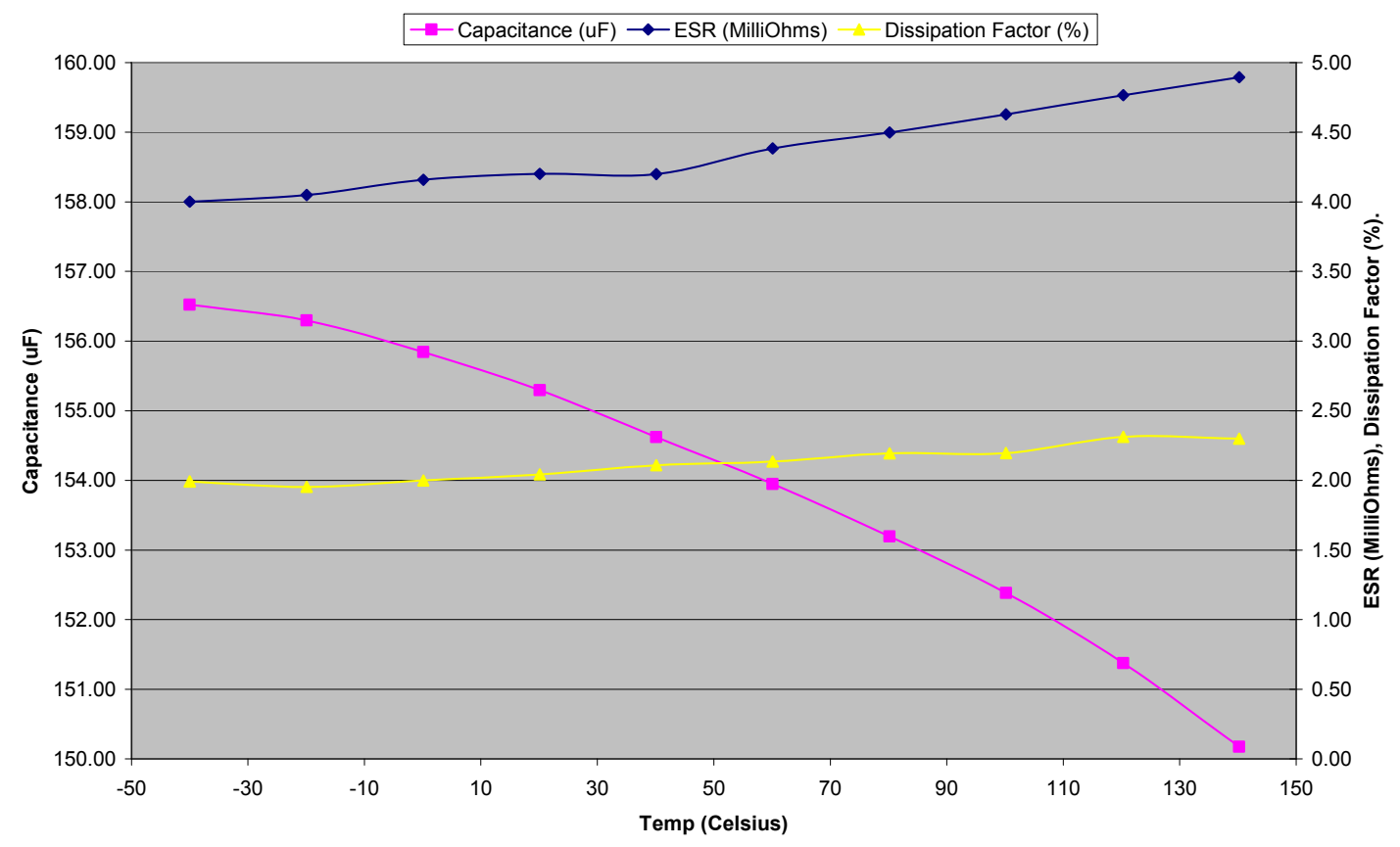

Fig. B.9. Prius single $141 \mu \mathrm{F}$ capacitor, capacitance, ESR, and DF vs. temperature at $5 \mathrm{kHz}$.

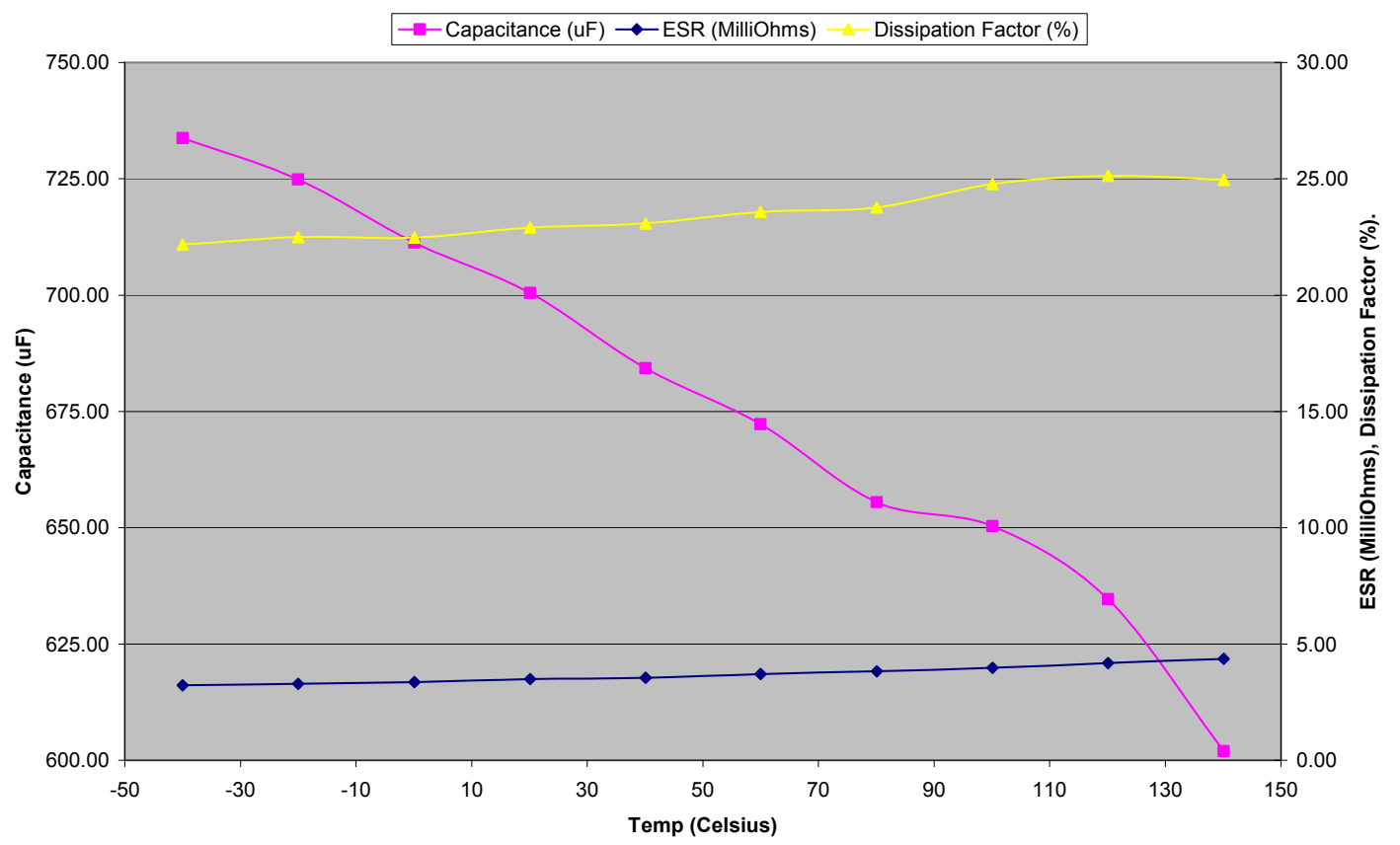

Fig. B.10. Prius single $141 \mu$ F capacitor, capacitance, ESR, and DF vs. temperature at $15 \mathrm{kHz}$. 


\section{APPENDIX C: 2004 PRIUS TRANSAXLE PACKAGING ASSESSMENTS}

\section{Prius Motor Mass and Volume Assessment}

The configuration of the motor rotor and stator are shown in Fig. C.1.

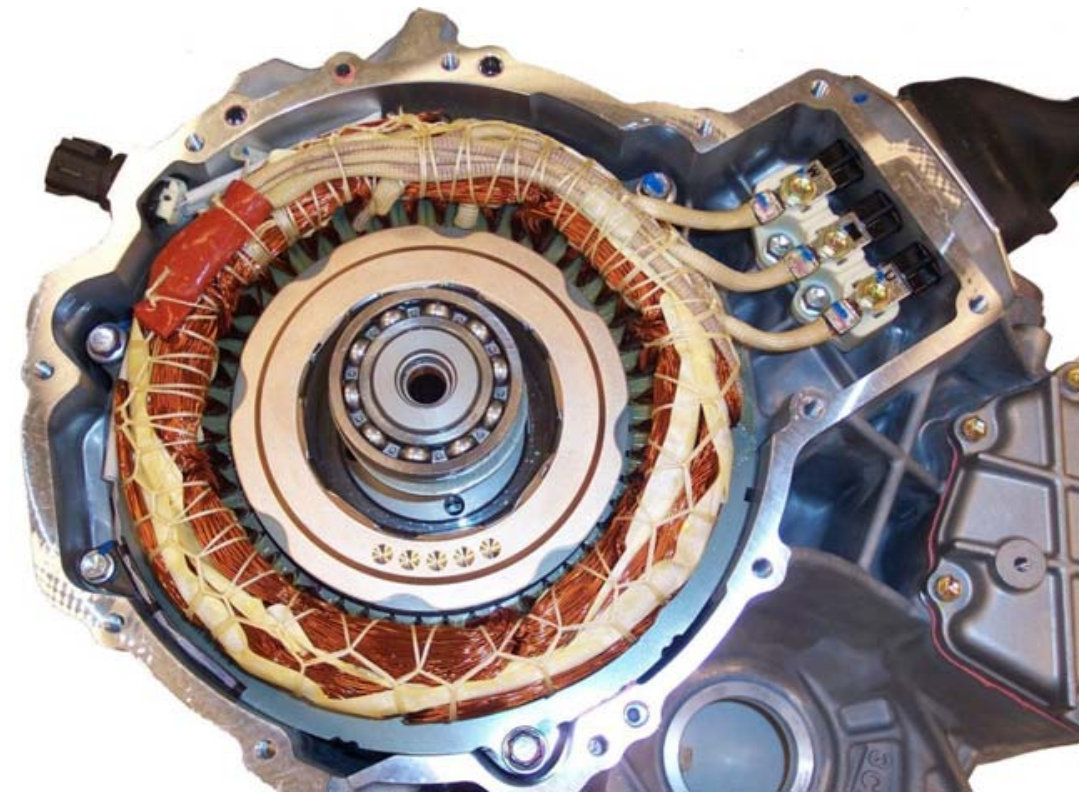

Fig. C.1. 2004 Prius motor rotor and stator.

Figure C.1 shows three views of the PMSM housing with selected dimensions called out. As indicated, about $3 / 4^{\text {th }}$ of the casing houses the PMSM rotor and stator and the remainder encloses part of the gearbox. The portion of the casing that houses the PMSM is roughly cylindrical and that is the geometry used for the purposes of estimating the PMSM casing volume. Based on the average of 3 measurements of casing diameter, the cylinder diameter can be assumed to be $\sim 29.9 \mathrm{~cm}$. The depth of the PMSM housing extending from the end plate to the surface identified in the upper left photo in Fig. C.2 is $20.5 \mathrm{~cm}$. This results in a volume of $14,400 \mathrm{~cm}^{3}$ excluding the three-phase terminal block housing and the cooling passages that protrude from the surface of the casing. Including all 3 volumes results in a total of $15,400 \mathrm{~cm}^{3}(15.4 \mathrm{~L})$. This volume and the $50 \mathrm{~kW}$ peak power specification result in a peak power density of $3.25 \mathrm{~kW} / \mathrm{L}$.

The mass of the PMSM was determined in order to estimate the specific power. The masses of the components of the Prius PMSM are:

$\begin{array}{ll}\text { Stator: } & 25.9 \mathrm{~kg} \\ \text { Rotor: } & 10.2 \mathrm{~kg} \\ \text { Case: } & 6.36 \mathrm{~kg} \text { (machined - see below) } \\ \text { Case cover: } & 2.49 \mathrm{~kg} \\ \text { Total mass of motor: } & \mathbf{4 4 . 9 5 ~ \mathbf { ~ g ~ }}\end{array}$

The casing for the PMSM has (1) a portion that encloses one end of the gear box, and (2) compartments that enclose the gear-shift-lever-to-shift-plunger linkages. These areas are unrelated to the PMSM and were therefore machined off of the structure to obtain a new $6.36 \mathrm{~kg}$ mass (the original casing mass was $13.9 \mathrm{~kg}$ ). The resulting specific power for the PMSM is $1.11 \mathrm{~kW} / \mathrm{kg}$. 

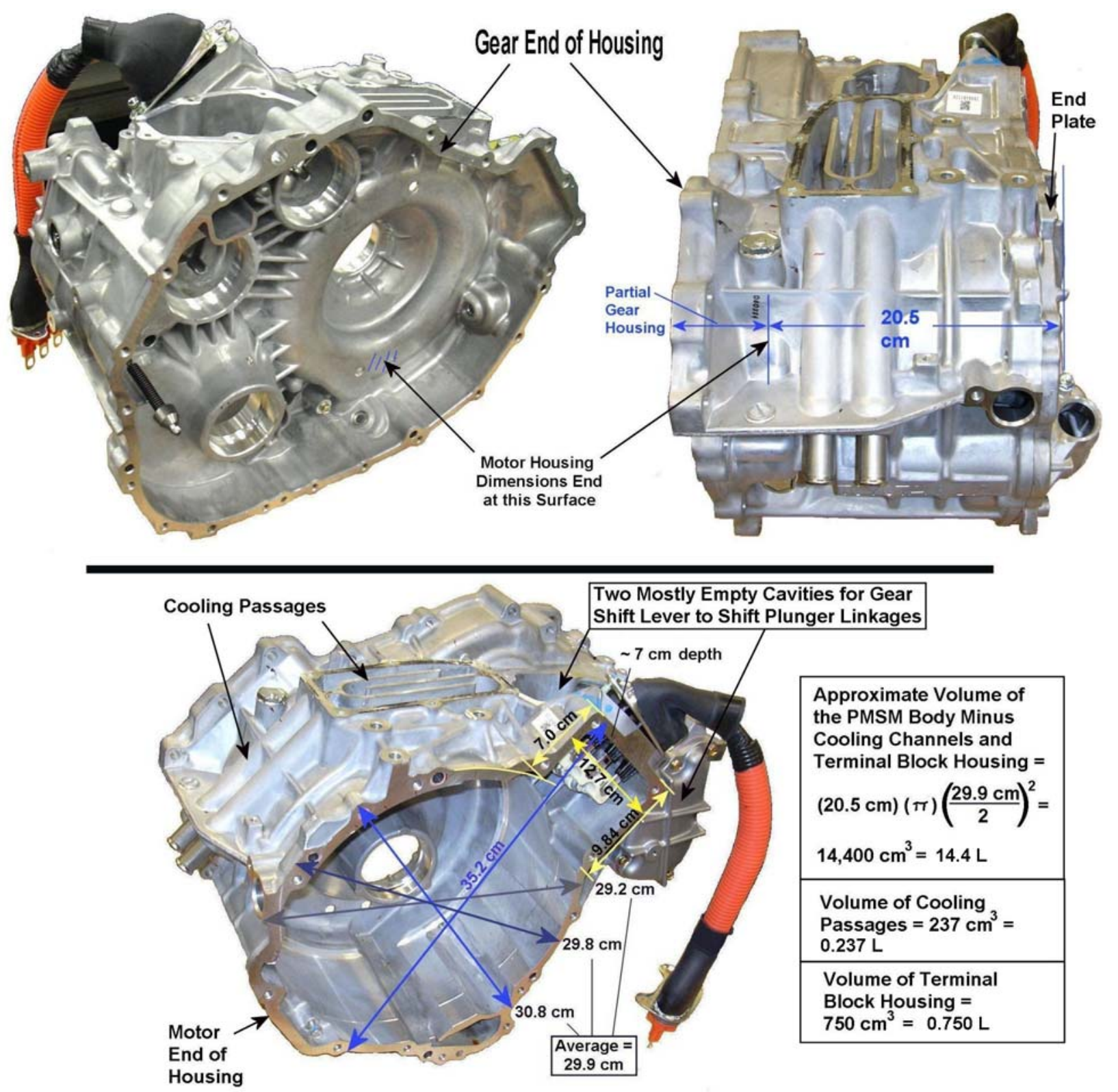

Fig. C.2. Casing of the 2004 Prius PMSM with dimensions and volume calculations. 


\section{DISTRIBUTION}

Internal

1. D. J. Adams

2. T. A. Burress

3. S. L. Campbell

4. C. L. Coomer

5. J. P. Cunningham

6. E. C. Fox

7. K. P. Gambrell
8. J. S. Hsu

9. L. D. Marlino

10. M. Olszewski

11. L. E. Seiber

12. R. H. Staunton

13. Laboratory Records

\section{External}

14. F. D. Barlow III, University of Idaho, Department of Electrical \& Computer Engineering, Buchanan Engineering Laboratory, Rm. 211, 607 Urquhart Avenue, Moscow, ID 83844-1023, fbarlow@uidaho.edu.

15. R. Al-Attar, DCX, raa9@dcx.com.

16. S. J. Boyd, U.S. Department of Energy, EE-2G/Forrestal Building, 1000 Independence Avenue, S.W., Washington, D.C. 20585.

17. T. Q. Duong, U.S. Department of Energy, EE-2G/Forrestal Building, 1000 Independence Avenue, S.W., Washington, D.C. 20585.

18. R. R. Fessler, BIZTEK Consulting, Inc., 820 Roslyn Place, Evanston, Illinois 60201-1724.

19. G. Hagey, Sentech, Inc., 501 Randolph St., Williamsburg, Virginia 23185.

20. E. Jih, Ford Motor Company, Scientific Research Laboratory, 2101 Village Road, MD-1170, Rm. 2331, Dearborn, Michigan 48121.

21. K. J. Kelly, National Renewable Energy Laboratory, 1617 Cole Boulevard, Golden, Colorado 80401.

22. A. Lee, Daimler Chrysler, CIMS 484-08-06, 800 Chrysler Drive, Auburn Hills, Michigan 483262757.

23. F. Leonardi, Ford Motor Company, 15050 Commerce Drive, North, Dearborn, Michigan 481201261.

24. F. Liang, Ford Motor Company, Scientific Research Laboratory, 2101 Village Road, MD1170, Rm. 2331/SRL, Dearborn, Michigan 48121.

25. M. W. Lloyd, Energetics, Inc., 7164 Columbia Gateway Drive, Columbia, Maryland 21046.

26. J. Maquire, General Motors Advanced Technology Center, 3050 Lomita Boulevard, Torrance, California 90505.

27. M. Mehall, Ford Motor Company, Scientific Research Laboratory, 2101 Village Road, MD-2247, Rm. 3317, Dearborn, Michigan 48124-2053.

28. J. A. Montemarano, Naval Surface Warfare Center, Carderock Division; Code 642, NSWD, 9500 MacArthur Boulevard; West Bethesday, Maryland 20817.

29. N. Olds, United States Council for Automotive Research (USCAR), nolds@uscar.org

30. S. A. Rogers, U.S. Department of Energy, EE-2G/Forrestal Building, 1000 Independence Avenue, S.W., Washington, D.C. 20585.

31. G. S. Smith, General Motors Advanced Technology Center, 3050 Lomita Boulevard, Torrance, California 90505.

32. E. J. Wall, U.S. Department of Energy, EE-2G/Forrestal Building, 1000 Independence Avenue, S.W., Washington, D.C. 20585.

33. B. Welchko, General Motors Advanced Technology Center, 3050 Lomita Boulevard, Torrance, California 90505.

34. P. G. Yoshida, U.S. Department of Energy, EE-2G/Forrestal Building, 1000 Independence Avenue, S.W., Washington, D.C. 20585. 